\title{
Entwicklung eines HTS-geeigneten Enzymtests für Histondeacetylasen zur Entwicklung von HDAC-Inhibitoren
}

\author{
Dissertation \\ zur Erlangung des Doktorgrades \\ der Mathematisch-Naturwissenschaftlichen Fakultäten \\ der Georg-August-Universität zu Göttingen
}

vorgelegt von

Dennis Wegener

aus Northeim

Göttingen 2003 
D7

Referent: PD Dr. Andreas Schwienhorst

Korreferent: PD Dr. Wilfried Kramer

Tag der mündlichen Prüfung: 21.1.2004 


\section{Inhaltsverzeichnis}

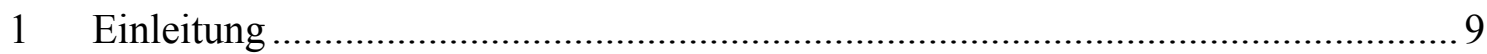

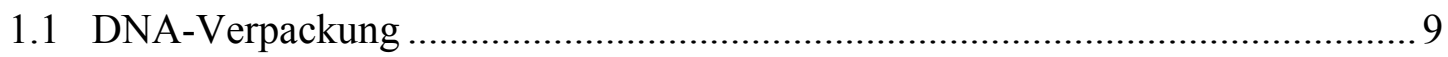

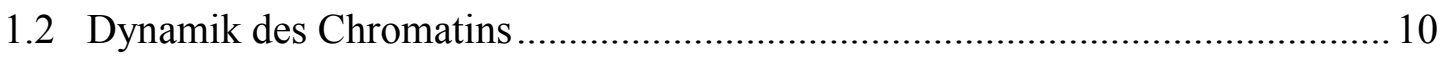

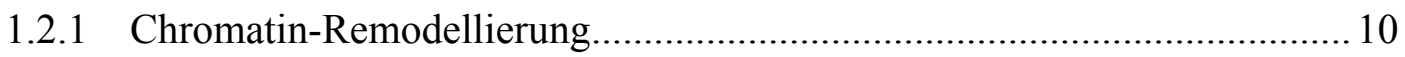

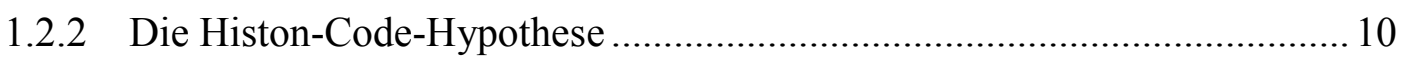

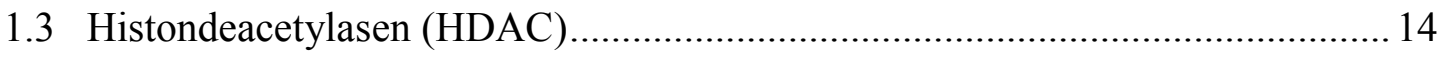

1.3.1 Acetylierung und Deacetylierung durch HAT und HDAC ........................ 14

1.3.2 HDAC als Mitglieder verschiedener Protein-Komplexe .......................... 15

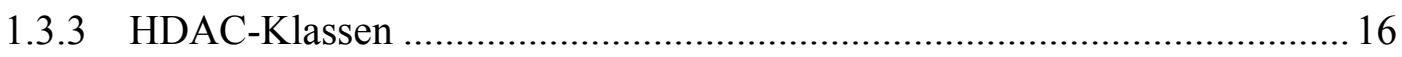

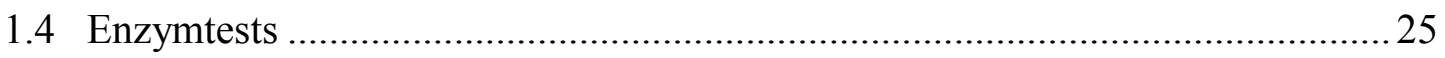

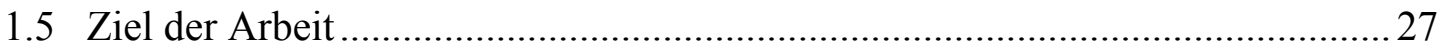

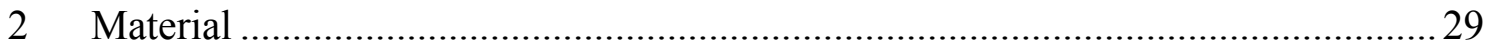

2.1 Bakterienstämme von Escherichia coli.......................................................229

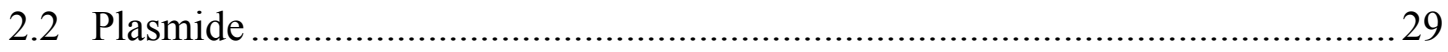

2.3 DNA-Längenstandards und Protein-Molekulargewichtsmarker......................... 31

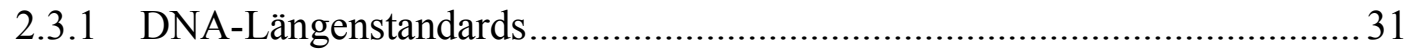

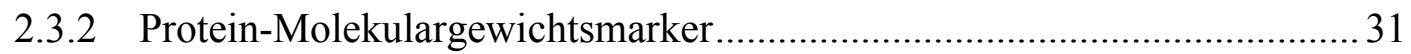

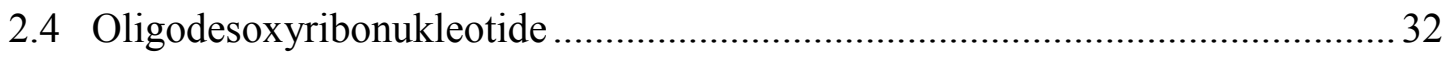

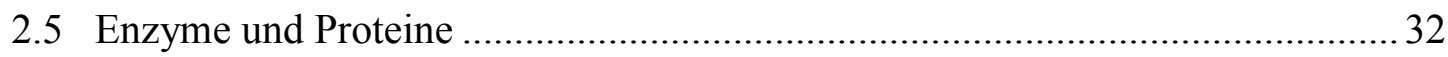

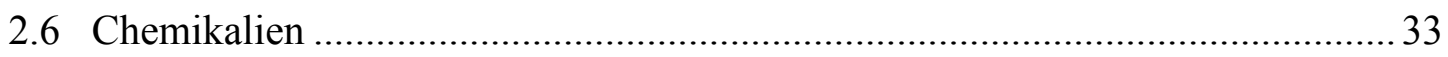

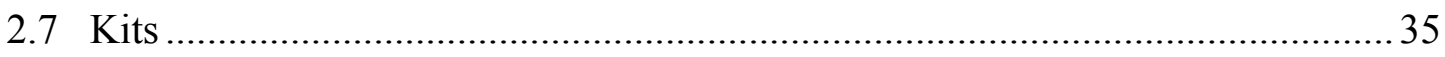

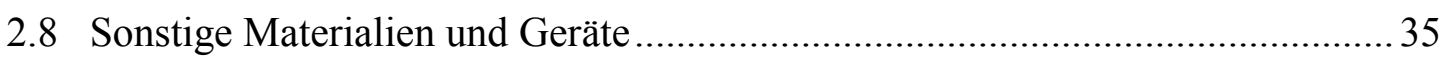

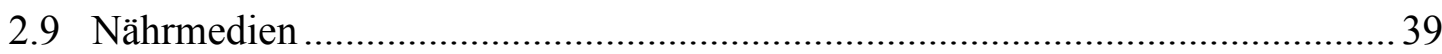




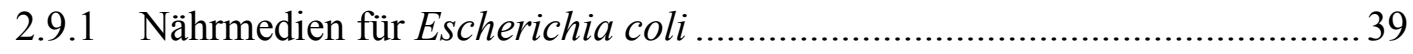

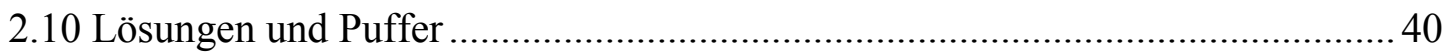

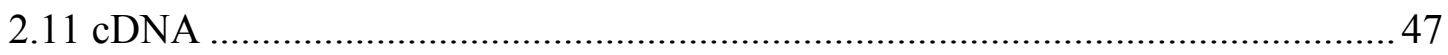

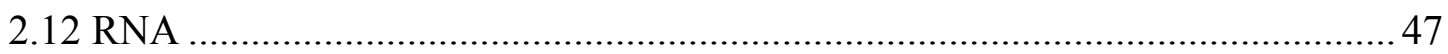

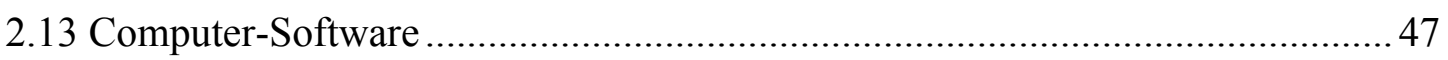

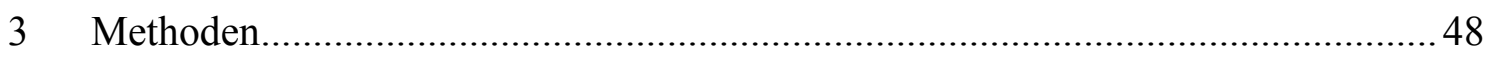

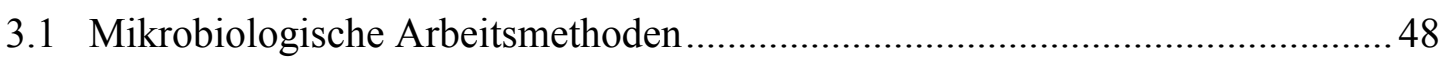

3.1.1 Kultivierung und Lagerung von Escherichia coli ................................. 48

3.1.2 Transformation von Escherichia coli .................................................. 49

3.1.2.1 Präparation und Transformation elektrokompetenter

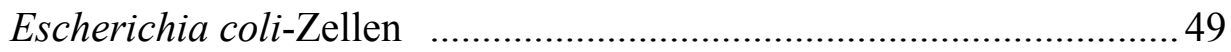

3.1.2.2 Präparation und Transformation $\mathrm{CaCl}_{2}$-kompetenter

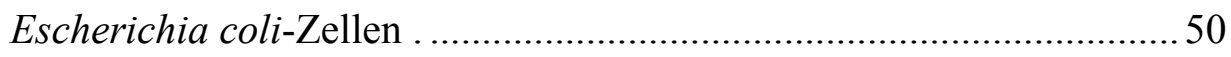

3.2 Molekularbiologische Arbeitsmethoden ….................................................... 51

3.2.1 Vorbereitung von Geräten und Lösungen ................................................ 51

3.2.2 Fällung von DNA aus wäßrigen Lösungen .......................................... 51

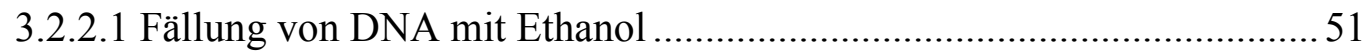

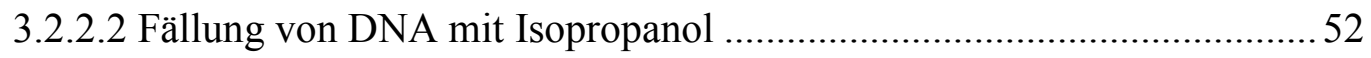

3.2.2.3 Extraktion von DNA aus wäßrigen Lösungen

mit organischen Lösungsmitteln ...................................................52

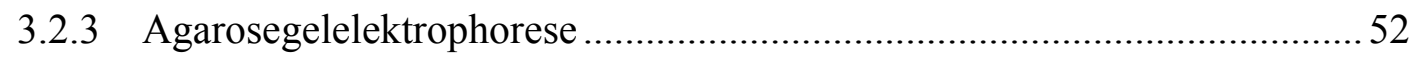

3.2.4 Isolierung von DNA-Fragmenten aus Agarosegelen ............................... 53

3.2.5 Abtrennung von Oligonukleotiden und kurzen DNA-Fragmenten

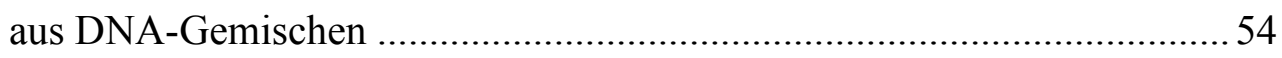

3.2.6 Isolierung von Plasmid-DNA aus Escherichia coli .................................54 
3.2.6.1 Isolierung von Plasmid-DNA aus Escherichia coli im analytischen Maßstab (Mini-Präparation). 54

3.2.6.2 Isolierung von Plasmid-DNA aus Escherichia coli im präparativen Maßstab (Midi-Präparation) 55

3.2.7 Konzentrationsbestimmung von Nukleinsäuren ....................................56

3.2.8 Enzymatische Spaltung von DNA mit Restriktionsendonukleasen .............56

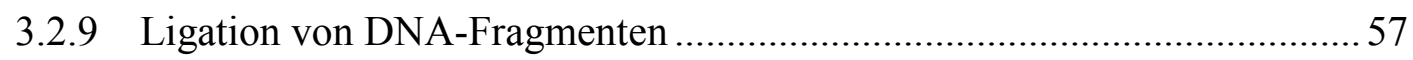

3.2.10 Direkte Klonierung von PCR-Produkten (TA-Cloning) ........................... 57

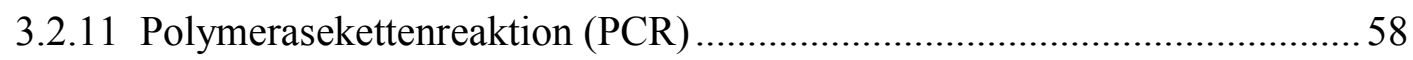

3.2.12 RT-PCR (Reverse Transcription-Polymerase Chain Reaction) ..................60

3.2.12.1 cDNA-Synthese durch Reverse Transkription................................... 60

3.2.12.2 Amplifikation der cDNA mittels PCR ............................................... 60

3.2.13 Direkte PCR-Mutagenese eines Zielvektors (QCM-Verfahren).................61

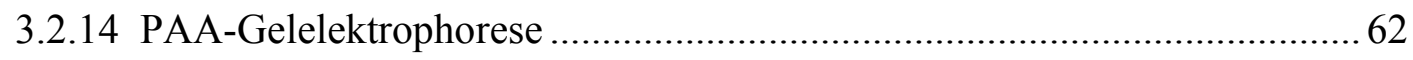

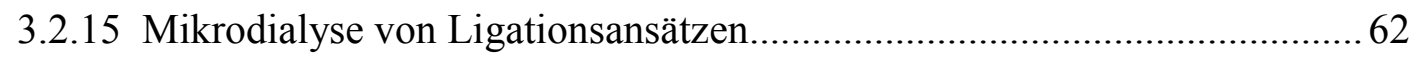

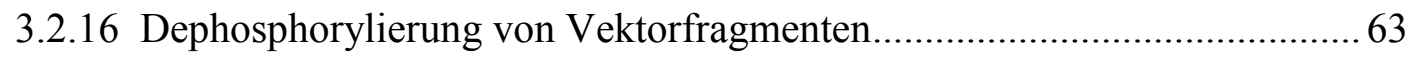

3.2.17 Sequenzierung von Plasmid-DNA nach der Kettenabbruch-Methode .......63

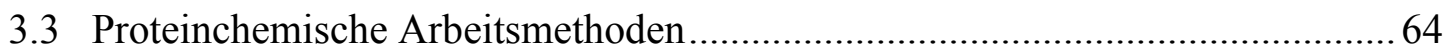

3.3.1 Protein-Konzentrationsbestimmung nach Bradford.................................. 64

3.3.2 Denaturierende Polyacrylamidgelelektrophorese (SDS-PAGE)................. 64

3.3.2.1 Herstellung 10\%iger Polyacrylamidgele.............................................. 65

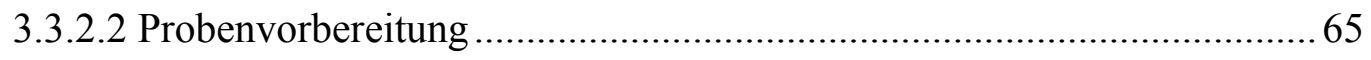

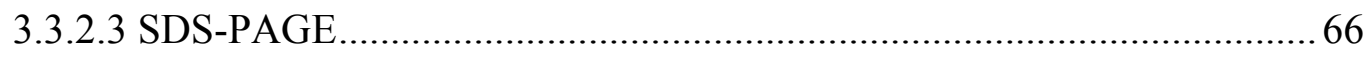

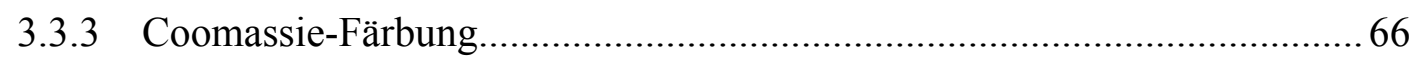

3.3.4 Transfer von Proteinen auf PVDF-Membranen (Blotting) ........................ 66 
3.3.5 Immunochem. Nachweis von Proteinen auf PVDF-Membranen (Western)67

3.3.6 Affinitätschromatographie an immobilisierten Metallionen (IMAC).........68

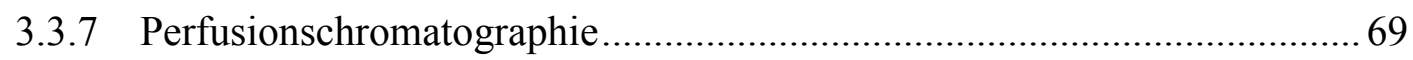

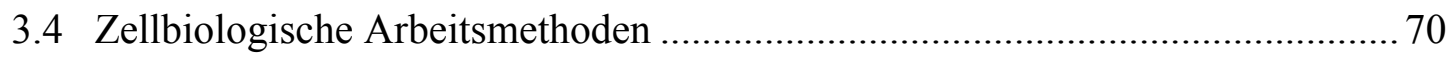

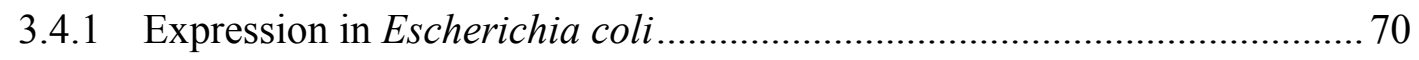

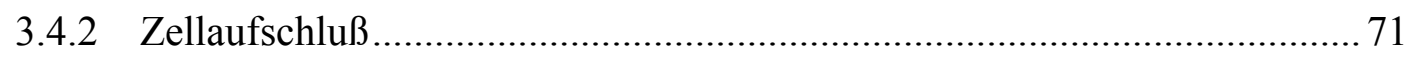

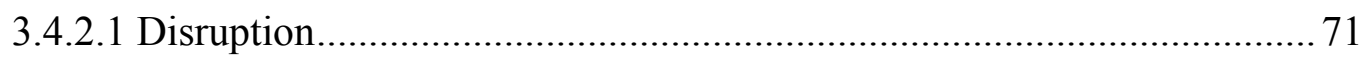

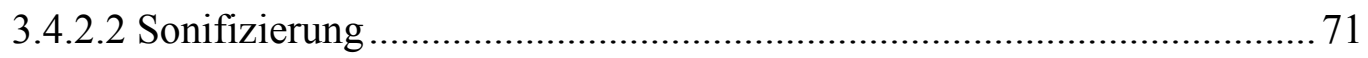

3.5 Enzymatische Aktivitätstests ................................................................. 71

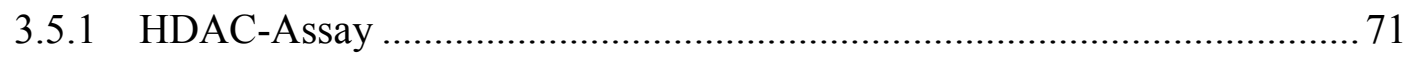

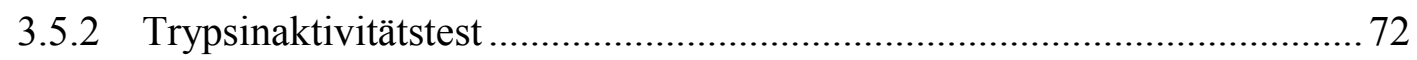

3.5.3 Bestimmung der $\mathrm{K}_{\mathrm{M}}$ und $\mathrm{V}_{\max }$ für Trypsin-Substrate ............................ 73

3.5.4 Bestimmung der $\mathrm{IC}_{50}$ von HDACI im 96 well-Format ............................ 73

3.5.5 Bestimmung der Salz- und Lösungsmitteltoleranz von HDAC ................... 74

3.5.6 Bestimmung der $\mathrm{K}_{\mathrm{M}}$ für HDAC-Substrate im 96 well-Format ................... 74

3.5.7 Umsatzkurven mit HDAC-Substraten und Bestimmung von $\mathrm{V}_{\max }$............. 75

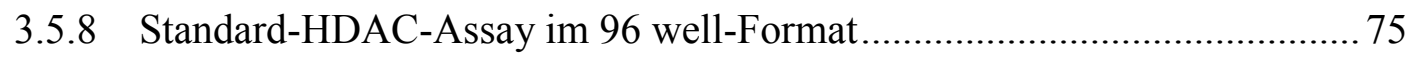

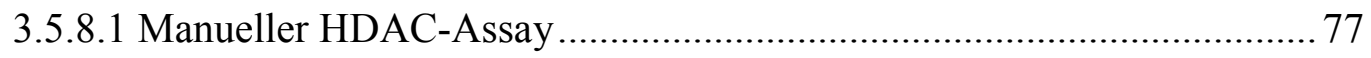

3.5.8.2 Robotische Ausführung des HDAC-Assay mit der CyBi-Anlage .......... 77

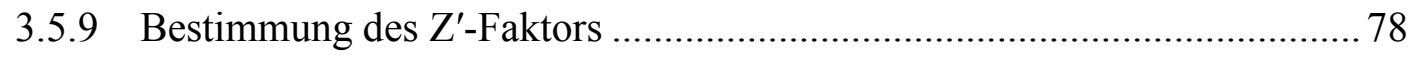

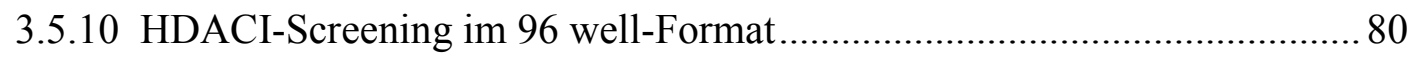

3.5.11 Bestimmung der $\mathrm{IC}_{50}$ von HDACI für FB188-HDAH …......................... 80

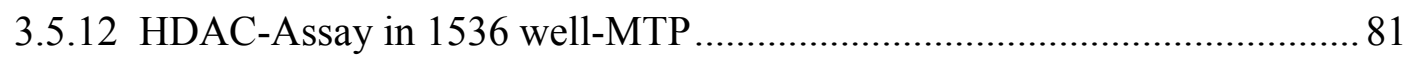

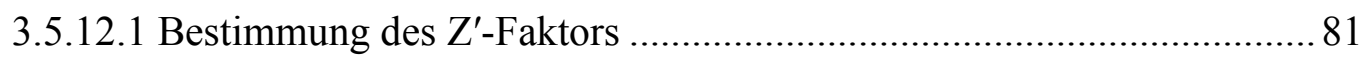

3.5.12.2 Bestimmung der $\mathrm{IC}_{50}$ von HDACI für HDAC aus Rattenleber ............ 83 


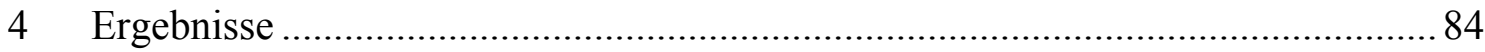

4.1 Entwicklung eines neuen fluorogenen HDAC Assays....................................... 84

4.1.1 Allgemeine Eigenschaften des Assays ...................................................... 85

4.1.2 Sequenzspezifität der Histondeacetylasen ............................................... 88

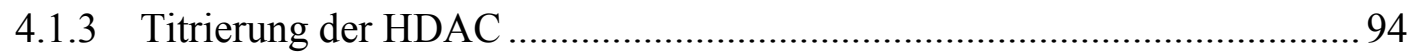

4.1.4 Bestimmung der $\mathrm{K}_{\mathrm{M}^{-}}$Werte und der $\mathrm{V}_{\max }$ der nicht-acetylierten

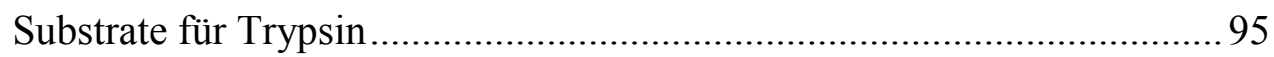

4.1.5 Bestimmung der $\mathrm{K}_{\mathrm{M}}$-Werte und der $\mathrm{V}_{\max }$ der Substrate für HDAC ........... 96

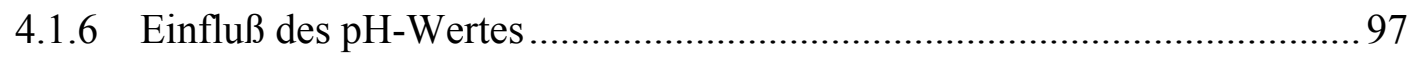

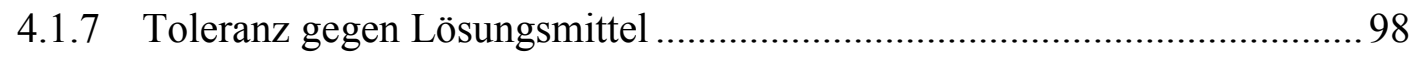

4.1.8 Inhibitionsversuche mit Standard-HDACI......................................... 100

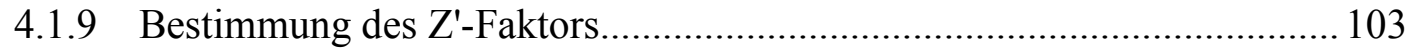

4.1.10 Miniaturisierung des HDAC-Assays...................................................... 107

4.2 Entwicklung von Histondeacetylase-Inhibitoren .......................................... 111

4.2.1 Durchmusterung von Molekülbibliotheken mit HDAC aus Rattenleber.. 111

4.2.2 Untersuchung zur Selektivität und Bestimmung des $\mathrm{IC}_{50}$ einiger

HDACI 116

4.3 Produktion von rekombinanter, humaner HDAC

4.3.1 Klonierung der humanen HDAC1 und heterologe Expression in E. coli 122

4.3.1.1 Expression mit N-terminalem Hexahistidin-tag. 123

4.3.1.2 Coexpression einer tRNA ${ }^{\mathrm{Arg}}$ 125

4.3.1.3 Expression mit C-terminalem Hexahistidin-tag..... 127

4.3.1.4 Expression einer C-terminal verkürzten HDAC1-Variante ... 130

4.3.1.5 Expression einer HDAC1-Variante ohne His-tag. 132

4.3.2 Klonierung der humanen HDAC8 und heterologe Expression in E. coli .133 
4.3.3 Aufreinigung mittels Affinitätschromatographie an immobilisierten

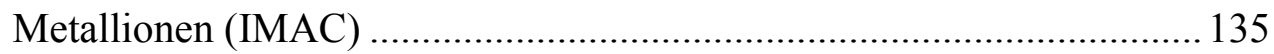

4.3.4 Aufreinigung mittels Anionenaustauschchromatographie....................... 138

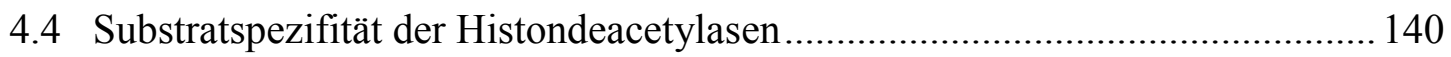

4.4.1 Inhibition durch putative Übergangszustandsmimetika.......................... 141

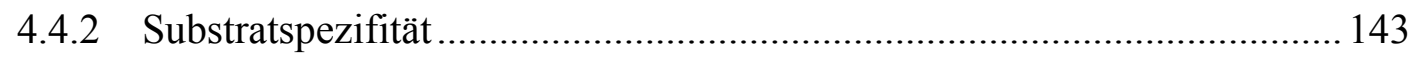

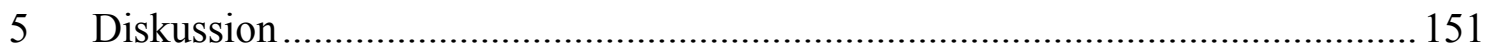

5.1 Ein Fluoreszenz-basierter, homogener HDAC-Assay .................................. 152

5.2 Potente und selektive Histondeacetylase-Inhibitoren ................................... 163

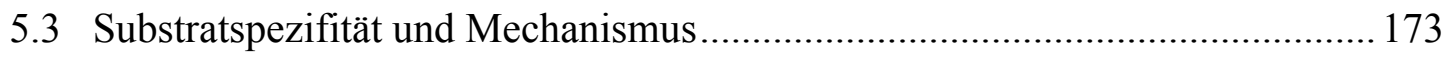

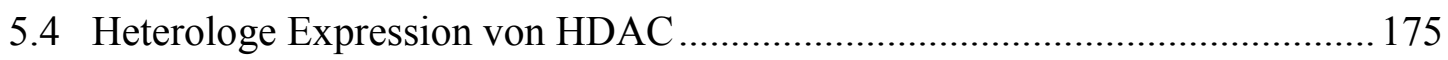

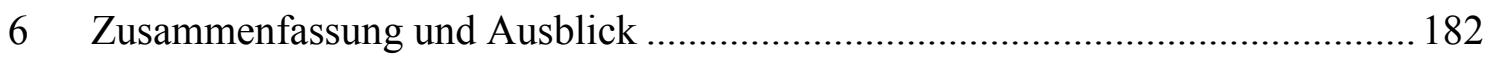

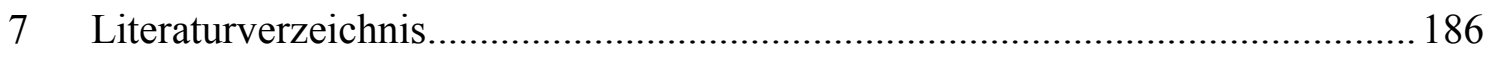

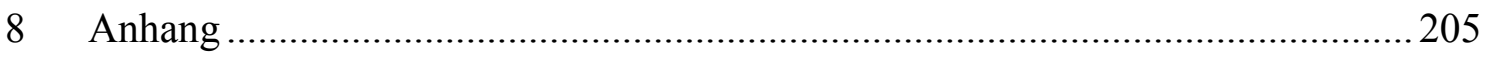

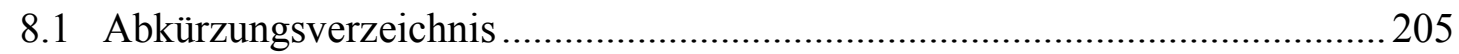

8.2 Fluoreszenz-Kalibrierungsgeraden (BMG-Reader) .......................................209

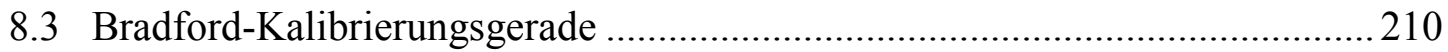

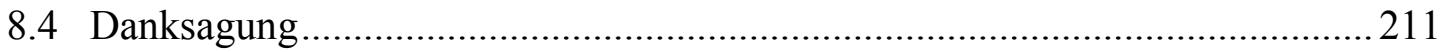

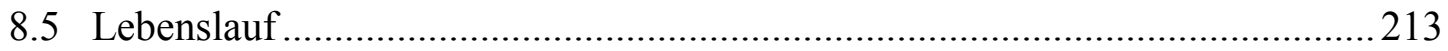




\section{Einleitung}

Die enorme Größe der Genome eukaryotischer Zellen ging mit einer Zunahme an Komplexität der Organismen im Zuge der Evolution einher, verlangte aber eine immer stärkere Kompaktierung des Erbmaterials (Lehninger et al., 1994). Dabei mußte die Zugänglichkeit der DNA für die molekulare Maschinerie der Replikation und Transkription gewahrt bleiben. Eine effiziente Lösung des Platzproblems in der eukaryotischen Zelle wurde durch die hierarchisch organisierte Verpackung der DNA mit Hilfe von assoziierten Gerüstproteinen realisiert, welche in letzter Stufe in der Bildung von Chromosomen gipfelt (Kornberg and Lorch, 1999). Das gesamte Geflecht aus diversen Proteinen und DNA nennt man Chromatin.

\subsection{DNA-Verpackung}

Auf der untersten Verpackungsebene liegt die DNA - ähnlich Perlen auf einer Schnur in regelmäßigen Abständen um Oktamere aus 4 verschiedenen basischen Proteinen gewickelt vor, wobei der Komplex aus diesen Histonen mit jeweils etwa 146 bp in ca. 1,8 Windungen darum geschlungener DNA ein sogenanntes Nukleosom ausmacht, dessen Struktur durch Röntgenkristallographie bei 2,8 $\AA$ bzw. bei 1,9 $\AA$ aufgelöst werden konnte (Luger et al., 1997; Richmond and Davey, 2003). Die Oktamere setzen sich aus je zwei der Kernhistone H2A, H2B, H3 und H4 von ca. 100 bis etwas mehr als 200 Aminosäuren zusammen. Die Sequenzen vor allem der Histone 3 und 4 sind bei fast allen Eukaryoten hochkonserviert, was auf eine evolutiv frühe Entstehung des Chromatins hindeutet (Reeve, 2003). Diese Aussage wird durch in Archaea vorhandene Histonäquivalente als Bestandteile einer vereinfachten Chromatinstruktur unterstützt (Reeve, 2003; Sandman et al., 1998; Sandman and Reeve, 1998).

Nukleosomen wiederum sind spiralig zu einer faserartigen Struktur verdrillt, welche aufgrund ihres Durchmessers $30 \mathrm{~nm}$-Filament genannt wird und ihrerseits weiter zu Schlaufen aufgewunden vorliegt, so daß sich letztlich eine Organisation aus Spiralen von Spiralen (bzw. Schleifen) an einem Chromatingerüst ergibt. Das fünfte im 
Chromatin vorkommende Histonprotein H1 spielt offenbar eine entscheidende Rolle bei zumindest der ersten dieser Spiralisierungen, indem es wahrscheinlich durch seine Positionierung an der Ein- bzw. Austrittsstelle der DNA am Nukleosom diese Struktur (als Chromatosom) stabilisiert und benachbarte Nukleosomen innerhalb des Filamentes verbindet (Hayes and Hansen, 2001; Zhou et al., 1998).

\subsection{Dynamik des Chromatins}

\subsubsection{Chromatin-Remodellierung}

Die beschriebene Kompaktierung ist zwar einerseits eine Notwendigkeit z. B. bei der Seggregation der Schwesterchromatiden vor der Zellteilung, steht aber z. B. der vorher ablaufenden Replikation und vielen anderen Vorgängen in der Zelle wie DNAReparatur und Transkription im Wege (Legube and Trouche, 2003; Wolffe and Hayes, 1999), da die involvierten Enzymkomplexe durch die Bindung der DNA in Nukleosomen behindert werden (Chang and Luse, 1997; Hansen and Wolffe, 1992; Hansen and Wolffe, 1994; Kornberg and Lorch, 1999). In den letzten Jahren wurden ganze Familien von Chromatin-Remodellierenden Enzymen entdeckt, welche die DNAHiston-Interaktion ATP-abhängig modulieren und z. B. Nukleosompositionen relativ zur DNA verschieben, wobei der Weg für RNA-Polymerasen geebnet oder Erkennungssequenzen für Transkriptionsfaktoren freigelegt werden (Becker and Horz, 2002; Belotserkovskaya et al., 2003; Clapier et al., 2001; Kornberg and Lorch, 1999; Kwon et al., 1994; Langst and Becker, 2001). Darüberhinaus werden Kernhistone unter bestimmten Umständen durch Histonvarianten ersetzt, was funktionelle Auswirkungen hat (Ahmad and Henikoff, 2002; Redon et al., 2002). So ist beispielsweise die Variante H3.3 gegen H3 in transkriptionell aktiven Bereichen ausgetauscht (Ahmad and Henikoff, 2002). Die Struktur des Chromatins ist also dynamisch und kann gleichzeitig partiell kondensiert in Form von Heterochromatin und relaxiert in Form von Euchromatin in einer Zelle vorliegen. Generell ist daher Euchromatin transkriptionell aktiv, während in Heterochromatin keine Gene abgelesen werden (Grunstein, 1997a).

\subsubsection{Die Histon-Code-Hypothese}

Trotz der Einsicht in die dynamischen Eigenheiten des Chromatins wurde die statische Natur der Histone als passive Transkriptionsblocker erst mit der (Wieder-)Entdeckung 
der Rolle zahlreicher posttranslationaler Modifikationen der Histone relativiert (Abb. 1), welche das Gleichgewicht zwischen den beiden Chromatintypen beeinflußt. Darunter sind Phosphorylierungen von Serinen und Mono-, Di- und Trimethylierungen von Lysinen und Mono- bzw. Dimethylierungen von Argininen der aus dem Nukleosom herausragenden Aminotermini der Kernhistone zu finden; vor allem Acetylierungen an bestimmten Lysinresten sind schon lange bekannt (Allfrey et al., 1964; Bannister et al., 2002; Contreras et al., 2003; Murray, 1964; Strahl et al., 2001; Strahl et al., 1999; Turner, 2003; Zhang et al., 2003a). Zusätzlich werden auch die C-terminalen Schwänze von H2A und H2B durch Ubiquitinierungen modifiziert (Sun and Allis, 2002). Erst kürzlich wurde auch eine Sumoylierung von H4 nachgewiesen (Shiio and Eisenman, 2003). Die Übertragung von Poly-ADP-ribosyl-Ketten unter bestimmten Bedingungen scheint hingegen eher ein Schutz vor proteolytischem Abbau der Histone zu sein (Morin et al., 1999).

Ein recht simpler Ansatz machte die Maskierung positiver Ladungen der Lysine durch Acetylierungen für die Schwächung der Histon-DNA-Bindung und damit für die Relaxierung eines Chromatinabschnittes verantwortlich (Allfrey et al., 1964; Norton et al., 1989; Norton et al., 1990; Puig et al., 1998; Wolffe and Hayes, 1999). Die Verstärkung von internukleosomalen Wechselwirkungen über die Histonschwänze nach deren Deacetylierung wurde demgegenüber als förderlich für die Kondensation des Chromatins in Betracht gezogen (Lee et al., 1993). Desweiteren wurde eine Konformationsänderung der Histonschwänze $\mathrm{zu} \alpha$-Helices nach Entfernung der Acetylgruppen beobachtet und als nicht allein ausreichend für eine Ablösung der DNA diskutiert (Wang et al., 2000). Der genaue Mechanismus, welcher letztlich zur Relaxation führt, ist nicht völlig verstanden, aber einen besonderen Anteil daran haben sicherlich verschiedenste Interaktionen von Nicht-Histonproteinen mit den beschriebenen Markierungen an den Histonen. Bei diesen Vorgängen dienen die Histonschwänze und ihre Markierungen als Plattform für die Bindung und Rekrutierung einer Vielzahl von Proteinen, die teilweise enzymatisch aktiv sind und oftmals bereits als Transkriptions(co)faktoren bekannt waren (Marmorstein, 2001a). So binden etwa Proteine mit Bromodomäne, darunter auch Komponenten der ChromatinRemodellierungskomplexe wie SWI/SNF, spezifisch an acetylierte Lysine (Dhalluin et al., 1999; Hassan et al., 2002; Zeng and Zhou, 2002), während Chromodomänen (wie 
etwa in TFIID) die Bindung von methylierten Lysinen vermitteln (Ball et al., 1997; Lachner et al., 2001).

In einigen Fällen sind die Auswirkungen dieser Signale näher untersucht (siehe unten) und mit einer Reihe von vitalen Zellabläufen in Verbindung gebracht worden wie Zellzykluskontrolle, DNA-Reparatur, Zelldifferenzierung und -alterung, Replikation und besonders der Transkriptionskontrolle (Bird et al., 2002; Grunstein, 1997a; Jenuwein and Allis, 2001; Legube and Trouche, 2003; Nielsen et al., 2001; Taverna et al., 2002; Tissenbaum and Guarente, 2001; Wade, 2001).

Bereits vor fast 40 Jahren wurden Acetylierungen (und Methylierungen) der Histonschwänze mit der Regulation der Transkription in Verbindung gebracht (Allfrey et al., 1964; Pogo et al., 1966). Aber erst wesentlich später wurde der direkte Kausalzusammenhang zwischen Acetylierung und transkriptioneller Aktivierung aufgezeigt (Hebbes et al., 1988). Generell konnte in den letzten Jahren eine Korrelation aktiver Gene mit einer Hyperacetylierung der Histone ihrer Nukleosomen und eine Stillegung der Transkription (silencing) infolge Hypoacetylierung festgestellt werden (Grunstein, 1997a; Jeppesen and Turner, 1993; Pogo et al., 1966; Wade et al., 1997). Eine sequenzielle Acetylierung von Lys8 am Histon H4 und Acetylierung von Lys9 und Lys14 am H3 führte zuerst zur Rekrutierung von SWI/SNF und schließlich des basalen Transkriptionsfaktors TFIID der RNA-Polymerase II und somit letztlich zur Aktivierung des IFN $\beta-G e n s$ in vitro (Agalioti et al., 2002). Es gibt allerdings Ausnahmen von diesem wahrscheinlich zu einfach vorgestellten Regelwerk. Eine Acetylierung von Lys12 an $\mathrm{H} 4$ ist nämlich entgegen der allgemeinen Regel in Heterochromatin von Hefe und Fruchtfliege $\mathrm{zu}$ finden und somit wohl ein Repressionssignal (De Rubertis et al., 1996; Grunstein, 1997a; Rundlett et al., 1996; Turner et al., 1992). 


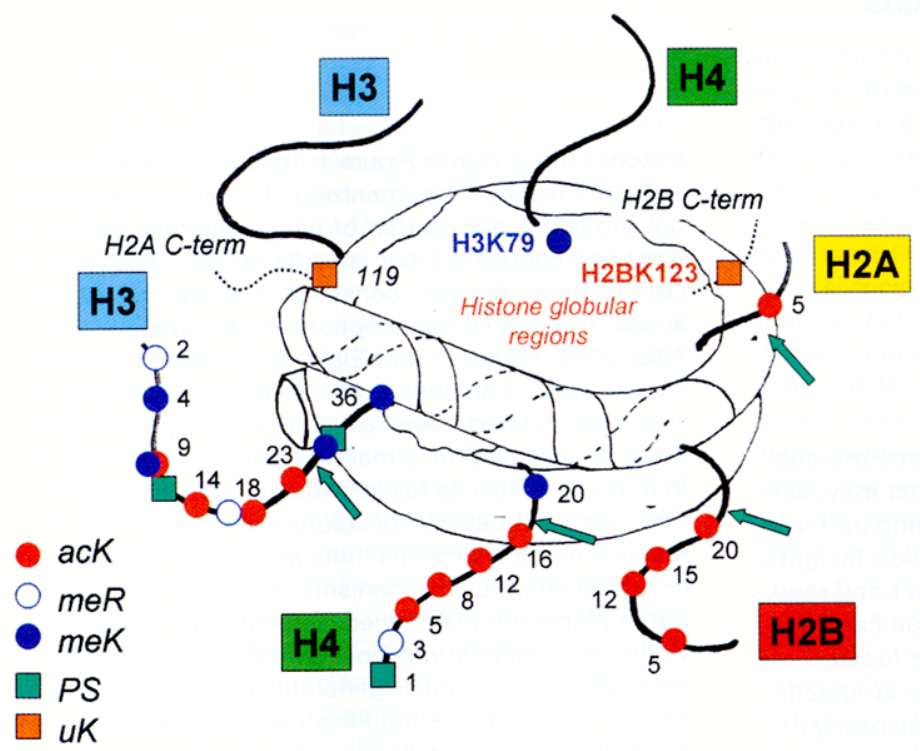

\section{Abb. 1: Modifikationen der Kernhistone.}

Einige der bislang bekannten Modifikationen an 6 der 8 Histonschwänzen eines Nukleosoms sind schematisch als Farbmarkierungen dargestellt. Die in einer linksgängigen Spirale um die Kernhistone geschlungene DNA ist angedeutet. Die Legende der Farbmarkierungen befindet sich links unten im Bild. Abkürzungen. acK, Acetyllysin, meK, Methyllysin, meR, Methylarginin, PS, Phosphoserin, uK, ubiquitiniertes Lysin (entnommen aus Turner, 2002).

Die Vielzahl an möglichen Markierungen an den Histonen (Abb. 1) und deren Kombinationen sowie die Belege, daß eine bestimmte Markierung die Anbringung weiterer Signale an diesem Histon (Clements et al., 2003; Makowski et al., 2001) oder gar an benachbarten Histonen (Briggs et al., 2002) bedingen bzw. behindern kann, ließen die Hypothese eines 'Histon-Codes' entstehen (Strahl and Allis, 2000). Dieser wird von einer Reihe modifizierender Enzym(komplex)e angebracht und von NichtHistonproteinen ausgelesen, um ein bestimmtes Ereignis anzustoßen. So ist etwa eine Phosphorylierung am Ser10 des Histons H3 eine Vorbedingung für die Acetylierung des benachbarten Lys14 durch GCN5 (Cheung et al., 2000; Lo et al., 2000), was dann transkriptionsaktivierend wirkt. Merkwürdigerweise ist die globale Phosphorylierung am Ser10 mit Chromatinkondensation und somit Genstillegung während der Mitose korreliert (De Souza et al., 2000). Dieser scheinbare Widerspruch löst sich auf, wenn man den jeweiligen Kontext an anderen Markierungen um das Phospho-Ser10 berücksichtigt (Fischle et al., 2003; Turner, 2000). 
Ein Beispiel mit dem wohl derzeit vollständigsten Bild einer derartigen (De-)Codierung ist die Stillegung von Genen in menschlichen Zellen durch die lysinspezifische Histonmethyltransfrease (HMT) SUV39H1, die das Lys9 des H3 methyliert, welches dann von der Chromodomäne des (Heterochromatin Proteins) HP1 gebunden werden kann und so zur Chromatinkondensation beiträgt (Jacobs and Khorasanizadeh, 2002; Lachner et al., 2001; Nielsen et al., 2001; Rea et al., 2000). Die Interaktion der HMT mit Lys9 wird dabei durch eine Methylierung durch eine weitere HMT Set9 an Lys4 des H3 stark gehemmt, welche ihrerseits ein Signal für eine Transkriptionsaktivierung darstellt (Nishioka et al., 2002). Dasselbe Signal hemmt auch die Rekrutierung des NuRD-Komplexes an $\mathrm{H} 3$ in logischer Konsistenz mit der durch seine Histondeacetylase-Untereinheiten (siehe unten) vermittelten Repressionsaktivität dieses Komplexes (Zegerman et al., 2002). Auch andere Markierungstypen beeinflussen das Setzen des Silencing-Signals Methyl-Lys9 am H3. So verhindert eine bereits vorhandene Markierung in Form von Acetyl-Lys9 die direkte Methylierung dieser Position, während eine Acetylierung von Lys14 in vitro kaum Einfluß hat (Rea et al., 2000; Zhang and Reinberg, 2001). Ein hemmender Einfluß auf die Aktion von SUV39H1 durch eine an H3 bestehende Phosphorylierung von Ser10 wurde ebenfalls berichtet (Rea et al., 2000; Zhang and Reinberg, 2001).

\subsection{Histondeacetylasen (HDAC)}

\subsubsection{Acetylierung und Deacetylierung durch HAT und HDAC}

Während Methylierungen als sehr stabile und langlebige Signale gelten, vor allem da bislang keine direkte Histondemethylase gefunden werden konnte (Bannister et al., 2002; Richards and Elgin, 2002), und daher neben der Transkriptionssteuerung besonders mit der epigenetischen Informationsweitergabe an die nächsten Zellgenerationen und mit dem Schalten von Entwicklungsstadien eines Organismus in Verbindung gebracht werden (Fuks et al., 2003; Hashimshony et al., 2003; Jenuwein et al., 1998; Min et al., 2003; Muegge et al., 2003; Richards and Elgin, 2002; Sedkov et al., 2003; Taverna et al., 2002; Turner, 2002), sind andere kovalente Signale wie Phosphorylierungen und besonders Acetylierungen der Histone nachweislich reversibler Natur (Bannister et al., 2002; Kouzarides, 2000). Die Halbwertszeit der Acetylierungen erstreckt sich von wenigen Minuten bis auf mehrere Stunden (Covault and Chalkley, 
1980; Katan-Khaykovich and Struhl, 2002), so daß von einem Fließgleichgewicht ausgegangen wird, das durch die gegensätzlichen enzymatischen Aktivitäten zweier Enzymfamilien einen bestimmten Acetylierungslevel aufrecht erhält (Fischle et al., 2003). Histonacetyltransferasen (HAT) übertragen Acetylgruppen von Acetyl-CoA auf bestimmte Lysine, die von Histondeacetylasen (HDAC) wieder entfernt werden können ((Grozinger and Schreiber, 2002), Abb. 2). Interessanterweise tragen viele dieser HAT wie z. B. GCN5 selbst eine Bromodomäne, andere wie ESA1 eine Chromodomäne (Marmorstein, 2001a) und können also an acetylierte bzw. methylierte Lysine binden.

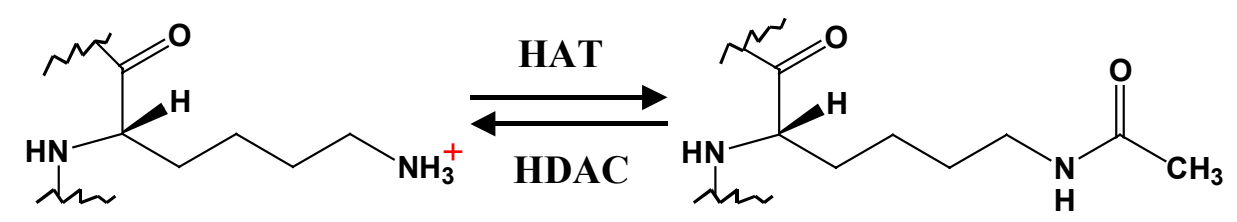

Abb. 2: Histonacetyltransferasen (HAT) und Histondeacetylasen (HDAC) katalysieren gegensätzliche Reaktionen an Lysinresten.

\subsubsection{HDAC als Mitglieder verschiedener Protein-Komplexe}

HDAC vermögen nicht direkt an DNA zu binden, sondern werden von Corepressoren lokal an das Zielgen und damit an die dort gebundenen Nukleosomen gebracht (Grozinger and Schreiber, 2002). In einigen Fällen konnte eine direkte Rekrutierung durch Transkriptionsfaktoren wie YY1, pRb (Retinoblastoma-Protein) oder MEF2 (myocyte enhancer factor 2) gezeigt werden (Magnaghi-Jaulin et al., 1998; Yang et al., 1996; Youn et al., 2000). In anderen Fällen spiegeln sich die auf ähnlichen funktionellen Ansprüchen an die Enzyme gründenden Gemeinsamkeiten zwischen HAT und HDAC auch in ihrer beider Vorkommen als katalytische Komponente in diversen, unterschiedlich zusammengesetzten Multienzymkomplexen wieder, welche auch für die jeweilige Substratspezifität verantwortlich gemacht wird (Carmen et al., 1999; Clemente et al., 2001; Grozinger and Schreiber, 2002; Johnson et al., 2002; Khochbin et al., 2001; Kolle et al., 1999; Rundlett et al., 1998; Verdin et al., 2003; Zhang et al., 1998), d. h. welche Acetylgruppe an welchem Histon deacetyliert wird. Diese Komplexe werden durch unterschiedliche DNA-Bindeproteinen wie NCoR, SMRT, REST sowie Kernrezeptoren rekrutiert (Huang et al., 1999; Li et al., 2000; Wen et al., 2000; Weston et al., 2003; You et al., 2001; Yu et al., 2003). Ein Kern aus HDAC1/2 
und den Histon-Bindeproteinen RbAp46/48 bildet u. a. mit diesen Faktoren größere Komplexe wie Sin3, NuRD und Co-REST (Alland et al., 1997; Heinzel et al., 1997; Nagy et al., 1997; Xue et al., 1998; You et al., 2001; Zhang et al., 1999b), welche auch andere enzymatische Aktivitäten aufweisen können. So enthält etwa NuRD das Dermatomyositis-spezifische Autoantigen Mi2 mit seiner SWI/SNF ähnlichen ATPaseDomäne (Zhang et al., 1998). Auch HDAC3 ist Mitglied von Enzymkomplexen (Li et al., 2000; Wen et al., 2000) und interagiert ebenso wie HDAC4, 5 und 7 direkt mit NCoR (Huang et al., 2000).

Dabei kommen mitunter HDAC und HMT gemeinsam in einem Komplex vor (Czermin et al., 2001). Überraschenderweise wurden mit Hilfe einer neuartigen FRET-Technik in vivo ebenfalls HDAC und HAT in einem Komplex assoziiert vorgefunden, was mit einer eher unspezifischen, globalen Gleichgewichtseinstellung des Acetylierungslevels in Zusammenhang stehen könnte (Katan-Khaykovich and Struhl, 2002; Yamagoe et al., 2003).

Die Komplexe Sin3 und NuRD können mit 5-Methyl-C-Bindeproteinen wie MeCP interagieren, was nach Deacetylierung und nachfolgender Methylierung der Histone eine Langzeit-Repression von Genen zur Folge hat (Bird, 2001; Hendrich et al., 2001; Jones et al., 1998; Muegge et al., 2003; Nan et al., 1998; Razin, 1998). Interessanterweise wurde kürzlich umgekehrt die Abhängigkeit der DNA-Methylierung von der Histon-Methylierung an Lys9 von H3 in Neurospora crassa beobachtet (Tamaru and Selker, 2001), welche selbst auch mit der Repression der Transkription korreliert ist (siehe oben).

\subsubsection{HDAC-Klassen}

Seit der Isolierung der ersten HDAC (HDAC1) durch Affinitätschromatographie mit einem natürlichen Inhibitor, der vorher Antitumorwirkung gezeigt hatte, und der Feststellung hoher Homologie zu dem bekannten Corepressor Rpd3 aus $S$. cerevisiae (Taunton et al., 1996) wurden neben vielen weiteren Mitgliedern der HDAC-Familie auch Enzyme eines anderen Typs mit Ähnlichkeit zu Sir2, einem anderen Repressor aus Hefe, entdeckt (Grozinger and Schreiber, 2002). Diese danach benannten Sirtuine katalysieren ebenfalls die Deacetylierung von Histonen, weisen allerdings eine völlig andere katalytische Domäne und die Abhängigkeit von NAD als zweitem Substrat auf 
(Frye, 1999; Landry et al., 2000; Marmorstein, 2001b). Enzyme der HDAC-Familie nutzen hingegen Zink als Cofaktor und arbeiten somit nach einem anderen Mechanismus (Finnin et al., 1999; Marmorstein, 2001b). Eine weitere Klasse wurde bislang nur in Pflanzen entdeckt und ist nicht homolog zur HDAC-Familie (Lusser et al., 1997).

Die bislang 11 bekannten humanen Enzyme der HDAC-Familie lassen sich aufgrund der Sequenzähnlichkeit zu den Hefe-Enzymen Rpd3 bzw. Hda1 weiter in zwei Klassen unterteilen, wobei die Rpd3-ähnlichen HDAC1, 2, 3, 8 und 11 der Klasse I und HDAC4, 5, 6, 7, 9 und 10 der Klasse II zugerechnet werden (Fischle et al., 2001b; Frye, 2000; Gao et al., 2002; Grozinger et al., 1999; Trojer et al., 2003; Verdin et al., 2003). Allerdings sind in einem phylogenetischen Baum HDAC8 und HDAC11 nahe der Wurzel der beiden Klassen angesiedelt (Gao et al., 2002; Hu et al., 2000; Van den Wyngaert et al., 2000). Enzyme beider Klassen enthalten einen gemeinsamen katalytischen Bereich mit hoher Homologie von etwa 390 As, divergieren am N- und CTerminus jedoch stark (Khochbin and Wolffe, 1997; Verdin et al., 2003). Der CTerminus ist bei HDAC1 essentiell, fehlt bei HDAC8 und 11 hingegen fast gänzlich (Gao et al., 2002; Hu et al., 2000; Pflum et al., 2001). HDAC der Klasse II tragen zusätzlich einen verlängerten Aminoterminus (Grozinger et al., 1999; Verdin et al., 2003). Die katalytische Domäne haben sie auch mit einigen prokaryotischen Enzymen, dem acetoin utilisation protein AcuC aus Bacillus subtilis und der AcetylpolyaminAmidohydrolase APAH aus Mycoplana ramosa gemeinsam (Khochbin and Wolffe, 1997; Leipe and Landsman, 1997), wobei letzteres ebenfalls Acetylgruppen (allerdings von Polyaminen wie Spermidin) abspaltet (Sakurada et al., 1996). Enzyme der Klasse II sind etwa 2-3 mal größer als die der Klasse I (von etwa 500 As) und HDAC6 und HDAC10 haben sogar eine doppelte HDAC-Domäne, die im Falle von HDAC10 aber nicht komplett ist (Grozinger et al., 1999; Verdin et al., 2003).

Im Gegensatz zu den meisten letztgenannten, nukleären Enzymen sind Klasse IIEnzyme auch cytoplasmatisch lokalisiert (Grozinger and Schreiber, 2002). HDAC6 kommt sogar hauptsächlich cytoplasmatisch vor (Verdin et al., 2003). Der Transport zwischen Kern und Cytoplasma spielt eine große Rolle bei der Regulation einiger HDAC der Klasse II. Eine Rückhaltung im Cytoplasma wird über Phosphorylierungen vermittelte Bindung an 14-3-3 Proteine reguliert. Die Phosphorylierung zerstört dabei 
auch die Interaktion mit den Transkriptionsfaktoren der MEF-Familie (McKinsey et al., 2000a; McKinsey et al., 2000b; McKinsey et al., 2001b; Verdin et al., 2003). Eine Ausnahme bildet der cytoplasmatische Export der Klasse I HDAC3 durch Interaktion mit TAB2 in Anwesenheit von IL1- $\beta$ (Baek et al., 2002). Auch Rpd3-ähnliche Enzyme werden phosphoryliert und ihre Aktivität dadurch direkt stimuliert (Pflum et al., 2001). Für HDAC4 wurde desweiteren eine Aktivitätssteigerung nach Sumoylierung festgestellt (Kirsh et al., 2002). Eine Oligomerisierung von HDAC1 in vitro gab Anlaß, homo- bzw. heterooligomere Komplexe von HDAC als weitere Regulationsmöglichkeit in Erwägung zu ziehen (Taplick et al., 2001). Kürzlich wurden Hinweise auf eine Beeinflussung der Repressionsaktivität einer HDAC der Klasse II aus Mais durch proteolytische Prozessierung $\mathrm{zu}$ einer enzymatisch aktiven, verkürzten Variante gefunden (Pipal et al., 2003).

Während HDAC der Klasse I mit Ausnahme von HDAC11 nahezu ubiquitär, wenn auch in unterschiedlichem Ausmaß, in verschiedenen Gewebetypen exprimiert werden, ist das Expressionsprofil von Klasse II Enzymen wie HDAC4, 5, 6, 7 spezifischer (de Ruijter et al., 2003; Dequiedt et al., 2003; Gao et al., 2002; Grozinger et al., 1999). Darüberhinaus werden einige HDAC in mehreren Spleißvarianten exprimiert (HDAC3, (Yang et al., 1997), HDAC7, (Kao et al., 2000), HDAC8, (Buggy et al., 2000), HDAC9, (Zhou et al., 2001), HDAC10, (Tong et al., 2002), HDAC11 (Gao et al., 2002)).

Eine weitere Regulation der HDAC-Aktivität findet auf der Ebene der HDACExpression statt, zumindest bei HDAC1, 2 und 3 (Bartl et al., 1997; Dangond and Gullans, 1998; Dangond et al., 1998; Hauser et al., 2002). So konnte z. B. die Aktivierung des HDAC1-Gens durch synergistische Phosphorylierung und Acetylierung am H3 eines Nukleosoms an dessen Promotor nach Stimulierung durch Wachstumsfaktoren und artifizieller Minderung der HDAC-Aktivität in Mauszellen beobachtet werden (Hauser et al., 2002).

Das Vorkommen der HDAC in unterschiedlichen Komplexen, ihre Rekrutierung durch unterschiedliche Transkriptionsfaktoren und ihre Expressionsprofile sowie die offensichtliche Arbeitsteilung an bestimmten Regionen des Genoms, die besonders bei genomweiten Untersuchungen der Acetylierungsmuster und Expressionsanalysen nach 
HDAC-Disruptionen zu Tage trat, weisen auf nicht-redundante Funktionen der HDAC hin (Bernstein et al., 2000; Gao et al., 2002; Grozinger and Schreiber, 2002; Peterson, 2002; Robyr et al., 2002; Verdin et al., 2003). Nur wenige Aufgaben und physiologische Rollen sind bislang bekannt; für einige HDAC wie z. B. HDAC8 sind nicht einmal Substrate bzw. Interaktionspartner oder ihre Zugehörigkeit zu einem bestimmten Signalweg gesichert.

Die am besten charakterisierten HDAC werden als generelle Transkriptionsregulatoren in einer Reihe von Regulationsnetzwerken der Zelle gesehen (Lagger et al., 2002; Peterson, 2002; Vogelauer et al., 2000). Verschiedene Multiproteinkomplexe mit HDAC1 und HDAC2 sorgen jeweils für die Repression an einem spezifischen Satz von Genen für Wachstumsfaktoren, Zyklinen, Transkriptionsfaktoren und vielen Tumorsuppressoren und greifen damit in Abläufe wie Zellzyklus und Zelldifferenzierung ein (Kim et al., 2003; Lagger et al., 2002; Magnaghi-Jaulin et al., 1998; Marks et al., 2000; Wade, 2001). Kürzlich wurde die Wichtigkeit dieser HDAC für eine korrekte Chromosomenseggregation in Säugerzellen unterstrichen, indem sie mit dem Sin3-Komplex durch mSds3 an die perizentrischen Chromosomenbereiche rekrutiert werden, um dort die Kondensation zu Heterochromatin einzuleiten (David et al., 2003).

Die Interaktion von HDAC4, 5, 7 und 9 mit Transkriptionsfaktoren der MEF-Familie ist Grundlage für die Schlüsselrolle, die diese HDAC in Entwicklungsprozessen wie Muskelzelldifferenzierung und der positiven Selektion von aktiven Neuronen spielt (Dressel et al., 2001; Linseman et al., 2003; McKinsey et al., 2000a; McKinsey et al., 2001a; Verdin et al., 2003; Youn et al., 2000). MEFs agieren sowohl als Transkriptionsaktivatoren als auch als Repressoren, abhängig davon, ob sie HAT oder HDAC binden (McKinsey et al., 2001a; McKinsey et al., 2001b).

Durch eine, den HDAC4, 5, 7, 9 gemeinsame, N-terminale Domäne binden sie MEFTranskriptionsfaktoren am Promotorbereich vieler Gene, die im Programm der Differenzierung zur Muskelzelle aktiviert werden, und reprimieren diese (Dressel et al., 2001; McKinsey et al., 2000a; Zhang et al., 2002b). Eine Regulation der HDAC erfolgt dabei vor allem über ihre Lokalisation in verschiedene Zellkompartimente (McKinsey et al., 2000a). Im Zuge der Aktivierung des $\mathrm{Ca}^{2+} /$ Calmodulin-Kinase-Signalwegs 
werden konservierte Serine am Aminoterminus phosphoryliert (McKinsey et al., 2000b; Youn et al., 2000). Diese Modifikationen vermitteln die Bindung an 14-3-3-Proteine und maskieren das Kernimportsignal von HDAC4 und 5, während wahrscheinlich ein Kernexportsignal der HDAC offengelegt wird (McKinsey et al., 2000a; McKinsey et al., 2001b; Verdin et al., 2003). Durch Rückhaltung im Cytoplasma wird die Interaktion mit MEF und somit die Repression durch HDAC verhindert (McKinsey et al., 2000a). Beleg für eine ähnliche Regulation von HDAC9 ist die Hemmung der Muskelzelldifferenzierung durch eine phosphorylierungsresistente HDAC9-Variante (Zhang et al., 2001b). HDAC4 enthält zusätzlich eine Calmodulin-Bindestelle, welche mit der MEF-Bindedomäne überlappt. Calmodulin kann HDAC4 von MEF ablösen (Youn et al., 2000) und MEF ist dann für die Bindung von Transkriptionsaktivatoren frei.

Für HDAC7 wurde kürzlich auch eine wichtige Funktion bei der Apoptose von bestimmten T-Zellen während der Negativen Selektion im Thymus beschrieben (Dequiedt et al., 2003). Dieser Vorgang wird durch den orphan-Rezeptor Nur77 aktiviert, dessen streng regulierte Expression von der Transkriptionsaktivierung durch MEF2 abhängig ist. Die Bindung von HDAC7 an MEF2 verhindert einerseits die Bindung von Coaktivatoren, andererseits sorgt die Deacetylaseaktivität für eine Stillegung der Basaltranskription am Nur77-Promotor (Youn and Liu, 2000; Youn et al., 1999). Im Zuge der Signaltransduktion vom Antigen-Rezeptor kommt es zur Unterbindung der Interaktion von MEF2 mit HDAC7. Dabei arbeiten Phosphorylierung der HDAC7 und die Verdrängung vom MEF durch Calmodulin Hand in Hand. Nach dem durch die Bindung an 14-3-3-Proteinen vermittelten Kernexport der HDAC7 kann ein transkriptionsförderlicher Komplex an MEF binden.

Ein ähnliches Modell wird für die Repression der MEF-abhängigen Gene für eine Proliferation durch HDAC5 in neuronalen Zellen in Abwesenheit des entsprechenden Stimulus für die Differenzierung diskutiert (Linseman et al., 2003; Mao et al., 1999; Verdin et al., 2003). Nur die Depolarisation aktiver Zellen führt zum Kernexport von HDAC5 und verhindert damit eine Apoptose.

Die Befunde, daß HDAC9 besonders stark in Herzmuskelzellen exprimiert wird und HDAC9-knock-out-Mäuse hypersensitiv für Signale sind, die eine Herzvergrößerung 
induzieren, haben HDAC der Klasse II auch als wichtige Elemente bei der Entwicklung der Herzmuskeln identifiziert, wo sie - ähnlich wie bei der Muskelzelldifferenzierung durch die Interaktion mit MEF-Proteinen den Signalweg blockieren, der das Wachstum des Herzmuskels fördert und bei Überstimulierung zu Hypertrophie führt (Zhang et al., 2002a). Interessanterweise wurde für HDAC der Klasse I (HDAC2) ein förderlicher Einfluß auf das Wachstum durch die über Hop (homeodomain-only protein) vermittelte Interaktion mit dem serum response factor (SRF) beobachtet (Kook et al., 2003). Dies belegt ein Beispiel für komplementäre Rollen von verschiedenen HDAC-Isotypen in ein und demselben Regulationsnetz, was die medizinische Wichtigkeit für möglichst selektive HDACI vor Augen führt (Hamamori and Schneider, 2003).

HDAC6 wurde nicht als Mitglied von bekannten transkriptionsreprimierenden Proteinkomplexen gefunden, sondern als Tubulin-Deacetylase charakterisiert (Hubbert et al., 2002; Zhang et al., 2003b). Da die Acetylierung von $\alpha$-Tubulin Mikrotubuli stabilisiert, kommt HDAC6 wohl eine Rolle bei der Regulation der Zellmotilität zu (Haggarty et al., 2003b; Hubbert et al., 2002; Piperno et al., 1987; Zhang et al., 2003b). Acetylierte Histone sind allerdings ebenfalls Substrate für dieses Enzym (Grozinger et al., 1999; Zhang et al., 2003b).

Dies ist wohl das beste Beispiel für eine HDAC mit Nicht-Histonproteinen als Substrat, aber auch für andere HDAC wie etwa HDAC8 werden andere Substrate in Erwägung gezogen (Van den Wyngaert et al., 2000). Im Hinblick auf die Vielzahl von Proteinen, die postranskriptional acetyliert in der Zelle vorgefunden werden, wird vor allem nach entsprechenden HDAC als Kandidaten für die Deacetylierung dieser Zielproteine gesucht (Polevoda and Sherman, 2002). Zumal die Acetylierungen teilweise durch HAT katalysiert werden (Fu et al., 2003) und mit der Acetylierung oft eine Regulation z. B. der Affinität zu DNA von Transkriptionsfaktoren wie p53 oder E2F1 verbunden ist (Martinez-Balbas et al., 2000; Sakaguchi et al., 1998). Für HDAC1 etwa wurde die Deacetylierung von p53 in vitro bereits gezeigt (Juan et al., 2000; Zeng et al., 2003).

Mittlerweile belegt eine wachsende Zahl von experimentellen Beobachtungen neben einem Einfluß der HDAC bei der Kontrolle des Zellzyklus und der Zelldifferenzierung auch eine Schlüsselrolle in der pathologischen Situation der Krebsentstehung (Chung, 2002). Sowohl zur Aufklärung der biologischen Rolle der HDAC als auch der 
Tumorgenese und anderer pathologischer Abläufe haben Histondeacetylasehemmer von Beginn an beigetragen. Interessanterweise konnte für HDAC-Inhibitoren (HDACI) wie Trichostatin A (TSA) und Trapoxin (TPX) in einer Reihe von Zellinien und im Tiermodell eine Induktion der Zelldifferenzierung, des Zellzyklusarrestes bzw. Apoptose und eine Reversion von transformierter Zellmorphologie gezeigt werden (Yoshida et al., 1995; Saito et al., 1999; Marks et al., 2000; He et al., 2001; Jung et al., 1999; Rosato et al., 2003; Bouchain et al., 2003). Dabei scheinen transformierte Zellen viel sensitiver auf HDACI zu reagieren als normale (Butler et al., 2000; Kim et al., 1999; Krämer et al., 2001). Interessanterweise wurde durch Analyse des Acetylierungsmusters der Histone und in Experimenten mit cDNA-Microarrays festgestellt, daß nur ein geringer Anteil $(<10 \%)$ der Gene durch HDACI beeinflußt werden (Butler et al., 2002; Marks et al., 2000; Van Lint et al., 1996). Darunter werden vor allem Tumorsuppressorgene wie der Zyklin-Kinase-Inhibitor p21 (WAF) durch HDACI dereprimiert (Butler et al., 2002; Kim et al., 2001; Krämer et al., 2001; Richon et al., 2000; Woo et al., 2002).

HDAC werden in einer Reihe von Tumoren überexprimiert (de Ruijter et al., 2003; Patra et al., 2001). Dies resultiert oftmals in einer Repression von Tumorsupressoren bzw. der Hochregulierung von bestimmten Tumoraktivatoren wie (hypoxia-induced factor) HIF-1 oder Wachstumsfaktoren wie VEGF (Kim et al., 2001).

Besonders häufig scheint aber die aberrante Rekrutierung von HDAC im Hinblick auf den Zielort im Genom oder die Dauer der Interaktion mit dem Zielbereich zu sein. Die gewichtige Rolle der HDAC wurde besonders durch den Befund hervorgehoben, daß mutierte Retinsäure-Kernrezeptoren bei der Akuten Promyelocytischen Leukämie (APL) HDAC, unbeeinflußt von deren Ligandenbindung, dauerhaft rekrutieren (Lin et al., 1998; Grignani et al., 1998; Warrell et al., 1998). Bei einer Variante, bei der ein anderer Fusionspartner beteiligt ist, kommt es statt $\mathrm{zu}$ der vorgesehenen Rekrutierung von HAT durch AML1 zu einer Deacetylierung durch einen HDAC-Komplex (Wang et al., 1998).

Die Beobachtung, daß HDACI über eine Hyperacetylierung des AndrogenKernrezeptors durch HAT eine aberrante Expression von Proliferationskontrollgenen und abnormes Zellwachstum verhindern können, rückte erst kürzlich die Verknüpfung 
der Regulation von Nicht-Histonproteinen durch HDAC mit der Tumorgenese ins Licht (Fu et al., 2003). Auch andere Proteine wie der Tumorsuppressor BRCA1 interagieren direkt mit HDAC (Juan et al., 2000; Yarden and Brody, 1999). Schon vorher wurde die Regulation einiger Tumorsuppressorproteine wie p53 und pRb über direkte Acetylierung durch HAT (dann meist FAT (factor acetyltransferase) genannt) beschrieben (Chan et al., 2001; Juan et al., 2000; Munshi et al., 2001) und eine Korrelation von Krebs mit Mutationen im Gen für die HAT BRCA2 bzw. CBP gefunden (Petrij et al., 1995; Siddique et al., 1998; Timmermann et al., 2001).

Eine Angiogenese, also die Bildung von neuen Blutgefäßen durch Endothelzellen, tritt bei vielen Tumoren auf und wird u. a. über die Acetylierung von Histonen reguliert (Kim et al., 2001; Kwon et al., 2002). Unter besonderen Umständen, bei denen verstärkt Wachstumsfaktoren ausgeschüttet werden, um die Bildung von Blutgefäßen anzuregen, wie etwa bei Hypoxie (Sauerstoffunterversorgung) kommt es zu einer Überexpression von HDAC, was in der Förderung der Angiogenese resultiert (Kim et al., 2001). Die Einwirkung von HDACI konnte durch Induktion von p53 und anderen Faktoren und Repression von VEGF und HIF-1 die Angiogenese inhibieren (Kim et al., 2003; Kwon et al., 2002).

Aufgrund vieler solcher Zusammenhänge ist es nicht verwunderlich, daß HDACI ein Potential als vielversprechende Antitumoragenzien zugesprochen wird (Johnstone, 2002; Jung, 2001; Yoshida et al., 2001; Yoshida et al., 2003). Die erst kürzlich gemachte Entdeckung einer Anti-Malaria-Wirkung bestimmter HDACI (Meinke et al., 2000; Meinke and Liberator, 2001) und der Wirksamkeit von Hydroxamaten auch gegen bakterielle Deacetylasen (Jackman et al., 2000; Kline et al., 2002; Li et al., 2003) sowie die Involvierung von HDAC in die Leukotrienantwort im Zuge von Entzündungsprozessen (Klan et al., 2003) unterstützt ebenfalls die Vorstellung von HDAC als Schlüsselenzyme bei der chemotherapeutischen Intervention bei einer Reihe von Krankheiten.

Sicher von großem Nutzen für das rationale Inhibitor-Design von HDACI war die Lösung der Kristallstruktur von HDLP, einem HDAC-ähnlichen Enzym aus Aquifex aeolicus mit etwa $35 \%$ Identität in der HDAC-Domäne (von 320 As) und nachgewiesener Deacetylase-Aktivität (Finnin et al., 1999; Marmorstein, 2001b). Das 
Enzym besteht aus einer einzigen Faltungsdomäne mit einer offenen $\alpha / \beta$-Topologie. Um ein paralleles $\beta$-Faltblatt aus acht Strängen im Zentrum gruppieren sich beiderseits je vier $\alpha$-Helices. Ein Teil der übrigen $\alpha$-Helices bilden zusammen mit langen Schleifen eine tiefe Tasche, welche mit der Enzymoberfläche durch einen engen, hydrophob ausgekleideten Tunnel verbunden ist. An der engsten Stelle dieses Tunnels befindet sich ein Zink-Ion, unter dem sich eine geräumige Höhlung weiter ins Innere des Proteins erstreckt. Der Metall-Cofaktor wird von mehreren Histidinen und Aspartaten komplexiert. Im Cokristall mit den Inhibitoren TSA bzw. SAHA komplexiert die zweizähnige Hydroxamat-Gruppe der Moleküle das Zink-Ion. Der lange Linker, der die funktionelle Gruppe mit der aromatischen Kappengruppe des Inhibitors verbindet, erstreckt sich entlang des Tunnels, so daß die Kappengruppe an dessen Rand mit aromatischen Resten des Enzyms wechselwirken kann. Besondere Bedeutung wird dabei Tyr91 zugedacht, welche nach Ligandenbindung eine andere räumliche Lage näher zur Kappengruppe einnimmt. Finnin und Mitarbeiter leiteten aus diesem Kristall auch ein Modell für den Katalysemechanismus ab, welcher sich eng an den von Metalloproteasen und Serinproteasen anlehnt und von einem tetrahedralen Übergangszustand des Carbonyl-Kohlenstoffs der $\varepsilon$-Amidbindung ausgeht (Finnin et al., 1999).

Bereits an der Isolation der ersten HDAC waren natürliche Substanzen mit inhibitorischer Wirkung auf Histondeacetylasen beteiligt (Taunton et al., 1996). Seitdem wurden aus einer Vielzahl von Organismen solche Moleküle wie schon vorher TPX und TSA gewonnen (Brosch et al., 1995; Furumai et al., 2002; Kwon et al., 1998; Meinke and Liberator, 2001; Nakajima et al., 1998; Pina et al., 2003; Sugita et al., 1992). Aber auch kurzkettige Fettsäuren wie Butyrat, die ernährungsbedingt teilweise im Magen-Darm-Trakt des Menschen vorkommen, haben eine moderate Hemmwirkung auf HDAC (Davie, 2003; Jung, 2001).

Zusätzlich wurden eine Reihe HDACI verschiedener chemischer Klassen entwickelt (Kim et al., 2003). Die bekanntesten, darunter TSA und SAHA, weisen einen aliphatischen Linker auf, der die funtionelle Hydroxamatgruppe mit einer Kappengruppe verbindet. Diese Kappengruppe besteht bei einer weiteren Gruppe aus meist vier zyklisch verbundenen Aminosäuren, darunter auch nicht-natürliche. Trapoxin (TPX) trägt am Ende des Linkers eine Epoxidgruppe anstatt einer Hydroxamatgruppe. 
Während die meisten HDACI reversibel hemmen, gibt es für TPX Evidenzen für eine irreversible Interaktion mit HDAC (Kijima et al., 1993). Dies gilt auch für den Inhibitor Depudecin, welcher Epoxidgruppen, aber keine Kappe aufweist (Kwon et al., 1998). TSA und TPX waren die Vorlagen für hybride Moleküle wie CHAP31, welche eine zyklische Kappe tragen und gleichzeitig Hydroxamate darstellen (Yoshida et al., 2001). Ein weiterer zyklischer Vertreter ist das Depsipeptid FK228, der nach Reduzierung seiner Disulfidbrücke wahrscheinlich über eine SH-Gruppe HDAC hemmt (Furumai et al., 2002). Einer völlig anderen chemischen Klasse gehören HDACI mit einer Benzamidgruppe wie MS275 (früher als MS-27-275 bezeichnet) an (Saito et al., 1999).

Einige HDACI wie z.B. SAHA und MS275 sind bereits in der klinischen Erprobungsphase I (Furumai et al., 2001; Jung, 2001; Kelly et al., 2003). Diese wurden allerdings nicht explizit auf eine besondere Isotypen-Affinität ausgelegt, und bislang wurden auch keine ausnehmend selektiven HDACI beschrieben (Kelly et al., 2002).

Bei der Therapie von malignen Erkrankungen, besonders im Hinblick auf die Beteiligung von verschiedenen HDAC mit entgegengesetzten Rollen im selben Funktionszusammenhang (Hamamori and Schneider, 2003), wären sicher möglichst selektive HDACI von immensem therapeutischen Wert, um mögliche Nebenwirkungen im Zuge der Beeinflussung kolateraler HDAC zu minimieren ( $\mathrm{Hu}$ et al., 2003; Jung, 2001; Kim et al., 2003; Kwon et al., 2003).

Aber auch bei der Aufklärung der physiologischen Funktionen einzelner HDAC und deren Einordnung in distinkte Signaltransduktionswege oder deren Zuordnung zu bestimmten Komplexen wären selektive HDACI sehr nützliche Werkzeuge (Kim et al., 2003; Krämer et al., 2001; Spotswood and Turner, 2002). Erste Unternehmungen, solche selektiven HDACI zu entwickeln, wurden gerade erst begonnen (Haggarty et al., 2003b; Hu et al., 2003; Wittich et al., 2002; Wong et al., 2003).

\subsection{Enzymtests}

Die Entwicklung von neuen HDACIs als neue Medikamente bei der Krebsabwehr und behandlung wurde jedoch in den letzten Jahren durch das Fehlen geeigneter Testsysteme erschwert. Sowohl diverse Zell-basierte als auch in vitro-Testsysteme zur Bestimmung der HDAC-Aktivität wurden beschrieben, allerdings waren diese oft nicht geeignet für ein hohes Aufkommen an Messungen, nutzten radioaktive Markierungen 
oder waren vor allem im Fall von Reportergen-basierten in vivo-Assays prinzipiell nicht sehr HDAC-spezifisch (Wegener et al., 2003b).

Anfängliche Zell-basierte Testsysteme nutzten Immunoblots mit Acetyl-spezifischen Antikörpern zum Nachweis der HDAC-Einwirkung auf Histone (Hebbes et al., 1989; Zhang et al., 1998), wobei eine Weiterentwicklung dieser Methode einen höheren Durchsatz an Messungen erlaubte (Stockwell et al., 1999). Der einzige echte HTSAssay für HDAC-Aktivität, über den zu Beginn dieser Arbeit berichtet worden war, ist Zell-basiert und nutzt ein stabil integriertes Reporterkonstrukt (Su et al., 2000). Dieses System diskriminiert jedoch nicht zwischen HDAC-Inhibitoren und jeder Art von anderen Substanzen, die in den verwendeten Tumor-Suppressor-Signalweg eingreifen. Die Schwierigkeit, auf sekundäre, meist in vitro ablaufende Testsysteme zur Aussiebung unspezifischer Kandidaten zurückgreifen zu müssen, hängt generell zellbasierten Testformaten an.

Der bei weitem verbreitetste in vitro-HDAC-Aktivitätstest beruht auf der Inkubation des Enzyms mit Histonen (Kolle et al., 1998) oder Peptiden (Taunton et al., 1996; Van den Wyngaert et al., 2000), die durch radioaktives Acetat markiert wurden. Durch HDAC freigesetztes Acetat wird mit organischen Lösungsmitteln extrahiert und mittels Szintillationsmessung quantifiziert. Obwohl der klassische, radioaktive Enzymtest bei HDAC aus einer Reihe von Quellen erfolgreich angewendet wurde, limitiert jedoch die Notwendigkeit, Produkt vom Substrat zu trennen, und die aufwendige Präparation der Substrate den Durchsatz der Messungen. Zusätzlich verursacht die Benutzung von Szintillationscocktails erhebliche Kosten im Sinne von Arbeitszeit und anfallenden radioaktiven Abfällen. Daher sind Assays dieses Typus nicht ohne weiteres für eine Automatisierung und ein Hochdurchsatz-Screening anpassbar. Eine teilweise Lösung des Problems lieferte der scintillation proximity assay (SPA) (Nare et al., 1999), indem hier ein homogenes Format realisiert wurde. Allerdings fallen immer noch die Probleme beim radioaktiven Arbeiten (Abfall, Strahlenschutzmaßnahmen) an.

Der einzige echte, nicht-radioaktive HDAC-Assay, der zu Beginn dieser Arbeit bekannt war, verwendete MAL (N-(4-methyl-7-coumarinyl)- $\mathrm{N}-\alpha$-(tert.-butyloxy-carbonyl)- $\mathrm{N}-\Omega$ acetyllysinamide) als Substrat (Hoffmann et al., 1999). Da Produkt und Substrat hier gleiche spektroskopische Eigenschaften aufweisen, muß ungünstigerweise die Entstehung des deacetylierten Produktes mittels Fluoreszenzdetektion nach Ethylacetat- 
Extraktion und HPLC gemessen werden (Hoffmann et al., 2000), was den Assay nicht besonders geeignet macht für einen hohen Meß-Durchsatz. Auch nach der Einführung von Fluoreszenz-markierten Oktapeptid-Substraten, die dem natürlichen ProteinKontext näher kommen (Hoffmann et al., 2001b), und der Einführung eines internen Fluoreszenz-Standards bei der HPLC-Reinigung des umgesetzten Produktes (Hoffmann et al., 2001a), bleibt auch dieser Assay wegen der verbleibenden Separationsschritte per HPLC nicht recht für den HTS-Einsatz geeignet. Dieser Test wurde aber immerhin erfolgreich eingesetzt, um die Zeit- und Sequenz-abhängige Deacetylierung zu studieren (Hoffmann et al., 2001a; Hoffmann et al., 2001b).

$\mathrm{Zu}$ alledem haben sich Aufreinigung und heterologe Expression von humanen HDAC in aktiver Form als schwierig erwiesen (Verdin et al., 2003). HDAC wurden bereits aus verschiedensten Organismen (u. a. aus Säugern und anderen Vertebraten, Fruchtfliege, Pilzen und Pflanzen) gewonnen (Gao et al., 2002; Graessle et al., 2001; Grozinger et al., 1999; Hoffmann et al., 1999; Huang and Kadonaga, 2001; Lusser et al., 1997; Taunton et al., 1996; Wade et al., 1999). Eine heterologe Expression für humane HDAC wurde allerdings nur in Insektenzellen beschrieben (Hu et al., 2003; Tong et al., 2002). Die Produktion von humaner HDAC8, HosB aus Aspergillus nidulans und Hos3 aus der Bäckerhefe in einem E. coli-System bilden die bislang einzigen Ausnahmen für eine bakterielle Expression (Carmen et al., 1999; Hu et al., 2000; Trojer et al., 2003). Ein leistungsstarkes Produktionssystem wäre eine wertvolle Hilfe bei der Entwicklung von Inhibitoren gegen HDAC sowie deren biochemischer Charakterisierung.

\subsection{Ziel der Arbeit}

Im Rahmen der vorliegenden Arbeit sollte ein neuer in vitro-Enzymtest für Histondeacetylasen entwickelt werden. Besonderes Augenmerk sollte dabei auf die Eignung des Assays für ein automatisiertes Durchmustern von großen Molekülbibliotheken (HTS) gerichtet werden, welche nach dem Nachweis des prinzipiellen Funktionierens u. a. durch Vermessen verschiedener HDAC-Inhibitoren wie TSA und schließlich durch Screeningversuche im kleineren Maßstab zu evaluieren war. Eine generelle Anwendbarkeit - auch für HDAC-ähnliche Enzyme bakteriellen Ursprungs - war zusätzlich erwünscht, um mit Hilfe des HDAC-Enzymtests erste 
Schritte in der Entwicklung selektiver Inhibitoren angehen zu können. Dabei sollten durch Untersuchungen zur Substratspezifität und mit potentiellen Übergangszustandsmimetika bestehende Ansichten über eine allgemeine HDACIStruktur wie auch über den Katalysemechanismus überprüft werden. Die Entwicklung eines für HDAC8 besser geeigneten Substrates sollte dabei ebenfalls versucht werden. Neben der Suche nach HDACI sollte der Assay schließlich auch genutzt werden, um einige biochemische Merkmale der HDAC selbst wie etwa die Substratspezifität oder etwaige Präferenzen im Aminosäurekontext des Substrates herauszuarbeiten. Aus diesen Untersuchungen lassen sich wertvolle Informationen zur in vivo-Funktion der Enzyme gewinnen. Eine Produktion humaner HDAC war für die Vielzahl der Messungen und für die Selektivitätsuntersuchungen von großem Interesse, wozu die für die Enzyme kodierende DNA zunächst zu klonieren, ein Expressionssystem zu etablieren und die Proteine schließlich aufzureinigen waren. 


\section{Material}

\subsection{Bakterienstämme von Escherichia coli}

\section{XL1-Blue (Stratagene, USA) (Bullock et al., 1987)}

recA1, end $\mathrm{A} 1$, gyr $\mathrm{A} 96$, thi-1, hsd $\mathrm{R} 17$, sup $\mathrm{E} 44$, relA1, lac [F' proAB $\left.\operatorname{lac} \mathrm{I}^{\mathrm{q}} Z \Delta M 15 \operatorname{Tn} 10\left(\mathrm{Tet}^{\mathrm{r}}\right)\right]$

BMH7118 (Yanisch-Perron et al., 1985)

[F' lac $^{\mathrm{q}}($ lacZ $\Delta \mathrm{M} 15)$ proAB $\Delta($ lac-pro $\mathrm{AB}) \sup \mathrm{E}$ thi-1]

BL21 (Stratagene, USA)

$\mathrm{F}^{-} d c m \operatorname{omp} \mathrm{T} h s d \mathrm{~S}\left(\mathrm{r}_{\mathrm{b}}{ }^{-} \mathrm{m}_{\mathrm{b}}{ }^{-}\right)$gal

HB101 (Maniatis et al., 1989; Studier et al., 1990)

$\mathrm{F}^{-} \Delta$ (gpt-proA)62 leuB6 gln $\mathrm{V} 44$ ara-14 galK2 lac 1 1 $\Delta($ mcrC-mrr $)$ rps $\mathrm{L} 20\left(\mathrm{Str}^{\mathrm{r}}\right) x y l-5$ mtl-1 recA13

\subsection{Plasmide}

pCRTM2.1-TOPO $^{\text {TM }}$ (Invitrogen, Leek, NL)

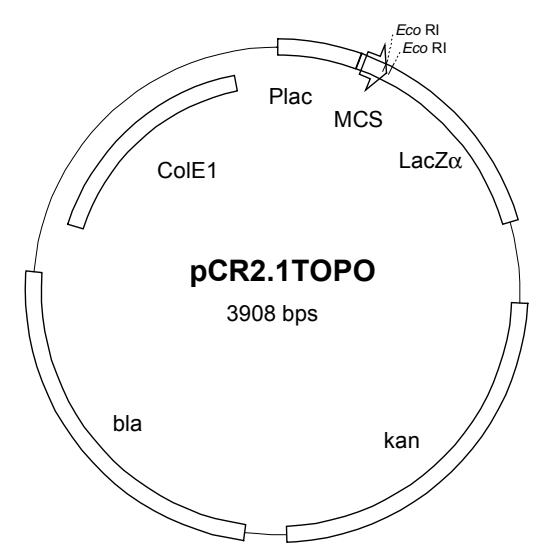

Größe: 3908 bp

Elemente: Gen für $\beta$-Laktamase (bla), Aminoglycosid-3'-Phosphotransferase-Gen (kan), ColE1Replikationsursprung (ColE1), Lac Promotor/Operator-Region $\left(P_{\text {lac }}\right)$, Multiklonierungsstelle $(M C S)$ mit flankierenden EcoRI-Schnittstellen, LacZ $\alpha$-Fragment (lacZ $\alpha$ ) 


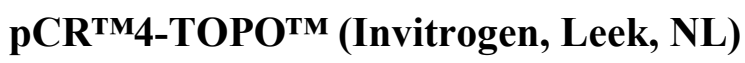

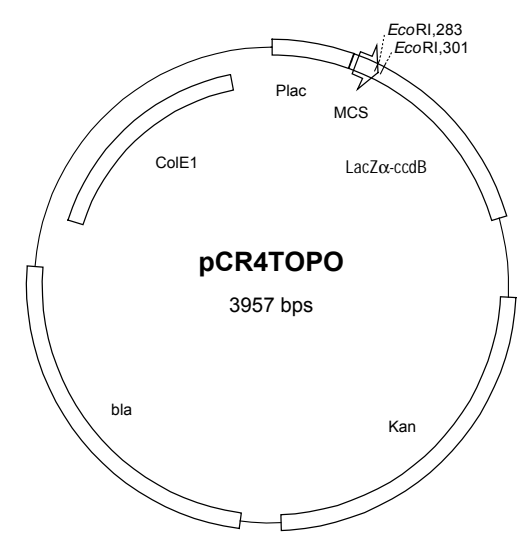

Größe: 3957 bp

Elemente: Gen für $\beta$-Laktamase (bla), Aminoglycosid-3'-Phosphotransferase-Gen (kan), ColE1Replikationsursprung (ColE1), Lac Promotor/Operator-Region $\left(P_{\text {lac }}\right.$ ), Multiklonierungsstelle (MCS) mit flankierenden EcoRI-Schnittstellen, LacZ $\alpha$-ccdB-Fusionsgen (lacZ $\alpha$-ccdB)

\section{pQE70 (Qiagen, Hilden)}

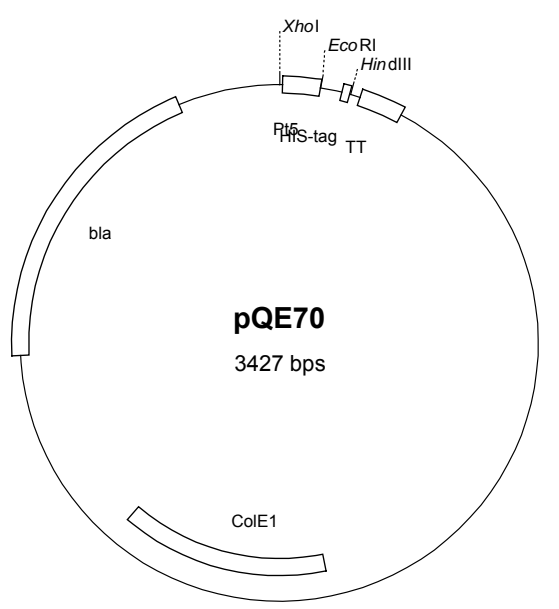

Größe: 3427 bp

Elemente: Gen für $\beta$-Laktamase (bla), ColE1-Replikationsursprung (ColE1), T5-Promotor/Lac-OperatorRegion $\left(P_{T 5}\right)$, Multiklonierungsstelle mit Codons für His-tag (HIS-tag), Transkriptionsterminator $(T T)$ 
pUBS520 (Brinkmann et al., 1989)

Größe: 5405 bp

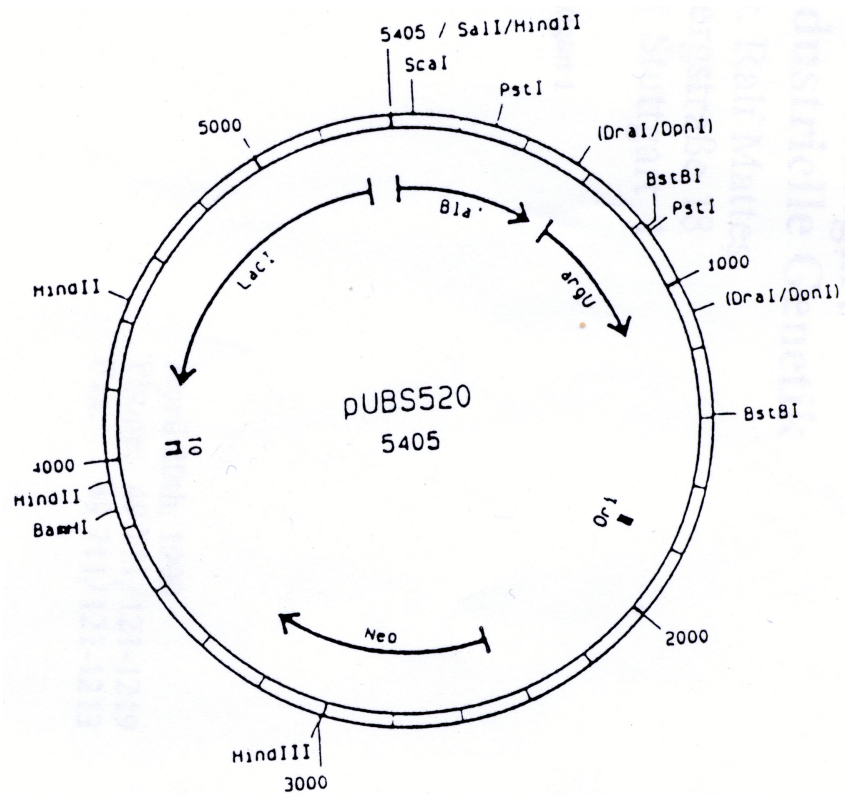

Elemente: Gen für ${ }^{\mathrm{AGA} / \mathrm{AGG}_{\mathrm{tRNA}}}{ }^{\mathrm{Arg}}$ (argU), Aminoglycosid-3'-Phosphotransferase-Gen (kan bzw. neo), p15A-Replikationsursprung (ori), Gen für den Lac-Repressor (lacl), 5'-Fragment des bla-Gens (Bla')

\subsection{DNA-Längenstandards und Protein Molekulargewichts- marker}

\subsubsection{DNA-Längenstandards}

DNA-Längenstandard-Lösungen wurden mit TE-Puffer und Sucrosefarbmarker auf eine Konzentration von $100 \mathrm{ng} / \mu 1$ eingestellt und bei $4{ }^{\circ} \mathrm{C}$ gelagert.

\section{$\lambda$-DNA/Eco47I (AvaII)-Marker (MBI Fermentas, Vilnius, Litauen)}

Fragmentgrößen [bp]: 8126, 6555, 6442, 3676, 2606, 2555, 2134, 2005, 1951, 1611, 1420, 1284, 985, 974, 894, 597, 590, 513, 511, 433, 398, 345, 310, 308, 272, 242, 215, $151,88,73,67,45,42,32,29,23$

\subsubsection{Protein-Molekulargewichtsmarker}

\section{BenchMark ${ }^{\mathrm{TM}}$ Prestained Protein Ladder (Gibco, Eggenstein)}

relatives Molekulargewicht der Proteine: 185380, 118900, 85080, 62130, 51190, 38200, 22380, 15390, 10080, 6540

\section{Prestained Protein Ladder 10-160 kDa (MBI Fermentas, Vilnius, Litauen)}

apparentes relatives Molekulargewicht der mit einem blauen Chromophor gekoppelten Proteine: 160000, 110000, 90000, 70000, 55000, 45000, 35000, 25000, 15000, 10000.

Das Protein mit einem $\mathrm{M}_{\mathrm{r}}$ von ca. 70000 wurde mit einem rotem Chromophor gekoppelt. 


\subsection{Oligodesoxyribonukleotide}

Alle synthetischen Oligodesoxyribonukleotide wurden lyophylisiert von der Fa. Metabion $\mathrm{GmbH}$ (Martinsried) bezogen, mit demineralisiertem Wasser zu $100 \mathrm{pmol} / \mu 1$ gelöst und bei $-20^{\circ} \mathrm{C}$ gelagert. Wichtige, in den Primern enthaltene Restriktionsschnittstellen sind unterstrichen, Nukleotide, die einen Basenaustausch bewirken, sind fett dargestellt.

\section{Primer zur Klonierung von HDAC1}

HDAC-RT2: 5'-GGAGATCCTTGAAGACCCAG-3'

NhisHDACpQEcoRIfw: 5'-GAGGAATTCATTAAAGAGGAGAAATTAAGCATGG CGCAGACGCAGGGCACC-3'

HDAC1EcoRIfw: 5-GAGAATTCATTAAAGAGGAGAAATTAAGCATGGCGCAG ACGCAGGGCACC-3'

HDACpQEHindIIIrv: 5'-AATTCAAGCTTAGAGAGGTCCATTCAGGCC-3

HDAC1HISHindIIIrev: 5'-GCAAGCTTTCAGTGATGGTGATGGTGATGGGCCAA CTTGACCTCCTCCTTG-3'

HDAC1PIC9rev: 5'-GGAGGAGGTCAAGTTGGCCTGAATGGACCTCTCCCTCCT CCAGTTCAA-3'

HDAC1Repfor: 5'-GAAGGTTAACTACCCGCTCCGAGACGGGATTGATGAC-3'

HDAC1deltaCXHrev: 5'-AAGCTTGGATCCTCAATGGTGATGGTGATGGTGGCT GCCGCGGCCTTCAATCAGCATTCTAAGGTTCTC-3'

\section{Primer zur Klonierung von HDAC8}

HDAC8pQEcoRIfor: 5'-GAGAATTCATTAAAGAGGAGAAATTAAGCATGGAGG AGCCGGAG-3'

HDAC8XaHISrev: 5'-TTATAAATTAAGCTTATCAATGGTGATGGTGATGGTGG CTGCCGCGGCCTTCAATGACCACATGCTTCAGATTCCCTTTG-3'

QCM-HD8for: 5'-CATGACTCCAGTGGGAATTGGC-3'

QCM-HD8rev: 5'-GCCAATTCCCACTGGAGTCATG-3'

\subsection{Enzyme und Proteine}

\section{Abcam Ltd., Cambridge, UK}

polyklonaler Antikörper (IgG) aus Kaninchen gegen humane HDAC1

Biomol, Hamburg oder Biomol Research Laboratories, Plymouth Meeting,USA rekombinante, humane HDAC8

\section{Boehringer Mannheim, Mannheim}

Ribonuklease A (RNase A) 
Calbiochem, Schwalbach am Taunus

HDAC aus Rattenleber (rat liver HDAC)

Hildmann, Christian, Abteilung für Molekulare Genetik und Präparative Molekularbiologie, Institut für Mikrobiologie und Genetik, Universität Göttingen

FB188-HDAH

\section{MBI Fermentas, Vilnius, Litauen}

Restriktionsendonukleasen und zugehörige Puffer, Rinderserumalbumin (BSA), T4 DNA-Ligase, SAP (shrimp alkaline phosphatase)

New England Biolabs, Bad Schwalbach

Restriktionsendonukleasen und zugehörige Puffer, Rinderserumalbumin (BSA)

Perkin Elmer, Branchburg, USA

Amplitaq DNA-Polymerase mit PCR-Puffer

Promega, Madison, USA

RNasin

Qiagen, Hilden

Omniscript Reverse Transkriptase, monoklonaler Anti-PentaHis-tag-Antikörper aus Maus, monoklonaler Anti-TetraHis-tag-Antikörper aus Maus

Roche Diagnostics GmbH, Mannheim

SAP (shrimp alkaline phosphatase)

Sigma, Deisenhofen

Trypsin (vom Schwein), Anti-Maus-IgG-AP-Konjugat, Anti-Kaninchen-IgGAP-Konjugat,

Stratagene, La Jolla,USA

$P f u$-DNA-Polymerase

\subsection{Chemikalien}

Alle nicht gesondert aufgeführten Chemikalien wurden von Merck (Darmstadt) bezogen. Die verwendeten, nicht gesondert aufgeführten Peptidyl-AMC-Substrate sowie einige der HDACI wurden von Daniel Riester in der AG Schwienhorst, Abteilung für Molekulare Genetik und Präparative Molekularbiologie, Institut für Mikrobiologie und Genetik, Universität Göttingen synthetisiert. Einige andere HDACI wurden von Dr. Michael Gebinoga in der AG Schwienhorst, Abteilung für Molekulare Genetik und Präparative Molekularbiologie, Institut für Mikrobiologie und Genetik, Universität Göttingen synthetisiert.

\section{Applichem, Darmstadt}

Isopropyl- $\beta$-D-thiogalactopyranosid (IPTG) 
Bachem Feinchemikalien, Bubendorf, $\mathrm{CH}$

Boc-Lys(Ac)-AMC, Boc-Lys-AMC, Tos-Gly-Pro-Lys-AMC, Tos-Gly-Pro-Arg$\mathrm{AMC}$

Baker, Deventer, NL

Dimethylformamid

Biomol, Hamburg

SAHA

BioRad, CA, USA

Tween ${ }^{\circledR}-20$

Biozym, Hess. Oldendorf

Biozym DNA Agarose

Boehringer Mannheim, Mannheim

Ampicillin (Natriumsalz), 2'-Desoxyribonukleosid-5'-triphosphate (dATP, dCTP, dGTP, dTTP), RNasin RNase-Inhibitor

Calbiochem-Novabiochem Corporation, La Jolla, USA

MS275

Difco, Dreieich

Bacto-Agar, Bacto-Peptone

Fluca, Neu-Ulm

DMSO, NMP, MeCN, Bromphenolblau, Glyzerin, $\beta$-Mercaptoethanol, Saccharose, Coomassie Brillant Blue R250, Natriumchlorid, D(+)-Glukose Monohydrat,

Gerbu, Gaiberg

Isopropyl- $\beta$-D-thiogalactopyranosid (IPTG)

Gibco BRL, Eggenstein

Hefe-Extrakt (Yeast Extract)

ICN Biochemicals, Aurora, USA

Borsäure, Ethylendiamintetraessigsäure Dinatriumsalz (EDTA), Tris(hydroxymethyl)-aminomethan (Tris)

Life Technologies Inc., Gaithersburg, USA

UltraPure Agarose (Electrophoresis Grade)

Metabion, Martinsried

Oligodesoxyribonukleotide

National Diagnostics, Simerville, USA

Protogel $^{\circledR} 30$ 
Oxoid, Wesel

Agar Bacteriological, Trypton, Pepton, Yeast Extract

Pharmacia Biotech AB, Uppsala, Schweden

Chelating Sepharose Fast Flow

Riedel-De Haen, Seelze

Ammoniumacetat, Chloroform, Ethanol, Methanol, Natriumchlorid, Salzsäure, Ammoniumsulfat

Roth, Karlsruhe

Einmalküvetten für das Photometer, Aqua Roti-Phenol, TEMED, Rotiphorese 30 bzw. 40

Scharlau Chemie S.A., Spanien

HPLC-grade Wasser, $\mathrm{MeOH}$ und $\mathrm{MeCN}$

Serva, Heidelberg

DTT, EDTA (Dinatriumsalz), D(+)-Glukose Monohydrat, SDS, TEMED, Ammoniumpersulfat, Glycin

Sigma, Deisenhofen

Ethidiumbromid, Polyethylenglycol 8000, Bromphenolblau, Triethanolamin,

Tris(hydroxymethyl)-aminomethan (Tris), Triton X-100, Kanamycin, Tween-20

(Polyethylen-Sorbitan-Monolaureat), Trichostatin A, Tos-Gly-Pro-Arg-AMC

\subsection{Kits}

Invitrogen, Groningen, $\mathrm{NL}$

TOPO TA Cloning Kit

\section{Pierce, Rockfort,USA}

Coomassie Protein Assay Reagent Kit

\section{Qiagen, Hilden}

Omniscript ${ }^{\mathrm{TM}}$-RT-Kit, QIAquick Gel Extraction Kit, Plasmid Midiprep Kit, PCR Purification Kit, Ni-NTA Purification Kit

\subsection{Sonstige Materialien und Geräte}

American National Can., Chicago, USA

Parafilm $^{\circledR}$ "M" Laboratory Film

Ansell, München

Nitrilierte Einmalhandschuhe 
Bender \& Hobein, Zürich, Schweiz

Vortex ${ }^{\circledR}$ Genie 2

\section{Biometra, Göttingen}

TRIO-Thermocycler, Elektrophoresekammern

\section{BioRad, München}

E. coli Pulser ${ }^{\circledR}$ Elektroporator, Gene Pulser ${ }^{\circledR}$ Elektroporator, Elektroporationsküvetten, Power Pac 200, Trans-Blot semi-dry Elektroblotapparat, Sequi-Blot PVDF-Membran $(0,2 \mu \mathrm{m})$

\section{Biozym, Hessisch Oldendorf}

Gestopfte, sterile Pipettenspitzen (Safeseal Tips, 10, 20, 100, $200 \mu 1$ )

\section{BMG LabTechnologies, Offenburg}

BMG Fluoreszenz-Reader POLARstar Galaxy

Branson Ultrasonics, Danbury, CT., USA

Sonifier Ultraschallstab und Steuereinheit

Brother, Japan

Mikrowellenherd Powerwave

\section{CEAG Schirp Reinraumtechnik}

Envirco Sterilbank

\section{Cybertech, Berlin}

Cybertech CS-1 Elektronische Sofortbildkamera

\section{CyBio AG, Jena}

CyBi-Screen-Machine mit $10 \mu 1$ und $250 \mu 1$ 96-Spitzen-Pipettierigel mit integriertem MTP-Fluoreszenzreader (BMG), Stacker, Übergabe-Dreharm, Inkubator/MTP-Paternoster und zwei Waschstationen

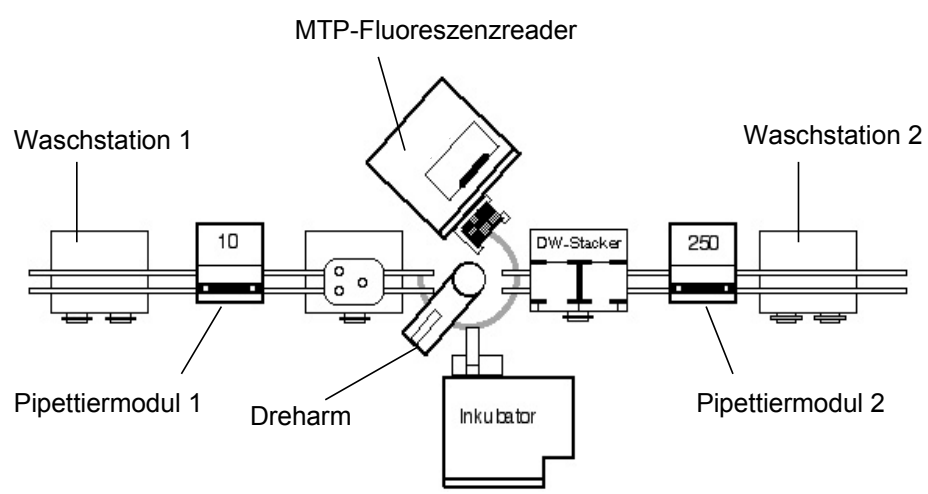

Abb. 3: Grundriß der CyBi-Screen-Machine. 


\section{Eppendorf-Netheler-Hinz, Hamburg}

Reaktionsgefäße 2,0 ml Safe-Lock, Reaktionsgefäße 1,5 ml, SpeedVac Concentrator 5301, Thermomixer 5436, Kühlzentrifuge 5804R

\section{Gilson, Medical Electronics, Frankreich}

Mikroliter-Pipetten, $1000 \mu 1,200 \mu 1,100 \mu 1,20 \mu 1,10 \mu 1$ und $2 \mu 1$

\section{Greiner Bio-One, Frickenhausen}

Petrischalen, Röhrchen 12 ml, schwarze 96-Well Mikrotiterplatten Fluotrac 200, schwarze 384-Well Mikrotiterplatten, Deep Well-Platten (Masterblock 96 well, $2 \mathrm{ml})$

\section{Helma, Müllheim/Baden}

Quarzküvetten (1 und $2 \mathrm{ml}, 1 \mathrm{~cm}$ Schichtdicke)

\section{Heraeus, Osterode}

Tischzentrifuge Biofuge pico, Brutschränke B6060 und 6420

\section{Herolab, Wiesloch}

UVT2035 302 nm UV-Leuchttisch

\section{Hettich Zentrifugen, Tuttlingen}

Kühlzentrifuge Mikro Rapid/K, Kühlzentrifuge Roto Silenta/RP, Kühlzentrifuge Rotixa/RP, Kühlzentrifuge Rotanta/RPC, Mikroliter-Tischzentrifuge

Hitachi, Tokio, Japan

Fluorimeter F-4500

Hoefer Scientific, San Francisco, USA

Platten für SDS-Gele

IKA-Labortechnik, Staufen

beheizbarer Magnetrührer IKAMAG RCT basic

Infors AG, Bottmingen, Schweiz

Kultur-Shüttler mit Inkubatorhaube

\section{IUL Instruments GmbH, Königswinter}

Constant Systems Hochdruck-Zellaufschlußsystem (Zelldisruptor)

\section{Kimberley-Clark, USA}

Kimwipes ${ }^{\circledR}$ fusselfreie Papiertücher, puderfreie Einmal-Handschuhe

\section{Knick, Berlin}

pH-Meter 761 Calimatic

\section{Kontron, Eching}

Zweistrahl-Spektrophotometer Uvicon ${ }^{\circledR} 930$ 
Köttermann Labortechnik, Uetze/Hänigsen

Wasserbad

\section{Labsystems}

Finnpipetten 8-Kanal Multipetten 0,5 - $10 \mu 1,50-300 \mu 1$

Matrix, Wilmslow Chesire, UK

Magazine mit je 96 mal $250 \mu$ Spitzen (D.A.R.T.s extended length),

Digitale Pipette Impact2 und digitale 8-Kanal-Pipette Impact8 mit zugehörigen gestopften Spitzen

Menzel-Gläser, Braunschweig

Objektträger (76 x 26 mm), Deckgläser (18 x $18 \mathrm{~mm})$

Merck, Darmstadt

$\mathrm{pH}$-Indikatorstreifen

Millipore, Eschborn

Filtereinheiten Millex FG13, Ultrafree-20 Nanopore-Wasser-Anlage,

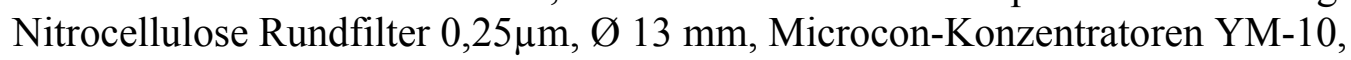

Nalgene, Hereford, England

Cryoware Cryovial (2 ml-Röhrchen für Gefrierkulturen)

neoLab, Heidelberg

8 ml-Braunglasröhrchen mit Schraubdeckel (Wheaton-Röhrchen)

Neschen

filmolux 609 (50 m x $10 \mathrm{~cm})$ selbstklebende Abdeckfolie

Nunc GmbH \& Co. KG, Wiesbaden

96 well Polypropylen-MTP mit V-Boden

Perseptive Biosystems Incorporated, Framingham, USA

Vision Workstation für Perfusions-Chromatographie, Poros 20 HQ-Säule

Pharmacia /LKB, Freiburg

Elektrophorese Stromversorger ECPS 3000/150

Sarsted, Nümbrecht; Newton, USA

Reaktionsgefäße 1,5 ml, Röhrchen $5 \mathrm{ml}$, Röhrchen $50 \mathrm{ml}$ (Falcon tubes), Multiple Well Plate 96-Well, Round bzw. Flat Bottom with Lid (Mikrotiterplatten, steril mit Deckel), PCR-cups 0,5 ml

\section{Sartorius, Göttingen}

Minisart NML Sterilfilter, Sartorius Universal U 4800P Feinwaage

\section{Schleicher und Schuell, Dassel}

Sterilfilter für Spritzen 0,2 und 0,45 $\mu \mathrm{m}, 3 \mathrm{MM}$-Filterpapier (Whatman), FaltenFilter, Ø $240 \mathrm{~mm}$, 
Schott, Mainz

Glaswaren

\section{Schütt Labortechnik, Göttingen}

pH-Meter 526, Schüttler Titramax und Inkubator 1000

\section{Serva, Heidelberg}

Visking Dialyseschläuche verschiedener Stärken und einem molecular cut off von $\mathrm{M}_{\mathrm{r}} \sim 12000-14000$

\section{Sorvall, Bad Nauheim}

Zentrifuge RC-5C, Rotortyp SS34

\section{Terumo, Leuven, Belgien}

Spritzen, $5 \mathrm{ml}, 10 \mathrm{ml}, 30 \mathrm{ml}$

\section{Wissenschaftlich-Technische Werkstätten, Weilheim}

pH-Meter-522

\section{Zeiss, Oberkochen}

Mikroskop Axioskop mit Durchlicht- und Auflichtfluoreszenz (Filtersätze: 487902 und 487909) und Kameraaufsatz, Okulare: Vergrößerung 10 x, Sehfeldzahl 20, Objektive: Plan Neofluar 63 x/1,25 Oil, 440480, Plan Neofluar 100 x/1,25 Oil, 440460, Acroplan 20 x, 440845, Immersionsöl

\section{Ziegra, Stockport, England}

Eismaschine

\subsection{Nährmedien}

Zur Sterilisation wurden die Nährmedien $20 \mathrm{~min}$ bei $121^{\circ} \mathrm{C}$ autoklaviert, wobei Glukose immer separat autoklaviert wurde. Festmedien (Platten) enthalten zusätzlich $1,5 \%(w / v)$ Agar. Hitzelabile Ingredienzen (z. B. Antibiotika) wurden nach Abkühlen des Mediums auf etwa $55^{\circ} \mathrm{C}$ zugesetzt. Platten wurden bei $4{ }^{\circ} \mathrm{C}$ gelagert und vor Benutzung auf RT gebracht.

\subsubsection{Nährmedien für Escherichia coli}

\section{dYT}

$1 \%(\mathrm{w} / \mathrm{v})$ Hefe-Extrakt, 1,6 \% (w/v) Trypton, $0,5 \%(\mathrm{w} / \mathrm{v}) \mathrm{NaCl}$

\section{LB}

0,5 \% (w/v) Hefe-Extrakt, $1 \%$ (w/v) Tryptone, $1 \%$ (w/v) $\mathrm{NaCl}$

\section{SOC}

$0,5 \%$ (w/v) Hefe-Extrakt, $2 \%$ (w/v) Trypton, 2,5 mM KCl, 0,05 \% (w/v) NaCl, nach dem Autoklavieren wurden $2 \%\left(\mathrm{w} / \mathrm{v}\right.$ ) Glukose und $10 \mathrm{mM}$ (Endkonzentration) $\mathrm{MgCl}_{2}$ und $\mathrm{MgSO}_{4}$ zugesetzt. 
Antibiotika wurden aus 1000fach konzentrierten Stammlösungen bis $\mathrm{zu}$ einer Endkonzentration von $100 \mu \mathrm{g} / \mathrm{ml}$ für Ampicillin, $75 \mu \mathrm{g} / \mathrm{ml}$ für Kanamycin bzw. $50 \mu \mathrm{g} / \mathrm{ml}$ für Tetracyclin zugegeben.

\subsection{Lösungen und Puffer}

\begin{tabular}{|c|c|}
\hline $\begin{array}{l}\text { Ac-Arg-Gly-Lys(Ac)-AMC } \\
\text { Arbeitslösung }\end{array}$ & $\begin{array}{l}\text { Boc-Lys(Ac)-AMC in DMSO angelöst und auf } 1 \mathrm{mM} \\
\text { mit HD-Puffer verdünnt, lichtgeschützt bei }-20^{\circ} \mathrm{C} \\
\text { gelagert (DMSO-Gehalt } 1,7 \% \text { ) }\end{array}$ \\
\hline $\begin{array}{l}\text { Ac-Arg-Gly-Lys-AMC } \\
\text { Arbeitslösung }\end{array}$ & $\begin{array}{l}\text { Boc-Lys(Ac)-AMC in DMSO angelöst und auf } 1 \mathrm{mM} \\
\text { mit HD-Puffer verdünnt, lichtgeschützt bei }-20^{\circ} \mathrm{C} \\
\text { gelagert (DMSO-Gehalt } 1,7 \% \text { ) }\end{array}$ \\
\hline $\begin{array}{l}\text { Ac-Gly-Ala-Lys(Ac)-AMC } \\
\text { Arbeitslösung }\end{array}$ & $\begin{array}{l}\text { Boc-Lys(Ac)-AMC in DMSO angelöst und auf } 1 \mathrm{mM} \\
\text { mit HD-Puffer verdünnt, lichtgeschützt bei }-20^{\circ} \mathrm{C} \\
\text { gelagert (DMSO-Gehalt } 1,7 \% \text { ) }\end{array}$ \\
\hline $\begin{array}{l}\text { Ac-Gly-Ala-Lys-AMC } \\
\text { Arbeitslösung }\end{array}$ & $\begin{array}{l}\text { Boc-Lys(Ac)-AMC in DMSO angelöst und auf } 1 \mathrm{mM} \\
\text { mit HD-Puffer verdünnt, lichtgeschützt bei }-20^{\circ} \mathrm{C} \\
\text { gelagert (DMSO-Gehalt } 1,7 \% \text { ) }\end{array}$ \\
\hline $\begin{array}{l}\text { Ac-Gly-Gly-Lys(Ac)-AMC } \\
\text { Arbeitslösung }\end{array}$ & $\begin{array}{l}\text { Boc-Lys(Ac)-AMC in DMSO angelöst und auf } 1 \mathrm{mM} \\
\text { mit HD-Puffer verdünnt, lichtgeschützt bei }-20^{\circ} \mathrm{C} \\
\text { gelagert (DMSO-Gehalt } 1,7 \% \text { ) }\end{array}$ \\
\hline $\begin{array}{l}\text { Ac-Gly-Gly-Lys-AMC } \\
\text { Arbeitslösung }\end{array}$ & $\begin{array}{l}\text { Boc-Lys(Ac)-AMC in DMSO angelöst und auf } 1 \mathrm{mM} \\
\text { mit HD-Puffer verdünnt, lichtgeschützt bei }-20^{\circ} \mathrm{C} \\
\text { gelagert (DMSO-Gehalt } 1,7 \% \text { ) }\end{array}$ \\
\hline $\begin{array}{l}\text { Ac-Leu-Gly-Lys(Ac)-AMC } \\
\text { Arbeitslösung }\end{array}$ & $\begin{array}{l}\text { Boc-Lys(Ac)-AMC in DMSO angelöst und auf } 1 \mathrm{mM} \\
\text { mit HD-Puffer verdünnt, lichtgeschützt bei }-20^{\circ} \mathrm{C} \\
\text { gelagert (DMSO-Gehalt } 1,7 \% \text { ) }\end{array}$ \\
\hline $\begin{array}{l}\text { Ac-Leu-Gly-Lys-AMC } \\
\text { Arbeitslösung }\end{array}$ & $\begin{array}{l}\text { Boc-Lys(Ac)-AMC in DMSO angelöst und auf } 1 \mathrm{mM} \\
\text { mit HD-Puffer verdünnt, lichtgeschützt bei }-20^{\circ} \mathrm{C} \\
\text { gelagert (DMSO-Gehalt } 1,7 \% \text { ) }\end{array}$ \\
\hline
\end{tabular}




\begin{tabular}{|c|c|}
\hline AMC-Stammlösung & $\begin{array}{l}10 \mathrm{mM} \text { in DMSO, lichtgeschützt und bei }-20{ }^{\circ} \mathrm{C} \\
\text { gelagert }\end{array}$ \\
\hline Ammoniumacetat-Puffer & 7,5 $\mathrm{M} \mathrm{NH}_{4} \mathrm{Ac}$ in Wasser, $\mathrm{pH}$ 7,5 \\
\hline Ampicillin-Stammlösung & $\begin{array}{l}100 \mathrm{mg} / \mathrm{ml} \text { Ampicillin (Na-Salz) in Wasser, } \\
\text { sterilfiltriert }\end{array}$ \\
\hline Anoden-Puffer I & $300 \mathrm{mM}$ Tris/ $\mathrm{HCl}, \mathrm{pH} 10,4$ in Wasser \\
\hline Anoden-Puffer II & 25 mM Tris/HCl, $\mathrm{pH} 10,4$ in Wasser \\
\hline AP-Entwicklungspuffer & $100 \mathrm{mM}$ Tris/HCl, $100 \mathrm{mM} \mathrm{NaCl}, 50 \mathrm{mM} \mathrm{MgCl}$, pH 9 \\
\hline APS & $10 \%$ APS in Wasser \\
\hline $\mathrm{BBT} / \mathrm{PBS}$ & $\begin{array}{l}\text { Blocking Buffer Tween zu gleichen Teilen mit PBST } \\
\text { vermischt }\end{array}$ \\
\hline $\mathrm{BCIP}$ & $50 \mathrm{mg} / \mathrm{ml}$ in Wasser, bei $-20^{\circ} \mathrm{C}$ gelagert \\
\hline Blocking Buffer & $5 \mathrm{~g}$ Magermilchpulver in PBS, frisch angesetzt \\
\hline Blocking Buffer Tween & Blocking Buffer mit 0,05 \% Tween 20 \\
\hline Boc-Lys(Ac)-AMC Stammlösung & $\begin{array}{l}30 \mathrm{mM} \text { Boc-Lys }(\mathrm{Ac}) \text {-AMC in DMSO gelöst, } \\
\text { lichtgeschützt bei }-20^{\circ} \mathrm{C} \text { gelagert }\end{array}$ \\
\hline Boc-Lys-AMC Stammlösung & $\begin{array}{l}\text { Boc-Lys-AMC in DMSO angelöst und auf } 1 \mathrm{mM} \text { mit } \\
\text { HD-Puffer verdünnt, lichtgeschützt bei }-20^{\circ} \mathrm{C} \text { gelagert } \\
\text { (DMSO-Gehalt } 1,7 \% \text { ) }\end{array}$ \\
\hline Chloroform/Isoamylalkohol & 24 Vol. Chloroform, 1 Vol. Isoamylalkohol \\
\hline Coomassie-Färbelösung & $\begin{array}{l}0,2 \% \text { Coomassie Brilliant Blue R250 in } 50 \% \text { EtOH } \\
\text { und } 10 \% \text { Eisessig, lichtgeschützt bei RT gelagert. }\end{array}$ \\
\hline dNTPs-Arbeitslösung (10 mM) & je 2,5 mM dATP, dCTP, dGTP, dTTP in Wasser \\
\hline DTT-Stammlösung & 1 M DTT in Wasser, sterilfiltriert \\
\hline EDTA & $0,5 \mathrm{M} \mathrm{Na}_{2} \mathrm{~K}-\mathrm{EDTA}, \mathrm{pH} 8,0$ \\
\hline
\end{tabular}




\begin{tabular}{|c|c|}
\hline $\begin{array}{l}\text { Ethidiumbromid-Stammlösung } \\
(1000 x)\end{array}$ & $10 \mathrm{mg} / \mathrm{ml}$ Ethidiumbromid in Wasser \\
\hline HDAC8-Puffer (I bzw. A) & $\begin{array}{llll}15 \mathrm{mM} \text { Tris/ } \mathrm{HCl}, \quad 3 \mathrm{mM} \quad \mathrm{MgCl}_{2}, \quad 10 \mathrm{mM} \quad \mathrm{KCl} \text {, } \\
10 \% \text { Glyzerin, } \mathrm{pH} 8,0\end{array}$ \\
\hline HDAC8-Puffer B & $\begin{array}{l}15 \mathrm{mM} \text { Tris/HCl, } 3 \mathrm{mM} \mathrm{MgCl}_{2}, 10 \mathrm{mM} \mathrm{KCl}, 3 \mathrm{M} \\
\mathrm{NaCl}, 10 \% \text { Glyzerin, } \mathrm{pH} 8,0\end{array}$ \\
\hline HDAC8-Puffer II & $\begin{array}{l}15 \mathrm{mM} \text { Tris/HCl, } 3 \mathrm{mM} \mathrm{MgCl}_{2}, 10 \mathrm{mM} \mathrm{KCl}, 1 \mathrm{M} \\
\text { Imidazol, } 10 \% \text { Glyzerin, } \mathrm{pH} 8,0\end{array}$ \\
\hline 2 x HDP-Puffer & $\begin{array}{l}1,5 \mathrm{ml} 1 \mathrm{M} \text { Tris/HCl, } \mathrm{pH} 8.1 \\
50 \mu 10,5 \mathrm{M} \text { EDTA, pH } 8 \\
6.25 \mathrm{ml} 4 \mathrm{M} \mathrm{NaCl} \\
200 \mu 150 \% \text { iges PEG } 8000 \\
\text { ad auf } 50 \mathrm{ml} \text { mit HPLC- } \mathrm{H}_{2} \mathrm{O}\end{array}$ \\
\hline $2 \times$ HD-Puffer & $\begin{array}{l}15 \mathrm{mM} \text { Tris/HCl, } 250 \mathrm{mM} \mathrm{NaCl}, 250 \mu \mathrm{M} \text { EDTA, } \\
10 \% \text { Glyzerin, } \mathrm{pH} 8,5\end{array}$ \\
\hline IMAC-Puffer I & $100 \mathrm{mM} \mathrm{NaP,} 100 \mathrm{mM} \mathrm{NaCl}, \mathrm{pH} 8$ \\
\hline IMAC-Puffer II & IMAC-Puffer I mit 1 M Imidazol \\
\hline IPTG-Stammlösung & $1 \mathrm{M}$ IPTG in Wasser, sterilfiltriert, bei $-20^{\circ} \mathrm{C}$ gelagert \\
\hline Kanamycin-Stammlösung & $\begin{array}{l}75 \mathrm{mg} / \mathrm{ml} \text { Kanamycin (Monosulfat) in Wasser, } \\
\text { sterilfiltriert }\end{array}$ \\
\hline Kaliumphosphat-Puffer & $1 \mathrm{M} \mathrm{KH}_{2} \mathrm{PO}_{4}$, pH 6,0 mit $1 \mathrm{M} \mathrm{K}_{2} \mathrm{HPO}_{4}$ einstellen \\
\hline Kathoden-Puffer & $\begin{array}{l}25 \mathrm{mM} \text { Tris/HCl, } \mathrm{pH} \mathrm{9,4,40} \mathrm{mM} \mathrm{D/L-Norleucin} \mathrm{in} \\
\text { Wasser }\end{array}$ \\
\hline Laemmli-Laufpuffer & $\begin{array}{l}33 \mathrm{mM} \text { Tris- } \mathrm{HCl}, 190 \mathrm{mM} \text { Glycin, } \\
0,1 \%(\mathrm{w} / \mathrm{v}) \mathrm{SDS}, \mathrm{pH} 8,3\end{array}$ \\
\hline
\end{tabular}




\begin{tabular}{|c|c|}
\hline DNA Loading Dye & $\begin{array}{l}10 \%(\mathrm{v} / \mathrm{v}) \text { Glyzerin, } 10 \mathrm{mM} \text { EDTA, } 0,03 \% \\
\text { Xylencyanol/Bromphenolblau, } 10 \mathrm{mM} \text { Tris-HCl, } \mathrm{pH} \\
7,6\end{array}$ \\
\hline MS275-Stammlösung & $1 \mathrm{mg} / \mathrm{ml}$ in $\mathrm{DMSO}$, bei $-20^{\circ} \mathrm{C}$ gelagert \\
\hline $\mathrm{NaAc}$ & $\begin{array}{l}2,5 \mathrm{M} \mathrm{NaAc} \text { in Wasser, mit Essigsäure auf } \mathrm{pH} 5.2 \\
\text { eingestellt }\end{array}$ \\
\hline $\mathrm{NaCl}$ & $4 \mathrm{M} \mathrm{NaCl}$ in Wasser, autoklaviert \\
\hline Natriumphosphat-Puffer & $1 \mathrm{M} \mathrm{Na}_{2} \mathrm{HPO}_{4}$ mit $1 \mathrm{M} \mathrm{NaH}_{2} \mathrm{PO}_{4}$ auf $\mathrm{pH} 8$ einstellen \\
\hline NBT & $75 \mathrm{mg} / \mathrm{ml}$ NBT in $70 \%$ igem DMF \\
\hline PBS & $\begin{array}{l}140 \mathrm{mM} \mathrm{NaCl} 10 \mathrm{mM} \mathrm{KCl}, 6,4 \mathrm{mM} \mathrm{Na} \mathrm{HPO}_{4}, 2 \mathrm{mM} \\
\mathrm{NaH}_{2} \mathrm{PO}_{4}\end{array}$ \\
\hline PBST & PBS mit $0,05 \%$ Tween 20 \\
\hline P1-Puffer & $\begin{array}{l}50 \text { mM Tris-HCl, pH 8,0, } 10 \text { mM EDTA, } \\
0,1 \text { g/1 RNase A }\end{array}$ \\
\hline P2-Puffer & $200 \mathrm{mM} \mathrm{NaOH}, 1 \% \mathrm{SDS}$ \\
\hline P3-Puffer & 2,55 mM KAc, $\mathrm{pH} 4,8$ \\
\hline PEG-Lösung & 13 bzw. $50 \%$ (w/v) PEG 8000 in Wasser, sterilfiltriert \\
\hline $10 \times$ Pfu-PCR-Puffer & $\begin{array}{l}200 \mathrm{mM} \text { Tris/HCl, } 100 \mathrm{mM}\left(\mathrm{NH}_{4}\right)_{2} \mathrm{SO}_{4}, 100 \mathrm{mM} \mathrm{KCl} \text {, } \\
20 \mathrm{mM} \mathrm{MgSO}_{4}, 1 \% \text { Triton-100, } 1 \mathrm{mg} / \mathrm{ml} \mathrm{BSA}, \mathrm{pH} \mathrm{8,8}\end{array}$ \\
\hline Phenol/TE & Phenol p.A. mit TE-Puffer gesättigt \\
\hline Proteinfärbelösung & $\begin{array}{l}45 \%(\mathrm{v} / \mathrm{v}) \text { Methanol, 0,2 \% (v/v) Coomassie Brilliant } \\
\text { Blue R250, } 10 \%(\mathrm{v} / \mathrm{v}) \text { Eisessig }\end{array}$ \\
\hline Proteinprobenpuffer & $\begin{array}{l}2,5 \mathrm{ml} 4 \text { x Sammelgelpuffer, } 3 \mathrm{ml} 10 \% \text { (w/v) SDS, } 300 \\
\mu 1 \beta \text {-Mercaptoethanol, 2,5 } \mathrm{ml} 80 \% \text { Glycerol, } 100 \mu 12 \\
\% \text { Bromphenolblau }\end{array}$ \\
\hline Protogel $^{\mathrm{TM}} 30$ & $30 \%(\mathrm{v} / \mathrm{v})$ Acrylamid, $0,8 \%(\mathrm{v} / \mathrm{v})$ Bisacrylamid \\
\hline
\end{tabular}




\begin{tabular}{|c|c|}
\hline Protogel ${ }^{\mathrm{TM}} 40$ & $40 \%$ (v/v) Acrylamid, $2 \%$ (v/v) Bisacrylamid \\
\hline QBT-Puffer & $\begin{array}{l}750 \mathrm{mM} \mathrm{NaCl}, 50 \mathrm{mM} \text { MOPS, } \mathrm{pH} \text { 7,0, } \\
15 \% \text { Isopropanol, } 0,15 \% \text { Triton X-100 }\end{array}$ \\
\hline QC-Puffer & $\begin{array}{l}1 \mathrm{M} \mathrm{NaCl}, 50 \mathrm{mM} \text { MOPS, pH 7,0, } \\
15 \% \text { Isopropanol }\end{array}$ \\
\hline QF-Puffer & $\begin{array}{l}1,25 \mathrm{M} \mathrm{NaCl}, 50 \mathrm{mM} \text { Tris-HCl, } \mathrm{pH} 8,5, \\
15 \% \text { Isopropanol }\end{array}$ \\
\hline Reaktionspuffer Blau (MBI) & $10 \mathrm{mM}$ Tris- $\mathrm{HCl}, \mathrm{pH} 7,5,10 \mathrm{mM} \mathrm{MgCl} 2$ \\
\hline Reaktionspuffer Grün (MBI) & $\begin{array}{l}10 \mathrm{mM} \text { Tris- } \mathrm{HCl}, \mathrm{pH} 7,5,10 \mathrm{mM} \mathrm{MgCl}_{2} \text {, } \\
50 \mathrm{mM} \mathrm{NaCl}\end{array}$ \\
\hline Reaktionspuffer Orange (MBI) & $\begin{array}{l}10 \mathrm{mM} \text { Tris- } \mathrm{HCl}, \mathrm{pH} 7,5,10 \mathrm{mM} \mathrm{MgCl}_{2} \text {, } \\
100 \mathrm{mM} \mathrm{NaCl}\end{array}$ \\
\hline Reaktionspuffer Rot (MBI) & $\begin{array}{l}10 \mathrm{mM} \text { Tris- } \mathrm{HCl}, \mathrm{pH} 8,5,10 \mathrm{mM} \mathrm{MgCl}_{2} \text {, } \\
100 \mathrm{mM} \mathrm{KCl}\end{array}$ \\
\hline Reaktionspuffer Gelb (MBI) & $\begin{array}{l}33 \mathrm{mM} \text { Tris-Essigsäure, } \mathrm{pH} \text { 7,9, } 10 \mathrm{mM} \mathrm{MgAc}, 66 \mathrm{mM} \\
\mathrm{Kac}\end{array}$ \\
\hline Reaktionspuffer NEB1 & $\begin{array}{l}10 \mathrm{mM} \text { Bis-Tris Propan-HCl, } \mathrm{pH} \text { 7,0, } \\
10 \mathrm{mM} \mathrm{MgCl}_{2}, 1 \mathrm{mM} \text { DTT }\end{array}$ \\
\hline Reaktionspuffer NEB2 & $\begin{array}{l}10 \mathrm{mM} \text { Tris- } \mathrm{HCl}, \mathrm{pH} \text { 7,9, } 10 \mathrm{mM} \mathrm{MgCl}_{2} \text {, } \\
50 \mathrm{mM} \mathrm{NaCl}, 1 \mathrm{mM} \text { DTT }\end{array}$ \\
\hline Reaktionspuffer NEB3 & $\begin{array}{l}50 \mathrm{mM} \text { Tris- } \mathrm{HCl}, \mathrm{pH} \text { 7,9, } 10 \mathrm{mM} \mathrm{MgCl}_{2} \text {, } \\
100 \mathrm{mM} \mathrm{NaCl}, 1 \mathrm{mM} \text { DTT }\end{array}$ \\
\hline Reaktionspuffer NEB4 & $\begin{array}{l}20 \mathrm{mM} \text { Tris-Essigsäure, } \mathrm{pH} \text { 7,9, } 10 \mathrm{mM} \mathrm{MgAc,} 50 \mathrm{mM} \\
\text { KAc, } 1 \mathrm{mM} \text { DTT }\end{array}$ \\
\hline
\end{tabular}




\begin{tabular}{|c|c|}
\hline RNase A Stammlösung & $\begin{array}{l}10 \mathrm{mg} / \mathrm{ml} \text { RNase, } 10 \mathrm{mM} \text { Tris-HCl, pH 7,5, } \\
15 \mathrm{mM} \mathrm{NaCl} \text {, erhitzt auf } 100^{\circ} \mathrm{C} \text { für } 20 \mathrm{~min} \text {, langsam } \\
\text { auf RT abgekühlt }\end{array}$ \\
\hline SAHA-Stammlösung & $10 \mathrm{mg} / \mathrm{ml}$ in DMSO \\
\hline Sammelgelpuffer (4 x) & 0,5 M Tris-HCl, 0,4 \% (w/v) SDS, $\mathrm{pH} 6,8$ \\
\hline Sammelgel, $5 \%$ ig für 2 Gele & $\begin{array}{l}3 \mathrm{ml} 4 \mathrm{x} \text { Sammelgelpuffer, } 2 \mathrm{ml} 30 \% \text { Protogel }^{\mathrm{TM}}, 7 \mathrm{ml} \\
\mathrm{H}_{2} \mathrm{O}, 50 \mu \mathrm{APS}, 25 \mu 1 \text { TEMED }\end{array}$ \\
\hline SDS & $10 \%(\mathrm{w} / \mathrm{v}) \mathrm{SDS}$ in Wasser \\
\hline Sucrosefarbmarker & $\begin{array}{l}60 \%(\mathrm{w} / \mathrm{v}) \text { Sucrose, } 0,1 \%(\mathrm{w} / \mathrm{v}) \text { Bromphenol-blau, } 0,1 \\
\%(\mathrm{w} / \mathrm{v}) \text { Xylencyanol FF in } 1 \times \mathrm{TAE}\end{array}$ \\
\hline T4 DNA-Ligase Puffer (10 x) & $\begin{array}{l}400 \mathrm{mM} \text { Tris- } \mathrm{HCl}, \mathrm{pH} \text { 7,8, } 100 \mathrm{mM} \mathrm{MgCl}_{2} \text {, } \\
100 \mathrm{mM} \text { DTT, } 5 \mathrm{mM} \text { ATP }\end{array}$ \\
\hline TAE-Puffer & $10 \mathrm{mM}$ Tris-Acetat, $1 \mathrm{mM}$ EDTA, $\mathrm{pH} 8,0$ \\
\hline TBE-Puffer & $\begin{array}{l}89 \mathrm{mM} \text { Tris-Base, } 89 \mathrm{mM} \text { Borsäure, } 2,5 \mathrm{mM} \text { EDTA, } \\
\mathrm{pH} 8,0\end{array}$ \\
\hline TE-Puffer & 10 mM Tris-HCl, 1 mM EDTA, pH 7,5 \\
\hline Tetracyclin-Stammlösung & $50 \mathrm{mg} / \mathrm{ml}$ Tetracyclin in EtOH (abs.), sterilfiltriert \\
\hline Thrombin-Puffer & $\begin{array}{l}50 \mathrm{ml} 1 \mathrm{M} \text { Tris/HCl } \\
20 \mathrm{ml} 5 \mathrm{M} \mathrm{NaCl} \\
10 \mathrm{ml} \mathrm{BSA}(10 \mathrm{mg} / \mathrm{ml}) \\
2 \mathrm{ml} \text { PEG8000 }(50 \%) \\
\text { ad } 1000 \mathrm{ml} \mathrm{A} \text {. dest., sterilfiltriert }(0,25 \mu \mathrm{m}) \text { bei } 4{ }^{\circ} \mathrm{C} \\
\text { gelagert. }\end{array}$ \\
\hline
\end{tabular}




\begin{tabular}{|c|c|}
\hline TI-Puffer & $\begin{array}{l}15 \mathrm{ml} \text { Isopropanol } \\
2.5 \mathrm{ml} 1 \mathrm{M} \text { Tris/HCl, } \mathrm{pH} 8.0 \\
1.25 \mathrm{ml} 4 \mathrm{M} \mathrm{NaCl} \\
\text { ad auf } 50 \mathrm{ml} \mathrm{mit} \mathrm{HPLC}-\mathrm{H}_{2} \mathrm{O}\end{array}$ \\
\hline Tos-GPK(Ac)-AMC Stammlösung & $\begin{array}{l}30 \mathrm{mM} \text { Tos-GPK(Ac)-AMC in DMSO, lichtgeschützt } \\
\text { bei }-20^{\circ} \mathrm{C} \text { gelagert }\end{array}$ \\
\hline Tos-GPK-AMC Stammlösung & $\begin{array}{l}\text { Tos-GPK-AMC in DMSO angelöst und auf } 1 \mathrm{mM} \text { mit } \\
\text { HD-Puffer verdünnt, lichtgeschützt bei }-20^{\circ} \mathrm{C} \text { gelagert } \\
\text { (DMSO-Gehalt } 1,7 \% \text { ) }\end{array}$ \\
\hline Tos-GPR-AMC Stammlösung & $\begin{array}{l}\text { Tos-GPK-AMC in DMSO angelöst, mit Thrombin- } \\
\text { Puffer bzw. HD-Puffer auf } 300 \mu \mathrm{M} \text { verdünnt, } \\
\text { lichtgeschützt bei }-20^{\circ} \mathrm{C} \text { gelagert }\end{array}$ \\
\hline Trenngelpuffer ( 4 x) & 1,5 M Tris-HCl, 0,4 \% (w/v) SDS, $\mathrm{pH} 8,8$ \\
\hline Trenngel, $10 \%$ ig für 2 Gele & $\begin{array}{l}4,5 \mathrm{ml} 4 \mathrm{x} \text { Trenngelpuffer, } 6 \mathrm{ml} 30 \% \text { Protogel }^{\mathrm{TM}}, 7,5 \mathrm{ml} \\
\mathrm{H}_{2} \mathrm{O}, 80 \mu \mathrm{l} \text { APS, } 40 \mu 1 \text { TEMED }\end{array}$ \\
\hline Trichostatin A-Stammlösung & $1 \mathrm{mg} / \mathrm{ml}$ in DMSO, bei $-20^{\circ} \mathrm{C}$ gelagert \\
\hline Tris/HCl-Puffer & $\begin{array}{l}1 \mathrm{M} \text { in Wasser, der } \mathrm{pH}-\text { Wert wurde mit } \mathrm{HCl} \text { eingestellt } \\
\text { (mit Hilfe von } \mathrm{pH}-\mathrm{Me} ß \text { streifen) }\end{array}$ \\
\hline Trituration-Buffer & $\begin{array}{l}100 \mathrm{mM} \mathrm{CaCl}_{2}, 70 \mathrm{mM} \mathrm{MgCl}_{2}, 40 \mathrm{mM} \mathrm{NaAc}, \mathrm{pH} 5,5 \text {, } \\
\text { sterilfiltriert }\end{array}$ \\
\hline Trypsin-Puffer & $\begin{array}{l}5 \mathrm{ml} 1 \mathrm{M} \mathrm{Tris} / \mathrm{HCl} \\
2 \mathrm{ml} 5 \mathrm{M} \mathrm{NaCl} \\
\text { ad } 100 \mathrm{ml} \text { A. dest. }\end{array}$ \\
\hline Trypsin-Stammlösung & $10 \mathrm{mg} / \mathrm{ml}$ Trypsin in Trypsin-Puffer \\
\hline Trypsin/TSA-Stoplösung & $\begin{array}{l}50 \mu 1 \text { Trypsin-Stammlösung mit } 50 \mathrm{ml} \text { TI-Puffer } \\
\text { verdünnt } \quad(1: 1000), \quad 100 \mu 1 \text { TSA-Stammlösung } \\
(2 \mu \mathrm{M} \text { TSA-Endkonzentration) }\end{array}$ \\
\hline
\end{tabular}




\subsection{1 cDNA}

Dr. Florentina Soto, Max-Planck-Institut für Biophysikalische Chemie in Göttingen

cDNA aus humanem Lebergewebe

\subsection{RNA}

PD Dr. Heide Siggelkow, Abteilung Gastroenterologie und Endokrinologie, UniKlinikum Göttingen

Gesamt-mRNA-Extrakt aus Osteoblasten (HOB MJ, 1,09 $\mu \mathrm{g} / \mu \mathrm{l}$ )

\subsection{Computer-Software}

Scientific and Educational Software

Clone 4.01

GraphPad Software Incorporated, San Diego, USA

Graph Pad Prism 3.03

\section{Corel Corporation}

Corel Draw 7 und 8

Conor McCarthy, School of Health Science, Griffith-University, Southport, Australia

Chromas 1.45

BMG LabTechnologies, Offenburg

FLUOStar Galaxy 4.01-0

CyBio AG, Jena

CyBio-Control 1.70

Netscape Communications Corporation

Netscape Communicator 4.7 und 7.01

Microsoft Corporation

Word 97, 2000; Excel 97, 2000

CambridgeSoft Corporation, Cambridge, USA

CS Chem Draw Std

Williamstone

Primer-Calculator

Julie Thompson, Toby Gibson, Des Higgins, EMBL Heidelberg, Cambridge,UK

ClustalW 1.6 


\section{Methoden}

\subsection{Mikrobiologische Arbeitsmethoden}

\subsubsection{Kultivierung und Lagerung von Escherichia coli}

Die Bakterien wurden in dYT- oder LB-Medium, dem das der plasmidcodierten Resistenz des Stammes entsprechende Antibiotikum (Endkonzentration bei Amp $100 \mu \mathrm{g} / \mathrm{ml}$, bei Kan $75 \mu \mathrm{g} / \mathrm{ml}$, bei Tet $25 \mu \mathrm{g} / \mathrm{ml}$ ) zugesetzt wurde, bei $37^{\circ} \mathrm{C}$ über Nacht angezogen. Kulturen bis zu einem Volumen von $5 \mathrm{ml}$ wurden in Kulturröhrchen im Roller, Kulturen von $50 \mathrm{ml}$ im 100 ml-Erlenmeyerkolben bei 150-200 Upm im Schüttelinkubator unter einer Wärmehaube inkubiert. Die Anzucht von 11-Kulturen erfolgte in der Regel in 31-Schikanekolben, indem mit $5 \mathrm{ml}$ einer $50 \mathrm{ml}$-Vorkultur beimpft wurde. Die Zelldichte der Flüssigkulturen wurde photometrisch bei $\mathrm{OD}_{600}$ gegen Medium bestimmt, wobei die Kultur immer so mit sterilem Medium verdünnt wurde, daß die gemessene Absorption kleiner als 0,8 und somit im linearen Meßbereich des Gerätes blieb.

Zur mittelfristigen Lagerung (wenige Wochen) wurden die Stämme auf Festmedien, ggf. mit dem erforderlichen Antibiotikum versehen, ausgestrichen und nach Anzucht bei $37^{\circ} \mathrm{C}$ bei $4{ }^{\circ} \mathrm{C}$ aufbewahrt. Zur dauerhaften Lagerung der Bakterien bei $-80{ }^{\circ} \mathrm{C}$ wurden Glyzerinkulturen mit einem Glyzeringehalt von etwa $30 \%$ angelegt. Dazu wurden Übernachtkulturen mit steriler 87\%iger Glyzerinlösung in einem Kryokulturröhrchen verdünnt. 


\subsubsection{Transformation von Escherichia coli}

\subsubsection{Präparation und Transformation elektrokompetenter Escherichia coli-} Zellen (Dower et al., 1988)

Zur Transformation von Escherichia coli nach der Elektroporationsmethode wurde das Protokoll nach Dower et al. (1988) verwendet. Zur Präparation elektrokompetenter Zellen wurden $50 \mathrm{ml} \mathrm{dYT/Tet} \mathrm{mit} \mathrm{Escherichia} \mathrm{coli} \mathrm{XL1-Blue} \mathrm{inokuliert} \mathrm{und} \mathrm{bis} \mathrm{zu}$ einer $\mathrm{OD}_{600}$ von ca. 0,5 herangezogen. Die Zellen wurden durch Zentrifugation (Hettich-Rotanta, $4000 \mathrm{Upm}, 10 \mathrm{~min}, 4{ }^{\circ} \mathrm{C}$ ) geerntet, in $50 \mathrm{ml}$ eiskaltem, sterilem Wasser resuspendiert (Waschen) und erneut pelletiert. Dieser Waschschritt wurde mehrmals wiederholt, wobei das Zellpellet nacheinander in $25 \mathrm{ml}$ und in $10 \mathrm{ml}$ eiskaltem, sterilem Wasser resuspendiert wurde. Nach dem letzten Zentrifugationsschritt wurde der Überstand abgegossen und das Zellpellet in $1 \mathrm{ml}$ $10 \%$ igem (v/v) Glyzerin resuspendiert. Während des gesamten Vorgangs wurden die Zellen auf Eis gehalten. $80 \mu \mathrm{l}$ Aliquots der Zellsuspension wurden in flüssigem Stickstoff schockgefroren und zur späteren Verwendung bei $-80^{\circ} \mathrm{C}$ eingefroren. Transformationstests mit $1 \mathrm{ng}$ pUC18-Plasmid ergaben normalerweise eine Transformationseffizienz von über $10^{7} \mathrm{cfu} / \mu \mathrm{g}$ DNA.

Zur Transformation wurden $80 \mu 1$ Zellsuspension auf Eis aufgetaut (45 min) mit 5-10 $\mu 1$ dialysiertem (3.2.15.) Ligationsansatz versetzt und in eine vorgekühlte Elektroporationsküvette überführt. Die Elektroporation wurde im E.coli-Pulser ${ }^{\circledR}$ (BioRad) bei folgenden Einstellungen durchgeführt: $25 \mu \mathrm{F}, 2,5 \mathrm{kV}, 200 \mathrm{Ohm}$, (meist 4,5 ms Zeitkonstante). Unmittelbar nach dem Potentialpuls wurde $1 \mathrm{ml}$ steriles SOC-Medium in die Elektroporationsküvette pipettiert, der Inhalt in ein Kulturröhrchen überführt, die Küvette zweimal mit einem weiteren Milliliter SOC-Medium in das Röhrchen ausgespült und die Zellsuspension für eine Stunde bei $37^{\circ} \mathrm{C}$ im Roller zur Ausprägung der Antibiotikaresistenz inkubiert. Anschließend wurden $200 \mu \mathrm{l}$ bzw. der durch Zentrifugation (Heraeus Biofuge pico, $20 \mathrm{~s}, 13000 \mathrm{Upm}, \mathrm{RT}$ ) pelletierte und in etwa $200 \mu \mathrm{l}$ resuspendierte Rest der Kultur auf Selektivplatten plattiert. Die Platten wurden über Nacht bei $37{ }^{\circ} \mathrm{C}$ inkubiert. Als Kontrollen wurde jeweils ein Ligationsansatz ohne Insert (Rezyklisierung) und ein Ansatz ohne Ligase und Insert (Anteil an ungeschnittenem Vektor) mitgeführt. 
3.1.2.2 Präparation und Transformation $\mathrm{CaCl}_{2}$-kompetenter Escherichia coliZellen (Mandel and Higa, 1970; modifiziert nach Cohen et al., 1972)

Mit je 0,5 ml einer Übernachtkultur von E. coli XL1-Blue (Stratagene) wurden $4 \mathrm{x}$ $50 \mathrm{ml} \mathrm{dYT-Medium} \mathrm{(mit} \mathrm{Tetracyclin)} \mathrm{angeimpft} \mathrm{und} \mathrm{diese} \mathrm{Kulturen} \mathrm{bei} 37{ }^{\circ} \mathrm{C}$ und 150 Upm im Schüttler inkubiert. Nach Erreichen einer OD $_{600}$ von etwa 0,5 wurden die Zellen für $1 \mathrm{~h}$ auf Eis inkubiert, nachfolgend pelletiert (Hettich-Rotanta/RPC, $4000 \mathrm{Upm}, 10 \mathrm{~min}, 4^{\circ} \mathrm{C}$ ) und in $50 \mathrm{ml}$ eiskaltem, sterilem Trituration-Buffer aufgenommen. Nach Inkubation auf Eis für 45 min und erneutem Pelletieren wurden die Zellen in $5 \mathrm{ml}$ Trituration-Buffer resuspendiert und gesammelt. Nach Zutropfen von 4 $\mathrm{ml}$ 87\%igem Glyzerin und leichtem Mischen, wurden $200 \mu$ l-Aliquots der Zellsuspension auf Trockeneis in Eppendorf-Reaktionsgefäße abgefüllt und bei $-80{ }^{\circ} \mathrm{C}$ bis zur späteren Verwendung eingefroren. Transformationstests mit $1 \mathrm{ng}$ pUC18Plasmid ergaben normalerweise eine Transformationseffizienz von über $10^{5} \mathrm{cfu} / \mu \mathrm{g}$ DNA.

Die Transformation erfolgte in modifizierter Form nach Sambrook et al. (1989). Auf Eis wurden $200 \mu \mathrm{C} \mathrm{CaCl}_{2}$-kompetente Zellen langsam aufgetaut, vorsichtig mit 5 oder $10 \mu 1$ Ligationsansatz vermischt und dann 30 min auf Eis inkubiert (Adsorption der DNA an die Zelloberfläche). Danach erhielten die Zellen einen Hitzeschock für $60 \mathrm{~s}$ bei $42{ }^{\circ} \mathrm{C}$ im Heizblock und wurden im Anschluß daran für 2 min auf Eis inkubiert. Nach Zugabe von $800 \mu 137^{\circ} \mathrm{C}$ warmen SOC-Medium wurde der Transformationsansatz zur Ausbildung der Antibiotikaresistenz für $1 \mathrm{~h}$ bei $37^{\circ} \mathrm{C}$ im Heizblock geschüttelt.

Beim direkten „TA-Cloning“ von PCR-Produkten (3.2.10.) wurden pro Ansatz jeweils $200 \mu 1$ und $800 \mu 1$ Zellsuspension auf LB-Amp/Kan-Platten ausgestrichen. Die Platten wurden üN bei $37^{\circ} \mathrm{C}$ inkubiert.

Bei Transformation Ligase-vermittelter Ligationsansätze wurden pro Ansatz jeweils $200 \mu \mathrm{l}$ Zellsuspension direkt auf LB-Platten mit entsprechendem Antibiotikum ausgestrichen. Nach Pelletierung und Resuspendierung der restlichen Zellen des Ansatzes in $200 \mu \mathrm{l}$ Medium wurde diese konzentrierte Zellsuspension ebenfalls ausplattiert. Die Platten wurden üN bei $37^{\circ} \mathrm{C}$ inkubiert. Als Kontrollen wurde jeweils ein Ligationsansatz ohne Insert (Rezyklisierung) und ein Ansatz ohne Ligase und Insert (Anteil an ungeschnittenem Vektor) mitgeführt. 


\subsection{Molekularbiologische Arbeitsmethoden}

Molekularbiologische Arbeitstechniken, die im folgenden nicht gesondert aufgeführt worden sind, wurden nach Standardverfahren durchgeführt (Maniatis et al., 1989).

\subsubsection{Vorbereitung von Geräten und Lösungen}

Hitzestabile Geräte wurden durch Erhitzen für $20 \mathrm{~min}$ auf $181{ }^{\circ} \mathrm{C}$ sterilisiert. Hitzestabile Lösungen wurden für $20 \mathrm{~min}$ bei $121^{\circ} \mathrm{C}$ autoklaviert. In der Hitze nicht beständige Geräte wurden mit $70 \%$ (v/v) Ethanol gereinigt und getrocknet. Hitzelabile Bestandteile von Lösungen wurden als konzentrierte Stammlösungen hergestellt und vor der Zugabe zu bereits sterilen Lösungen durch einen Membranfilter der Porengröße von $0,2 \mu \mathrm{m}$ sterilfiltriert.

\subsubsection{Fällung von DNA aus wäßrigen Lösungen}

\subsubsection{Fällung von DNA mit Ethanol}

Die Fällung von DNA mit Ethanol dient der Konzentrierung der nukleinsäurehaltigen Lösung und der Entfernung von Salzen, Proteinen sowie Minderung des Gehaltes an freien Nukleotiden bzw. Oligonukleotiden. Bei dieser Methode wird die Konzentration monovalenter Kationen $\left(\mathrm{NH}_{4}^{+}\right.$oder $\left.\mathrm{Na}^{+}\right)$stark erhöht und so die negativ geladenen Phosphatgruppen der Nukleinsäuren neutralisiert. Durch Zugabe von Ethanol (abs.) wird das Lösungsmittel $\left(\mathrm{H}_{2} \mathrm{O}\right)$ entzogen und der Nukleinsäure-Salz-Komplex ausgefällt. DNA wurde mit 1/10 Vol. 7,5 $\mathrm{M} \mathrm{NH}_{4} \mathrm{Ac}$ (oder 0,5 Vol. 2,5 M NaAc) und 2-3 Vol. eiskaltem Ethanol (abs.) versetzt und anschließend $30-45$ min bei $-80{ }^{\circ} \mathrm{C}$ oder mindestens $1 \mathrm{~h}$ bei $-20^{\circ} \mathrm{C}$ gefällt. Anschließend wurde die DNA pelletiert (Eppendorf 5804R, $30 \mathrm{~min}, 14000 \mathrm{Upm}, 4{ }^{\circ} \mathrm{C}$ ). Der Überstand wurde vorsichtig abpipettiert und das DNA-Pellet mit 70\%igem (v/v) Ethanol gewaschen, um verbliebene Salze zu entfernen. Es folgte eine weitere Zentrifugation (15 min, $14000 \mathrm{Upm}, 4{ }^{\circ} \mathrm{C}$ ), wonach der Überstand sorgfältig entfernt und das DNA-Pellet anschließend bei $37^{\circ} \mathrm{C}$ oder $3-5$ min in der SpeedVac (Eppendorf) getrocknet wurde, um das restliche Ethanol zu verdampfen. Die gereinigte DNA wurde dann in einem geeigneten Volumen sterilem demineralisiertem $\mathrm{H}_{2} \mathrm{O}$ oder TE-Puffer aufgenommen und bei $-20{ }^{\circ} \mathrm{C}$ gelagert. 


\subsubsection{Fällung von DNA mit Isopropanol}

DNA wurde alternativ auch mit Isopropanol anstelle von Ethanol gefällt. Bei der Verwendung von Isopropanol wird dabei die Präzipitation von Salzen vermindert. Dazu wurde analog zur DNA-Fällung mit Ethanol verfahren. Im Unterschied dazu wurden jedoch nur 0,7 Vol. bis 1 Vol. Isopropanol zugesetzt und bei RT gefällt. Wie auch nach der Ethanolfällung wurde anschließend mit 70\%igem (v/v) Ethanol gewaschen und das getrocknete Pellet in $\mathrm{H}_{2} \mathrm{O}$ oder TE aufgenommen.

\subsubsection{Extraktion von DNA aus wäßrigen Lösungen mit organischen Lösungsmitteln}

Zur Entfernung von Proteinen aus einer wässerigen DNA-Lösung, wurde diese mit 1 Vol. Phenol/Chloroform/Isoamylalkohol (25:24:1) versetzt und gründlich gemischt. Die anschließende Trennung der Phasen wurde durch eine Zentrifugation (Tischzentrifuge, $1 \mathrm{~min}, 13000 \mathrm{Upm}, \mathrm{RT}$ ) beschleunigt. Im Anschluß wurde die obere, wässerige und DNA-haltige Phase abgenommen und mit 1 Vol. Chloroform/Isoamylalkohol (24:1) versetzt, ebenfalls gründlich gemischt und anschließend zentrifugiert (5 min $13000 \mathrm{Upm}, \mathrm{RT}$ ). Es wurde erneut die obere wässerige Phase abgenommen und in ein neues Reaktionsgefäß überführt. Aus dieser Lösung konnte die nun proteinfreie DNA mit Ethanol ausgefällt (3.2.2.1.) werden. Bei Bedarf konnte die Extraktion auch einmal mit TE-gesättigtem Phenol und danach zweimal mit Chloroform/Isoamylalkohol (24:1) durchgeführt werden. Diese Art der Extraktion kam zur Anwendung, wenn DNA von DNA-Polymerasen oder hitzestabilen Restriktionsendonukleasen abgetrennt werden sollte.

\subsubsection{Agarosegelelektrophorese}

Diese Methode kann zur relativ genauen Größenbestimmung von linearen DNAFragmenten genutzt werden, da wegen des Polyanion-Charakters der DNA über einen breiten Bereich eine lineare Beziehung zwischen relativer Wanderungsstrecke und dem Logarithmus der Länge der Fragmente besteht (Lottspeich and Zorbas, 1998). Zirkuläre Moleküle wie Plasmide zeigen in relaxierter oder ihrer überspiralisierten (supercoiled) Form ein aberrantes Wanderungsverhalten. Ein Vergleich mit DNA-Längenstandards erlaubt eine Größenbestimmung der aufgetrennten DNA-Fragmente, als Referenz bei Plasmiden wurden andere überspiralisierte Plasmide eingesetzt. 
Diese Art der Gelelektrophorese wurde zur analytischen und präparativen Auftrennung von DNA-Fragmenten angewendet. Es wurden Agarosegele unterschiedlicher Größe und Konzentration $(0,7-2 \%(\mathrm{w} / \mathrm{v}))$ eingesetzt, wobei kurze DNA-Fragmente in hochprozentigen und lange in niederprozentigen Gelen aufgetrennt wurden. Die Agaroselösung wurde in $1 \mathrm{x}$ TAE-Puffer $(50-150 \mathrm{ml})$ in einer Mikrowelle aufgekocht und nach dem Abkühlen auf $50^{\circ} \mathrm{C}$ wurde in eine Flachbettgelapparatur mit einem darüberhängenden Taschenformer der erforderlichen Größe gegossen. Nach der Verfestigung des Gels konnte der Kamm vorsichtig herausgelöst und das Gel in eine mit $1 \times$ TAE-Puffer gefüllte Elektrophoresekammer überführt werden. Die DNA-Proben wurden mit 1/6 Volumen an DNA Loading Dye versetzt und in die Geltaschen pipettiert. Bei präparativen Gelen ist pro Spur maximal $5 \mu \mathrm{g}$ DNA aufgetragen worden, um eine Überladung des Gels zu vermeiden. Die anschließende Auftrennung der DNAFragmente entsprechend ihrer Größe erfolgte bei einer Feldstärke von 5-10 Volt/cm $(60-120 \mathrm{~V})$. Nach Anfärbung der DNA im Gel in einem Ethidiumbromidbad $(10 \mu \mathrm{g} / \mathrm{ml})$ konnten die DNA-Banden im UV-Durchlicht (UV-Leuchttisch, Herolab) bei einer Wellenlänge von $302 \mathrm{~nm}$ sichtbar gemacht und mit einer Videoprinteinheit (Cybertech) dokumentiert werden.

\subsubsection{Isolierung von DNA-Fragmenten aus Agarosegelen}

Die durch Agarosegelelektrophorese aufgetrennte DNA wurde mit Hilfe des Gel Extraction Kit (Qiagen) aus dem Gel isoliert. Dazu wurde das gewünschte Fragment mit einem sterilen Skalpell unter UV-Belichtung aus dem Gel ausgeschnitten und gewogen. Nach Zugabe von 3 Volumen chaotropem QG-Puffer pro $100 \mathrm{mg}$ Gel wurde das Gelstück durch eine 15 minütige Inkubation bei $50^{\circ} \mathrm{C}$ aufgelöst, anschließend auf eine Zentrifugationssäule gegeben und in diese hineinzentrifugiert (Tischzentrifuge, 13000 Upm, 60 s, RT). Die gebundene DNA wurde nacheinander mit $500 \mu 1$ QG und $750 \mu 1$ PE-Puffer gewaschen (Zentrifugation: 13000 Upm, 60 s, RT). Die DNA konnte dann mit $50 \mu 10$ mM Tris/HCl, pH 8,5 oder $\mathrm{H}_{2} \mathrm{O}$ von der Säule eluiert werden (durch Zentrifugation: $13000 \mathrm{Upm}, 60 \mathrm{~s}, \mathrm{RT})$. 


\subsubsection{Abtrennung von Oligonukleotiden und kurzen DNA-Fragmenten aus DNA-Gemischen}

PCR-Produkte wurden mit Hilfe des QIAquick PCR Purification Kits über eine SilikaMatrix aufgereinigt. Durch diese Methode konnten besonders PCR-Produkte sowohl von Salzen und Enzymen als auch große Vektorfragmente von kleinen DNAFragmenten $(<100 \mathrm{bp})$ befreit werden. Für die Aufreinigung durch den QIAquick PCR Purification Kit wurde die zu reinigende Probe mit 5 Volumen PB-Puffer (v/v) verdünnt, auf eine QIAqick Säule gegeben und zentrifugiert (Heraeus Biofuge pico, $1 \mathrm{~min}, 13000 \mathrm{Upm}, \mathrm{RT})$. DNA-Fragmente (> 100bp) binden dabei an eine SilikaMembran, wobei Enzyme und Salze durch Abzentrifugieren und einen anschließenden Waschschritt mit 0,75 ml PE-Puffer entfernt werden. Zur Elution der DNA von der Säule wurden $50 \mu$ l Elutions-Puffer auf die Silika-Membran pipettiert und die Säule anschließend zentrifugiert (1 min, $13000 \mathrm{Upm}, \mathrm{RT}$ ).

\subsubsection{Isolierung von Plasmid-DNA aus Escherichia coli}

\subsubsection{Isolierung von Plasmid-DNA aus Escherichia coli im analytischen} Maßstab (Mini-Präparation)

Die Mini-Präparation erfolgte nach dem Prinzip der alkalischen SDS-Lyse (Birnboim and Doly, 1979). In diesem Protokoll wurde die DNA durch wiederholte Fällung aus der wäßrigen Phase aufgereinigt. Da im für die Plasmidpräparation verwendeten Stamm E. coli XL1-Blue (Stratagene) das Gen endA disruptiert war (2.1), welches für eine Endonuklease codiert, konnte auf eine schnelle und absolute Abtrennung von Proteinen aus dem Lysat mittels Phenol-Extraktion verzichtet werden.

Im ersten Schritt erfolgt die alkalische Lyse von 1,5 ml Übernachtkultur in $200 \mu 1 \mathrm{P} 1$ Puffer und $300 \mu 1$ P2-Puffer. Dabei sorgt die Alkalisierung durch das $\mathrm{NaOH}$ auch für das Aufschmelzen von dsDNA und das SDS für die Denaturierung der Proteine, die RNase entfernt die RNA. Nach fünfminütiger Inkubation auf Eis und schlagartiger Neutralisation durch Zugabe von $300 \mu$ P3-Puffer aggregieren zufällig homologe Bereiche der relativ langen genomischen DNA-Moleküle und fallen aus. Die zirkulären, relativ kurzen, komplementären Einzelstränge der freigesetzte Plasmid-DNA sind topologisch verbunden und können daher mit hoher Wahrscheinlichkeit wieder zum dsDNA-Ring hybridisieren. Bei der folgenden Zentrifugation (Eppendorf 5804R, 30 min, $14000 \mathrm{Upm}, 4{ }^{\circ} \mathrm{C}$ ) werden Zelltrümmer, Proteine und die unlöslichen SDS- 
Membran-DNA-Knäule pelletiert. Der Plasmid-DNA-haltige Überstand wurde in ein neues Eppendorf-Reaktionsgefäß überführt und die Plasmide nach Versetzen mit $800 \mu 1$ Isopropanol und Zentrifugation (20 min, $14000 \mathrm{Upm}, 4{ }^{\circ} \mathrm{C}$ ) gefällt. Nach Waschen des Pellets mit $500 \mu \mathrm{l}$ 70\%igem (v/v) EtOH und Trocknen in der SpeedVac (Eppendorf) wurde die DNA in $20 \mu 1 \mathrm{H}_{2} \mathrm{O}$ oder TE aufgenommen.

Die Ausbeute lag bei ca. $20 \mu \mathrm{g}$ Plasmid-DNA. Die so gewonnene DNA war qualitativ für den Verdau mit Restriktionsenzymen, für Transformationen und PCR geeignet.

Sollte die Plasmid-DNA sequenziert werden, wurde die DNA nach dem Waschen in $32 \mu 1 \mathrm{H}_{2} \mathrm{O}$ aufgenommen, mit $8 \mu \mathrm{l} 4 \mathrm{M} \mathrm{NaCl}$ und $40 \mu \mathrm{l}$ 13\%igem (w/v) PEG 8000 versetzt und erneut zentrifugiert (20 min, $14000 \mathrm{Upm}, 4{ }^{\circ} \mathrm{C}$ ). Nach zweimaligem Waschen der Plasmid-DNA mit 70\%igem EtOH wurde das Pellet luftgetrocknet und in $25 \mu \mathrm{l} \mathrm{H}_{2} \mathrm{O}$ resuspendiert. Diese weitere Aufreinigungsprozedur ergab für die Sequenzierung qualitativ geeignete DNA (Giorgia Riboldi, persönliche Mitteilung).

\subsubsection{Isolierung von Plasmid-DNA aus Escherichia coli im präparativen Maßstab (Midi-Präparation)}

Die Gewinnung der Plasmid-DNA in größerem Maßstab erfolgte mit dem Plasmid Midiprep Kit (Qiagen) prinzipiell in analoger Weise wie in 3.2.6.1, allerdings wurde mehr Zellmaterial aufgearbeitet und die freigesetzte Plasmid-DNA an eine Anionentauscher-Säule gebunden. Die Bindung der Plasmid-DNA erfolgte bei $750 \mathrm{mM}$ $\mathrm{NaCl}$, durch Erhöhung der Salzkonzentration auf 1,25 $\mathrm{M} \mathrm{NaCl}$ konnte sie eluiert werden.

Zellen einer $50 \mathrm{ml}$ Übernachtkultur wurden geerntet (Hettich Rotanta/RPC, $10 \mathrm{~min}$, 4000 Upm). Der Überstand wurde entfernt und das Pellet in $4 \mathrm{ml} \mathrm{P1-Puffer}$ resuspendiert. Nach Zugabe von $4 \mathrm{ml}$ P2-Puffer und Umschwenken wurde die Lösung für 5 min auf Eis inkubiert, nach Zugabe von $5 \mathrm{ml} \mathrm{P3-Puffer} \mathrm{und} \mathrm{Umschwenken} \mathrm{für}$ weitere $15 \mathrm{~min}$ auf Eis belassen. Das Lysat wurde auf eine mit $10 \mathrm{ml}$ QBT-Puffer äquilibrierte Midi-100-Säule filtriert (Falten-Filter, Ø $240 \mathrm{~mm}$, Schleicher \& Schüll). Beim Durchlaufen der Säule wurde Plasmid-DNA selektiv gebunden, während Proteine, Zelltrümmer usw. im Durchfluß zu finden waren. Nach Waschen der Säule mit zweimal $10 \mathrm{ml}$ QC-Puffer, wurde die Plasmid-DNA mit $5 \mathrm{ml}$ QF-Puffer eluiert. Die mit 
Isopropanol gefällte DNA (3.2.2.2) wurde mit 70\%igem (v/v) EtOH gewaschen, getrocknet und in insgesamt $125 \mu 1$ TE oder Wasser aufgenommen.

Die Ausbeuten lagen für Plasmide mit ColE1-Replikationsursprung normalerweise bei 90-120 $\mu \mathrm{g}$ DNA pro $50 \mathrm{ml}$ Kultur.

\subsubsection{Konzentrationsbestimmung von Nukleinsäuren}

Eine grobe Abschätzung der Nukleinsäurekonzentration erfolgte, indem ein Aliquot der Probe zusammen mit einem DNA-Längenstandard bekannter Konzentration auf einem Agarosegel aufgetrennt wurde (3.2.3). Durch den Vergleich der mit Ethidiumbromid gefärbten Nukleinsäuren konnte die Konzentration der Probe abgeschätzt werden. Die Konzentration einer Probe wurde alternativ auch photometrisch bei $260 \mathrm{~nm}$ bestimmt, da nach dem Lambert-Beerschen Gesetz die Absorption einer Lösung der Konzentration der gelösten Substanz bei konstantem Lichtweg proportional ist und Nukleinsäuren ein Absorptionsmaximum bei ca. $260 \mathrm{~nm}$ aufweisen. Für die Berechnung der Nukleinsäurekonzentration gelten folgende Entsprechungen:

$$
\begin{aligned}
1 \mathrm{OD}_{260} & \hat{=} 50 \mathrm{ng} / \mu 1 \text { doppelsträngige DNA bzw. } \\
& \cong 40 \mathrm{ng} / \mu 1 \text { RNA bzw. } \\
& \cong 20 \mathrm{ng} / \mu 1 \text { Oligonukleotide (ssDNA) }
\end{aligned}
$$

Die Extinktion der Probe wurde außerdem bei $280 \mathrm{~nm}$ gemessen, da hier das Absorptionsmaximum von Proteinen liegt. Der Quotient $\mathrm{OD}_{260} / \mathrm{OD}_{280}$ gibt daher den Grad der Verunreinigungen der Probe durch Proteine oder phenolische Substanzen an. Reine Präparationen sollen einen Quotienten von über 1,6 aufweisen, wenn es sich um DNA handelt. RNAs weisen idealerweise einen Quotienten von 2,0 auf. Alle photometrischen Messungen wurden in einer Quarzküvette (Helma, Schichtdicke = $1 \mathrm{~cm}$ ) gegen reines $\mathrm{H}_{2} \mathrm{O}$ als Referenzwert durchgeführt, wobei die DNA meist in 50facher Verdünnung in $1 \mathrm{ml}$ Endvolumen vermessen und die tatsächliche Konzentration der Probe mit Berücksichtigung des Verdünnungsfaktors berechnet wurde.

\subsubsection{Enzymatische Spaltung von DNA mit Restriktionsendonukleasen}

Restriktionsendonukleasen vom Typ II wurden benutzt, um DNA an definierten Stellen zu schneiden. Dabei wurden die empfohlenen Temperatur- und Pufferbedingungen ( $\mathrm{pH}$, 
Salz, Ionenstärke) eingehalten, da diese Parameter für die Enzymaktivität und -spezifität kritisch sind. Falls ein Doppelverdau wegen inkompatibler Pufferanforderungen der benutzten Restriktionsenzyme nicht möglich war, wurden die Spaltungen nacheinander durchgeführt. Plasmide wurden mit 5-10 U Enzym pro Mikrogramm DNA in der Regel für $2 \mathrm{~h}$ bei der für die benutzten Restriktionsenzyme optimalen Temperatur (meist $37^{\circ} \mathrm{C}$ ) inkubiert. Bei Inkubationen über Nacht wurde weniger Enzym eingesetzt. Das Volumen des Restriktionsansatzes betrug zwischen 20 und $100 \mu 1$, wobei darauf geachtet wurde, daß die Endkonzentration des Glyzerins aus dem Enzymlagerungspuffer im Reaktionsansatz unter $5 \%$ (v/v) lag, um eine mögliche StarAktivität mancher Enzyme zu vermeiden. Sofern vom Hersteller vorgeschlagen, wurde auch acetyliertes BSA in einer Endkonzentration von $100 \mathrm{ng} / \mu 1$ zugesetzt. Die Reaktion wurde anschließend auf einem 1\%igen Agarosegel analysiert. Hitzelabile Restriktionsendonukleasen wurden durch Hitze inaktiviert (meist $65{ }^{\circ} \mathrm{C}$ für $20 \mathrm{~min}$ ), andere durch Extraktion mit organischen Lösungsmitteln (3.2.2.3) und präparative Agarosegelelektrophorese (3.2.4) abgetrennt oder mit organischen Lösungsmitteln behandelt (3.2.2.3) und gefällt (3.2.2.1).

\subsubsection{Ligation von DNA-Fragmenten}

Die Ligation von DNA-Fragmenten zu einem zirkulären Ligationsprodukt wurde in einem variablen molaren Verhältnis (von etwa $1 / 10$ bis 1/1) an entsprechend verdauten (3.2.8) DNA-Insert-Fragment gegenüber dem DNA-Vektor-Fragment durchgeführt. Verwendet wurde der T4 DNA-Ligase-Puffer unter Zusatz von ca. 5 U T4 DNA-Ligase in einem Endvolumen von 10-15 $\mu$ l. Die Reaktion erfolgte in der Regel über Nacht bei ca. $15^{\circ} \mathrm{C}$ im Wasserbad.

\subsubsection{Direkte Klonierung von PCR-Produkten (TA-Cloning)}

Mit Amplitaq-DNA-Polymerase generierte PCR-Produkte konnten direkt in den Vektor pCR2.1TOPO bzw. pCR4-TOPO aus dem TA Cloning ${ }^{T M}$ Kit (Invitrogen) ligiert werden. Das bereits vom Hersteller linearisierte Plasmid trägt kovalent an die ungepaarten 3'-Desoxythymidin-Überhänge (activated vector) gebundene Topoisomerase I, welche Inserts mit dem Plasmid ligiert und sich dabei ablöst (Shuman, 1994). Durch die kovalente Anknüpfung der Topoisomerase wurde aus der normalen trimolekularen Ligation eine sehr viel effizienter ablaufende bimolekulare. Durch die Insertion eines 
Fremdgenes in den Vektor wird der ORF des flankierenden $c c d \mathrm{~B}-\mathrm{Genes}$ unterbrochen und daher das vom unveränderten Ursprungsvektor exprimierte, für $E$. coli letale Genprodukt nicht gebildet. So wird erreicht, daß nur Klone, die mit einem rekombinanten Plasmid transformiert wurden, anwachsen können. Hierbei wurde normalerweise soviel Insert wie möglich eingesetzt. Für optimale Ligationsraten wurden frische PCR-Produkte verwendet, da die Desoxyadenosinreste an den 3'-Enden degradieren können. Der Ligationsansatz aus $1 \mu \mathrm{l}$ pCR4-TOPO-Vektor, $1 \mu$ Salzlösung (1,2 $\left.\mathrm{M} \mathrm{NaCl}, 60 \mathrm{mM} \mathrm{MgCl}_{2}\right)$ und 1-4 $\mu$ l einer typischen PCR-Reaktion wurde bei Bedarf mit sterilem $\mathrm{H}_{2} \mathrm{O}$ auf $6 \mu$ aufgefüllt und für 5-30 min bei RT inkubiert. Der Reaktionsansatz wurde bis zur weiteren Verwendung auf Eis belassen. Das entstandene genickte, aber zirkuläre Ligations-Produkt konnte direkt zur Transformation kompetenter XL1-Blue-Zellen (3.1.2) verwendet werden.

\subsubsection{Polymerasekettenreaktion (PCR)}

Die Polymerasekettenreaktion (PCR; (Mullis and Faloona, 1987; Saiki et al., 1988)) dient der enzymatischen in vitro Amplifikation spezifischer DNA-Fragmente auch aus einem hohen und komplexen Hintergrund an unspezifischer DNA. Die Reaktion besteht aus aufeinanderfolgenden Amplifikationszyklen, die jeweils durch drei Phasen unterschiedlicher Temperatur charakterisiert sind. In der ersten Phase, der Denaturierungsphase, wird eine doppelsträngige DNA-Matrize (Template) bei einer Temperatur von $94-95{ }^{\circ} \mathrm{C}$ in eine von Sekundärstrukturen freie Einzelstrang-DNA überführt. In der zweiten (Anlagerungs-) Phase (annealing), wird die Temperatur soweit abgesenkt, daß sich spezifische Oligodesoxynukleotide (Primer), die jeweils in entgegengesetzter Orientierung flankierenden Bereichen der $\mathrm{zu}$ amplifizierenden Zielregion in einer Duplex-DNA homolog sind, an den jeweils komplementären Strang der denaturierten Template-DNA anlagern. In der Extensionsphase bei meist $72{ }^{\circ} \mathrm{C}$ werden dann die Oligodesoxynukleotide durch eine thermostabile DNA-Polymerase in $5 \rightarrow 3$ '-Richtung komplementär zur Zielregion verlängert. In den aufeinanderfolgenden Amplifikationszyklen kommt es idealerweise zur exponentiellen Anreicherung der durch die beiden Primer flankierten Ziel-Sequenz. Um optimale Anlagerungsbedingungen für beide Primer $\mathrm{zu}$ schaffen und damit eine spezifische Amplifikation zu gewährleisten, sollten sich die eingesetzten Oligodesoxynukleotide 
nur wenig im Schmelzpunkt und GC-Gehalt voneinander unterscheiden. Zusätzlich sollten selbst-komplementäre Sequenzen innerhalb der Oligodesoxynukleotide vermieden werden, um die Ausbildung von Sekundärstrukturen oder Dimeren zu unterdrücken. Eine Vorabkontrolle der Primer im Hinblick auf diese Phänomene und deren theoretischen Schmelzpunkt $\left(\mathrm{T}_{\mathrm{m}}\right)$ erfolgte mit dem Programm Primer-Calculator (Williamstone). Die Berechnung erfolgte nach der empirischen Beziehung

$$
\mathrm{T}_{\mathrm{m}}\left[{ }^{\circ} \mathrm{C}\right]=69.3+0,41 \times(\% \mathrm{GC})-650 / \mathrm{n}
$$

wobei $n$ für die Anzahl der Nukleotide des Primers und (\% GC) für den prozentualen Anteil von $\mathrm{G}$ und $\mathrm{C}$ aller Nukleotide des Primers steht. Für die Amplifikation bei der RT-PCR (3.2.12.2) und den Klonierungsarbeiten wurde Amplitaq-DNA-Polymerase und der mitgelieferte Puffer verwendet, für die QCM-Prozedur (3.2.13) wurde PfuDNA-Polymerase benutzt. Die PCR-Reaktionen wurden in 0,5 ml-Reaktionsgefäßen in 50-100 $\mu$ l-Ansätzen in 1 x PCR-Puffer durchgeführt, die außer der Template-DNA dNTPs (je 2,5 mM) und 40-50 pmol von beiden Primern enthielten. Für alle PCRReaktionen wurde ein hot start durchgeführt, d.h., die DNA-Polymerase wurde erst bei hoher Temperatur im ersten Zyklus zum Ansatz gegeben. Auf diese Weise konnte die Bildung unspezifischer PCR-Produkte vor dem Beginn der Reaktionszyklen verhindert werden. Diese können durch die Verlängerung falsch angelagerter oder durch Ausbildung von Sekundärstrukturen veränderter Primer entstehen. Für die Reaktionen wurde das PCR-Gerät von Biometra (Trio) verwendet, das mit einem beheizbaren Deckel ausgestattet ist, so daß auf eine Überschichtung mit Mineralöl oder Wachs als Verdunstungsschutz verzichtet werden konnte. Die PCR-Programme wurden jeweils den unterschiedlichen Primerpaaren und Template-Bedingungen angepaßt.

Sollte das PCR Produkt für eine direkte Klonierung (3.2.10) mittels TA-KlonierungsSystem eingesetzt werden, wurde der Ansatz nach dem letzten Zyklus für mindestens 10 min bei $72{ }^{\circ} \mathrm{C}$ inkubiert. Durch die matrizenunabhängige Aktivität der TaqPolymerase werden hierbei einzelne Desoxyadenosin-Reste am 3'-Ende des DuplexMoleküls angefügt. Das PCR-Produkt konnte daher direkt für eine Ligationsreaktion mit einem dT-Überhänge tragenden Vektor eingesetzt werden. 


\subsubsection{RT-PCR (Reverse Transcription-Polymerase Chain Reaction)}

Durch Kombination von Reverser Transkription und anschließender PCR (RT-PCR) ist es möglich, selektiv in einer Zelle exprimierte Gene in Form ihrer cDNA so zu vervielfältigen, daß genügend Moleküle für eine Klonierung zur Verfügung stehen. Zuerst wird durch Reverse-Transkriptase cDNA synthetisiert, die dann mittels PCR amplifiziert wird. Bei der in dieser Arbeit eingesetzten Zweischritt-(two tube)-RT-PCR erfolgen Reverse Transkription und Amplifikation der cDNA-Spezies in unabhängigen Puffer-Systemen, was einerseits den Einsatz vieler spezialisierter und optimierter Polymerasen möglich macht, andererseits aber die Gefahr der Kontamination durch DNA oder RNasen (beim Pipettieren) erhöht. Die PCR-Produkte konnten anschließend für die direkte TA-Klonierung eingesetzt werden.

\subsubsection{1 cDNA-Synthese durch Reverse Transkription}

Das Enzym Reverse Transkriptase, eine RNA-Matritzen abhängige DNA-Polymerase, vermag an einzelsträngiger RNA aus dNTPs einen dazu komplementären ssDNAStrang zu synthetisieren. Diese Aktivität nutzt man im ersten Abschnitt einer RT-PCR, um mRNA in cDNA umzuschreiben. Dazu benötigt das Enzym einen Primer, der auch ein synthetisches Oligo-Desoxyribonukleotid sein kann. Viele Reverse Transkriptasen besitzen eine RNase H-Aktivität, durch die der transkribierte RNA-Strang abgebaut wird. Zur Gewinnung der für HDAC1 codierenden cDNA wurde (anstelle eines zum Poly-A-Schwanz der mRNA komplementären Poly-dT-Primer) ein genspezifischer RTPrimer (HDAC-RT 2) verwendet. Es wurde das Omniscript ${ }^{\text {TM}}-$ RT-Kit (Qiagen) verwendet und variable Mengen (etwa 2-2200 ng) an mRNA als Template eingesetzt, welches erst kurz vor Start der Reaktion auf Eis aufgetaut wurde. Der $20 \mu 1$ Ansatz enthielt neben dem Template noch $2 \mu 110$ x RT-Buffer, $2 \mu 1$ dNTP-Mix (5 mM je dNTP) und $10 \mathrm{U}$ RNasin, einen RNase-Inhibitor. Ohne vorherige Hitze-Denaturierung zur Beseitigung von etwaigen Sekundärstrukturen wurde durch Zugabe von $4 \mathrm{U}$ Omniscript ${ }^{\mathrm{TM}}$-Reverser Transcriptase die Reaktion gestartet und der Ansatz bei $37{ }^{\circ} \mathrm{C}$ für 80 min inkubiert.

\subsubsection{Amplifikation der cDNA mittels PCR}

Die Amplifikation der mittels reverser Transkription gewonnenen cDNA erfolgte durch eine nachfolgende PCR-Reaktion (3.2.12) unter Verwendung eines für die HDAC1- 
cDNA spezifischen Primerpaares und Amplitaq-DNA-Polymerase. Auf eine thermische Inaktivierung der Reversen Transkriptase und Abtrennung des RT-Primers wurde verzichtet. $\mathrm{Zu}$ einem $100 \mu \mathrm{l}$ PCR-Ansatz mit je 50 pmol der Primer NhisHDACpQEcoRIfw und HDAC1PIC9rev und $200 \mu \mathrm{M}$ dNTPs wurden $2 \mu$ RTProdukt als Template gegeben und mittels hot start PCR unter Verwendung folgender Parameter amplifiziert: Denaturierung bei $95^{\circ} \mathrm{C}$ für $3 \mathrm{~min}$, Annealing bei $52{ }^{\circ} \mathrm{C}$ für 2 min, Verlängerung bei $72^{\circ} \mathrm{C}$ für $2 \mathrm{~min}$, daran anschließend 30 Zyklen von Denaturierung bei $95{ }^{\circ} \mathrm{C}$ für $1 \mathrm{~min}$, Annealing bei $58^{\circ} \mathrm{C}$ für $90 \mathrm{~s}$, Verlängerung bei $72{ }^{\circ} \mathrm{C}$ für $2 \mathrm{~min}$. Nach dem letzten Zyklus wurden unvollständig synthetisierte Moleküle bei $72{ }^{\circ} \mathrm{C}$ für 20 min zur vollen Länge aufgefüllt.

\subsubsection{Direkte PCR-Mutagenese eines Zielvektors (QCM-Verfahren, modifiziert nach (Li and Wilkinson, 1997; Wang and Malcom, 2002))}

Mit dem PCR-basierten Quik ${ }^{\mathrm{TM}}$-Change Mutagesis (QCM)-Verfahren als einer Spielart der site-directed mutagenesis lassen sich einzelne oder mehrere Basen (z. B. ein oder einige aufeinander folgende Codons) sequenzspezifisch direkt im bestehenden Vektorkontext mutieren, deletieren oder inserieren, ohne daß eine Subklonierung nötig wäre. Dabei werden zwei direkt zueinander komplementäre Oligonukleotide, die beide die gewünschte Mutation beinhalten, in eine PCR eingesetzt, wobei die Primer sich mit ihren beiderseits der Mutagenesestelle völlig zum Template komplemetären Bereichen anlagern und von dort in mehreren Zyklen der gesamte Zielvektor (mit den Mutationen) amplifiziert wird. Da hier normalerweise recht lange DNA-Fragmente amplifiziert werden müssen, bedient man sich zur Fehlerunterdrückung der $P f u$-DNA-Polymerase. Die Abtrennung des parentalen Plasmides (ohne Mutation) und der Hybride mit nur einem mutierten DNA-Strang, die anteilsmäßig immer erhalten bleiben bzw. entstehen, erfolgt durch den Verdau dieser Spezies mit der methylierungsabhängigen Restriktionsendonuklease DpnI, welche ausschließlich 5'-Gm ${ }^{6}$ ATC-3'-Sequenzen schneidet. Die in vitro amplifizierte DNA ist nicht methyliert und bleibt daher intakt.

Dazu wurde eine Standard-PCR in $100 \mu \mathrm{l}$ mit Pfu-PCR-Puffer, 10-200 ng des zu mutierenden Zielvektors, je 40 pmol der Mutagenese-Primer QCM-HD8for und QCMHD8rev, $200 \mathrm{mM}$ dNTPs und $1 \mathrm{U} P f u$-DNA-Polymerase angesetzt. Nach dem Aufschmelzen der Plasmid-DNA bei $95^{\circ} \mathrm{C}$ für 1 min wurde zyklisch 12-18 mal die Schritte des Aufschmelzens für $30 \mathrm{~s}$ bei $95^{\circ} \mathrm{C}$, des Anlagerns der Primer für $1 \mathrm{~min}$ bei 
normalerweise $55^{\circ} \mathrm{C}$ und nachfolgender Elongation für 5-15 min (je nach Templatelänge, ca. 1 min pro $1000 \mathrm{bp}$ des Plasmides) bei $68^{\circ} \mathrm{C}$ wiederholt. Der Verdau der methylierten Moleküle geschah direkt im PCR-Reaktionsgefäß durch Zugabe von $1 \mu \mathrm{l}$ pn I für 1-2 h bei $37^{\circ} \mathrm{C}$. 1-2 $\mu \mathrm{l}$ des Ansatzes wurden direkt zur Transformation von $\mathrm{CaCl}_{2}$-kompetenten $E$. coli XL1-Blue eingesetzt (3.1.2.2). Die unverdauten, genickten Plasmide wurden dann in den transformierten Zellen vervollständigt.

\subsubsection{PAA-Gelelektrophorese}

Zur Analyse kürzerer DNA-Fragmente ( $<700 \mathrm{bp}$ ) bietet sich Polyacrylamid (PAA) als Matrix für die Elektrophorese (Ogden and Adams, 1987) an, da darin eine bessere Auftrennung kleiner Fragmente als bei Agarosegelen erreicht wird. Je hochprozentiger die PAA-Lösung und der Anteil an Bisacrylamid gewählt wird (bis zu einer minimalen Porengröße), desto besser lassen sich kurze Nukleinsäuren in dieser netzartigen Matrix auftrennen.

$\mathrm{Zu} 10 \mathrm{ml}$ 12\%iger PAA-Lösung wurden $25 \mu \mathrm{l}$ TEMED und $50 \mu 1$ APS gegeben und damit die Polymerisation gestartet, wobei Acrylamid zu langen Molekülketten kondensiert, die durch das ebenfalls enthaltene Bisacrylamid stochastisch quervernetzt werden. Die noch flüssige Lösung wird zwischen zwei mit Abstandhaltern und einer Gummidichtung versehenen Glasplatten gegossen. Nach Erstarren des Gels wurden die Platten in eine Vertikalgelelektrophoreseapparatur (Biometra) eingespannt. Als Laufpuffer für die Elektrophorese bei $25 \mathrm{~mA}$ wurde TBE-Puffer verwendet.

\subsubsection{Mikrodialyse von Ligationsansätzen}

Um bei der Elektroporation von E. coli (3.1.2.1) einem Kurzschlußstrom durch die Zellsuspension (arcing) vorzubeugen, wurde die Konzentration an Elektrolyten in den Ligationsansätzen gesenkt, indem der Ligationsansatz auf eine Nitrocellulosemembran $(0,025 \mu \mathrm{m}$, Schleicher und Schüll) pipettiert wurde, welche auf einem 10\%igen Glyzerinbad schwamm. Die Mikrodialyse erfolgte für 20 min bei RT. $2 \mu 1$ des vom Filter mittels Pipette aufgenommen Ligationsansatz wurde direkt für die Elektrotransformation eingesetzt. 


\subsubsection{Dephosphorylierung von Vektorfragmenten}

Mit dem aus einem Krebs stammenden Enzym SAP lassen sich 5'-Phosphatgruppen von DNA-Molekülen abspalten. So dephosphorylierte, linearisierte Vektorfragmente können beispielsweise in einem Ligationsansatz (3.2.9) nicht wieder religiert werden, da Ligase die 5'-Phosphatgruppe am Substrat benötigt. Diese wird ihr von der zu klonierenden Insert-DNA zur Verfügung gestellt, so daß die Ligase die 5'-Enden des Inserts mit dem Vektor kovalent verknüpfen kann. Das zirkuläre Produkt enthält noch zwei Einzelstrangbrüche, die erst nach Transformation in vivo repariert werden. Durch Verwendung dephosphorylierter Vektoren kann der Hintergrund an Religanden bei einer Klonierung gesenkt werden. Da SAP in allen verwendeten Restriktionspuffern eine hohe Aktivität aufweist, konnte nach der Restriktion (3.2.8) von Vektoren dem Ansatz das Enzym zugesetzt werden (etwa 1 U pro 20 pmol 5'-Enden) und die Dephosphorylierung für $1-24 \mathrm{~h}$ bei $37^{\circ} \mathrm{C}$ ablaufen. Um eine Dephosphorylierung der zu klonierenden Insert-Fragmente durch verschleppte SAP zu verhindern, wurde das Enzym bei $80{ }^{\circ} \mathrm{C}$ für 10 min inaktiviert. Falls der Verdacht bestand, daß dies das Enzym nicht zu $100 \%$ inaktiviert hatte, wurde es ggf. zusätzlich mittels PhenolExtraktion (3.2.2.3) entfernt.

\subsubsection{Sequenzierung von Plasmid-DNA nach der Kettenabbruch- Methode (Sanger et al., 1977)}

Alle Sequenzierungsarbeiten wurden vom Göttingen Genomics Laboratory (G2L) dieses Institutes durchgeführt. Dabei wurde die Kettenabbruch-Methode nach Sanger et al. (1977) verwendet. Fluoreszenz-markierte ddNTPs wurden dazu der SequenzierungsPCR zugesetzt, welche nach Einbau in den neusynthetisierten DNA-Strang zum Abbruch der Elongation führen, weil sie kein 3'-OH zur Verknüpfung mit dem nachfolgenden dNTP zur Verfügung stellen. Die ddNTPs werden in einem so starken Unterschuß im Vergleich zu den dNTPs eingesetzt, daß im statistischen Mittel etwa ein Abbruch pro Molekül erfolgt. Da für die 4 verschiedenen ddNTPs unterschiedliche Flourophore verwendet werden, können sie zusammen in einer PCR-Reaktion eingesetzt werden. Die entstandenen DNA-Fragmente wurden mit dem DNA-Sequenzer ABI-Prism 377 oder dem Megabase-Sequencer (kappilar-)elektrophoretisch aufgetrennt, detektiert und die Sequenz automatisch ausgelesen. Die Überprüfung der 
Sequenzen auf Lese-Fehler und Abweichungen erfolgte allerdings von eigener Hand mit Hilfe des Programms Chromas V1.45 (McCarthy, 1995).

\subsection{Proteinchemische Arbeitsmethoden}

\subsubsection{Protein-Konzentrationsbestimmung nach Bradford (Bradford, 1976)}

Proteine lassen sich in aller Regel unspezifisch mit Coomassie Blue anfärben. Dabei bildet sich um so mehr von dem tiefblauen Protein-Farb-Komplex, je mehr Protein vorliegt. Durch Bestimmung der OD der Probe bei geeigneter Wellenlänge (normalerweise $595 \mathrm{~nm}$ ) läßt sich durch Vergleich mit einer mit Proteinlösungen bekannter Konzentration erstellten Kalibrierungsgerade (siehe Anhang) der Proteingehalt darin unter Berücksichtigung des Verdünnungsfaktors berechnen. In dieser Arbeit wurde die Kalibrierung durch Versetzen von je $10 \mu$ l bekannter BSAVerdünnungen in Wasser mit $150 \mu$ l Coomassie Reagenz (Pierce) und Messung der Extinktion bei $\lambda=580 \mathrm{~nm}$ im MTP-Reader (BMG Polarstar) erstellt. Proben wurden immer so in Wasser verdünnt, daß die gemessenen Extinktionswerte im linearen Bereich der Kalibrierungskurve (entspricht 20-150 $\mu \mathrm{g} / \mathrm{ml}$ Protein) lagen.

\subsubsection{Denaturierende Polyacrylamidgelelektrophorese (SDS-PAGE)}

Proteine lassen sich unter denaturierenden Bedingungen mittels Elektrophorese in Polyacrylamidgelen der Größe nach auftrennen (Laemmli, 1970). Die Porengröße der inerten Matrix läßt sich über die Acrylamidkonzentration und den Anteil an Quervernetzer steuern. Das im Proben- und Gelpuffer enthaltene SDS ist ein stark negativ geladenes amphipatisches Molekül, welches sich mit seinem hydrophoben Kohlenwasserstoffschwanz an hydrophobe Bereiche von Proteinen anlagert und dabei die hydrophoben, stabilisierenden Wechselwirkungen in den Proteinen selbst aufbricht. So werden Strukturen höherer Ordnung aufgelöst und insbesondere Untereinheiten voneinander getrennt. Die zahlreichen negativen Ladungen des SDS überlagern die proteinspezifische Ladung, so daß im elektrischen Feld die Wanderungsgeschwindigkeit der SDS-Peptid-Micellen nur durch ihr Molekulargewicht bestimmt wird. Bei der häufig angewendeten Variante der diskontinuierlichen Gelelektrophorese durchlaufen die Proben ein dem Trenngel vorgeschaltetes Sammelgel, welches durch langsamen Einlauf der Proben aus den Taschen und den sogenannten Stapeleffekt einer 
Aggregation der Proteine vorbeugt und diese grob vorsortiert und konzentriert. Die Proteine werden zwischen den schnell wandernden $\mathrm{Cl}^{-}$-Ionen und den kaum bewegten Glycinat-Zwitterionen im Sammelgel fokussiert, bei dem veränderten $\mathrm{pH}-\mathrm{Wert}$ im Trenngel wandern die Glycin-Ionen dann vor der Protein-Front. Bei der Elektrophorese im Trenngel mit SDS erhält man über einen bestimmten Bereich eine lineare Beziehung zwischen dem Logarithmus der Molekulargewichte und den Wanderungsstrecken der Proteine. Über den Abgleich mit einem Proteinstandard lassen sich die Molekulargewichte abschätzen. Es wurden standardmäßig 10\%ige (v/v) bzw. ausnahmsweise 12\%ige (v/v) SDS-Polyacrylamidgele verwendet.

\subsubsection{Herstellung 10\%iger Polyacrylamidgele}

Die Gele wurden zwischen eine Aluminiumoxid- und eine Glasplatte gegossen. Das (untere) Trenngel wurde zuerst gegossen. Für zwei Gele wurden $6 \mathrm{ml}$ 30\%iges Protogel $^{\circledR}, 4,5 \mathrm{ml} 4$ x Trenngelpuffer, 7,5 ml Wasser, $40 \mu 1$ TEMED und zuletzt $80 \mu$ APS zusammengebracht und bis zu einer Höhe von ca. 2/3 zwischen die Platten gegossen. Jedes Gel wurde mit $500 \mu 1$ Isopropanol überschichtet, welches für eine wellen- und blasenfreie Gelkante sorgte. Nach vollständiger Polymerisation des Acrylamids zu Polyacrylamid wurde das Isopropanol vollständig von den Gelen entfernt. Nach Ansetzen der Sammelgellösung aus $2 \mathrm{ml} 30 \%$ Protogel $^{\circledR}, 3 \mathrm{ml} 4 \mathrm{x}$ Sammelgelpuffer, $7 \mathrm{ml}$ Wasser, $25 \mu \mathrm{l}$ TEMED und $50 \mu \mathrm{l}$ APS wurde diese bis zur Oberkante der Platten eingefüllt und sofort der jeweilige Taschenkamm gesteckt. Beim Gießen und der Handhabung der Gele wurden Handschuhe getragen, da nichtpolymerisierte PAA-Lösung toxisch ist und Hautschuppen bzw. Fette einen nachfolgenden Immunoblot beeinträchtigen könnten.

\subsubsection{Probenvorbereitung}

Proteinhaltige Proben wurden 1:5 mit Proteinprobenpuffer versetzt und für 5-10 min bei $99^{\circ} \mathrm{C}$ im Heizblock inkubiert. Dabei bewirkt das im Puffer enthaltene $\beta$-Mercaptoethanol eine Reduktion von möglichen Disulfidbrücken, das SDS wirkt denaturierend auf die Proteine. Bei nicht sofortiger Verwendung wurden die Proben bei $-20{ }^{\circ} \mathrm{C}$ eingefroren. 


\subsubsection{SDS-PAGE}

Die bei RT für mindestens 30 min auspolymerisierten Polyacrylamidgele wurden in die Laufkammer (Biometra) eingesetzt und der Taschenkamm entfernt. Die obere und untere Kammer wurden mit Laemmli-Puffer befüllt und die Proben in die Geltaschen gefüllt. Als Protein-Molekulargewichtsstandard dienten $4 \mu 1$ eines Proteinmarkers (2.3.2). Die Elektrophorese wurde bis zum Einlauf der Farbmarkerbande in das Trenngel bei einer Stromstärke von $10 \mathrm{~mA} / \mathrm{Gel}$ durchgeführt, dann wurde die Stromstärke auf 25 mA/Gel erhöht und in der Regel bis zum Auslaufen der Farbbande am unteren Gelrand beibehalten.

\subsubsection{Coomassie-Färbung}

Die aufgetrennten Proteinbanden wurden durch Färben des Polyacrylamidgels in einer Schale mit Coomassie Brilliant Blue R250 Protein-Färbelösung für mindestens 45 min bei Raumtemperatur unter leichtem Schütteln sichtbar gemacht. Zum Entfärben wurde das Gel mehrmals für 2-3 min in der Mikrowelle (Brother Powerwave) in demineralisiertem Wasser aufgekocht, wobei das Wasser jeweils gewechselt wurde.

\subsubsection{Transfer von Proteinen auf PVDF-Membranen (Blotting)}

Zum immunochemischen Nachweis von elektrophoretisch aufgetrennten Proteinen müssen diese aus der Gelmatrix befreit werden, um dem Antikörper zugänglich zu werden. Dies wird standardmäßig durch den Transfer der Proteine auf eine Membran erreicht. In dieser Arbeit wurden die Proteine aus den PAA-Gelen mittels Elektrophorese (semi dry Elektroblotter, Biorad) auf PVDF-Membranen $(0,2 \mu \mathrm{m}$, Biorad) überführt.

Dazu wurden auf der Anode des Gerätes ein mit Anoden-Puffer I getränktes und darauf zwei mit Anoden-Puffer II getränkte Filterpapiere (Whatman-Papier) gestapelt. Darauf wurden nacheinander die Membran, das PAA-Gel und drei mit Kathoden-Puffer getränkte Filterpapiere luftblasenfrei aufgelegt. Das PAA-Gel wurde vorher 10 min in Kathodenpuffer äquilibriert und die PVDF-Membran durch kurzes Schwenken in $\mathrm{MeOH}$ aktiviert. Nach Schließen des Gerätes mit der Kathoden-Platte wurde der Blot für $60 \mathrm{~min}$ bei $170 \mathrm{~mA}$ pro Gel $(9 \mathrm{~cm} \times 7 \mathrm{~cm})$ gefahren. Der vollständig erfolgte Transfer ließ sich anhand des ebenfalls transferierten farbigen Proteinmarkers verifizieren. 


\subsubsection{Immunochemischer Nachweis von Proteinen auf PVDF-Membranen (Western)}

Auf einer Membran immobilisierte (und normalerweise vorher elektrophoretisch aufgetrennte) Proteine sind für die Erkennung und die Bindung durch einen für das Zielprotein spezischen Antikörper zugänglich. Durch direkte kovalente oder indirekte Kopplung (z. B. über einen anderen Antikörper) eines Reporterenzyms, welches ein detektierbares Signal generiert, an den primären Antikörper wird das Signal ortsspezifisch am nachzuweisenden Zielprotein konzentriert. In dieser Arbeit wurde ausschließlich die an den jeweiligen sekundären Antikörper gekoppelte Alkalische Phosphatase verwendet, welche aus den dem AP-Entwicklungspuffer frisch zugesetzten farblosen Substraten BCIP (200 $\mu 1 / 50 \mathrm{ml}$ Puffer) und NBT (150 $\mu 1 / 50 \mathrm{ml}$ Puffer) einen unlöslichen, violetten Farbstoff generiert.

Die PVDF-Membran mit den anheftenden Proteinen wurden zur Blockierung unspezifisch proteinbindender Bereiche üN bei $4{ }^{\circ} \mathrm{C}$ in $\mathrm{BB}$ und darauf mit dem spezifischen, primären Antikörper für mindestens $1 \mathrm{~h}$ bei RT in BBT unter leichtem Schütteln inkubiert. Überschüssiger, nicht gebundener Antikörper wurde durch Waschen der Membran für je 5 min bei RT unter leichtem Schwenken nacheinander in PBST und viermal in PBS entfernt. Dann wurde dem sekundären Antikörper ermöglicht, den konstanten Teil des primären Antikörpers zu binden, indem dieser mit der Membran für mindestens $60 \mathrm{~min}$ in BBT/PBS bei RT leicht geschwenkt wurde. Anschließend wurde wie oben beschrieben gewaschen und schließlich der Blot in APEntwicklungspuffer mit BCIP und NBT bei RT im Dunkeln entwickelt, bis die violetten Banden ausreichend deutlich hervortraten.

Verwendete Kombinationen und Verdünnungen der Antikörper (AK):

Primärer AK: $\quad$ monoklonaler Anti-PentaHis-tag-Antikörper aus Maus (1:5000)

Sekundärer AK: $\quad$ Anti-Maus-IgG-AP-Konjugat (1:5000) 
Primärer AK: $\quad$ monoklonaler Anti-TetraHis-tag-Antikörper aus Maus (1:5000)

Sekundärer AK: $\quad$ Anti-Maus-IgG-AP-Konjugat (1:5000)

Primärer AK: polyklonaler Antikörper ( $\operatorname{IgG}$ ) aus Kaninchen gegen humane HDAC1 $(1: 5000)$

Sekundärer AK: $\quad$ Anti-Kaninchen-IgG-AP-Konjugat (1:5000)

\subsubsection{Affinitätschromatographie an immobilisierten Metallionen (IMAC) (Porath et al., 1975)}

Exprimierte rekombinante Proteine mit einem terminalen Hexahistidinschwanz (Histag) wurden über Affinitätschromatographie an immobilisierten $\mathrm{Ni}^{2+}$-Ionen aufgereinigt. Dies ist möglich, weil der Schwanz an zusätzlichen sechs Histidinen (His-tag) 3 freie Valenzen eines bereits über 3 Valenzen an die über einen 7-Atomspacer gekoppelten Iminodiacetylsäuregruppen der Sepharose-Matrix gebundenen $\mathrm{Ni}^{2+}$-Ions komplexieren kann (Porath et al., 1975). Proteine ohne diesen Polyhistidin-Schwanz haben normalerweise keine Affinität zum Liganden und eluieren größtenteils im Durchlauf einer IMAC-Säule, während jene mit His-tag an die Säule binden und sich mit Imidazol wieder eluieren lassen, weil dieses dabei mit dem Histidin um die Komplexierungsstellen am Nickel konkurriert.

In dieser Arbeit wurden selbst hergestellte IMAC-Säulen verwendet, wobei die gesamte Chromatographie mit der Flußrate durchgeführt, die durch Gravitation vorgegeben wurde. IMAC-Säulen wurden gepackt, indem in eine geleerte MIDI100-Kartusche $1 \mathrm{ml}$ in demineralisiertem Wasser gewaschene Chelating-Sepharose Fast Flow (Pharmacia Biotech AB) gefüllt wurde und nach dem Setzen der Matrix eine obere Fritte eingesetzt wurde. Nach zweimaligem Waschen der Matrix mit je $10 \mathrm{ml}$ demineralisiertem Wasser wurde die Säule durch zweimal $5 \mathrm{ml} 100 \mathrm{mM} \mathrm{NiCl}{ }_{2}$ mit Nickel beladen und nach Fortspülen des überschüssigen Nickels mit zweimal $10 \mathrm{ml}$ demineralisiertem Wasser durch zweimal $10 \mathrm{ml}$ IMAC-Puffer I bzw. HDAC8-Puffer I äquilibriert. Variable Volumina an Probe wurden auf die Säule geladen und der Durchfluß (FT) aufgefangen. Ein- bis dreimal wurde mit dem jeweiligen Puffer I gewaschen und die Fraktionen ebenfalls aufgefangen (W1 bis W3), bevor mit einem Stufengradienten steigender 
Imidazol-Konzentration (je $2 \mathrm{ml}$ von 20, 40, 80, 100, 200, 300, $500 \mathrm{mM}$ ElutionsPuffer, hergestellt durch Mischung von Puffer I mit Puffer II) das Zielprotein in 2 mlReaktionsgefäße eluiert wurde. Je $50 \mu 1$ des Durchflusses und der Fraktionen wurde als zur Analyse über SDS-PAGE vorbereitet (3.3.2.2). Die Fraktionen wurden bis zur weiteren Verwendung auf Eis gelagert. Die Fraktionen wurden normalerweise anschließend in Dialyseschläuche (Ausschlußgrenze Mr 12000) gefüllt und ü. N. bei $4{ }^{\circ} \mathrm{C}$ unter leichtem Rühren gegen 21 des entsprechenden Puffers ohne Imidazol dialysiert. Die Dialyse wurde dann gegen 11 frischen Puffer für mindestens weitere $2 \mathrm{~h}$ fortgesetzt.

\subsubsection{Perfusionschromatographie}

Die Perfusionschromatographie erlaubt eine sehr hohe Flußrate ohne nennenswerte Beeinträchtigung der Auflösung oder der Kapazität der Säule aufgrund des speziellen Säulenmaterials (Poros 20, Pharmazia) und beschleunigt dadurch die Proteinaufreinigung erheblich. Daher konnte die Reinigung von HDAC8 auch bei RT statt bei $4{ }^{\circ} \mathrm{C}$ erfolgen, wobei das Lysat und die relevanten Fraktionen dabei die meiste Zeit auf Eis gelagert wurden.

Die Chromatographie wurde mit einer an die Vision Workstation (Perseptive Biosystems) angeschlossene Anionenaustauschersäule (Poros $20 \mathrm{HQ}, 7,5 \mathrm{ml} \mathrm{SV}$ ) und sterilfiltriertem Wasser und Puffern nach einem spezifischen Programm bei einer Flußrate von $10 \mathrm{ml} / \mathrm{min}$ durchgeführt. Dabei wurde ein biphasischer, linearer SalzGradient durch Mischen von HDAC8-Puffer A und B erzeugt. Vorab wurde sowohl die Säule als auch alle relevanten Schläuche und Bauteile (wie z. B. Pumpen) mit ca. $5 \mathrm{SV}$ $3 \mathrm{M} \mathrm{NaCl}$ bei $10 \mathrm{ml} / \mathrm{min}$ gespült, um etwaige Proteinreste $\mathrm{zu}$ entfernen. Danach wurde mit ca. 5 SV Wasser das Salz aus dem System gewaschen. Das verwendete Programm beinhaltete folgende Schritte:

- Äquilibrierung mit 5 SV HDAC8-Puffer A

- Laden von 5-15 ml sterilfiltriertem Lysatüberstand und Sammeln von $8 \mathrm{ml}$ Fraktionen

- Waschen mit 4 SV HDAC8-Puffer A und Sammeln von 8 ml-Fraktionen 
- Elution mit einem Gradienten mit $10 \mathrm{SV}$ von 0-1,8 $\mathrm{M} \mathrm{NaCl}$ in HDAC8-Puffer bei Sammeln von 2 ml-Fraktionen und $3 \mathrm{SV} 1,8-3 \mathrm{M} \mathrm{NaCl}$ in HDAC8-Puffer bei Sammeln von 4 ml-Fraktionen

- $\quad$ Stufe mit 2 SV HDAC8-Puffer B

- Zurückfahren der Salzkonzentration auf $0 \mathrm{mM}$ in $2 \mathrm{SV}$

- Äquilibrierung mit 4 SV HDAC8-Puffer A

Während der gesamten Chromatographie wurde die $\mathrm{OD}_{260}$ und $\mathrm{OD}_{280}$ verfolgt. ElutionsFraktionen mit $\mathrm{OD}_{280}>\mathrm{OD}_{260}$ wurden auf Eis gelagert und ein $50 \mu 1$-Aliquot davon und einiger anderer Fraktionen zur Analyse per SDS-PAGE vorbereitet (3.3.2.2).

\subsection{Zellbiologische Arbeitsmethoden}

\subsubsection{Expression in Escherichia coli}

Im Rahmen dieser Arbeit wurden zur heterologen Expression von Proteinen in E. coli der Vektor pQE70 (Qiagen) verwendet, bei dem das Fremdgen unter der Kontrolle eines T5-Promotors mit lac-Operator steht. Die Induktion der Expression wurde durch Zugabe von IPTG ins Medium einer in der logarithmisch Wachstumsphase befindlichen Kultur erreicht.

Zur Expression von HDAC1 wurden $50 \mathrm{ml} \mathrm{LB/Amp} \mathrm{mit} 50 \mu 1$ einer üN gewachsenen 4 ml-Vorkultur des entsprechenden Expressionsstammes inokuliert und bei einer $\mathrm{OD}_{600}$ von 0,4-0,6 durch Zugabe von 0,5 bzw. 1 mM IPTG induziert. Für die Aufnahme von Wachstumskurven wurde die $\mathrm{OD}_{600}$ in Abständen bestimmt. Sonst wurden die Zellen nach Bestimmung der $\mathrm{OD}_{600} 16 \mathrm{~h}$ nach Induktion pelletiert (Hettich-Rotanta, $4000 \mathrm{Upm}, 10 \mathrm{~min}, 4{ }^{\circ} \mathrm{C}$ ) und das Zellpellet in $1 \mathrm{ml}$ kaltem HD-Puffer resuspendiert. Wurden zusätzlich mit pUBS520 transformierte Stämme angezogen, wurde dem Medium ebenfalls Kanamycin $(75 \mu \mathrm{g} / \mathrm{ml})$ zugesetzt.

Zur Expression von HDAC8 wurden $11 \mathrm{LB} / \mathrm{Amp}$ mit $5 \mathrm{ml}$ einer üN gewachsenen $50 \mathrm{ml-Vorkultur}$ (dYT/Amp) von XL1-Blue-pQEHDAC8 inokuliert und bei einer $\mathrm{OD}_{600}$ von 0,6 durch Zugabe von $1 \mathrm{mM}$ IPTG induziert. Nach etwa $16 \mathrm{~h}$ Wachstum wurde die $\mathrm{OD}_{600}$ bestimmt, die Zellen nach Abkühlung auf etwa $8^{\circ} \mathrm{C}$ pelletiert (Hettich 
Silenta, $4000 \mathrm{Upm}, 30 \mathrm{~min}, 4{ }^{\circ} \mathrm{C}$ ) und das Zellpellet in $50 \mathrm{ml}$ kaltem HDAC8-Puffer resuspendiert.

\subsubsection{Zellaufschluß}

\subsubsection{Disruption}

Um die cytoplasmatisch exprimierten Enzyme freizusetzen, wurden die $\mathrm{OD}_{600}$ der Zellen der 11-Expressionskulturen gegen Medium bestimmt, diese geerntet (Hettich Silenta, $30 \mathrm{~min}, 4000 \mathrm{Upm}, 10^{\circ} \mathrm{C}$ ) und in $50 \mathrm{ml}$ des jeweiligen kalten Aufschlußpuffers resuspendiert. Mit Hilfe eines Zelldisruptors (mit wassergekühltem (auf $12{ }^{\circ} \mathrm{C}$ ) Basic ZAufschluß-Kopf, IUL Instruments $\mathrm{GmbH}$ ) wurden die Zellen lysiert, indem sie unter hohem Druck (1,8 kbar) durch eine Düse $(0,18 \mathrm{~mm})$ gepreßt wurden. Zusätzlich zu den Scherkräften prallte der Strahl der Zellsuspension danach gegen ein Metallhindernis. Das aufgefangene Lysat wurde durch Zentrifugation von Zelltrümmern befreit (Sorval, $\left.30 \mathrm{~min}, 9000 \mathrm{Upm}, 4^{\circ} \mathrm{C}\right)$, der geklärte ÜS filtriert $(0,25 \mu \mathrm{m})$ und bis zur Verwendung auf Eis gelagert.

\subsubsection{Sonifizierung}

Bei Testexpressionen im $50 \mathrm{ml}-\mathrm{Ma} ß \mathrm{stab}$ wurde das Zellpellet in $1 \mathrm{ml}$ des entsprechenden Aufschlußpuffers resuspendiert und auf Eis mittels der Micro tip des Ultraschallgerätes (Branson Sonifier) 2 mal für $30 \mathrm{~s}$ Ultraschall ausgesetzt (Duty cycle $50 \%$, Output control Stufe 5). Die lysierte Probe wurde nach Abnahme eines $100 \mu \mathrm{l}$ Aliquots ebenfalls durch Zentrifugation geklärt (Eppendorf 5804R, 30 min, 13000 Upm, $4{ }^{\circ} \mathrm{C}$ ) und der ÜS auf Eis gelagert.

\subsection{Enzymatische Aktivitätstests}

\subsubsection{HDAC-Assay (Wegener et al., 2003a; Wegener et al., 2003c)}

Zur Bestimmung der Enzymaktivität wurde in der Regel ein homogener, zweistufiger, gekoppelter Endpunkt-Assay mit peptidischen, fluorogenen Substraten durchgeführt (Abb. 4). In der ersten Phase erfolgte durch das Zielenzym eine Deacetylierung der $\varepsilon$ Aminogruppe eines Lysylrestes der Substrate, welche nur dadurch in der zweiten Stufe als Substrate von Trypsin erkannt und gespalten werden konnten. Trypsin spaltete dabei die Amidbindung zwischen dem Lysyl-Rest und dem nachfolgenden Fluorophor AMC, 
welches nur in ungebundener Form eine starke Fluoreszenz bei $460 \mathrm{~nm}$ nach Anregung bei $390 \mathrm{~nm}$ zeigt (Ninkovic et al., 2001; Zimmerman et al., 1977). Der beschriebene Endpunkt-Assay wurde vor allem zur Messung der Aktivität von HDAC aus Rattenleber und humaner HDAC8 verwendet.

In bestimmten Fällen ermöglicht eine Resistenz des Zielenzyms gegen die Proteolyse durch das zugesetzte Trypsin die direkte Verfolgung der Enzymkinetik in einer kontinuierlichen, einstufigen Assay-Variante (Wegener et al., 2003b), Dissertation C. Hildmann, in Vorbereitung). Dieser Umstand wurde in dieser Arbeit zur Messung der Aktivität der FB188-HDAH ausgenutzt.

Die jeweilige Trypsinkonzentration im Assay richtete sich nach der Art der jeweils vermessenen Substrate. Zur Spaltung von Monopeptidyl-AMC-Substraten wurden 0,5-5 mg/ml Trypsin eingesetzt, zur Spaltung von Tripeptidyl-AMC-Substraten reichte eine 100-1000fach geringere Trypsinkonzentration aus. Alle Messungen erfolgten, wenn nicht explizit anders angeführt, in einem MTP-Fluoreszenzreader (BMG Polarstar) bei einer Anregungswellenlänge von $390 \mathrm{~nm}$ und einer Detektionswellenlänge von $460 \mathrm{~nm}$ bei $30^{\circ} \mathrm{C}$ und bei Empfindlichkeitsstufe (Gain) 73 .

\subsubsection{Trypsinaktivitätstest}

Zur Überprüfung und Einstellung der Trypsinaktivität in der Trypsin/TSA-Stoplösung für den Endpunkt-Assay oder im kontinuierlichen HDAC-Assay wurde eine Reihenverdünnung der angesetzten Trypsin-Stammlösung $(10 \mathrm{mg} / \mathrm{ml})$ in ThrombinPuffer angelegt, indem je $90 \mu 1$ Puffer mit $10 \mu 1$ der Trypsinstammlösung in einem $200 \mu 1$-well gemischt wurden $\left(10^{-1}\right.$-Verdünnung) und daraus wiederum $10 \mu 1$ mit weiteren $90 \mu \mathrm{l}$ Puffer verdünnt wurden. Dies wurde analog bis $\mathrm{zu}$ einer Verdünnungsstufe von $10^{-8}$ wiederholt. Je $50 \mu 1$ dieser Trypsinverdünnungen wurden zu je $150 \mu 130 \mu \mathrm{M}$ Tos-GPR-AMC in den Kompartimenten einer 96 well-MTP pipettiert und die Kinetik mit dem BMG-Reader verfolgt. Dabei sollte die Aktivität in der 10 ${ }^{6}$ fachen Verdünnung standardmäßig $10000 \mathrm{FE} /$ min betragen. Die Trypsinstammlösung bzw. die daraus abgeleiteten Arbeitslösungen wurden ggf. unter Berücksichtigung des ermittelten Korrekturfaktors $\left(\mathrm{k}=\mathrm{v}_{\text {gemessen }} / \mathrm{v}_{\text {Std. }}\right)$ so eingestellt ( $\mathrm{k}$-fache Verdünnung der Arbeitslösung mit Puffer bzw. Einsatz von k mal mehr Trypsinstammlösung in die Arbeitslösung), daß sie bei erneuter Überprüfung in einer anschließenden analogen 
Reihenverdünnung bei $10^{-6}$ eine Enzymaktivität von etwa $10000 \mathrm{FE} / \mathrm{min}$ aufwiesen.

\subsubsection{Bestimmung der $\mathrm{K}_{\mathrm{M}}$ und $\mathrm{V}_{\max }$ für Trypsin-Substrate}

Zur Bestimmung des $\mathrm{K}_{\mathrm{M}}$-Wertes eines fluorogenen Substrates für Trypsin wurden in Dreifachbestimmungen verschiedene Substratkonzentrationen (1-400 $\mu \mathrm{M})$ im BMGReader vermessen (Gain 73 oder Gain 65). Dazu wurden mit der CyBi-Screen-Machine $60 \mu 1$ Thrombin-Puffer, $50 \mu 1$ einer Substratverdünnung und $90 \mu 1$ Trypsinlösung (Konzentrationen s.u.) in die Kompartimente einer 96 well-MTP gegeben und die Kinetik in 1minütigen Abständen über 10 min vermessen. Die Berechnung des $\mathrm{K}_{\mathrm{M}}$-Wertes erfolgte mit dem Tabellenkalkulationsprogramm Excel durch Auftragung des Quotienten aus der Substratkonzentration und der Reaktionsgeschwindigkeit (S/V) über der Substratkonzentration (S) aus einem sogenannten Hanes plot (CornishBowden, 1999).

Bei der Vermessung von Boc-Lys-AMC wurde eine $10 \mathrm{mg} / \mathrm{ml}$ Trypsinlösung verwendet, für Tripeptidyl-AMC-Substrate eine $10^{-2}$-Verdünnung bzw. $0,05 \mathrm{mg} / \mathrm{ml}$ Endkonzentration eingesetzt, außer bei Tos-GPK-AMC und Tos-GPR-AMC, wo eine $10^{3}$ fache $(0,005 \mathrm{mg} / \mathrm{ml}$ Endkonzentration $)$ bzw. eine $10^{6}$ fache Verdünnung $(0,005 \mu \mathrm{g} / \mathrm{ml}$ Endkonzentration) benutzt wurde.

Die Berechnung des $\mathrm{V}_{\max }-$ Wertes erfolgte aus der Steigung des Hanes plot nach:

$$
\mathrm{V}_{\max }=1 / \text { Steigung }
$$

\subsubsection{Bestimmung der $\mathrm{IC}_{50}$ von $\mathrm{HDACl}$ im 96 well-Format}

Zur Bestimmung der Konzentration an HDACI, welche die HDAC-Aktivität um 50 \% inhibiert $\left(\mathrm{IC}_{50}\right)$, wurde der Standard-HDAC-Assay (3.5.8) leicht modifiziert, indem zusätzliche $10 \mu$ l einer HDACI-Verdünnung (in HD-Puffer bzw. HDP-Puffer) durch die Reduzierung des Volumens an Assay-Puffer um diese $10 \mu \mathrm{l}$ ausgeglichen wurde. Im allgemeinen wurden 6-10 HDACI-Verdünnungen hergestellt und in einer 96 well-MTP vorgelegt. Nach Zugabe von Puffer und Enzym, entweder manuell oder mittels der CyBi-Screen-Machine (CyBio), wurden die Ansätze für 10 min bei RT inkubiert, um auch slow-binding HDACI korrekt zu erfassen, bevor die Reaktion mit Zusetzen des Substrates gestartet wurde. Dabei wurde darauf geachtet, daß die DMSO-Konzentration im Ansatz nicht über $2 \%$, in aller Regel nicht über $1 \%$ lag. Die Messungen wurden in 
Triplikaten durchgeführt und die relativen Fluoreszenzeinheiten gegen die HDACIKonzentration halblogarithmisch aufgetragen. Die Auswertung erfolgte mit dem Programm GraphPad Prism, das durch die Meßpunkte eine sigmoidale DosisWirkungskurve mit variabler Steigung fittete.

\subsubsection{Bestimmung der Salz- und Lösungsmitteltoleranz von HDAC}

Die Toleranz des Assays bzw. der Zielenzyme gegenüber verschiedenen Agenzien, vor allem häufig verwendeter Lösungsmittel (wie z. B. DMSO) wurde getestet, indem Standard-HDAC-Assays in Triplikaten für verschiedene Konzentrationen der fraglichen Stoffe durchgeführt wurden. Dazu wurden abweichend vom Standard-Protokoll für $\mathrm{IC}_{50}$-Bestimmungen in den Kompartimenten einer 96 well-MTP zuerst für 10 min bei RT $60 \mu \mathrm{l}$ Assay-Puffer einer bestimmten Agenz-Konzentration mit $10 \mu 1$ Enzym inkubiert und anschließend die Reaktion durch Zugabe von $50 \mu 1$ $300 \mu \mathrm{M}$ Substratlösung (mit entsprechender Agenz-Konzentration) gestartet. Wobei die Agenz-Konzentrationen so gewählt wurden, daß im Ansatz immer die gewünschte Endkonzentration vorlag. Auf diese Weise wurde dafür Sorge getragen, daß das Zielenzym immer mit der gewünschten Agenz-Konzentration inkubiert wurde. Nach Abstoppen der Reaktion bei $30^{\circ} \mathrm{C}$ nach 60 min durch Zusatz von $80 \mu 1$ Trypsin/TSAStoplösung wurde die MTP im BMG-Reader vermessen.

$\mathrm{Zu}$ Kontrollzwecken wurde der Einfluß derselben Agenzien auf Trypsin untersucht, indem die Trypsinaktivität (einer $10^{-6}$ Verdünnung des Trypsins), wie unter (3.5.2) beschrieben, verfolgt wurde, mit der Abweichung, daß zusätzliche $10 \mu \mathrm{l}$ der Agenzverdünnung im Ansatz enthalten waren, welche durch Minderung des Puffervolumens kompensiert wurde.

\subsubsection{Bestimmung der $\mathrm{K}_{M}$ für HDAC-Substrate im 96 well-Format}

Zur Bestimmung des $\mathrm{K}_{\mathrm{M}}$-Wertes eines fluorogenen Substrates für HDAC wurden in Dreifachbestimmungen verschiedene Substratkonzentrationen (S) (1-400 $\mu \mathrm{M})$ im BMGReader vermessen (Anregung bei $380 \mathrm{~nm}$, Detektion bei $460 \mathrm{~nm}$, Gain 73 oder Gain 65). Dabei wurde ansonsten (außer bei den Substratkonzentrationen) wie für den Standard-HDAC-Assay beschrieben (3.5.8) verfahren. Die Berechnung des $\mathrm{K}_{\mathrm{M}^{-}}$Wertes erfolgte mit dem Tabellenkalkulationsprogramm Excel durch Auftragung des 
Quotienten aus der Substratkonzentration und der Reaktionsgeschwindigkeit (S/V) über der Substratkonzentration (S) aus einem sogenannten Hanes plot (Cornish-Bowden, 1999). Die Berechnung des $\mathrm{V}_{\max }$-Wertes erfolgte aus der Steigung des Hanes plot nach:

$$
\mathrm{V}_{\max }=1 / \text { Steigung }
$$

Teilweise erfolgte die Berechnung des $\mathrm{V}_{\max }$-Wertes auch aus den Messwerten bei der Substratkonzentration, welche mindestens 2 mal höher als der vorher ermittelte $\mathrm{K}_{\mathrm{M}}$-Wert lag.

\subsubsection{Umsatzkurven mit HDAC-Substraten und Bestimmung von $\mathrm{V}_{\max }$}

Um den Bereich zu Bestimmen, in dem die Kinetik des Zielenzyms im HDAC-Assay stabil war und die Zunahme des Produktes annähernd linear mit der Zeit voranschritt, wurden Umsatzkurven in Dreifach-Bestimmungen über 60-90 min aufgenommen, indem identische HDAC-Standard-Assays in 96 well-MTP (3.5.8) nach bestimmten Reaktionszeiten durch Zugabe der Trypsin/TSA-Stoplösung abgestoppt und die Fluoreszenz im BMG-Reader ausgelesen wurde. Nach Abzug des Blank-Mittelwertes wurden die FE-Mittelwerte der jeweiligen Zeitpunkte über der Zeit aufgetragen und eine Regressionsgerade mit Excel (lineare Regression) bestimmt. Normalerweise wurde dabei eine Substratkonzentration eingestellt, welche mindestens 2 mal höher als der vorher ermittelte $\mathrm{K}_{\mathrm{M}}$-Wert lag. Die Berechnung des $\mathrm{V}_{\max }$-Wertes erfolgte dabei aus der Steigung der mit Excel kalkulierten Regressionsgeraden unter Berücksichtigung der AMC-Kalibrierungskurve (siehe Anhang).

Die Umsatzkurven wurden teilweise auch in Anwesenheit von Inhibitoren wie z.B. TSA oder Salzen wie NaAc aufgenommen. Dies erfolgte wie oben beschrieben, allerdings wurde analog wie bei der $\mathrm{IC}_{50}$-Bestimmung (3.5.4) das zusätzliche Volumen an Inhibitorverdünnung jeweils durch entsprechende Minderung des Puffervolumens kompensiert.

\subsubsection{Standard-HDAC-Assay im 96 well-Format}

Die Bestimmung der HDAC-Aktivität wurde für HDAC aus Rattenleber und rekombinanter HDAC8 unter variablen Bedingungen (wie etwa unterschiedliche Substrate und deren Konzentrationen, Anwesenheit verschiedener Agenzien unterschiedlicher Konzentration) und unter Verwendung unterschiedlicher 
Puffersysteme ermittelt. Trotzdem wurden normalerweise die pipettierten Volumina und die Inkubationszeiten und -temperatur aus Gründen der besseren Vergleichbarkeit und akkurater Pipettierbarkeit konstant gehalten.

Aber auch Proben von Expressionskulturen (3.4.1) oder Fraktionen aus der Chromatographie (3.3.6/7) wurden im Hinblick auf HDAC-Aktivität untersucht, wobei standardmäßig ein leicht modifiziertes Pipettierschema befolgt wurde.

Falls nicht anders angegeben setzte sich standardmäßig der Ansatz für einen HDACAssay wie folgt zusammen:

- Für Umsatzkurven oder zur $\mathrm{K}_{\mathrm{M}}$-Bestimmung:

$60 \mu 1$ Assay-Puffer

$10 \mu 1$ Zielenzym (HDAC)

$\underline{50 \mu 1 \text { Substrat, gelöst in Assay-Puffer }}$

Abstoppen mit $80 \mu 1$ Trypsin/TSA-Stoplösung

- Zur Bestimmung des $\mathrm{IC}_{50}$ oder für das Screening:

$10 \mu 1$ HDACI, gelöst in Assay-Puffer

$50 \mu 1$ Assay-Puffer

$10 \mu 1$ Zielenzym (HDAC)

\section{$\underline{50 \mu 1 \text { Substrat, gelöst in Assay-Puffer }}$}

Abstoppen mit $80 \mu 1$ Trypsin/TSA-Stoplösung

Puffer (und ggf. Inhibitor oder andere Agenzien) und Enzym (normalerweise bei HDAC aus Rattenleber 1:6 bzw. bei humaner HDAC8 1:4 in Assay-Puffer vorverdünnt) wurden normalerweise zusammen 10 min bei RT vorinkubiert, bevor die Reaktion mit der Substratzugabe gestartet wurde. Zur Inkubation für 60 min bei $30{ }^{\circ} \mathrm{C}$ wurden die Meßplatten mit selbstklebender Folie abgedeckt und so Verdunstungseffekte minimiert. Das Auslesen der Fluoreszenzwerte erfolgte bei $30{ }^{\circ} \mathrm{C}$ in einem MTP-Fluoreszenzreader (Fluostar, BMG Labsystems) in 1minütigen Abständen für 50 min direkt nach dem Abstoppen bzw. für $10 \mathrm{~min}$, falls die Meßplatte nicht sofort vermessen wurde, sondern sich vorher für mind. 20 min bei RT entwickeln konnte. Entwicklung bedeutet in 
diesem Zusammenhang die völlige Spaltung des deacetylierten Produktes aus dem ersten Schritt des Assays durch Trypsin in der zweiten Stufe, so daß sich das Fluoreszenzniveau nicht weiter änderte.

\subsubsection{Manueller HDAC-Assay}

Beim manuellen Standard-HDAC-Assay mußte darauf geachtet werden, daß alle Reaktionen eines Experimentes die gleiche Inkubationsdauer aufwiesen, indem sie entweder mittels einer 12-Kanalpipette gleichzeitig oder mit Hilfe einer digitalen Multipette vernachlässigbar zeitversetzt nacheinander gestartet und beendet wurden. Darüber hinaus wurde zum Starten und zum Abstoppen dieselbe Pipettierfolge eingehalten, was den Zeitversatz nochmals minimierte. Neben dem verbesserten Protokoll und Puffersystem (Wegener et al., 2003a)

a) Tos-GPK(Ac)-AMC in HDP-Puffer und $10 \mu \mathrm{g} / \mathrm{ml}$ Trypsin/2 $\mu \mathrm{M}$ TSA in TI-Puffer, wurde in dieser Arbeit auch mit anderen Puffersystemen und Substraten gearbeitet, was allerdings an gegebener Stelle explizit angemerkt wurde:

b) Substrat in HD-Puffer und Trypsin in Thrombin-Puffer,

c) Substrat in HDAC8-Puffer und Trypsin in TI-Puffer

\section{Aktivitätstest von Chromatographie-Fraktionen}

Zur Durchmusterung von Fraktionen nach HDAC-Aktivität wurde der StandardHDAC-Assay leicht modifiziert durchgeführt, indem $50 \mu$ Probe aus einer Fraktion mit $50 \mu 1$ Substrat (300 $\mu$ M Boc-Lys(Ac)-AMC oder Tos-GPK(Ac)-AMC) für 60-120 min bei $30^{\circ} \mathrm{C}$ in einem Kompartiment einer 96 well-MTP inkubiert wurden, bevor die Reaktion durch Zugabe von $100 \mu \mathrm{l}$ Trypsin/TSA-Stoplösung (mit $10 \mathrm{mg} / \mathrm{ml}$ bzw. $10 \mu \mathrm{g} / \mathrm{ml}$ Trypsin) beendet wurde.

Bei Fraktionen der HDAC8-Aufreinigung wurde $300 \mu \mathrm{M}$ Boc-Lys(Ac)-AMC in HDAC8-Puffer und $1 \mathrm{mg} / \mathrm{ml}$ Trypsin in TI-Puffer verwendet.

\subsubsection{Robotische Ausführung des HDAC-Assay mit der CyBi-Screen- Machine}

Mit einer robotische HTS-Anlage ist es möglich viele Assays automatisch und reproduzierbar hintereinander in vergleichsweise kurzer Zeit durchzuführen. Dabei 
erfolgen der Transport der MTP und alle Pipettierschritte nach einem vorher erstellten Programm und normalerweise ohne späteren Eingriff des Bedieners.

In dieser Arbeit wurde die CyBi-Screen-Machine mit zwei 96-SpitzenPipettiermodulen, Plattenstaker mit 2 Schächten und Inkubator (CyBio AG) mit integriertem MTP-Fluoreszenzreader (BMG Labsystems) verwendet (Abb. 3, 2.8). Bei dieser Anlage wurde der Transport der MTP durch zwei auf Schienen bewegliche Schlitten verwirklicht und das etwaige Umsetzen der MTP zwischen den Pipettierigeln oder dem Fluoreszenzreader durch Ausheber und einen Dreharm gelöst. Auch beim Pipettieren an den Modulen wird die MTP durch einen Ausheber vertikal zu den fixen Spitzen bewegt.

Zur Vorbereitung der Durchführung eines HDAC-Assays mit der Anlage (z.B. zur Durchmusterung einer Substanz-Bibliothek, aber auch für $\mathrm{K}_{\mathrm{M}^{-}}$oder $\mathrm{IC}_{50}$-Bestimmungen und Umsatzkurven) wurden ausreichende Volumina an Puffer und Substratlösungen oder -verdünnungen (d. h. für alle Meßdurchläufe benötigte Volumina plus ein Bonus von mindestens $200 \mu \mathrm{l}$ pro Kompartiment) manuell in MTP mit 2 ml-Kompartimenten vorgelegt und in die Anlage eingebracht. Die Kompartimente einer 96 well-MTP wurden mit ausreichenden Volumina HDAC-Verdünnung (d. h. für alle Meßdurchläufe benötigte Volumina plus ein Bonus von mindestens $50 \mu \mathrm{l}$ ) versehen. Diese und eine leere (bzw. mit $10 \mu$ l HDACI-Lösung pro Kompartiment befüllte) 96 well-Meßplatte wurden ebenfalls auf der Anlage positioniert. Mit der CyBi-Screen-Machine (CyBio AG) wurden sodann programmgesteuert 60 (bzw. 50) $\mu 1$ Puffer, $10 \mu 1$ HDAC-Lösung und nach 10 Minuten $50 \mu \mathrm{l}$ Substrat in die Kompartimente einer 96 well-MTP gegeben (die ggf. bereits $10 \mu \mathrm{l}$ HDACI-Verdünnung bzw. Puffer enthielten) und nach 60 minütiger Inkubation bei $30^{\circ} \mathrm{C}$ im BMG-Reader und Zusatz von $80 \mu 1$ Trypsin/TSAStoplösung die Kinetik in 1minütigen Abständen über 40 min vermessen.

\subsubsection{Bestimmung des Z'-Faktors}

Das wichtigste Ziel bei der Entwicklung eines HTS-Assays ist sicherlich die sichere und verlässliche Identifikation von aktiven Substanzen (hits) aus einer (normalerweise) sehr großen chemischen Bibliothek vor einem Hintergrund an inerten Komponenten (Sittampalam, 1997). Erst vor relativ kurzer Zeit wurde mit dem Z-Faktor ein einfacher und effektiver Qualitätsparameter (screening window coefficient) eingeführt, der es als 
dimensionslose Zahl erstmals erlaubt, verschiedene Assaysysteme qualitativ miteinander zu vergleichen (Zhang et al., 1999a). In den Z-Faktor gehen sowohl die Schwankungen der Meßdaten (Standardabweichungen, SD, $\sigma$ ) als auch die Größe des Meßfensters (dynamischer Bereich) ein (Abb. 14, 4.1.9). Zur Qualitätsbestimmung des Assays nach einem bestimmten Protokoll und mit Hilfe einer robotischen Anlage wird oft vor dem eigentlichen Einsatz des Assays in einer HTS-Campagne der sogenannte Z'Faktor (also ohne Beeinflussung durch die chemischen Komponenten einer Kandidatenbibliothek) bestimmt, welcher sich wie folgt berechnet:

oder nach Umstellung

$$
Z=\left[\left|\mu_{\mathrm{s}}-\mu_{\mathrm{c}}\right|-\left(3 \sigma_{\mathrm{s}}+3 \sigma_{\mathrm{c}}\right)\right] /\left|\mu_{\mathrm{s}}-\mu_{\mathrm{c}}\right|
$$

$$
\begin{array}{ll}
\mu_{\mathrm{s}}: & \mathrm{MW}(\text { Probe }) \\
\mu_{\mathrm{c}}: & \mathrm{MW}(\text { Kontrolle, 100\%- } \\
& \text { Inhib. bzw. Blank); } \\
\sigma_{\mathrm{s}}: & \mathrm{SD}(\text { Probe) } \\
\sigma_{\mathrm{c}}: & \mathrm{SD} \text { (Kontrolle, 100\%- } \\
& \text { Inhib. })
\end{array}
$$

Hier wird deutlich, daß der höchstmögliche Z-Wert 1 ist.

Dazu wurden drei Arten von jeweils 10 identischen HDAC-Assays robotisch in den Kompartimenten einer 96 well-MTP angesetzt und mit dem BMG-Reader vermessen. Neben ungehemmten Reaktionen wurden Kontroll-Ansätze pipettiert, die a) kein Zielenzym (Blanks) und b) zusätzlich $300 \mathrm{nM}$ TSA (100\%ige Hemmung) enthielten. Dabei wurde in verschiedenen Experimenten sowohl das Substrat (Boc-Lys(Ac)-AMC, AcRGK(Ac)-AMC, Tos-GPK(Ac)-AMC) variiert als auch das Puffersystem (HD-Puffer und Thrombin-Puffer bzw. HDP-Puffer und TI-Puffer) und die Trypsinkonzentration ( $10 \mathrm{mg} / \mathrm{ml}$ bis $10 \mu \mathrm{g} / \mathrm{ml})$. 


\subsubsection{HDACl-Screening im 96 well-Format}

Zur Durchmusterung von Substanzbibliotheken nach inhibitorischer Wirkung auf das Zielenzym (HDAC aus Rattenleber), wurden mehrfach hintereinander je 96 parallele Standard-HDAC-Assays im 96 well-Format robotisch mit der CyBi-Screen-Machine durchgeführt und vermessen (3.5.8.2). Auf jeder Meßplatte wurden zusätzlich zu den Testansätzen mit Kandidatenmolekülen einer bestimmten Konzentration drei Kontrollen mit $2 \mathrm{nM}$ (ca. 50\%ige Hemmung) und drei mit $300 \mathrm{nM}$ TSA (100\%ige Hemmung), sowie vier ungehemmte Ansätze (Maximalsignal) mitgeführt. Wie beschrieben (3.5.8.2) wurden die Reagenzien-Vorratsplatten befüllt und in die Anlage eingebracht. Je $10 \mu 1$ einer HDACI-Kandidaten-Lösung wurde manuell in die Kompartimente der Meßplatte eingebracht und diese in der Anlage positioniert. Der Assay wurde dann programmgesteuert abgearbeitet.

Es wurde dabei neben dem verbesserten Protokoll und Puffersystem (Tos-GPK(Ac)-AMC in HDP-Puffer und $10 \mu \mathrm{g} / \mathrm{ml}$ Trypsin/2 $\mu \mathrm{M}$ TSA in TI-Puffer, (Wegener et al., 2003a)) anfangs (beim ersten Screening) auch mit einem anderen Puffersystem (Tos-GPK(Ac)-AMC in HD-Puffer und $10 \mu \mathrm{g} / \mathrm{ml}$ Trypsin/2 $\mu \mathrm{M}$ TSA in Thrombin-Puffer) gearbeitet.

\subsubsection{Bestimmung der IC $_{50}$ von HDACI für FB188-HDAH}

Zur Bestimmung der Konzentration an HDACI, welche die FB188-HDAH zu 50 \% inhibiert $\left(\mathrm{IC}_{50}\right)$, wurde die Enzymaktivität mit dem kontinuierlichen HDAC-Assay bei verschiedenen Inhibitorkonzentrationen im BMG-Reader vermessen. Dazu wurde ein modifizierter HDAC-Assay-Ansatz manuell in das Kompartiment einer 96 well-MTP pipettiert, indem $10 \mu 1$ Inhibitorverdünnung in Assay-Puffer, $90 \mu 1$ Trypsinlösung ( $1 \mathrm{mg} / \mathrm{ml}$ in Assay-Puffer), und $70 \mu 1300 \mu \mathrm{M}$ Boc-Lys(Ac)-AMC in Assay-Puffer zusammengegeben wurden. Als Assay-Puffer wurde meist $50 \mathrm{mM} \mathrm{KP}, \mathrm{pH} 8$ oder ausnahmsweise zu Vergleichszwecken HDP-Puffer verwendet. Die Reaktion wurde nach 10 min durch Zugabe von $20 \mu 1$ FB188-HDAH (1:70 vorverdünnt in AssayPuffer) gestartet und sofort über einen Zeitraum von mindestens 40 min vermessen. Ausgewertet wurden nur der auf eine Verzögerungsphase folgende, linear verlaufende Bereich der Kinetik (meist nach 20 min). 
Dabei wurde darauf geachtet, daß die DMSO-Konzentration im Ansatz nicht über $2 \%$, in aller Regel nicht über $1 \%$ lag. Die Messungen wurden in Triplikaten durchgeführt und die Reaktionsgeschwindigkeit (in FE/min) gegen die HDACI-Konzentration halblogarithmisch aufgetragen. Die Auswertung erfolgte mit dem Programm GraphPad Prism, das durch die Meßpunkte eine sigmoidale Dosis-Wirkungskurve mit variabler Steigung fittete.

\subsubsection{HDAC-Assay in 1536 well-MTP}

Die Versuche im 1536 well-Format wurden bei der AG Schober in Darmstadt mit dem Prototypen einer robotischen, kombinierten Combi-Chem- und HTS-Screening-Anlage (Groß, 2002; Schlingloff, 1999) durchgeführt, deren in dieser Arbeit verwendeter Pipettor mit 96 Mikrospritzen versehen ist. Mittels eines integrierten Fluorimeters mit CCD-Kamera können alle Kompartimente einer Meßplatte simultan ausgelesen werden. Es wurden weitestgehend die Vorgaben (z. B. Puffer und Inkubationszeiten) nach dem verbesserten HDAC-Assay-Protokoll (Wegener et al., 2003a) befolgt, die Endkonzentration an Tos-GPK(Ac)-AMC betrug hier $100 \mu \mathrm{M}$. Alle $\mathrm{IC}_{50^{-}}$ Bestimmungen wurden 6 fach, alle Messungen für den $Z^{\prime}$-Faktor 12 fach redundant ausgeführt. Alle Lösungen und Puffer wurden jeweils in 384 well-MTP (Vorratsplatten) zu $100 \mu 1$ pro Kompartiment manuell vorgelegt. Der Raum war bei allen Vorgängen auf etwa $25^{\circ} \mathrm{C}$ temperiert. Die Fluoreszenzsignale wurden sowohl mit der CCD-Kamera als auch mit einem MTP-Fluoreszenzreader ausgelesen.

\subsubsection{Bestimmung des Z'-Faktors}

Die Befüllung der Vorrats-MTP (384 Kompartimente) mit den Reagenzien erfolgte nach identischem Raster manuell mit einer 12-Kanalpipette, so daß jedes zweite Kompartiment einer Zeile oder Spalte dieselbe Lösung erhielt. Als Inhibitor wurde in jeweils 12 Kompartimente der Vorratsplatten $80 \mu$ einer 6 nM bzw. 3 nM TSA-Lösung eingefüllt, sonst überall HDP-Puffer. Bei der Enzym-MTP wurde in 4 Zeilen je 12 Kompartimente mit je $80 \mu \mathrm{l}$ HDAC-Lösung befüllt, sonst HDP-Puffer. Die Trypsin/TSA-Stoplösung wurde entsprechend zu je $80 \mu 1$ pro Kompartiment befüllt. 
Ansatz:

$2 \mu 1$ HDACI-Verdünnung (0, 3, 6 nM TSA in HDP-Puffer)

$2 \mu 1$ HDAC (aus Rattenleber, 1:20 in HDP-Puffer vorverdünnt) bzw. Puffer

$2 \mu 1$ Substrat (300 $\mu \mathrm{M}$ TosGPK(Ac)AMC in HDP-Puffer)

Abstoppen nach 65 min bei $30{ }^{\circ} \mathrm{C}$ mit $4 \mu 1$ Trypsin/TSA-Stoplösung.

Zuerst wurden robotisch nach kurzem Mischen durch zweimaliges Aufsaugen und Ausstoßen von $5 \mu 1$ der Lösung je $2 \mu 1$ aus der Inhibitor-MTP in eine schwarze 1536er MTP gegeben. Danach wurden die Spitzen mit Wasser in einer 1 well-Platte durch viermaliges Aufziehen und Ausstoßen von je $8 \mu 1$ gewaschen. Nach der Zugabe von $2 \mu \mathrm{l}$ HDAC und nochmaligem Aufsaugen und Ausstoßen (Mischen) und einem anschließenden Waschzyklus wie oben beschrieben (von ca. 5 min Dauer und damit gleichzeitiger Inkubationspause für die Gleichgewichtseinstellung des Ansatzes), wurde die Reaktion mit der Zugabe von $2 \mu 1$ Substrat gestartet (wiederum mit einem Durchmischen durch Aufsaugen/Abgeben). Die Meßplatte wurde manuell gedeckelt und bei ca. $30{ }^{\circ} \mathrm{C}$ für 65 min inkubiert. Die abermals gewaschenen Spitzen gaben dann $4 \mu 1$ Trypsin/TSA-Stoplösung dazu, und die Fluoreszenzsignale wurden mit dem CCDImager der Anlage ausgelesen. Zusätzlich wurde die Meßplatte auch in einem BMGReader vermessen (Gain 120). Nach dem Trypsin-Pipettierschritt wurden die Spitzen erst 10 mal mit 10\%igem SDS in einer Wannenplatte, dann 10 mal mit Wasser in einer neuen Wannenplatte gewaschen.

Als Test auf verbliebene Trypsinkontamination in den Spritzen des Pipettors wurden je $5 \mu 130 \mu \mathrm{M}$ Tos-GPR-AMC aus einer mit $200 \mu \mathrm{l}$ davon befüllten 96er MTP aufgesogen und in dieselben Kompartimente wieder abgegeben. Die Messung wurde im CCDImager der Anlage mit der vorherigen Messung derselben Testplatte vor dem Test verglichen.

Zusätzlich wurde ein hoch-skalierter Enzymtest im 96 well-Maßstab mit bzw. ohne HDAC angesetzt und im MTP-Fluoreszenzreader vermessen, bei dem alle Volumina verzwanzigfacht wurden und wobei die in den 384 well MTP vorgelegten Lösungen verwendet wurden. 
Der Z'-Faktor wurde aus den jeweils 12 Meßwerten für die 100\%-Kontrollen und den Blanks wie für 96 well-Formate beschrieben berechnet.

\subsubsection{Bestimmung der $\mathrm{IC}_{50}$ von $\mathrm{HDACI}$ für HDAC aus Rattenleber}

Mit derselben robotischen Screening-Station wurden drei Dosis-Wirkungs-Kurven von HDACI zur Bestimmung des jeweiligen $\mathrm{IC}_{50}$ für HDAC aus der Rattenleber in je 6facher Ausführung aufgenommen.

Dazu wurden in die Kompartimente einer Inhibitor-Vorratsplatte mit 384 Kompartimenten je $100 \mu 1$ aller Verdünnungen der drei HDACI-Verdünnungsreihen in HDP-Puffer manuell vorgelegt, wobei drei Kompartimente eines Quadranten der Platte belegt wurden. Alle Verdünnungen waren jeweils im Bezug auf die im Ansatz herrschende Endkonzentration des Inhibitors 3fach-konzentriert. Die Befüllung der 384 well-MTP für HDAC (1:24 in HDP-Puffer), Substrat und Trypsin/TSA-Stoplösung erfolgte ebenfalls manuell, aber wie oben beschrieben(3.5.12.1). Der Ansatz in der 1536 well-Meßplatte wurde wie schon beschrieben pipettiert, inkubiert und vermessen, wobei hier nach jedem Dispensieren eines Inhibitors ein Spitzen-Waschschritte mit Wasser eingeschoben worden war, um eine Verschleppung eines Inhibitors in die Vorrats-wells des als nächstes pipettierten zu vermeiden. Aus demselben Grunde wurde ebenfalls auch nach jeder Enzym- oder Substratzugabe gewaschen, da ja die Reaktanden mehrfach aus denselben Kompartimenten der Vorrats-MTP aufgenommen wurden. Für die Zugabe der Stoplösung wurden die Waschschritte beibehalten, da es ansonsten $\mathrm{zu}$ Unterschieden in der Inkubationszeit zwischen den drei $\mathrm{IC}_{50^{-}}$ Bestimmungen gekommen wäre. Abschließend wurden die Spritzen des Pipettors mit 10\%igem SDS, dann mit Wasser gewaschen und der Test auf Trypsinkontamination durchgeführt. Die $\mathrm{IC}_{50}$-Werte wurden sowohl aus den mit dem CCD-Imager als auch dem BMG-Reader gemessenen Fluoreszenz-Daten mit dem Programm GraphPad-Prism errechnet. 


\section{Ergebnisse}

\subsection{Entwicklung eines neuen fluorogenen HDAC Assays}

Die reversible Acetylierung von bestimmten Lysinen der Kern-Histone ist von entscheidender Bedeutung für die Regulation der Genexpression in eukaryotischen Zellen. Im allgemeinen korreliert eine Hyperacetylierung mit einer Transkriptionsaktivierung, eine Hypoacetylierung mit Transkriptionsrepression (Grunstein, 1997a; Peterson, 2002; Wade et al., 1997), wobei aber Ausnahmen bekannt sind (1.2.2). Zwei Enzymgruppen, die Histon-Acetyltransferasen (HAT) und die HistonDeacetylasen (HDAC) halten den Acetylierungslevel der Kernhistone im delikaten Gleichgewicht und mögen sehr wohl auch an der Regulation anderer zellulärer Prozesse beteiligt sein (Grozinger and Schreiber, 2002). Eine wachsende Zahl von experimentellen Beobachtungen belegen einen Einfluß der HDAC bei der Kontrolle des Zellzyklus, der Zelldifferenzierung und in der pathologischen Situation der Krebsentstehung (Chung, 2002). Die gewichtige Rolle der HDAC für die Tumorgenese wurde besonders durch den Befund hervorgehoben, daß mutierte RetinsäureKernrezeptoren bei der Akuten Promyelocytischen Leukämie (APL) HDAC dauerhaft rekrutieren (Grignani et al., 1998; Lin et al., 1998; Warrell et al., 1998). Interessanterweise konnte durch HDAC-Inhibitoren (HDACI) wie Trichostatin A (TSA) und Trapoxin (TPX) eine Induktion der Zelldifferenzierung, des Zellzyklusarrestes und eine Reversion von transformierter Zellmorphologie erreicht werden (Jung et al., 1999; Marks et al., 2000; Yoshida et al., 1995). Daher ist es nicht verwunderlich, daß HDACI ein Potential als vielversprechende Antitumoragenzien zugesprochen wird (Jung, 2001; Kwon et al., 2003; Saito et al., 1999; Saunders et al., 1999).

Eine in der pharmazeutischen Forschung oft angewandte Strategie zur Entwicklung von Leitstrukturen für Wirkstoffe ist die Durchmusterung von Molekülbibliotheken. Dazu wurden wegen der großen Zahl an Substanzen, die getestet werden müssen, um mit einiger Sicherheit einen Wirkstoff zu finden (Spencer, 1998), Hochdurchsatzverfahren entwickelt, welche eine möglichst parallele und automatisierte Wirkstoffsuche in 
Mikrotiterformaten ermöglichen. Die Entwicklung von Inhibitoren für Histondeacetylasen war bislang allerdings insofern erschwert, daß kein für den Einsatz in in vitro-Hochdurchsatzformaten (high throughput screening, HTS) geeigneter Assay zur Verfügung stand. Bestehende Testsysteme beruhten auf radioaktiv markierten Histonen oder Peptidsubstraten und/oder verlangten eine recht aufwendige Abtrennung der Produkte vom Substrat (Gao et al., 2002; Hoffmann et al., 1999; Kölle et al., 1998; Van den Wyngaert et al., 2000; Wegener et al., 2003b). Während Immunoblots mit gegen acetylierte Lysine gerichteten Antikörpern zwar als nicht-radioaktive Testsysteme die HDAC-Aktivität beispielsweise in Form von hypoacetylierten Histonen wiedergeben (Carmen et al., 1999; Zhang et al., 1998), aber wohl eher ungeeignet für HTS sind, verwendete der erste echte, nicht-radioaktive HDAC-Assay MAL (N-(4methyl-7-coumarinyl)-N- $\alpha$-(tert.-butyloxy-carbonyl)-N- $\Omega$-acetyllysinamide) als Substrat (Hoffmann et al., 1999). Ungünstigerweise muß hier ebenfalls das Produkt vom Substrat getrennt werden, indem das deacetylierte Produkt mittels Fluoreszenzdetektion nach Ethylacetat-Extraktion und HPLC quantifiziert wird, was den Assay für einen hohen Durchsatz nicht besonders geeignet macht.

Dieselben Schwierigkeiten taten sich bei der biochemischen Charakterisierung und Funktionszuweisung der Histondeacetylasen und ähnlicher Enzyme auf. Auch hier fehlte es an einem nicht-radioaktiven aber homogenen und sensitiven Enzymtest. Daher sollte mit dieser Arbeit ein neues Konzept zur Fluoreszenz-basierten Aktivitätsmessung von HDAC in vitro entwickelt werden.

\subsubsection{Allgemeine Eigenschaften des Assays}

Nicht nur für HTS-Assays sind grundlegende Anforderungen Präzision und Reproduzierbarkeit der damit erhaltenen Daten. Eine möglichst hohe Spezifität, z. B. für einen Reaktionstypus oder eine Enzymklasse, erleichtert die Interpretation der Ergebnisse und hilft, Artefakte und Interferenzen durch andere Reaktionen chemischer oder biologischer Natur zu erkennen bzw. zu vermeiden. Ein HTS-geeigneter Enzymtest muß darüberhinaus aber auch noch anderen Ansprüchen genügen. So sollte die Meßdauer für eine Probe möglichst kurz bleiben, da trotz normalerweise hochparallelen Ablaufs vieler Messungen gleichzeitig immer noch viele dieser Meßblöcke seriell durchlaufen werden müssen, um die oft riesigen Probenzahlen zu 
bewältigen. Das wichtigste Kriterium speziell für eine Eignung eines Assays für HTSAnwendungen ist seine Automatisierbarkeit. Im Gegensatz zum einzigen anderen vor Beginn dieses Promotionsprojektes veröffentlichten, nicht-radioaktivem HDAC-Assays mit einem gewissen Potential für höheren Durchsatz (Hoffmann et al., 2000), wurde in dieser Arbeit ein homogenes Assay-Format entwickelt, um den Einsatz von handelsüblichen Pipettierrobotern zu ermöglichen, ohne die ein echtes HTS nicht realisierbar ist. Eine wenig arbeitsintensive Durchführung und ein möglichst einfaches Pipettierschema, d.h. eine geringe Akkumulation einzelner Meßfehler, und die Verwendung von kostengünstigen Reagenzien sollten ebenfalls eine breite, routinemäßige Anwendung in vielen, auch nicht speziell (z. B. mit einer HPLC) ausgerüsteten oder gar robotisch operierenden Labors gestatten. Eine hohe Sensitivität des Assays erschien als ein wichtiges Kriterium, da die bekannte Funktion der HDAC als regulatorische Enzyme (Grunstein, 1997b; Rundlett et al., 1996) nahelegte, mit im Vergleich zu katabolischen Enzymen recht geringen Umsatzraten rechnen zu müssen. Um radioaktive Substrate unter Erhaltung einer großen Sensitivität vermeiden zu können, wurde ein Fluoreszenz-basierter Enzymtest entworfen.

Der neu entwickelte HDAC-Enzymtest besteht aus zwei aufeinanderfolgenden Enzymkatalysierten Reaktionsschritten, wobei erstens die HDAC die $\varepsilon$-Aminogruppe des Lysins in einem peptidischen Kontext deacetyliert und zweitens eine Protease alle so entstandenen acetylfreien Substratmoleküle proteolytisch nach dem Lysin spaltet und somit das dann stark fluoreszierende AMC freisetzt (Abb. 4). Dabei darf weder die Protease bei vorhandener $\varepsilon$-Acetylgruppe am Lysin spalten noch das peptidgebundene AMC bei der verwendeten Detektionswellenlänge von $360 \mathrm{~nm}$ nennenswert fluoreszieren. Als ein guter Kandidat für das Reporterenzym der zweiten Assaystufe ist sicherlich die Lysin-spezifische Protease LysC (Allan, 1989) zu nennen. Allerdings wäre dies Enzym wohl schnell recht kostenintensiv bei Einsatz in HTS-Projekten. Es ist ferner nicht so gut untersucht und stabil unter vielen Pufferbedingungen wie Trypsin (Allan, 1989; Khmelnitsky et al., 1991; Russell et al., 2001). Für Trypsin war außerdem bereits berichtet worden, daß das Enzym einen positiv geladenen Aminosäurerest des Substrates etwa von Arginin, aber auch Lysin in der S1-Tasche verlangt (Evnin et al., 1990; Grahn et al., 1998; Zimmerman et al., 1977). Eine Acetylierung der $\varepsilon-$ Aminogruppe dieses Lysinrestes im Substratmolekül beseitigt diese für die Spaltung 
erforderliche positive Ladung. Zudem dürfte der acetylierte Lysinrest aufgrund seiner Größe kein idealer P1-Rest mehr sein .

Das Trypsin spaltet normalerweise ebenfalls die HDAC und beendet somit die eigentliche Reaktion. Daher kann mit diesem Assay in der Regel nur eine Endpunktbestimmung der HDAC-Reaktion erfolgen. Um die HDAC-Reaktion in Fällen, bei denen diese proteolytische Inaktivierung langsam verläuft oder das Zielenzym sogar resistent gegen Trypsinspaltung ist, sicher sofort abzustoppen, wird Trichostatin A, ein HDAC-Standardinhibitor, in hoher Dosis der Trypsin-Stoplösung zugesetzt. Eine Trypsinresistenz ermöglicht interessanterweise eine kontinuierliche Verfolgung der HDAC-Reaktion. Hier kann die Deacetylierung in Anwesenheit eines Trypsinüberschusses erfolgen, wobei das entstehende Produkt der HDAC sofort gespalten wird und die AMC-Fluoreszenz im MTP-Reader vermessen wird (Dissertation C. Hildmann, in Vorbereitung, (Wegener et al., 2003a)). 


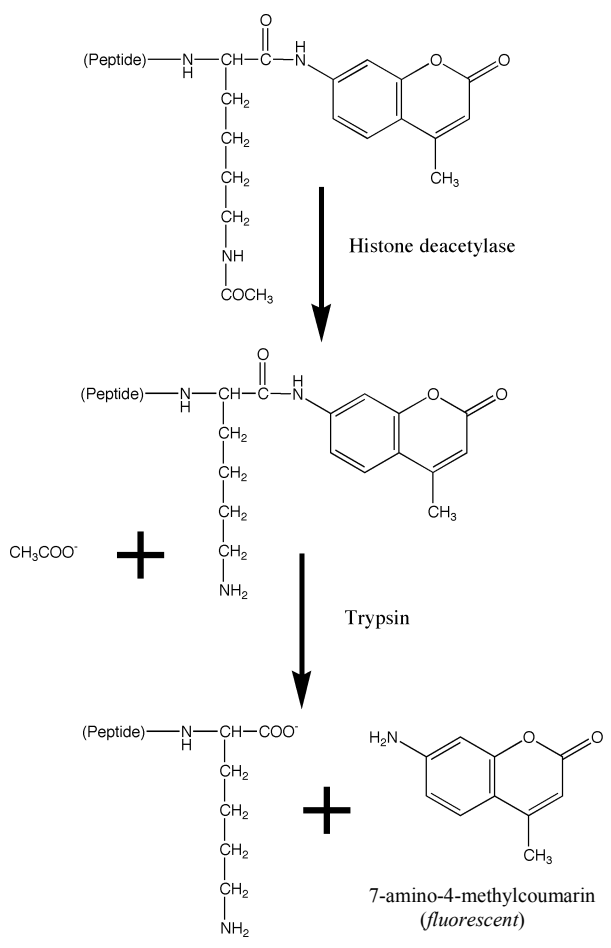

Abb. 4.: Schema des zweistufigen, fluorogenen HDAC-Assays.

Im ersten Schritt deacetyliert die HDAC die $\varepsilon$-Aminoacetylgruppen von Lysinresten in peptidischen Substraten direkt N-terminal vor dem fluorogenen AMC. Das Fluoreszenzsignal wird im zweiten Schritt nach Spaltung des so entstandenen, deacetylierten Substrates durch Trypsin generiert, indem das nun stark fluoreszierende AMC in die Lösung freigesetzt wird.

\subsubsection{Sequenzspezifität der Histondeacetylasen}

Als mögliche Substrate für Histondeacetylasen wurden Tripeptide aus dem Kontext des Histons H4 abgeleitet (Kervabon et al., 1979). Die Substrate bestanden aus einem $\varepsilon$-acetylierten Lysinrest, dem N-terminal verschiedene Dipeptide vorausgingen, und dessen C-Terminus amidisch mit einer AMC-Gruppe verknüpft war (Abb.4). Die Tripeptid-Substrate wurden von D. Riester hergestellt (Wegener et al., 2003c). Bedingt durch die Synthesestrategie, tragen alle Tripeptid-Substrate aminoterminal eine Acetylgruppe. Mit diesen, von einem natürlichen Substrat abgeleiteten, Peptiden sollte eine mögliche Sequenzspezifität erfaßt werden. Ebenfalls interessierte die Fragestellung, ob diese längeren Peptide einen besseren Umsatz zeigen würden als das bekannte MAL für HDAC aus der Rattenleber (Hoffmann et al., 1999), welches ja 
eigentlich, als ein an der $\alpha$-Aminogruppe Boc-geschütztes, $\varepsilon$-acetyliertes Lysin mit Cterminalem AMC-Fluorophor, ein verkürztes Minimalsubstrat vom oben beschrieben Typus darstellt. MAL wird in dieser Arbeit daher Boc-Lys(Ac)-AMC genannt (Abb. 33).

Um zu bestätigen, daß weder Trypsin bei vorhandener $\varepsilon$-Acetylgruppe am Lysin spaltet noch das peptidgebundene AMC bei der verwendeten Detektionswellenlänge von $460 \mathrm{~nm}$ fluoresziert (Abb. 4, (Zimmerman et al., 1977)), wurden Trypsin-Assays in 96 well-MTP mit verschiedenen, nicht-acetylierten Peptidyl-AMC-Substraten und einer Konzentration von $200 \mu \mathrm{M}$ bei unterschiedlichen Trypsinkonzentrationen von $5 \mathrm{mg} / \mathrm{ml}$ bis $5 \mathrm{ng} / \mathrm{ml}$ durchgeführt (Wegener et al., 2003c). Dazu wurde eine Trypsinverdünnungsreihe angelegt und in einem Standard-Trypsin-Assay eingesetzt, wie unter 3.5.2 beschrieben, mit dem Unterschied, daß hier die angeführten fluorogenen Substrate in acetylierter bzw. nicht-acetylierter Form vermessen wurden. Die Fluoreszenzsignale wurden mit Hilfe eines MTP-Fluoreszenzreaders bei einer Detektionswellenlänge von $460 \mathrm{~nm}$ (Anregung bei $390 \mathrm{~nm}$ ) über mindestens $20 \mathrm{~min}$ verfolgt. Ansätze ohne Trypsin dienten als Kontrolle, um die spontane Substrathydrolyse zu erfassen. Auch nach mehrstündiger Inkubation bei $30^{\circ} \mathrm{C}$ konnte keine Spaltung der acetylierten Tripeptid-Substrate bei bis zu $50 \mu \mathrm{g} / \mathrm{ml}$ Trypsin bzw. des Boc-Lys(Ac)-AMC bei der höchsten untersuchten Trypsinkonzentration von $5 \mathrm{mg} / \mathrm{ml}$ im Ansatz beobachtet werden, während die jeweilige Trypsinkonzentration ausreichte, die nicht-acetylierten Substratvarianten mindestens innerhalb von $20 \mathrm{~min}$ vollständig umzusetzen. Daraufhin wurde der HDAC-Assay mit den jeweiligen HDACSubstraten bei $5 \mathrm{mg} / \mathrm{ml}$ Trypsin abgestoppt. Bei dieser Konzentration wurden die nichtacetylierten Tripeptid-Substrate innerhalb weniger Minuten quantitativ umgesetzt. Im Vergleich dazu wurde das Trypsinsubstrat Tos-GPR-AMC bereits bei $5 \mathrm{ng} / \mathrm{ml}$ Trypsin mit ca. $15 \mathrm{pmol} / \mathrm{min}$ sogar noch schneller umgesetzt (Abb. 5). 

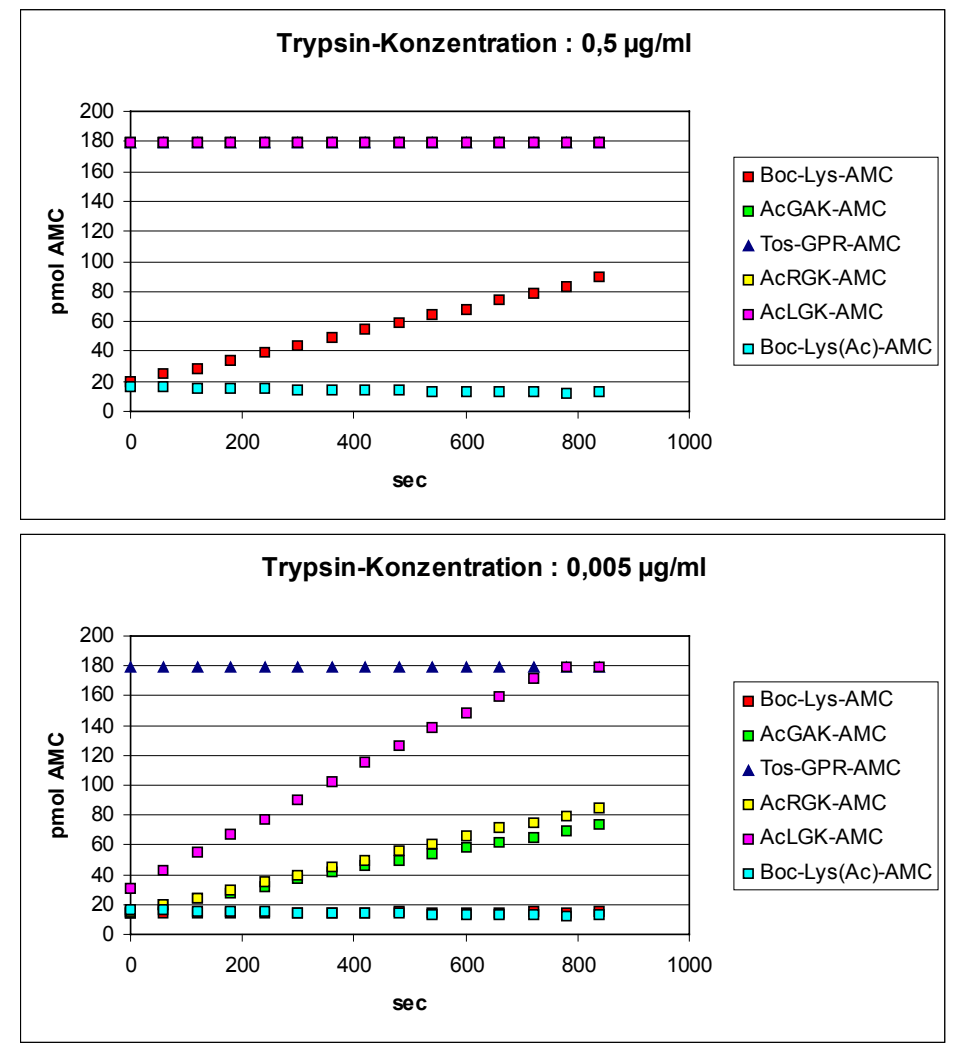

Abb. 5: Zeitverlauf des Umsatzes von verschiedenen Substraten durch Trypsin.

Die in der Legende angegebenen fluorogenen Substrate wurden in MTP mit Trypsin bei (A) $0.5 \mu \mathrm{g} / \mathrm{ml}$ bzw. (B) $5 \mathrm{ng} / \mathrm{ml}$ umgesetzt und der zeitliche Verlauf der AMC-Freisetzung im MTP-Fluoreszenzreader verfolgt, indem minütlich eine Messung erfolgte. Boc-Lys-AMC wurde erst bei $0,5 \mu \mathrm{g} / \mathrm{ml}$ nennenswert umgesetzt, während alle nicht-acetylierten Tripeptid-Substrate bereits bei $5 \mathrm{ng} / \mathrm{ml}$ umgesetzt wurden und Boc-Lys(Ac)-AMC auch bei $0,5 \mu \mathrm{g} / \mathrm{ml}$ Trypsin nicht gespalten wurde. Die Meßkurven von Ac-LGKAMC, Ac-GAK-AMC, Ac-RGK-AMC und Tos-GPR-AMC verlaufen nahezu gleich in (A) und liegen daher übereinander.

Nachdem die Trypsin-Experimente bestätigt hatten, daß sich die Substrate in den Kontrollen wie gewünscht verhielten, wurden diese mit HDAC aus Rattenleber im 96 well-Format umgesetzt, indem identische HDAC-Assays mit 20 pmol des jeweiligen Substrates nach verschiedenen Reaktionszeiten abgestoppt wurden und das freigesetzte AMC im Fluoreszenzreader detektiert wurde (Wegener et al., 2003c). Dazu wurden mit der CyBio-Screening-Anlage $60 \mu \mathrm{l}$ HD-Puffer, $10 \mu 1$ (1:6 vorverdünnte) HDAC aus Rattenleber in die Kompartimente einer Meßplatte aus den Reagenzien-Vorratsplatten transferiert. Die Reaktionen wurden mit $30 \mu$ Substratlösung gestartet und die Meßplatte wurde bei $30^{\circ} \mathrm{C}$ inkubiert. Nach den entsprechenden Zeitintervallen wurden die HDAC-Reaktionen in jeweils 3 identischen Ansätzen durch manuelle Zugabe der Trypsin/TSA-Stoplösung beendet. Die jeweils freigesetzte AMC-Menge wurde für die 
umgesetzten Substrate Boc-Lys(Ac)-AMC, Ac-Arg-Gly-Lys(Ac)-AMC, Ac-Gly-GlyLys(Ac)-AMC, Ac-Leu-Gly-Lys(Ac)-AMC und Ac-Gly-Ala-Lys(Ac)-AMC gegen die Zeit aufgetragen (Abb. 6). Es zeigte sich, daß alle diese acetylierten Peptide von HDAC aus Rattenleber als Substrate erkannt wurden. Zusätzlich konnte eine lineare Zunahme der Fluoreszenz mit der Zeit bis 60 min beobachtet werden. Auffällig war die relativ ähnliche Effizienz, mit der die Substrate von diesem Enzym umgesetzt wurden.

Analog durchgeführte Umsatzkurven mit Boc-Lys(Ac)-AMC und Ac-Arg-GlyLys(Ac)-AMC belegen diesen linearen Verlauf der Reaktion ebenfalls für HDAC8 (Daten nicht gezeigt). Auch HDAC-ähnliche Enzyme wie HDAH aus dem Alcaligenes/Bordetella-Stamm FB188 (Hildmann et al., 2003) konnten mit diesem zweistufigen HDAC-Assay vermessen werden. Abbildung 7 zeigt die Umsatzkurve dieses Enzyms mit $125 \mu \mathrm{M}$ Boc-Lys(Ac)-AMC. Die benutzte FB188-HDAH wurde von C. Hildmann exprimiert und über IMAC aufgereinigt.

Eine Besonderheit weist der HDAC-Assay mit FB188-HDAH auf. Da dieses bakterielle Enzym inert gegen die Spaltung und Inaktivierung durch Trypsin sogar bei hohen Konzentrationen dieser Protease ist, konnte die Deacetylase-Aktivität hier auch kontinuierlich im MTP-Fluoreszenzreader verfolgt werden (Wegener et al., 2003a). Der Standard-HDAC-Assay wurde insofern modifiziert, als Trypsin von Beginn an im Ansatz vorlag und die Reaktion durch Substratzugabe gestartet wurde. Dazu wurden $50 \mu \mathrm{l}$ FB188-HDAH $(100 \mu \mathrm{g} / \mathrm{ml}$ in HD-Puffer $)$ und $50 \mu \mathrm{l}$ Trypsin $(10 \mathrm{mg} / \mathrm{ml}$ in Trypsin-Puffer) in die Kompartimente einer Meßplatte pipettiert und die Reaktion nach Start mit $100 \mu 1$ Boc-Lys(Ac)-AMC (100 $\mu \mathrm{M}$ Endkonzentration) im MTP-Fluorimeter bei $30{ }^{\circ} \mathrm{C}$ verfolgt. Nach einer kurzen Anlaufphase zeigte sich auch hier eine stabile lineare Kinetik der Reaktion über den Meß-Zeitraum von mindestens 20 min (Abb. 7). Eine ausführlichere Beschreibung der Eigenschaften der FB188-HDAH erfolgt in der Parallelarbeit von C. Hildmann. 


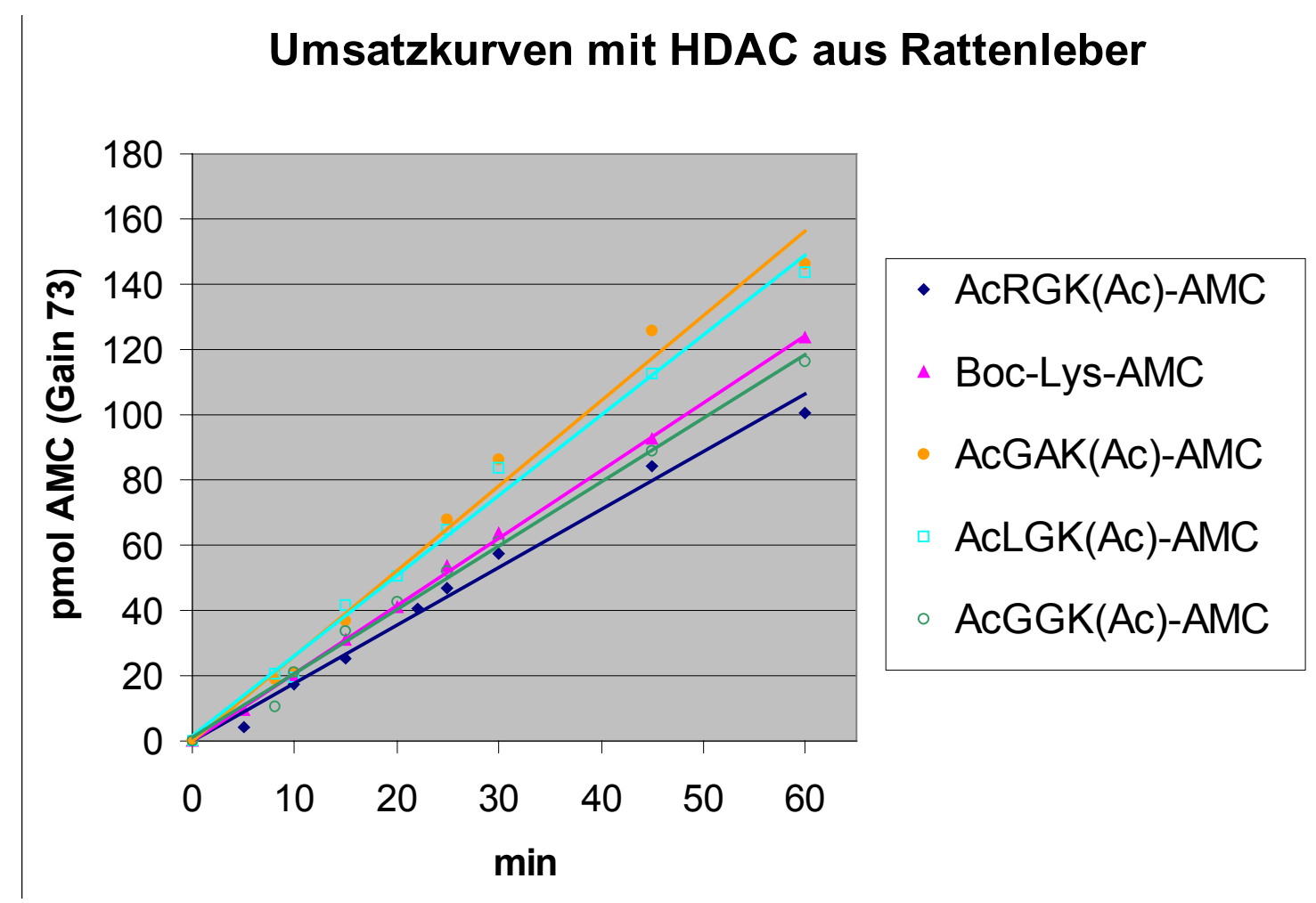

Abb. 6: Umsatzkurven verschiedener Substrate mit HDAC aus Rattenleber.

Verschiedene fluorogene Substrate wurden im HDAC-Assay mit HDAC aus Rattenleber inkubiert und die Reaktionsansätze nach den angegebene Zeiten abgestoppt. Die Fluoreszenzsignale durch freigesetztes AMC wurden in einem MTP-Fluoreszenzreader vermessen.

Da aus den oben beschriebenen Messungen ersichtlich wurde, daß die HDAC aus Rattenleber unter diesen Bedingungen in vitro keine ausgeprägte Sequenzspezifität aufwies, wurde versucht, ein im Hinblick auf Umsatz durch Trypsin optimiertes Substrat zu generieren. Dazu wurde das bekanntermaßen effektive Trypsinsubstrat TosGPR-AMC zum Vorbild genommen und modifiziert, indem der P1-Rest von Arginin in Lysin abgewandelt wurde. Das korrespondierende acetylierte HDAC-Substrat TosGPK(Ac)-AMC und die nicht-acetylierte Variante wurden analog $\mathrm{zu}$ den anderen fluorogenen Tripeptiden in Trypsin-Standard-Assays vermessen. Auch in diesem Fall konnte ein Trypsinkonzentrationsbereich gefunden werden, in dem Tos-GPK(Ac)-AMC nicht gespalten wird, während das nicht-acetylierte Substrat schnell zur Gänze umgesetzt wurde. Zusätzlich wurden Trypsin-Assays mit beiden Substratformen bei $300 \mu \mathrm{M}$ in einem Fluorimeter durchgeführt, um den schnellen Anstieg der Fluoreszenz bei der nicht-acetylierten Variante erfassen zu können. Der HDAC-Assay mit TosGPK(Ac)-AMC als Substrat wurde daraufhin standardmäßig mit $5 \mu \mathrm{g} / \mathrm{ml}$ Trypsinendkonzentration im Ansatz abgestoppt. 
Umsatzkurven mit diesem neuen Substrat bei $125 \mu \mathrm{M}$ und HDAC aus Rattenleber bzw. mit HDAC8 wurden ähnlich wie bereits für die anderen Tripeptid-Substrate beschrieben durchgeführt (Wegener et al., 2003a). Hier wurde die HDAC-Reaktion allerdings in $120 \mu 1$ durch Zugabe von $50 \mu 1$ Substrat gestartet. Als Assay-Puffer wurde HDP-Puffer und für die Trypsin/TSA-Stoplösung TI-Puffer verwendet.

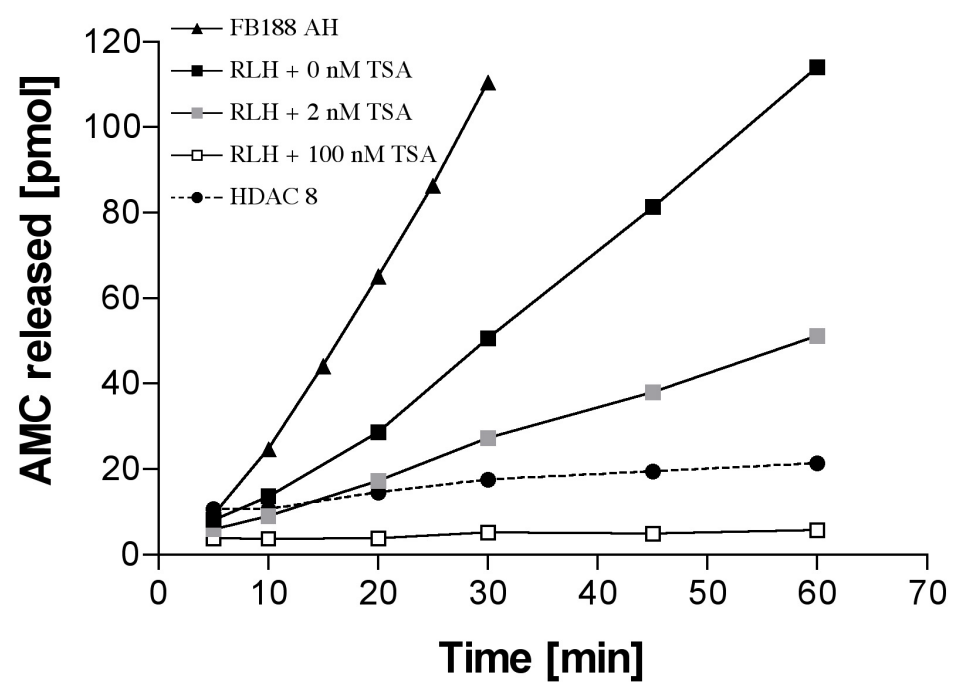

Abb. 7: Zeitabhängiger Umsatz von Tos-GPK(Ac)-AMC durch HDAC aus Rattenleber bzw.

\section{HDAC8.}

$125 \mu \mathrm{M}$ Tos-GPK(Ac)-AMC wurden im HDAC-Assay mit HDAC aus Rattenleber mit unterschiedlichen Konzentrationen an TSA bzw. HDAC8 inkubiert und die Reaktionsansätze nach den angegebene Zeiten abgestoppt. Zu Vergleichszwecken wurden parallel Assays mit FB188-HDAH (FB188 AH) und $125 \mu \mathrm{M}$ Boc-Lys(Ac)-AMC als Substrat durchgeführt. Die Fluoreszenzsignale durch freigesetztes AMC wurden in einem MTP-Fluoreszenzreader vermessen.

$125 \mu \mathrm{M}$ Tos-GPK(Ac)-AMC wurden im HDAC-Assay mit HDAC aus Rattenleber bzw. HDAC8 inkubiert und die Reaktionsansätze nach den angegebene Zeiten abgestoppt. Parallel wurden Reaktionen in Anwesenheit verschiedener Konzentrationen des HDACI TSA analysiert. Die Fluoreszenzsignale durch freigesetztes AMC wurden in einem MTP-Fluoreszenzreader vermessen. Zusätzlich wurde analog der Umsatz von Boc-Lys(Ac)-AMC bei $125 \mu \mathrm{M}$ durch FB188-HDAH verfolgt.

Auch mit diesem Substrat wurde eine lineare Zunahme der Fluoreszenz mit der Zeit für beide HDAC verzeichnet, welche sich auch durch TSA konzentrationsabhängig senken ließ (am Beispiel der HDAC aus Rattenleber gezeigt). Mit dem neuen Substrat wurde allerdings unter Standardbedingungen durch HDAC8 wesentlich geringere Fluoreszenzsignale erreicht. 


\subsubsection{Titrierung der HDAC}

Den Bereich des linearen Anstiegs des Fluoreszenzsignals mit steigender HDACEnzymkonzentration im Assay zu kennen, erlaubt den flexiblen Einsatz der Enzymmenge in diesen Grenzen bei der Anpassung des Assays an verschiedene Mikrotiterformate oder besondere Fragestellungen, die z. B. eine Reduzierung des Enzymvolumens im Ansatz erforderlich machen. Darüberhinaus sorgt eine Optimierung der eingesetzten Enzymmenge für einen schonenderen Umgang mit dieser Resource.
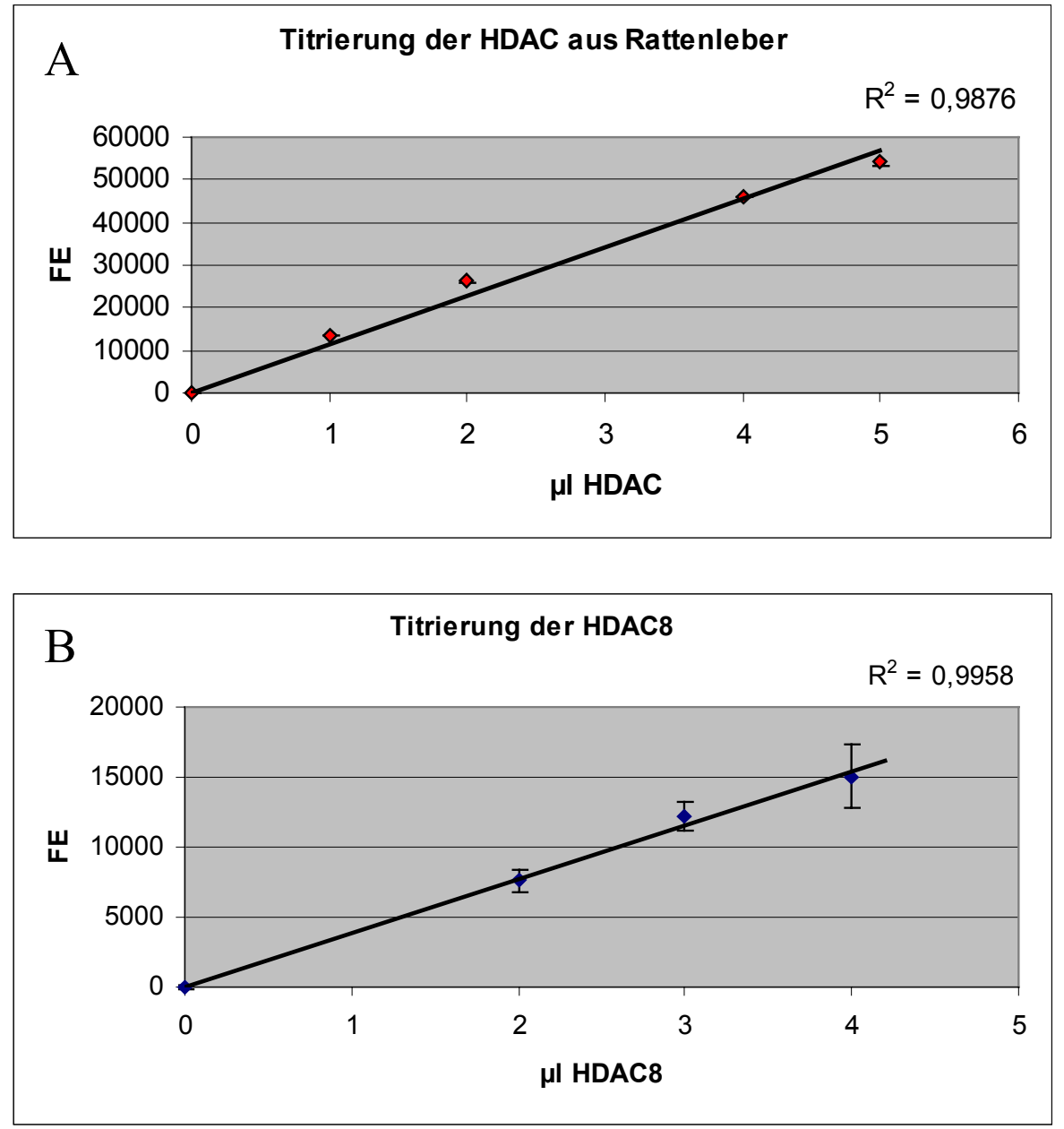

Abb. 8: Titrierung der HDAC-Konzentration im Assay.

Standard-HDAC-Assays wurden mit unterschiedlicher HDAC-Konzentration im Ansatz mit $125 \mu \mathrm{M}$ TosGPK(Ac)-AMC durchgeführt. Die Auftragung der Fluoreszenz (FE) über der Enzymmenge belegt eine lineare Zunahme des Signals mit steigender Enzymkonzentration für A) HDAC aus Rattenleber und B) HDAC8.

Zur Ermittlung der Beziehung zwischen HDAC-Konzentration und Fluoreszenzsignal wurden parallele HDAC-Assays mit $125 \mu \mathrm{M}$ Tos-GPK(Ac)-AMC und steigenden Konzentrationen HDAC aus Rattenleber bzw. humaner HDAC8 durchgeführt (Wegener 
et al., 2003a). Dabei wurden die Ansätze bei $30^{\circ} \mathrm{C}$ für $53 \mathrm{~min}$ bzw. für $60 \mathrm{~min}$ inkubiert, also unter Bedingungen, die typischerweise bei einem Screening eingestellt würden. Wie Abbildung 8 zeigt, besteht für HDAC aus der Rattenleber (Calbiochem) ein linearer Zusammenhang mindestens bis $5 \mu$ HDAC im Ansatz (gemessen bei Gain 65), für HDAC8 (Biomol) mindestens bis $4 \mu 1$ Enzym (gemessen bei Gain 73) (Abb. 8). Für Standard-HDAC-Assays mit den erwähnten Substraten wurden dem Ansatz fortan 1,7 $\mu 1$ HDAC aus Rattenleber bzw. 2,5 $\mu 1$ HDAC8 zugesetzt.

\subsubsection{Bestimmung der $\mathrm{K}_{\mathrm{M}}$-Werte und der $\mathrm{V}_{\max }$ der nicht-acetylierten Substrate für Trypsin}

Zur Bestimmung des $\mathrm{K}_{\mathrm{M}}$-Wertes und des $\mathrm{V}_{\max }$ von Trypsin für die jeweiligen nichtacetylierten Substrate wurden Trypsin-Assays bei verschiedenen Substratkonzentrationen durchgeführt (Wegener et al., 2003a; Wegener et al., 2003c). Dabei wurden die in 4.1.2 als günstig erkannten Trypsinkonzentrationen eingesetzt. Die Ansätze wurden robotisch mit der CyBio-Screening-Anlage in den Kompartimenten einer 96 well-Meßplatte zusammenpipettiert und durch Trypsinzugabe gestartet. Die Fluoreszenzentwicklung der Reaktionen wurden mit Hilfe eines MTPFluoreszenzreaders verfolgt. Die Berechnung der kinetischen Parameter erfolgte aus einer Auftragung des Quotienten aus Substratkonzentration und freigesetzter AMCMenge pro Minute über der Substratkonzentration nach Hanes (Cornish-Bowden, 1999) und der eingesetzten Enzymmenge. Die Ergebnisse sind in Tabelle 1 zusammengefaßt.

Tab. 1: $K_{M}$ und $V_{\max }$ für verschiedene Trypsin-Substrate.

\begin{tabular}{c|c|c|c}
\hline Substrat & $\mathbf{K}_{\mathbf{M}}$ & $\mathbf{V}_{\mathbf{m a x}}$ & Referenz \\
& {$[\boldsymbol{\mu M}]$} & {$\left[\boldsymbol{\mu m o l ~ \mathbf { ~ m i n } ^ { - 1 } \mathbf { ~ m g } ^ { - 1 } ]}\right.$} & \\
\hline Boc-Lys-AMC & $>500$ & - & \\
Ac-Arg-Gly-Lys-AMC & $>500$ & - & \\
Ac-Gly-Gly-Lys-AMC & $>500$ & - & \\
Ac-Leu-Gly-Lys-AMC & $>500$ & - & $37 \mu \mathrm{M},($ Grahn et al., 1998)* \\
Ac-Gly-Ala-Lys-AMC & $>500$ & 14,4 & $14 \mu \mathrm{M},($ Grahn et al., 1998)* \\
Tos-Gly-Pro-Lys-AMC & 7,37 & 35,7 &
\end{tabular}




\subsubsection{Bestimmung der $\mathrm{K}_{\mathrm{M}}$-Werte und der $\mathrm{V}_{\max }$ der Substrate für HDAC}

Zur Bestimmung des $\mathrm{K}_{\mathrm{M}}$-Wertes und des $\mathrm{V}_{\max }$ der HDAC für die jeweiligen acetylierten Substrate wurden HDAC-Assays bei verschiedenen Substratkonzentrationen durchgeführt (Wegener et al., 2003a; Wegener et al., 2003c). Dabei wurden die in 4.1.2 als günstig erkannten Trypsinkonzentrationen eingesetzt. Die Ansätze wurden robotisch mit der CyBio-Screening-Anlage in den Kompartimenten einer 96 well-Meßplatte zusammenpipettiert, durch Substratzugabe gestartet und bei $30^{\circ} \mathrm{C}$ für 60 min inkubiert. Nach dem Abstoppen der HDAC-Reaktionen durch robotische Zugabe der Trypsin/TSA-Stoplösung wurden die Fluoreszenzsignale mit Hilfe eines MTPFluoreszenzreaders vermessen. Die Berechnung der kinetischen Parameter erfolgte aus einer Auftragung des Quotienten aus Substratkonzentration und freigesetzter AMCMenge pro Minute über der Substratkonzentration nach Hanes ((Cornish-Bowden, 1999), Abb. 9) und der eingesetzten Enzymmenge. Die Ergebnisse sind in Tabelle 2 zusammengefaßt.

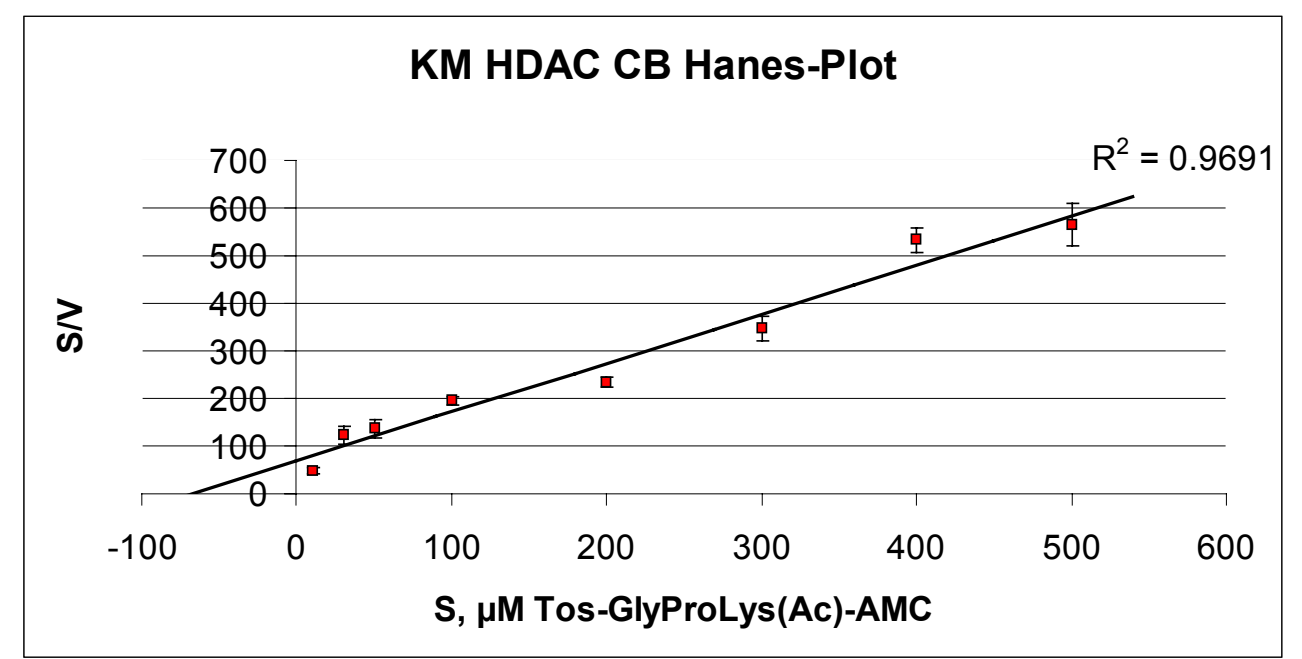

Abb. 9: Beispiel eines Hanes-Plot zur Bestimmung von $K_{M}$ und $V_{\max }$ mit Tos-GPK(Ac)-AMC für HDAC aus Rattenleber.

Standard-HDAC-Assays wurden bei unterschiedlichen Substratkonzentrationen durchgeführt und die Fluoreszenz im MTP-Fluoreszenzreader vermessen. Der Quotient aus Substratkonzentration und freigesetzter AMC-Menge pro Minute wurde über der Substratkonzentration aufgetragen. Der Schnittpunkt der Regressionsgeraden mit der Abszisse gibt den negativen Wert des $\mathrm{K}_{\mathrm{M}}$, die Steigung das Reziproke des $\mathrm{V}_{\max }$ an. 
Tab. 2: $K_{M}$ und $V_{\max }$ der HDAC für verschiedene Substrate.

HDAC aus Rattenleber*

HDAC 8**

\begin{tabular}{c|cc|cc} 
Substrat & $\mathbf{K}_{\mathbf{M}}$ & $\mathbf{V}_{\mathbf{m a x}}$ & $\mathbf{K}_{\mathbf{M}}$ & $\mathbf{V}_{\mathbf{m a x}}$ \\
& $\boldsymbol{[ \boldsymbol { \mu M } ]}$ & {$\left[\mathbf{p m o l ~ s} \mathbf{~ m g}^{-\mathbf{1}}\right]$} & {$[\boldsymbol{\mu M}]$} & {$\left[\mathbf{p m o l ~ s}^{-\mathbf{1}} \mathbf{~ m g}^{-\mathbf{1}}\right]$} \\
\hline Boc-Lys(Ac)-AMC & $3,7 \pm 1,7$ & $4,41 \pm 0,10$ & $\geq 500$ & - \\
Ac-Arg-Gly-Lys(Ac)-AMC & $27,5 \pm 4,9$ & $3,61 \pm 0,29$ & $\geq 500$ & - \\
Ac-Gly-Gly-Lys(Ac)-AMC & $32,6 \pm 3,2$ & $4,27 \pm 0,26$ & & \\
Ac-Leu-Gly-Lys(Ac)-AMC & $44,2 \pm 1,0$ & $5,26 \pm 0,28$ & \\
Ac-Gly-Ala-Lys(Ac)-AMC & $35,2 \pm 3,4$ & $5,59 \pm 0,74$ & \\
TosGly-Pro-Lys(Ac)-AMC & $68,6 \pm 11,9$ & $6,10 \pm 0,29$ &
\end{tabular}

* $\quad 89 \mathrm{U} / \mathrm{ml}, 4,7 \mathrm{mg} / \mathrm{ml}$

** $0,6 \mathrm{U} / \mu \mathrm{l}, 1,3 \mathrm{U} / \mu \mathrm{g}$

\subsubsection{Einfluß des $\mathrm{pH}-$ Wertes}

Im Rahmen der Optimierung des HDAC-Assays wurden Standard-HDAC-Assays bei verschiedenen $\mathrm{pH}-$ Werten mit $125 \mu \mathrm{M}$ Tos-GPK(Ac)-AMC und HDAC aus Rattenleber bzw. $125 \mu \mathrm{M}$ Boc-Lys(Ac)-AMC und heterolog exprimierter HDAC8 durchgeführt. Die Fluoreszenzsignale schwankten im untersuchten Bereich von $\mathrm{pH}$ 5-10 nur um den Faktor 2. Für beide Enzyme arbeitete der Enzymtest am besten bei pH 9 und zeigte ein annähernd glockenförmiges pH-Profil zwischen pH 6 und pH 10 (Abb. 10). Auffällig war das geringer ausfallende Fluoreszenzsignal bei pH 8 im Vergleich zu pH 7,5 und pH 9 für HDAC8. 

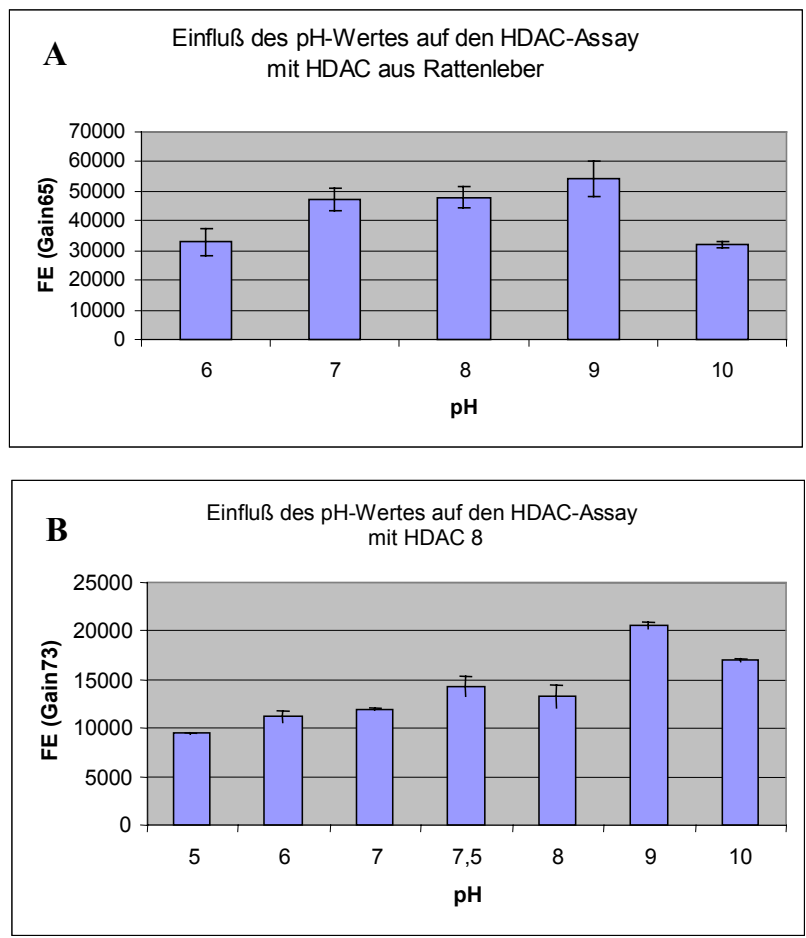

Abb. 10: Einfluß des pH-Wertes auf den HDAC-Assay.

Standard-HDAC-Assays wurden bei $125 \mu \mathrm{M}$ Tos-GPK(Ac)-AMC für HDAC aus Rattenleber (A) bzw. $125 \mu \mathrm{M}$ Boc-Lys(Ac)-AMC für heterolog exprimierte HDAC8 (B) bei pH-Werten zwischen 5 und 10 durchgeführt.

Für die HDAC-Assays wurde fortan mit dem entsprechenden Assay-Puffer ein pH-Wert von 8,5 eingestellt.

\subsubsection{Toleranz gegen Lösungsmittel}

Sowohl synthetische Substrate als auch die Substanzen der $\mathrm{zu}$ durchmusternden Molekülbibliotheken liegen normalerweise in einem organischen Lösungsmittel gelöst vor. Chemische Bibliotheken werden standardmäßig 50-100\%ig in einem Lösungsmittel gelöst gelagert (Cheng et al., 2003; Kozikowski et al., 2003) und zumindest im initialen HTS-Durchlauf werden recht hohe Substanzkonzentrationen von etwa 100-200 $\mu \mathrm{M}$ eingestellt, um die Chance, einen Wirkstoff zu finden, zu erhöhen. Dadurch kann das Lösungsmittel oftmals nur etwa 100fach auf $1 \%$ Endkonzentration im Ansatz verdünnt werden. Dazu kommt noch der Lösungsmittelanteil, den das gelöste Substrat bedingt, so daß eine Endkonzentration von 1-2\% eines dieser Lösungsmittel im Ansatz typischerweise bei vielen HTS-Assays zu finden und oftmals auch nicht unterschreitbar ist. 
Der Einfluß einiger oft verwendeter Lösungsmittel - Dimethylsulfoxid (DMSO), Acetonitril (MeCN) und Methylpyrrolidone (NMP) - auf den HDAC-Assay und HDAC aus der Rattenleber wurde untersucht, indem parallele Standard-HDAC-Assays mit $125 \mu \mathrm{M}$ Tos-GPK(Ac)-AMC und steigender Konzentration an organischem Lösungsmittel durchgeführt wurden (Wegener et al., 2003a). Dabei war in jedem Ansatz neben den mit ihrer jeweiligen Endkonzentration im Ansatz angegeben Lösungsmitteln mindestens $0,4 \%$ DMSO, bedingt durch das darin vorab gelöste Substrat, enthalten. Ein Ansatz mit $0 \%$ Zusatz an Lösungsmittel diente als Referenz, d. h. als die maximal unbeeinflußte Reaktion, wobei auch hier die erwähnten $0,4 \%$ DMSO enthalten waren. Während der Einfluß von bis zu $2 \%$ DMSO mit einer Verringerung des Fluoreszenzsignals um $<9 \%$ vernachlässigbar war, senkte der Zusatz von $1 \%$ NMP das Signal bereits um ca. $42 \%$ (Abb. 11). Der Einfluß von MeCN war wiederum nicht ganz so drastisch, ein Zusatz von $2 \%$ verringerte die AMC-Freisetzung um etwa $20 \%$. Aus den in Abbildung 11 gezeigten Ergebnissen geht eindeutig DMSO als das zum Lösen von Substraten oder Inhibitoren bzw. bei der Erstellung von chemischen Bibliotheken zum HTS nach HDACI zu verwendende Lösungsmittel hervor. Der Einfluß von DMSO auf HDAC8 war bis zu $2 \%$ vernachlässigbar (wiederum im Vergleich mit der Referenz bei 0,4 \% DMSO). Die Lösungsmittel hatten dabei keinen nenneswerten Einfluß auf Trypsin (Daten nicht gezeigt, (Khmelnitsky et al., 1991; Russell et al., 2001)). 


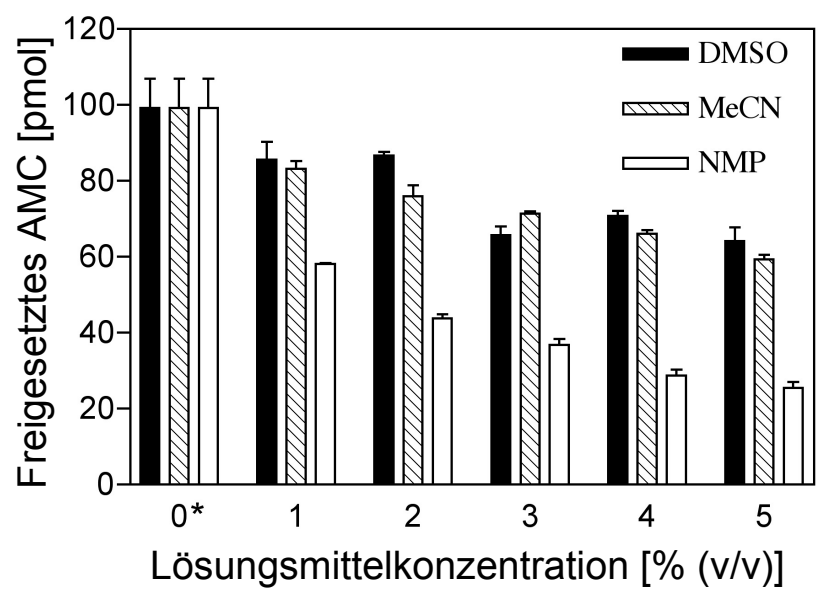

\begin{abstract}
Abb. 11: Einfluß organischer Lösungsmittel auf den HDAC-Assay mit HDAC aus Rattenleber.
Standard-HDAC-Assay mit HDAC aus Rattenleber wurden parallel mit $125 \mu \mathrm{M}$ Tos-GPK(Ac)-AMC und steigenden Konzentrationen an DMSO, MeCN und NMP durchgeführt. Das nach Abstoppen des Assays freigesetzte AMC ist für das jeweilige Lösungsmittel bei der angegebenen Endkonzentration im Ansatz aufgetragen. Als Referenz dienten Ansätze ohne zusätzliches Lösungsmittel (0). * Wie bei allen Ansätzen war auch in diesen $0,4 \%$ DMSO aufgrund des darin gelösten Substrates enthalten.
\end{abstract}

\title{
4.1.8 Inhibitionsversuche mit Standard-HDACI
}

Die Hemmwirkung des bekannten Histondeacetylase-Hemmers TSA wurde bereits in den Umsatzkurven mit HDAC aus Rattenleber in 4.1.2 deutlich und wird zum Abstoppen der HDAC-Reaktion in der zweiten Stufe des HDAC-Assays ausgenutzt (4.1.1). Mit HDAC-Assays in Anwesenheit von TSA und einigen anderen gut charakterisierten, d.h. in anderen Testsystemen bereits als Histondeacetylase-Hemmer dokumentierten Substanzen sollte die Eignung des neuen Assays zur Identifizierung von HDACI in konzentrationsabhängiger Weise noch gründlicher belegt werden.

Bereits mit dem anfänglichen Puffersystem (HD-Puffer und $10 \mathrm{mg} / \mathrm{ml}$ Trypsin in Trypsin-Puffer) und $250 \mu \mathrm{M}$ Ac-RGK(Ac)-AMC als Substrat konnten dabei für HDAC aus Rattenleber bzw. HDAC8 Dosis-Wirkungskurven für TSA aufgenommen werden (Wegener et al., 2003c), die sowohl den typisch sigmoidalen Verlauf als auch eine halbmaximale Hemmwirkung bei einer Inhibitorkonzentration $\left(\mathrm{IC}_{50}\right)$ aufwiesen, die gut mit den Literaturwerten übereinstimmte (Abb. 12, Tab. 3). 

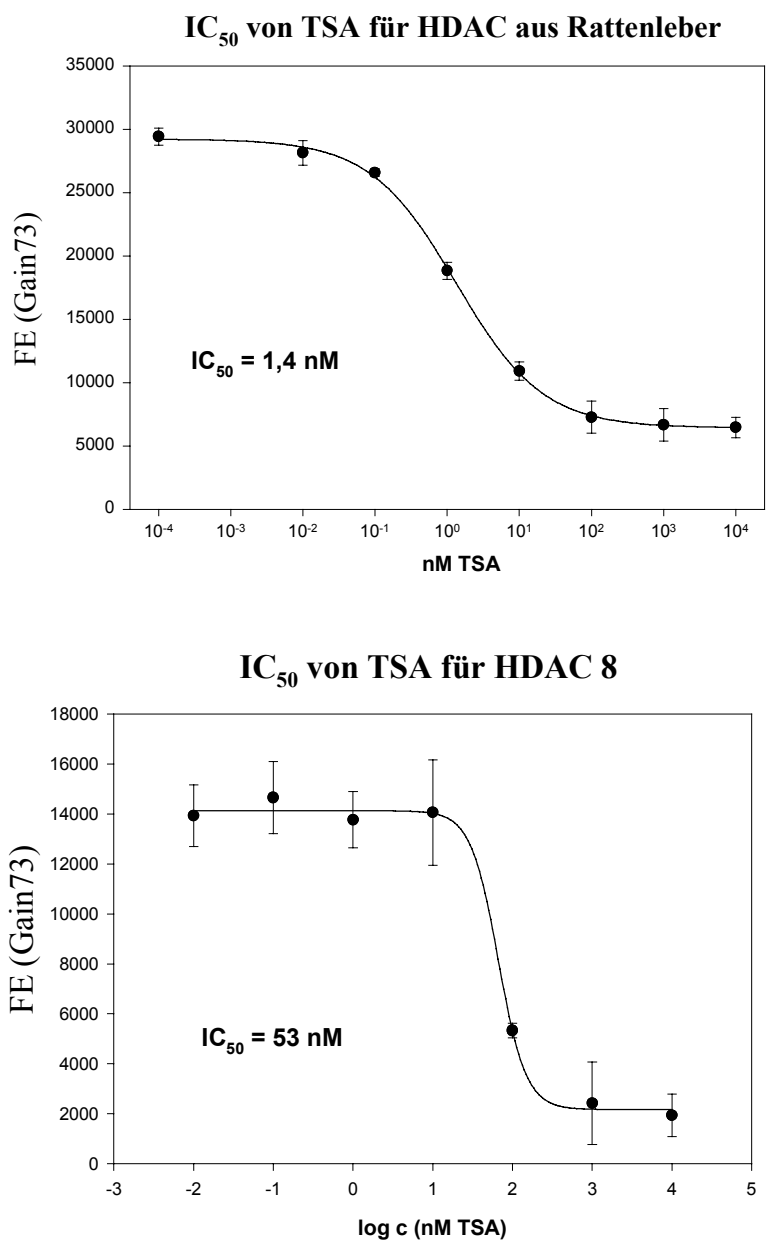

Abb. 12: IC $_{50}$-Bestimmungen für HDAC mit TSA als Inhibitor.

HDAC-Assays wurden in Anwesenheit von unterschiedlichen Konzentrationen an TSA mit HDAC aus Rattenleber (oben) bzw. HDAC8 (unten) und $250 \mu \mathrm{M}$ Ac-RGK(Ac)-AMC als Substrat in HD-Puffer durchgeführt. Die ermittelten $\mathrm{IC}_{50}$-Werte sind jeweils unter der Kurve angegeben.

Tab. 3: Mit einigen Standard-HDACI für HDAC aus Rattenleber bzw. HDAC8 bestimmte IC $_{50^{-}}$ Werte.

$\mathrm{Zu}$ Vergleichszwecken sind Literaturwerte angegeben, dabei ist zu beachten, daß in manchen Fällen andere Testsysteme (\#) oder Substrate $(*)$ verwendet wurden.

\begin{tabular}{c|c|c|c|c}
\hline HDAC & HDACI & IC50 & $\begin{array}{c}\text { IC50 } \\
\text { (Literatur) }\end{array}$ & Referenz \\
\hline aus der Rattenleber & TSA & $1,4 \mathrm{nM}$ & $2.6 \mathrm{nM}$ & $\begin{array}{c}\text { (Hoffmann } \text { et al., } \\
2001 \mathrm{a}) \#\end{array}$ \\
\hline HDAC8 & TSA & $53 \mathrm{nM}$ & $100-300 \mathrm{nM}$ & $($ Hu et al., 2003) *
\end{tabular}


Analog angelegte Experimente mit $125 \mu \mathrm{M}$ Tos-GPK(Ac)-AMC ergaben für HDAC aus Rattenleber im verbesserten Puffersystem ebenfalls Ergebnisse in guter Übereinstimmung mit in der Literatur verzeichneten Werten (Abb. 13, Tab. 4, (Wegener et al., 2003a)). Dabei wurden HDACI mit unterschiedlicher Potenz und aus verschiedenen Stoffklassen eingesetzt. Der HDAC-Assay konnte also, auch bei einem nicht $\mathrm{zu}$ den Hydroxamaten gehörigen Inhibitor, über einen weiten Konzentrationsbereich differenzieren. Bei der Bestimmung des $\mathrm{IC}_{50}$ von MS275 erreichte die Kurve zwar nicht ganz den Nullwert, da bei noch höheren Konzentrationen an MS275 der DMSO-Anteil im Ansatz zu hoch ausgefallen wäre und diese daher nicht vermessen wurden. Allerdings konnte trotzdem ein $\mathrm{IC}_{50}$-Wert ermittelt werden, der den Erwartungen entsprach.

Tab. 4: Mit einigen Standard-HDACI für HDAC aus Rattenleber bestimmte $\mathrm{IC}_{50}$-Werte.

$\mathrm{Zu}$ Vergleichszwecken sind Literaturwerte angegeben, dabei ist zu beachten, daß in manchen Fällen andere Enzyme $(*)$ oder Testsysteme (\#) verwendet wurden.

\begin{tabular}{c|c|c|c}
\hline HDACI & IC $_{\mathbf{5 0}}$ & $\begin{array}{c}\mathbf{I C}_{\mathbf{5 0}} \\
\text { (Literaturwert) }\end{array}$ & Referenz \\
\hline TSA & $1.3 \mathrm{nM}$ & $1.4 \mathrm{nM}$ & (Wegener et al., 2003a) \\
& & $2.6 \mathrm{nM}$ & (Hoffmann et al., 2001a) \# \\
SAHA & $9.6 \mathrm{nM}$ & $127 \mathrm{nM}$ & (Heltweg and Jung, 2002b) \# \\
& & $259 \mathrm{nM}$ & (Heltweg and Jung, 2003)\# \\
MS275 & $8.8 \mu \mathrm{M}$ & $4.8 \mu \mathrm{M}$ & (Suzuki et al., 1999) * \#
\end{tabular}




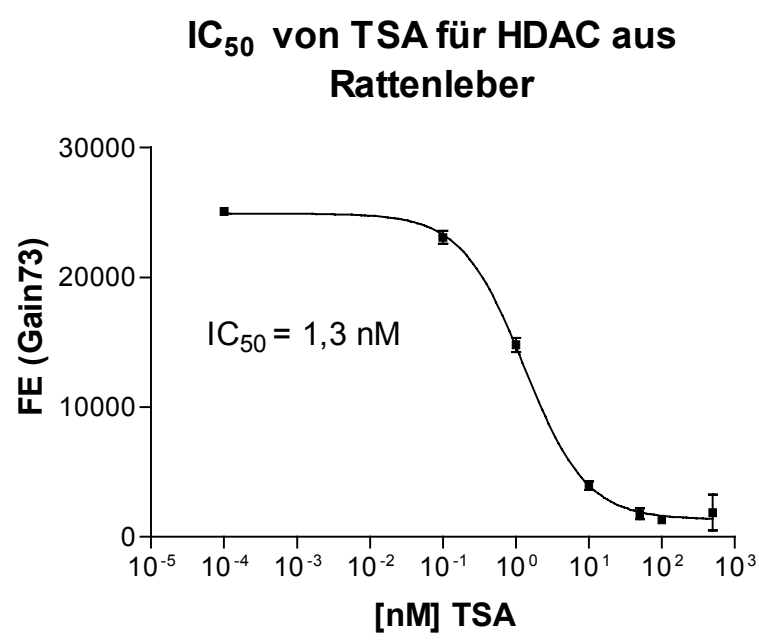<smiles>CC(/C=C/C(=O)NO)=C\C(C)C(=O)c1ccc(N(C)C)cc1</smiles><smiles>O=C(CCCCC(=O)Nc1ccccc1)NO</smiles><smiles>Nc1ccccc1NC(=O)c1ccc(CNC(=O)OCc2ccccc2)cc1</smiles>

\section{$\mathrm{IC}_{50}$ von SAHA für HDAC aus Rattenleber}

$I_{50}$ von MS-275 für HDAC aus Rattenleber
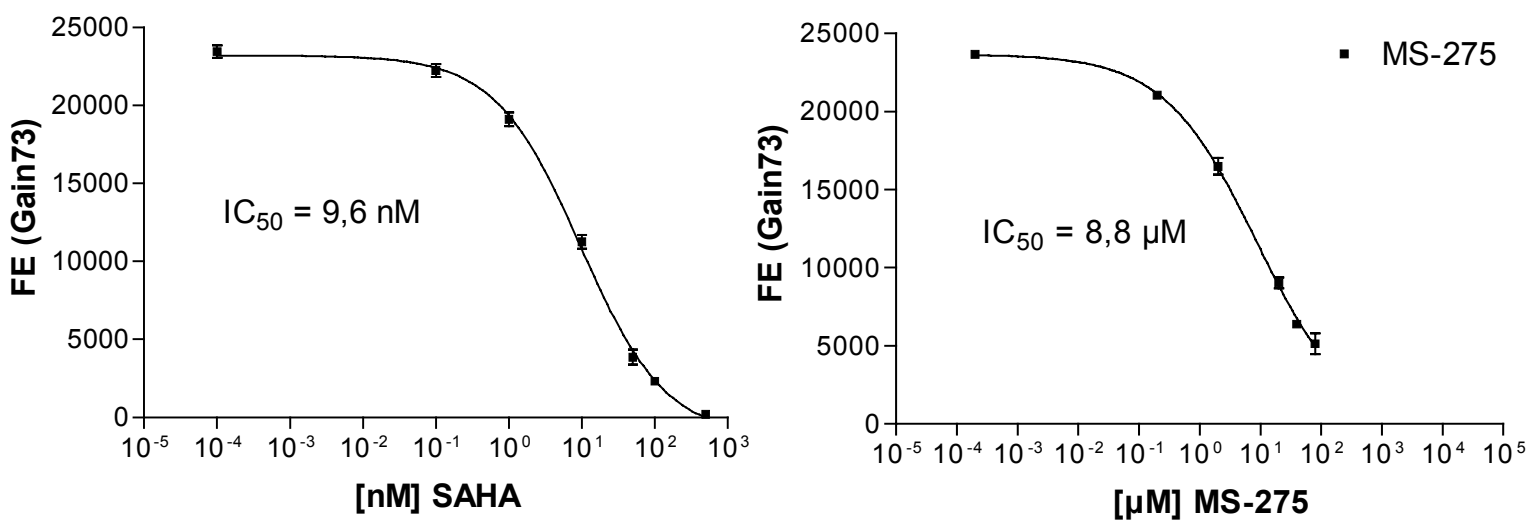

Abb. 13: IC $_{50}$-Bestimmungen für HDAC aus Rattenleber mit verschiedenen Inhibitoren.

HDAC-Assays wurden in Anwesenheit von unterschiedlichen Konzentrationen an bekannten HDACI mit HDAC aus Rattenleber und $125 \mu \mathrm{M}$ Tos-GPK(Ac)-AMC als Substrat in HDP-Puffer durchgeführt. Die ermittelten $\mathrm{IC}_{50}$-Werte sind jeweils unter der Kurve, die Strukturen der Inhibitoren rechts oben angegeben.

\subsubsection{Bestimmung des Z'-Faktors}

Das wichtigste Ziel bei der Entwicklung eines HTS-Assays ist sicherlich die sichere und verlässliche Identifikation von aktiven Substanzen (Hits) aus einer (normalerweise) sehr großen chemischen Bibliothek vor einem Hintergrund an inerten Komponenten (Sittampalam, 1997; Zhang et al., 1999a). Das Erreichen dieses Ziels hängt entscheidend von der Eignung und Qualität des benutzten Assays ab. Eine statistische 
Analyse der Messungen ist für eine Beurteilung der gewonnenen Daten unerläßlich. Erst vor relativ kurzer Zeit wurde mit dem Z-Faktor (Zhang et al., 1999a) ein einfacher und effektiver Qualitätsparameter (screening window coefficient) eingeführt, der es als dimensionslose Zahl erstmals erlaubt, verschiedene Assaysysteme miteinander zu vergleichen. In den Z-Faktor gehen sowohl die Schwankungen der Meßdaten (Standardabweichungen, SD, $\sigma$ ) als auch die Größe des Meßfensters (dynamischer Bereich) zwischen den Mittelwerten (MW, $\mu$ ) ein. In den vorher gebräuchlichen Qualitätsparametern (z. B. S/N und S/B, Gleichung (1) bzw. (2)) wurden diese nicht gleichberechtigt einbezogen, was unter Umständen zur Fehleinschätzung des Assays verleiten kann (Zhang et al., 1999a). Die erwähnten Qualitätsparameter berechnen sich wie folgt:

(1) $\mathrm{S} / \mathrm{N}($ signal-to-noise ratio $)=[\mathrm{MW}($ Signal $)-\mathrm{MW}($ Hintergrund $)]$ $\mathrm{SD}$ (Hintergrund)

(2) $\quad \mathrm{S} / \mathrm{B}$ (signal-to-background ratio) $=\mathrm{MW}($ Signal $) / \mathrm{MW}($ Hintergrund $)$

$$
Z=\left[\left|\mu_{\mathrm{s}}-\mu_{\mathrm{c}}\right|-\left(3 \sigma_{\mathrm{s}}+3 \sigma_{\mathrm{c}}\right)\right] /\left|\mu_{\mathrm{s}}-\mu_{\mathrm{c}}\right|
$$

$\mu_{\mathrm{s}}: \mathrm{MW}($ Probe);

oder nach Umstellung

$\mu_{\mathrm{c}}$ : MW(Kontrolle, 100\%-Inhib.); $\sigma_{\mathrm{s}}: \mathrm{SD}($ Probe);

(4) $\mathrm{Z}=1-\left(3 \sigma_{\mathrm{s}}+3 \sigma_{\mathrm{c}}\right) /\left|\mu_{\mathrm{s}}-\mu_{\mathrm{c}}\right|$. $\sigma_{\mathrm{c}}: \mathrm{SD}$ (Kontrolle, $100 \%$-Inhib.)

Hier wird deutlich, daß der höchstmögliche Z-Wert 1 ist. In Abbildung 14 werden die verwendeten Größen graphisch verdeutlicht. 


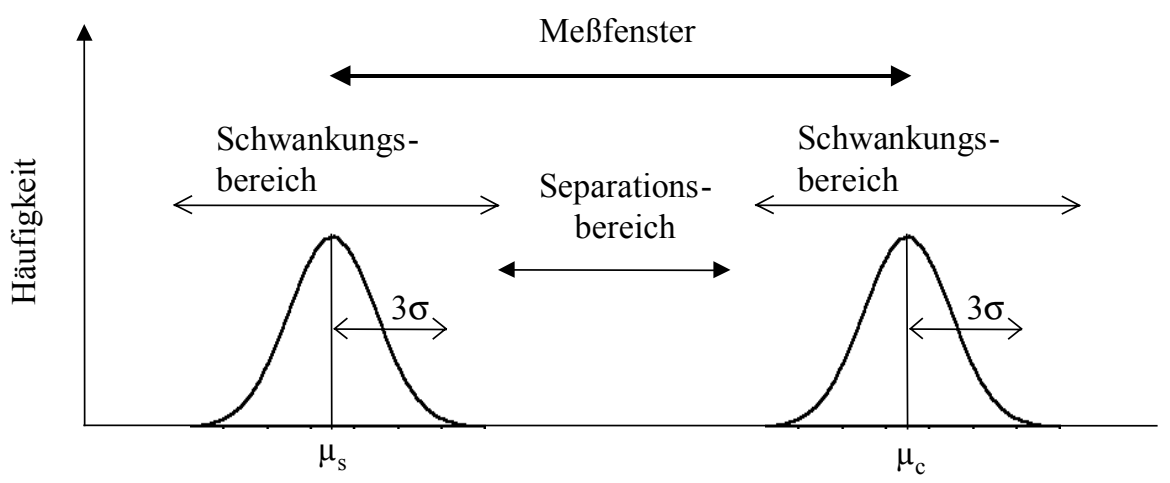

Fluoreszenzsignal

\section{Abb. 14: Illustrierung der im Text eingeführten Größen und ihrer Beziehungen (nach Zhang et al., 1999).}

Sowohl die Fluoreszenzwerte der ungehemmten HDAC-Assay-Ansätze als auch die der 100\%ig gehemmten (bzw. die der Ansätze ohne Enzym) schwanken und häufen sich nach einer Normalverteilung um den jeweiligen Mittelwert $\mu_{\mathrm{s}}$ bzw. $\mu_{\mathrm{c}}$. Der Bereich zwischen den Mittelwerten umfasst das Meßfenster, innerhalb dessen der von beiden Schwankungsbereichen eingeschränkte Separationsbereich liegt.

Im Vorfeld des eigentlichen Screenings gibt ein „Screening“ von Kontrollen und Analyse nach Gleichung (4) Aufschluß über die Eignung des Assays und erlaubt eine Bewertung der unternommenen Optimierungsmaßnahmen. Bei Inhibitionsexperimenten werden ungehemmte Reaktionen und geeignete Blanks betrachtet. Bei gekoppelten Assays fehlt hier das untersuchte (limitierende) Enzym. Oft setzt man auch bekannte Inhibitoren bei ihrem $\mathrm{IC}_{50}$ als $50 \%$-Kontrollen ein. Ein steigender Z'-Faktor (Z-Faktor ohne Einwirkung der Substanzbibliothek) indiziert eine qualitative Verbesserung des Assays. Dies kann sowohl durch eine Vergrößerung des dynamischen Bereiches (Abstand der Mittelwerte von Signal und Hintergrund (Blanks), auch Signalfenster genannt), als auch durch Minimierung der Schwankungen von Signal $\left(\sigma^{+}\right)$und/oder Hintergrund ( $\sigma-)$ erfolgen (vergleiche Abb. 14).

Zur Bestimmung des Qualitätsparameters wurden 3 verschiedene Ansätze in je 10 Replikaten robotisch mit der CyBio-Screening-Anlage zusammenpipettiert, nach 60 minütiger Inkubation bei $30^{\circ} \mathrm{C}$ abgestoppt und die Fluoreszenzsignale mit dem BMG-Reader vermessen (Wegener et al., 2003a). Neben ungehemmten Reaktionen ohne Inhibitor wurden Negativ-Kontrollen mit 300 nM TSA (für 100\%ige Hemmung) bzw. ohne Zielenzym und $50 \%$-Referenzen mit 2 nM TSA angesetzt. Die Reagenzien und Trypsin wurden dabei in jeweils einer 2 ml-MTP (96 Kompartimente), das 
Zielenzym in einer 96er MTP vorgelegt. Die Inhibitorlösung der Negativ-Kontrollen wurde manuell in den entsprechenden $200 \mu 1$-Kompartimenten der Meßplatte vorgelegt. In einigen Experimenten dieser Art wurden die Assays in HD-Puffer durchgeführt und mit Trypsin in Thrombin-Puffer abgestoppt. Dabei wurde der HDAC aus Rattenleber zum einen $175 \mu \mathrm{M}$ Boc-Lys(Ac)-AMC, ein anderes Mal $125 \mu \mathrm{M}$ Tos-GPK(Ac)-AMC als Substrat angeboten. Schließlich wurde in weiteren Experimenten das Glyzerin im Assay-Puffer gegen 0,1\% PEG8000 (HDP-Puffer) ausgetauscht und das Trypsin in isopropanolhaltigem TI-Puffer gelöst. Tos-GPK(Ac)-AMC wurde durch HDAC aus Rattenleber wesentlich besser umgesetzt als Boc-Lys(Ac)-AMC (vergleiche 4.1.2), weshalb in der gegebenen Reaktionszeit ein größeres Signal und somit ein besseres Signal/Hintergrund-Verhältnis (S/N) erreicht wurde. Zusätzlich konnte durch die Verwendung dieses (in seiner deacetylierten Form) für Trypsin optimierten Substrates (Grahn et al., 1998) die für eine völlige Spaltung des Produktes der HDAC-Reaktion nötige Trypsinkonzentration stark herabgesetzt werden (1000fache Reduzierung), was ebenso wie das Isopropanol die Viskosität der Lösung herabsetzte und sich gleichzeitig mit der geringeren Eigenfluoreszenz positiv auf die Pipettiergenauigkeit bei der Trypsinzugabe auswirkte sowie die Signal-Varianz verringerte. Durch den Verzicht auf Glyzerin konnte der Fluoreszenzhintergrund ebenfalls deutlich gesenkt werden, wodurch wiederum das Meßfenster vergrößert wurde.

Tab. 5: Ermittelte Z'-Faktoren für den HDAC-Assay bei unterschiedlichen Bedingungen.

\begin{tabular}{c|c|c|c|c|}
\hline Enzym & Substrat & Assay-Puffer & Stop-Puffer & Z'-Faktor \\
\hline & Boc-Lys(Ac)-AMC & HD-Puffer & Thrombin-Puffer & 0,07 \\
HDAC aus & Tos-GPK(Ac)-AMC & HD-Puffer & Thrombin-Puffer & 0,39 \\
Rattenleber & Tos-GPK(Ac)-AMC & HDP-Puffer & TI-Puffer & 0,84 \\
\hline HDAC8 & Tos-GPK(Ac)-AMC & HDP-Puffer & TI-Puffer & 0,25
\end{tabular}

Wie aus der Tabelle $5 \mathrm{zu}$ entnehmen ist, erreichte der HDAC-Assay mit Tos-GPK(Ac)AMC in HDP-Puffer bei Verwendung von Trypsin in TI-Puffer den höchsten Z'-Faktor von ca. 0,8 und ist damit nach der Einteilung von Zhang und Mitarbeitern als „exzellent“ zu bewerten (Zhang et al., 1999a). Der Wert für den Assay mit HDAC8 ist 
mit 0,25 wesentlich geringer, da hier das Meßfenster im Vergleich deutlich kleiner ausfiel. Dies lag vor allem an dem für HDAC8 wenig geeigneten Substrat (4.1.2).

\subsubsection{Miniaturisierung des HDAC-Assays}

Eine oft verfolgte Strategie bei der Durchmusterung von Substanzbibliotheken ist die Beschleunigung des Verfahrens unter gleichzeitiger Einsparung von Reagenzien und Zielenzym durch Miniaturisierung und Parallelisierung (Hüser et al., 2002; Köhler, 1995). Eine unerläßliche Voraussetzung für die Realisierung dieser Strategie ist eine immer weiter fortschreitende Miniaturisierung der Assay-Formate. Die Eignung des HDAC-Assays für den Bereich bis $10 \mu \mathrm{l}$ pro Ansatz in dem bereits bei vielen Screening-Labors der Pharmaforschung standardmäßig eingesetzten 1536 well-Format wurde daher anhand von $\mathrm{IC}_{50}$-Bestimmungen mit bekannten HDACI mit $100 \mu \mathrm{M}$ TosGPK(Ac)-AMC als Substrat und HDAC aus Rattenleber in 1536 well-MTP untersucht.

Dazu wurden robotisch mit der NanoSynTest-Anlage der AG Schober bei der Merck KGaA in Darmstadt HDAC-Assays durchgeführt. Bei der NanoSynTest-Anlage handelt es sich um den Prototypen einer kombinierten Synthese- und Meßstation, bei der die mittels kombinatorischer Chemie an Mikro-Harzkügelchen in einem Teil der Anlage generierten Substanzen in einem anderen Teil in Bioassays auf ihre Wirkung hin vermessen werden können. Mittels eines integrierten Fluorimeters mit CCD-Kamera können alle Kompartimente einer Meßplatte simultan ausgelesen werden. Dabei kommen sowohl Standard-MTP bis 1536 Kompartimente als auch sogenannte Chips für Nanoliterformate (bis $100 \mathrm{nl}$ ) zur Anwendung. Während letztere mit einer speziellen piezoelektrischen Mikrodosiertechnik befüllt werden müssen (Schlingloff, 1999), können Flüssigkeiten im unteren Mikroliterbereich für die 1536 well-Formate mit einem gebräuchlichen 96fach-Pipettierer, ähnlich kommerzieller Geräte (Berg, 1998), verarbeitet werden. Für die HDAC-Assays im 1536er-Format wurden hier bereits fertig synthetisierte HDACI und der 96fach Pipettierer der NanoSynTest-Anlage eingesetzt.

Ein Vortest sollte zeigen, ob der Assay im $10 \mu 1$-Maßstab durchgeführt werden kann. Dazu wurden alle Volumina im Vergleich $\mathrm{zu}$ parallel aus denselben Reagenzienlösungen erstellten Referenzansätzen im 96 well-Format um den Faktor 20 reduziert und ansonsten soweit als möglich die Vorgaben (z. B. Puffer und Inkubationszeiten) nach dem verbesserten HDAC-Assay-Protokoll beibehalten. 
Genauer war die Frage, ob die verringerte, freigesetzte AMC-Menge noch verlässlich detektiert werden kann und wie sich Effekte wie Verdunstung, Mischverhalten oder Konvektion, aber auch Pipettier- und Mischgeschwindigkeiten auf die Signalstärke (Meßfenster) bzw. Schwankung (Standardabweichungen) auswirken. Die Reagenzlösungen wurden jeweils in 384er MTPs vorgelegt und daraus in den Kompartimenten robotisch zu einem Ansatz vereinigt. Abgestoppt wurde nach einer Inkubation bei $30{ }^{\circ} \mathrm{C}$ für $65 \mathrm{~min}$ bei gedeckelter Meßplatte mit $4 \mu 1$ Trypsin/TSAStoplösung. Nach jedem Pipettierschritt wurden die Spitzen des Pipettierkopfes einem Waschzyklus unterworfen. Nach dem Trypsin-Schritt wurden die Spitzen zusätzlich vorab 10 mal mit 10\%igem SDS gewaschen. Die Fluoreszenzsignale wurden sowohl mit der CCD-Kamera als auch mit einem MTP-Fluoreszenzreader ausgelesen.

Das Signal der ungehemmten, der 50\%-inhibierten und der Ansätze ohne HDAC konnten gut voneinander unterschieden werden. Die Fluoreszenzsignale der ungehemmten Reaktionen waren allerdings nur etwa doppelt so hoch wie der Fluoreszenzhintergrund der Ansätze ohne Enzym, allerdings auf dem gleichen Niveau wie bei den Kontrollansätzen im 96er MTP-Format, was somit eher auf eine bereits teilweise inaktivierte Enzymcharge schließen ließ. Der aus den Messungen im MTPFluoreszenzreader (Gain 120) ermittelte Z'-Faktor lag trotzdem bei 0,47.

Als Test auf verbliebene Trypsinkontaminationen an den Spitzen wurden $5 \mu 130 \mu \mathrm{M}$ Tos-GPR-AMC aus einer 96er MTP aufgesogen und in dieselben Kompartimente wieder abgegeben. Die anschließende Messung mit der CCD-Kamera wurde mit der vor diesem Pipettierschritt verglichen. Es zeigte sich keine Trypsinaktivität, das Waschprotokoll war hinreichend.

Da keine grundsätzlichen Schwierigkeiten gegen eine Miniaturisierung des Assays im 1536er-Maßstab sprachen, wurden in der geschilderten Weise HDAC-Assays durchgeführt, um den $\mathrm{IC}_{50}$ dreier unterschiedlich potenter HDACI zu bestimmen und damit die Eignung des Assays auch in diesem Format für die konzentrationsabhängige Bewertung von Wirkstoffen $\mathrm{zu}$ belegen. Dazu wurden Verdünnungsreihen der Inhibitoren TSA, SAHA und CYPX in Assay-Puffer angelegt und diese robotisch in Triplikaten in die Kompartimente eine Meßplatte überführt. 
Die aufgenommenen Dosis-Wirkungskurven für alle drei HDACI wiesen sowohl den typisch sigmoidalen Verlauf als auch eine halbmaximale Hemmwirkung bei einer Inhibitorkonzentration ( $\mathrm{IC}_{50}$ ) auf, die gut mit den Literaturwerten bzw. den im 96 wellFormat ermittelten Werten übereinstimmte (Abb. 15, Tab. 6). Auffällig war der im Vergleich zu den mit den Signalen der CCD-Kamera erstellten Kurven flachere Verlauf und die stärkeren Schwankungen der Werte vom MTP-Fluoreszenzreader. 
$\mathrm{IC}_{50}$ von CYPX

im 1536 well-Format

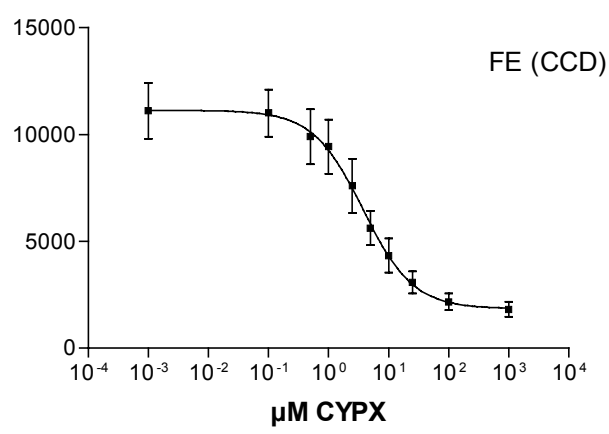

$\mathrm{IC}_{50}$ von TSA

im 1536 well-Format

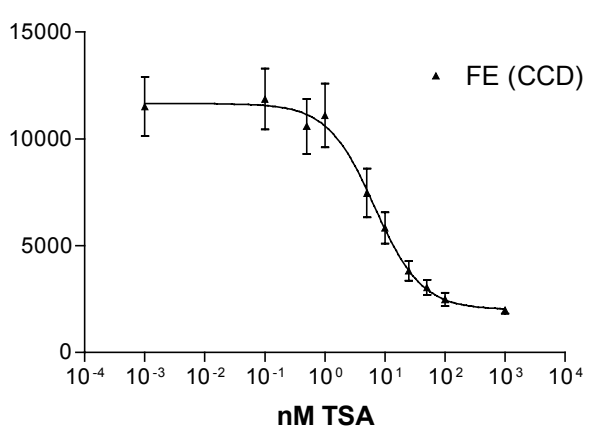

$\mathrm{IC}_{50}$ von SAHA

im 1536 well-Format

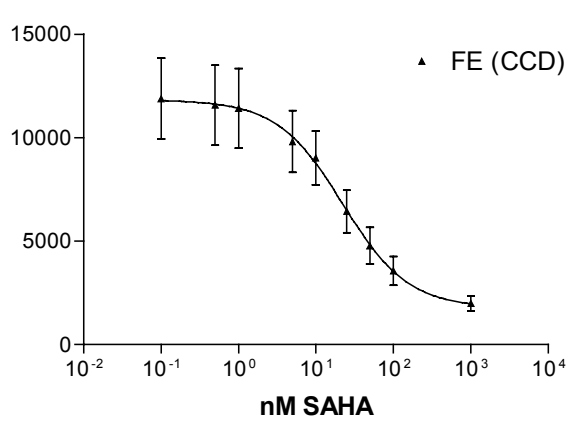

$\mathrm{IC}_{50}$ von CYPX

im 1536 well-Format

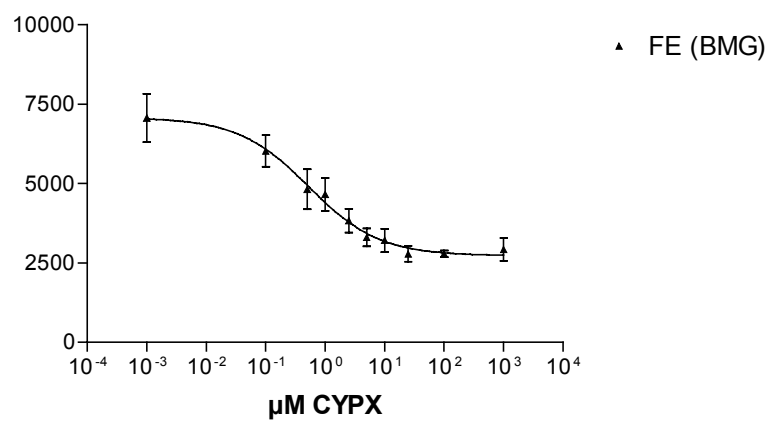

$\mathrm{IC}_{50}$ von TSA

im 1536 well-Format

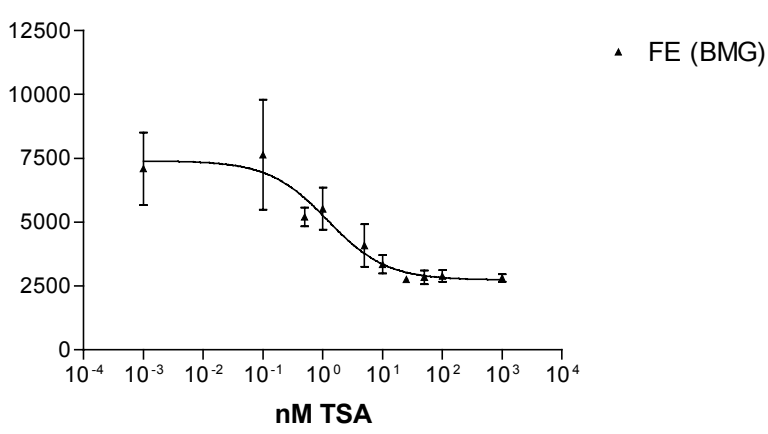

$\mathrm{IC}_{50}$ von SAHA

im 1536 well-Format

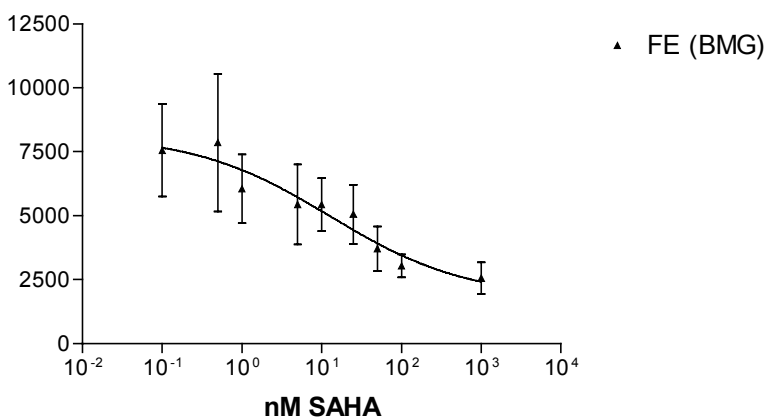

Abb. 15: IC $_{50}$-Bestimmungen für HDAC aus Rattenleber mit verschiedenen Inhibitoren im 1536 well-Format.

HDAC-Assays wurden in Anwesenheit von unterschiedlichen Konzentrationen an HDACI mit HDAC aus Rattenleber und $125 \mu \mathrm{M}$ Tos-GPK(Ac)-AMC als Substrat in HDP-Puffer durchgeführt. Links sind jeweils die durch Messungen mit der integrierten CCD-Kamera, rechts die mit dem MTPFluoreszenzreader erhaltenen Kurven dargestellt. Die ermittelten $\mathrm{IC}_{50}$-Werte sind in Tabelle 6 angegeben. 
Tab. 6: Vergleich der in verschiedenen Formaten (96er bzw. 1536er MTP) ermittelten IC $_{50}$-Werte. Die mit der CCD-Kamera der NanoSyntest-Anlage (linke Spalte) sowie die mit einem MTPFluoreszenzreader ermittelten Werte (rechte Spalte) sind für das 1536-Format angegeben.

\begin{tabular}{c|c|c|c}
\hline HDACI & \multicolumn{2}{|c|}{ IC $_{\mathbf{5 0}}$ (1536 well) } & IC $_{\mathbf{5 0}}$ (96 well) \\
\hline TSA & $6.7 \mathrm{nM}$ & $1.3 \mathrm{nM}$ & $1.3 \mathrm{nM}$ \\
SAHA & $22.3 \mathrm{nM}$ & $12.8 \mathrm{nM}$ & $9.6 \mathrm{nM}$ \\
CYPX & $3.8 \mu \mathrm{M}$ & $0.5 \mu \mathrm{M}$ & $1 \mu \mathrm{M}$
\end{tabular}

\subsection{Entwicklung von Histondeacetylase-Inhibitoren}

Grundsätzlich werden bei der Entwicklung von Wirkstoffen bzw. neuen Leitstrukturen als deren Vorläufer zwei Strategien verfolgt. Das rationale Wirkstoff-Design erfordert normalerweise ein Mindestmaß an Strukturinformation über das Zielenzym oder zumindest über bekannte, empirisch gefundene oder natürliche vorkommende Wirkstoffe bzw. Substrate, ist aber vor allem nach Auflösung der Enzymstruktur ein oft beschrittener Weg, durch kleine Modifikationen viel potentere Wirkstoffe zu entwerfen (Kuntz, 1992; Kubinyi, 1998).

Das andere Extrem ist die pure Durchmusterung von Substanzsammlungen, was im Gegensatz zu rationalen Design-Bestrebungen keine besonderen Vorabinformationen verlangt und vielleicht als wichtigster Gesichtspunkt die Möglichkeit beinhaltet, ganz neue Substanzklassen als geeignete Ausgangs-Kandidaten zu identifizieren (Spencer, 1998).

Selbstverständlich gibt es alle denkbaren Zwischenlösungen und Kombinationen der beiden Ansätze wie etwa das Screening fokussierter Molekülbibliotheken, deren Elemente auf einen Teil des chemischen Raums beschränkt sind, von dem man bei einigen Vertretern oder deren zugrundeliegendem, chemischen Motiv bereits einer Wirkung sicher ist.

\subsubsection{Durchmusterung von Molekülbibliotheken mit HDAC aus Rattenleber}

Nachdem das grundsätzliche Funktionieren des HDAC-Assays sichergestellt war (4.1), wurde eine erste Screening-Runde mit einer relativ kleinen, jedoch recht diversen Kollektion von etwa 400 Substanzen in Angriff genommen. Darunter befanden sich ca. 
200 Oligopeptide von 4-9 Aminosäuren Länge, die auch nicht-natürliche Aminosäurebausteine enthielten, etwa 100 Lysin-Derivate, die eine DipeptidylKopfgruppe aus 8 verschiedenen Aminosäuren und jeweils eine von 4 Gruppen trugen, welche eine Aminooxosäure, ein Dimethylglyzin, eine Mercaptonikotinsäure oder eine Dithizongruppe war. Bei den Lysin-Derivaten bestand die Hoffnung auf ein Komplexieren des Zink-Atoms des aktiven Zentrums analog zur Hydroxamatgruppe. Zusätzlich sollten 80 Hydroxamate getestet werden, welche aus 4 unterschiedlichen Linkern und einer von 20 Kopfgruppen zusammengesetzt waren. Die Substanzen lagen als $40 \mathrm{mM}$ Lösungen in DMSO vor, gelagert bei $-20{ }^{\circ} \mathrm{C}$.
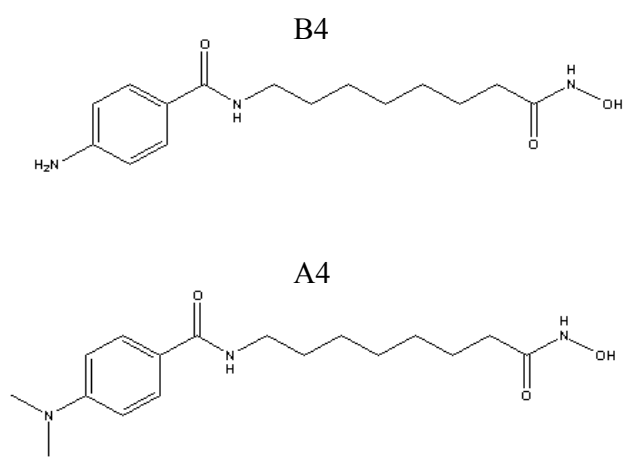

F5

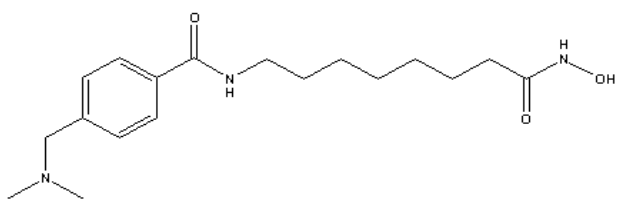

Abb. 16: Strukturformeln dreier durch Screening gefundener HDACIs mit $\mathrm{IC}_{50}<15 \mu \mathrm{M}$.

Die Substanzen wurden mit dem ursprünglichen HDAC-Assay mit $125 \mu \mathrm{M}$ TosGPK(Ac)-AMC bei $167 \mu \mathrm{M}$ in MTP mit 96 Kompartimenten mit Hilfe der CyBiScreen-Machine (Abb. 3) auf eine Wirkung gegen HDAC aus Rattenleber getestet. Dazu wurden die Substanzen manuell 1:20 mit HD-Puffer vorverdünnt und in den Meßplatten vorgelegt. Zusätzlich wurden auf jeder Meßplatte Referenzansätze mitgeführt, für die entsprechend Puffer (für ungehemmte Reaktionen bzw. Blanks ohne HDAC) bzw. 2 nM (für 50\%ige Inhibition) oder 300 nM TSA (für 100\%ige Inhibition) pipettiert wurden. Die DMSO-Konzentration blieb dabei unter $1 \%$. Die Reagenzien wurden in 2 ml-MTP vorgelegt, die HDAC-Verdünnung in einer 96er MTP. Vorab wurde der Fluoreszenhintergrund des neu gelösten Substrates sowie die Abwesenheit einer Trypsinkontamination des Substrates und des Puffers überprüft, indem die 
Lösungen in Anwesenheit von Tos-GPR-AMC inkubiert und im MTP-Fluoreszenreader vermessen wurden. Die Ansätze wurden dann robotisch zusammenpipettiert und die jeweilige Meßplatte bei $30{ }^{\circ} \mathrm{C}$ für $60 \mathrm{~min}$ im MTP-Fluoreszenzreader inkubiert und anschließend abgestoppt. Da technisch bedingt alle Meßplatten seriell abgearbeitet werden mußten und automatische Waschprotokolle zur Säuberung der Spitzen nach Trypsinkontakt scheiterten, wurde für die Trypsinzugabe jeweils manuell ein gesonderter Spitzensatz eingesetzt.

Leider waren viele der Substanzen nicht gut löslich, einige stark gelb oder rot gefärbt. Beide Phänomene könnten mit dem Assay durch Konzentrationsabweichungen, Lichtstreuung oder durch Absorption entweder des Emissions- oder des Anregungslichtes interferieren. So könnten stark absorbierende Substanzen eine starke Inhibition vortäuschen, während fluoreszierende Substanzen falsch-negative Ergebnisse liefern könnten. Scheinbar besonders potente HDACIs der Bibliothek wurden später auf ihre Absorptionseigenschaften bei gleicher Konzentration wie im Screening (170 $\mu \mathrm{M})$ untersucht. Um diese Effekte bei der Beurteilung gefundener Hits berücksichtigen zu können, wurde einerseits die Absorption der HDACI in Assay-Puffer bei 380 bzw. 450 nm (Emissions- bzw. Anregungswellenlänge des HDAC-Assays) bestimmt. Eine auch jetzt noch ungelöste Schwierigkeit dabei war die Unmöglichkeit, Absorption durch gefärbte Substanzen von der Absorption durch Lichtstreuung an ungelösten Partikeln zu unterscheiden. Andererseits wurden dieselben HDACI-Verdünnungen im MTPFluoreszenzreader auf Eigenfluoreszenz untersucht.

Bei dieser eingestellten Inhibitorkonzentration zeigten eine Reihe von Substanzen auch nach Berücksichtigung und Ausfiltern der gefärbten Kandidaten eine 100\%ige Inhibition. Daher wurden einige Kandidaten nocheinmal bei $170 \mu \mathrm{M}$ getestet und darüberhinaus einem weiteren Screening bei ca. $1,7 \mu \mathrm{M}$ Inhibitorkonzentration unterzogen. Hier zeigten allerdings viele Substanzen in beiden Konzentrationen keinen eindeutigen Hemmeffekt mehr. Abbildung 16 zeigt drei bei diesem Screening als aktiv aufgefallene Substanzen. Alle drei Inhibitoren waren sich chemisch und strukturell sehr ähnlich, indem sie TSA/SAHA-ähnliche Hydroxamate, allerdings mit gesättigten Linkern gleicher Länge darstellten. Die Unterschiede in der Kappengruppe waren ebenfalls nur marginal. 
Eine zweite, andersgeartete Substanzbibliothek wurde mit dem verbesserten HDACAssay mit Hilfe der CyBi-Screen-Machine gegen HDAC aus Rattenleber gescreent. Bei den ca. 500 von D. Riester synthetisierten Substanzen handelte es sich um Tripetide, welche sich aus 20, teilweise nicht-biogenen Bausteinen und D-Aminosäuren zusammensetzten und die entweder N-terminal einen Homocitrullinrest (C), einen Formyllysinrest (F) bzw. einen Nicotinylrest (N) trugen oder C-terminal einen Acryloylsäureamid-Rest (A) bzw. einen Mercaptobernsteinsäureamid-Rest (M). Die $\alpha$ Aminogruppe des N-Terminus lag frei vor. Die mit Assay-Puffer aus der $40 \mathrm{mM}$ Stammlösung in DMSO manuell auf $1,8 \mathrm{mM}$ vorverdünnten Substanzen wurden diesmal bei einer Endkonzentration von $150 \mu \mathrm{M}$ und mit $125 \mu \mathrm{M}$ Tos-GPK(Ac)-AMC vermessen. Auch hier fielen beim Verdünnen einige Substanzen als gelb bzw. rötlich gefärbt auf, einige fielen auch als weißer Niederschlag aus. Dieses wurde vermerkt, aber die betroffenen Substanzen trotzdem mitgeführt, da ohnehin ein Abgleich der 'Treffer' (Hits) mit Messungen der Eigenfluoreszenz bzw. Absorptionseigenschaften vorgesehen war.

Die Referenzansätze und die Positionen in der Meßplatte sowie die robotische Durchführung mit den Inkubationsbedingungen wurde wie oben beschrieben beibehalten, allerdings wurden einige Pipettier- und Mischschritte des SteuerungsProgramms optimiert bzw. an die verringerte Viskosität der Puffer angepasst (4.1.9). So erlaubte die CyBio-Anlage beispielsweise, mit den Spitzen in der 96er-Meßplatte auch die vier etwas versetzten Positionen für 384er MTP anzufahren. In Verbindung mit einer Optimierung der Ausheberhöhen wurde ein blasenfreies Mischen auch am Rand der Kavitäten möglich (Berg, 1998). Ein Schritt zum Abstreifen etwaiger, an den Spitzen hängender Tropfen an den Wänden der Meßplatte wurde ebenfalls eingebaut (3.5.8.2).

Nur bei den Teilbibliotheken C, F und N wurden aktive Substanzen gefunden. Alle Substanzen der Typen C, F und N wurden einem weiteren Screening bei $30 \mu \mathrm{M}$ unterzogen. Bei den nach Abgleich mit den Absorptionsmessungen als wahrscheinliche Inhibitoren verbliebenen Kandidaten wurde zusätzlich der $\mathrm{pH}$-Wert unter den MeßAnsätzen analogen Bedingungen überprüft, dieser lag in allen Fällen wie erwartet bei pH 8.5. 
Die hier mehr als 50\%ig hemmend wirkenden Kandidaten wurden mit dem Syntheseraster abgeglichen (Abb. 17), um eine erste, grobe Struktur-Aktivitäts-Analyse durchzuführen.

\begin{tabular}{|c|c|c|c|c|c|c|c|c|c|c|c|c|c|}
\hline 1. P & 2.Pos & $\begin{array}{l}1 \\
\mathbf{A} \\
\end{array}$ & $\begin{array}{l}2 \\
R\end{array}$ & $\begin{array}{l}3 \\
\mathrm{~N}\end{array}$ & $\begin{array}{l}4 \\
\mathrm{D} \\
\end{array}$ & $\begin{array}{l}5 \\
C \\
\end{array}$ & $\begin{array}{l}6 \\
Q \\
Q\end{array}$ & $\begin{array}{r}7 \\
\mathrm{E} \\
\end{array}$ & $\begin{array}{l}8 \\
\text { G }\end{array}$ & $\begin{array}{l}9 \\
\mathrm{H} \\
\end{array}$ & $\begin{array}{l}10 \\
1 \\
\end{array}$ & $\begin{array}{l}11 \\
\mathrm{~L}\end{array}$ & $\begin{array}{l}12 \\
\mathrm{~K}\end{array}$ \\
\hline A & $\mathbf{M}$ & & $\mathrm{N}$ & & & & & & & & & & C \\
\hline B & $\mathbf{F}$ & & CFN & & & & & & & & & $\bar{F}$ & $\mathrm{~N}$ \\
\hline c & $\mathbf{P}$ & & C & & & & & & & & & $F$ & \\
\hline D & $\mathbf{s}$ & & & & & & & & & & & & $\mathrm{CN}$ \\
\hline $\mathrm{E}$ & $\mathrm{T}$ & C & c & & & & & & & & & & CN \\
\hline$F$ & w & & & & & & & C & & & & & CFN \\
\hline G & $Y$ & & & & & & & & & & & & $\mathrm{CN}$ \\
\hline $\mathrm{H}$ & $\mathrm{v}$ & & & & & & & & & & & & CN \\
\hline
\end{tabular}

\section{Abb. 17: Syntheserraster der Dipeptidylgruppen.}

Zuerst wurden spaltenweise die C-terminalen Bausteine (A, R, N...) an das Syntheseharz gekoppelt, dann zeilenweise die Bausteine für die zweite (mittlere) Position (M, F, P...). Zuletzt wurde jeweils die Nterminale Aminosäure des Typs C, F bzw. N gekoppelt.

Hier fallen erstens Substanzen auf, die unabhängig von der N-terminalen Aminosäure hemmen, solange sie nur das Dipeptid D-Phe-D-His (FR) oder Trp-Lys (WK) aufweisen.

Zweitens waren Substanzen dabei, deren Dipeptide aus den Kombinationen Ser-Lys (SK), Thr-Lys (TK), (Trp-Lys,WK), Val-Lys (VK) oder Tyr-Lys (YK) bestanden und deren N-Terminus nicht vom Typ F war.

Drittens waren auch die Tripeptide CIA, CPR, CIR, CME, CWE, CMK, FFQ, FFH, FWI, FML, FFL, FPL, NMR und NFK aktiv.

Die meisten Substanzen dieser Teilbibliotheken waren allerdings unwirksam gegen HDAC aus Rattenleber.

Zur Abschätzung des $\mathrm{IC}_{50}$ wurden Standard-HDAC-Assays mit 400-0,4 $\mu \mathrm{M}$ der Tripeptide mit den Bausteinen FR und WK der Typen C, F, N und zusätzlich auch der Typen $\mathrm{A}$ und $\mathrm{M}$ in Einfachansätzen durchgeführt. Zusätzlich wurden auch alle Tripetide mit -TA vermessen. 
Tab. 7: Abgeschätzte $\mathrm{IC}_{50}$-Werte der aktiven Substanzen des zweiten Screenings.

\begin{tabular}{|c|c|c|c|c|c|}
\hline \multicolumn{6}{|c|}{ Teilbibliothek } \\
\hline Dipeptid & A & C & F & M & N \\
\hline TA & - & $95 \mu \mathrm{M}$ & $374 \mu \mathrm{M}$ & - & $246 \mu \mathrm{M}$ \\
\hline FR & - & $10 \mu \mathrm{M}$ & $34 \mu \mathrm{M}$ & - & $7 \mu \mathrm{M}$ \\
\hline WK & - & $4 \mu \mathrm{M}$ & $4-40 \mu \mathrm{M}$ & - & $5 \mu \mathrm{M}$ \\
\hline
\end{tabular}

Die Tripeptide der Teilbibliotheken A und M zeigten auch bei $400 \mu \mathrm{M}$ so gut wie keine Hemmwirkung. Die Peptide mit -TA zeigten auch bei den Typen C, F, N selbst nur sehr moderate Hemmung.

\subsubsection{Untersuchung zur Selektivität und Bestimmung des $I_{50}$ einiger HDACI}

Wie bereits eingangs erwähnt (1.3.3), kommen in menschlichen Zellen mindestens 11 verschiedene $\left(\mathrm{NAD}^{+}\right.$-unabhängige) HDAC vor, die aufgrund ihrer unterschiedlichen Homologien zu zwei Corepressoren aus $S$. cerevisiae in zwei Klassen eingeteilt werden (Grozinger and Schreiber, 2002). Neben den Unterschieden z. B. in Größe, Primärsequenz und Lokalisation läßt auch das Vorkommen einiger HDAC in unterschiedlichen Multienzym-Komplexen bzw. deren Abwesenheit in allen bekannten Komplexen vermuten, daß HDAC unterschiedliche Aufgaben bekleiden (Grozinger and Schreiber, 2002). So ist etwa für HDAC6 acetyliertes Tubulin als Substrat identifiziert worden und eine Rolle in der Regulation des Zytoskeletts wahrscheinlich (Haggarty et al., 2003b; Hubbert et al., 2002), für viele andere Mitglieder ist jedoch noch nichts über ihre Funktion bekannt. Spezifische Inhibitoren wären wertvolle Instrumente zur Aufklärung der Funktion in vivo (Krämer et al., 2001). Natürlich ist auch die Möglichkeit zur selektiven Inhibition einzelner HDAC in einer pathologischen Situation von großem therapeutischem Interesse (Johnstone, 2002; Kim et al., 2003).

Darüberhinaus sind bakterielle Enzyme wie etwa HDLP und FB188-HDAH als HDACähnlich bekannt (Finnin et al., 1999; Leipe and Landsman, 1997), Dissertation C. Hildmann). Dabei ist FB188-HDAH zu 35 \% (über 291 As) identisch bzw. zu 53 \% (104 As von 291 As der katalytischen Domäne) homolog zur C-terminalen 
Aktivitätsdomäne von HDAC6 ((Hildmann et al., 2003), C. Hildmann, pers. Mitteilung) und könnte somit als Modellenzym für Enzyme der Klasse II dienen. Analog zu den Bestimmungen mit Standard-HDAC-Inhibitoren (4.1.8) wurden die $\mathrm{IC}_{50}$-Werte der bei der Durchmusterung von Substanzbibliotheken gefundenen (4.2.1) und einiger von M. Gebinoga synthetisierter Moleküle für drei verschiedene HDAC ermittelt (Abb. 18, Tab. 8). Die Inhibitionsexperimente mit FB188-HDAH wurden mit der kontinuierlichen HDAC-Assay-Variante durchgeführt (3.5.11). Zur Erstellung der Testsubstanzen wurde teilweise eine neuartige Synthesestrategie herangezogen, indem die Horner-WittigEmmons (HWE)-Reaktion (Bonadies et al., 1994) ausgenutzt wurde, um HDACI mit ungesättigten Linkern unterschiedlicher Länge zwischen der Kappe und der Hydroxamatgruppe zugänglich zu machen (M. Gebinoga, in Vorbereitung). Im letzten Syntheseschritt wurden alle Kandidaten mit einer starken Base zu Hydroxamaten umgesetzt (Remiszewski et al., 2002). SAOH, ein Carbonsäure-Derivat des Hydroxamates SAHA, wurde von D. Riester synthetisiert.

Aus dem Vergleich der Werte für HDAC aus Rattenleber, der humanen HDAC8 und FB188-HDAH bakteriellen Ursprungs sollte eine mögliche Spezifität des untersuchten Inhibitors erkennbar sein. 
\#123

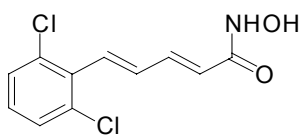

\#124

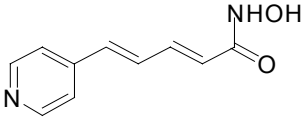

\#125

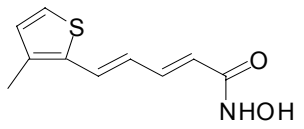

\#127

(noch nicht genau

identifiziert)

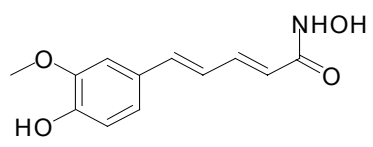

Thiox

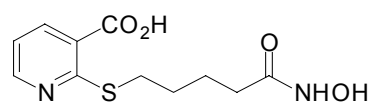

CYPX

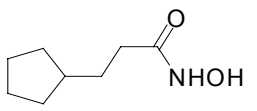

Abb. 18: Strukturformeln der auf Selektivität untersuchten HDACI.

Die Strukturen von TSA und SAHA sind in Abbildung $13 \mathrm{zu}$ finden. Die Struktur von HDACI \#127 wurde noch nicht bestätigt. Bei allen anderen Molekülen wurde die erwartete Masse bei LC-MSAnalysen gefunden (M.Gebinoga, persönliche Mitteilung).

Aus Tabelle 8 ist zu entnehmen, daß durchaus Werte im nanomolaren Bereich erreicht wurden. Einige Inhibitoren zeigten darüberhinaus ein differenziertes Wirkprofil, allerdings unterschieden sich bis auf eine Ausnahme die Potenzen der Inhibitoren um weniger als den Faktor 100. In den meisten Fällen wurden jedoch alle drei HDAC unspezifisch mit ungefähr derselben $\mathrm{IC}_{50}$ gehemmt. CYPX zeigte nur gegen FB188HDAH eine Hemmung im nanomolaren Bereich, HDACI \#123 zeigte im Gegensatz dazu nur bei einem Enzym, der HDAC8, keine besonders ausgeprägte Hemmung. Die sehr verwandten Moleküle HDACI\#124 und A08/P03hx weisen fast identische Wirkprofile auf. Für TSA konnte bei FB188-HDAH eine knapp 1000fach geringere Hemmung festgestellt werden als bei HDAC aus Rattenleber. Die Hemmung im Vergleich zu HDAC8 war im Gegensatz dazu nur 7fach geringer. HDACI\#127 ist insofern ein spezieller Fall, da hier selbst bei der geringsten Inhibitorkonzentration (2 nM) keine verbliebene Aktivität der FB188-HDAH mehr zu detektieren war, wenn die standardmäßige Vorinkubation von Inhibitor und Enzym von 10 Minuten 
eingehalten wurde, während bei sofortiger Vermessung der Ansätze eine fortschreitende Inhibierung/Inaktivierung des Enzyms $\mathrm{zu}$ beobachten war (Daten nicht gezeigt). Entweder handelt es sich bei HDACI \#127 um einen irreversiblen oder einen langsam bindenden (slow-binding), aber hochaffinen Inhibitor für FB188-HDAH. Demgegenüber zeigte die Substanz bei der Bestimmung des $\mathrm{IC}_{50}$ für $\mathrm{HDAC}$ aus der Rattenleber eine typische Dosis-Wirkungskurve mit einer eher moderaten halbmaximalen Hemmung bei $154 \mu \mathrm{M}$. Leider wurden noch keine Daten über die Wirkung dieses Inhibitors auf HDAC8 generiert. Ein Vergleich mit dem Verhalten von letztgenannter HDAC gegenüber HDACI\#127 und weitere Inhibitions-Experimente mit Analysen mittels doppeltreziproker Auftragungen nach Lineweaver-Burke sollten den Inhibitionstypus klären helfen. Bestätigte sich der irreversible Charakter der Hemmwirkung, wäre mit diesem Inhibitor nicht nur ein wertvolles Instrument zur Unterscheidung bakterieller von eukaryotischen HDAC sondern auch zur exakten Bestimmung der aktiven Enzymfraktion im Assay mittels active-site titration (Knight, 1995) gewonnen.

Der große Verlust in der Potenz von SAOH im Vergleich zu SAHA durch die Substituierung der Hydroxamtgruppe mit einer Carbonsäurefunktion bestätigte die erwartete Wichtigkeit, das Zink-Atom im Katalysezentrum des Enzyms komplexieren zu können, für eine potente Hemmwirkung.

Wie aufgrund der Ähnlichkeit der Strukturen zu erwarten war, zeigten die bei der ersten Screening-Runde (4.2.1) aktiven HDACI A4, B4 und F5 auch ähnliche Potenz in der Hemmung in den Sondierungsmessungen bei unterschiedlichen SubstanzKonzentrationen.

Alle HDACI zeigten keine oder nur vernachlässigbare Trypsininhibition (Daten nicht gezeigt). 
Tab. 8: IC $_{50}$ von HDACI der Hydroxamatklasse für verschiedene HDAC.

FB188-HDAH wurde von C. Hildmann präpariert.

\begin{tabular}{|c|c|c|c|}
\hline HDACI & HDAC aus Rattenleber & HDAC8 & FB188-HDAH \\
\hline 83 & $130 \mathrm{nM}$ & $517 \mathrm{nM}$ & $33 \mathrm{nM}$ \\
\hline 123 & $53 \mathrm{nM}$ & $2,8 \mu \mathrm{M}$ & $48 \mathrm{nM}$ \\
\hline 124 & $2,3 \mu \mathrm{M}$ & $4 \mu \mathrm{M}$ & $5,7 \mu \mathrm{M}$ \\
\hline 125 & $255 \mathrm{nM}$ & nicht fitbar & $60 \mathrm{nM}$ \\
\hline 127 & $154 \mu \mathrm{M}$ & - & irreversibel? \\
\hline Thiox & - & $25 \mu \mathrm{M} \#$ & - \\
\hline CYPX & $1 \mu \mathrm{M}$ & $2 \mu \mathrm{M}$ & $70 \mathrm{nM}$ \\
\hline TSA & $1,3 \mathrm{nM}$ & $170 \mathrm{nM}(53 \mathrm{nM} *)$ & $1,2 \mu \mathrm{M}^{* *}$ \\
\hline SAHA & $9,6 \mathrm{nM}$ & $400 \mathrm{nM}$ & $950 \mathrm{nM} * *$ \\
\hline $\mathrm{SAOH}$ & $>1000 \mu \mathrm{M}$ & - & $\begin{array}{c}10 \% \text { Inh. bei } 100 \mu \mathrm{M} \\
* *\end{array}$ \\
\hline A08/P03hx & $3,5 \mu \mathrm{M} \#$ & $10 \mu \mathrm{M} \#$ & - \\
\hline A4 & $<15 \mu \mathrm{M} \# \&$ & - & - \\
\hline B4 & $<1 \mu \mathrm{M} \quad \# \&$ & - & - \\
\hline F5 & $<1 \mu \mathrm{M} \quad \# \&$ & - & - \\
\hline \multicolumn{4}{|c|}{ * Wert wurde mit $250 \mu \mathrm{M}$ Ac-RGK(Ac)-AMC und dem ursprünglichen Puffersystem bestimmt (4.1.8). } \\
\hline \multicolumn{4}{|c|}{ ** Wert entnommen aus Hildmann et al., 2003, ermittelt mit $50 \mu \mathrm{M}$ Boc-Lys(Ac)-AMC } \\
\hline \# Abschätzung aus & infachmessung; \& S & 4.2 .1 & \\
\hline
\end{tabular}

\subsection{Produktion von rekombinanter, humaner HDAC}

Eine wichtige Voraussetzung für die erfolgreiche Durchführung einer HTS-Kampagne und der nachfolgenden bzw. begleitenden Sekundär- und ADME/Tox-Assays oder auch für die generelle biochemische Charakterisierung eines (Ziel-)Enzyms stellt die Verfügbarkeit ausreichender Mengen dieses Enzyms in hinreichender Qualität dar. Dabei sind oft Mengen vonnöten, die gar nicht oder nicht unter vertretbarer Aufwendung von Zeit, Mühe und Kosten durch direkte Isolierung aus dem Ursprungsgewebe oder -organismus gewonnen werden könnten. Bei humanen Enzymen gelten darüberhinaus besondere Beschränkungen ethischer Natur. In all diesen Fällen besteht der Ausweg in der heterologen Expression des gewünschten Proteins mit einem der vielen, in der Literatur beschriebenen Expressionssysteme (Edwards and Aruffo, 1993; Fischetti et al., 1993; Geisse et al., 1996; Hollenberg and Gellissen, 1997; Ikonomou et al., 2003; Kost, 1997; Kost and Condreay, 1999; Oka and Rupp, 1990; 
Schillberg et al., 2003; Sudbery, 1996; Werner et al., 1998). Besonders gut untersucht und oft sehr erfolgreich genutzt werden wohl diverse, oft speziell modifizierte Stämme von Escherichia coli mit einem oder mehreren der zahlreichen Vektorkonstrukte dafür eingesetzt (Balbas, 2001; Studier et al., 1990). Die heterologe Produktion eines Proteins - besonders als Fusion mit einem Aufreinigungs-tag (Nygren et al., 1994) - erleichtert nicht nur generell die Aufreinigung, sie vermeidet ebenfalls das Risiko, bei der Isolierung unbemerkt Enzymgemische aus Isoformen oder in Funktion, d. h. vor allem vom Substratspektrum her ähnlichen Enzymen als Kontamination zu erhalten, welche Meßergebnisse verfälschen können. Vor allem bei der Durchmusterung von Molekülbibliotheken nach Inhibitoren kann sich dies fatal auswirken, indem sowohl Wirkstoffe durch andere Enzymaktivitäten maskiert (falsch-negatives Ergebnis) als auch falsch-positive Hits durch deren Hemmung generiert werden.

Bei der Entwicklung des neuen Assays und für das Screening nach HDACI wurde in dieser Arbeit vor allem eine kommerziell erhältliche Histondeacetylase-Präparation (2.5) aus der Rattenleber als Modellenzym verwendet. Es ist allerdings nicht ganz klar, um welches Enzym es sich dabei handelt bzw. welchem menschlichen Homologen es entspricht. Letztlich kann auch nicht explizit ausgeschlossen werden, daß es sich dabei um ein Enzymgemisch handelt. Allerdings konnte in einem Immunoblot mit polyklonalem Anti-HDAC1-AK (2.5) ein deutliches Proteinsignal in der HDACPräparation detektiert werden (Daten nicht gezeigt). Kürzlich wurde HDAC3 als die am stärksten vertretene HDAC in Rattenleberzellen beschrieben, welche zu HDAC1 eine sehr hohe Homologie in der HDAC-Domäne aufweist (Van Ommeslaeghe et al., 2003) und Referenz 19 darin). Darüberhinaus muß in jedem Fall eines gefundenen Wirkstoffs überprüft werden, ob sich die Ergebnisse prinzipiell oder im Speziellen auf eine oder mehrere humane HDAC übertragen lassen, da die entwickelten Inhibitoren bzw. deren optimierte Nachfolger ja schließlich im Patienten hemmen sollen. Dahingehende Untersuchungen sind allerdings generell zu unternehmen, um die Selektivität der Inhibitoren $\mathrm{zu}$ untersuchen. Unspezifische Inhibitoren bergen in der Regel ein großes Risiko für Nebenwirkungen in sich, da sie in wichtige nicht-pathogene Zellabläufe eingreifen und daher mehr schaden als nutzen könnten. Aus diesen Gründen und weil die zelluläre Funktion wie auch die Rolle bei der Tumorgenese vergleichsweise gut belegt ist, sollte zunächst die HDAC1 des Menschen als Referenzenzym herangezogen 
werden. So ist neben der Wichtigkeit für die Regulation der Transkription vieler Tumorsuppressorgene und die Involvierung in die Zellzykluskontrolle (Lagger et al., 2002; Magnaghi-Jaulin et al., 1998; Wade, 2001; Zhou et al., 2000) zum Beispiel eine aberrante Rekrutierung eines HDAC1-Komplexes durch einen mutierten RARKernrezeptor eine Ursache für akute promyelocytische Leukämie (Grignani et al., 1998). Die erhöhte Expression von HDAC1 in Prostatakrebszellen und bei Hypoxie (Kim et al., 2001; Patra et al., 2001) und die Deacetylierung von p53, einem Schlüsselfaktor des Apoptosesignalweges, durch HDAC1 ist ebenfalls belegt (Juan et al., 2000).

\subsubsection{Klonierung der humanen HDAC1 und heterologe Expression in E. coli}

Als Referenzenzym für Selektivitätsuntersuchungen mit den HDACI und als mögliches späteres primäres Zielenzym für HTS-Kampagnen und zur biochemischen Charakterisierung wurde die humane HDAC1 in E. coli exprimiert. Dazu wurde die codierende cDNA (ca. 1450 bp) mittels RT-PCR von Osteoblasten-mRNA als Template (ca. 200 ng mRNA) amplifiziert und subkloniert. Unter Benutzung eines spezifischen RT-Primers (HDAC-RT2) und des Omniscript-RT-Kits (Qiagen) wurde durch reverse Transkription $\left(37^{\circ} \mathrm{C}, 90 \mathrm{~min}\right)$ die cDNA synthetisiert. Unter Verwendung der genspezifischen Primerpaare NhisHDAC1pQEfw und HDAC1PICrev konnte ein PCRProdukt erhalten und in pCR2.1TOPO kloniert werden. Dabei wurden über die Primer terminale EcoRI-Schnittstellen angefügt. Trotz einer nach der Sequenzierung (durchgeführt vom G2L) als wahrscheinlich einzustufenden Basendeletion wurde das HDAC1-Fragment mit EcoR1 aus dem resultierenden Plasmid pTH108 ausgeschnitten, mit SAP dephosphoryliert und in den Expressionsvektor pQE70 kloniert. Dabei wurde in einigen Fällen das Insert in der richtigen Orientierung ligiert und die 3'-wärts der in der RBS gelegenen EcoRI-Erkennungsstelle gelegene RBS-Bereich des Vektors durch den 5'-Primer restauriert. Das resultierende Plasmid wurde mit pQEHDAC1-5 benannt. Um die erwähnte Deletion zu reparieren, wurde ein PCR-Primer HDAC1Repfor definiert, der die Schadensstelle überlappt und eine endogene HincII-Schnittstelle einschließt. Zusammen mit dem Primer HDACpQEHindrev wurde via PCR ein 800 bpFragment ausgehend von pTH108 als Template generiert und in pCR4TOPO subkloniert. Über HincII und HindIII wurde das Fragment in den ebenso geöffneten und 
vom Insert-Fragment abgetrennten pQEHDAC1-5 umkloniert, so das im resultierenden Expressionsvektor pQEHDAC1NHIS das gewünschte HDAC1-Konstrukt mit Nterminalem Hexahistidin-tag vorlag, dessen Fehlerfreiheit durch Sequenzierung bestätigt wurde (Abb. 19).

\subsubsection{Expression mit N-terminalem Hexahistidin-tag}

Im so entstandenen Expressionsvektor pQEHDAC1NHIS steht das HDAC1-Konstrukt unter der Kontrolle des IPTG-induzierbaren T5/Lac-Promotor/Operators. Nach Überprüfung der korrekten Basenabfolge durch Sequenzierung (im G2L) wurden erste Testexpressionen im 50 ml-Maßstab durchgeführt. 


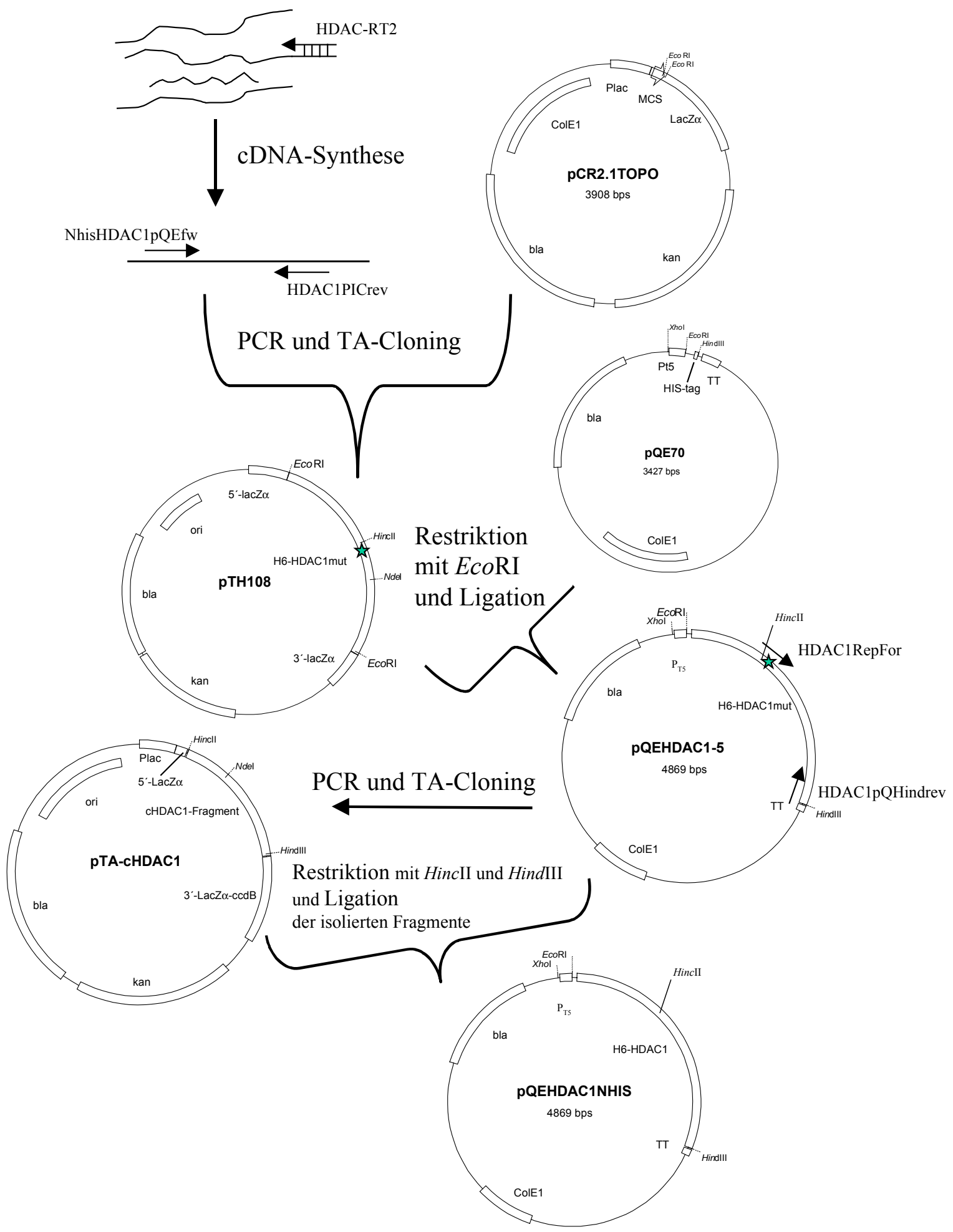

Abb. 19: Schema der Klonierung des Expressionsvektors für HDAC1 mit N-terminalem His-tag.

HDAC1 wurde mittels RT-PCR aus Osteoblasten-mRNA amplifiziert und nach Reparatur einer Punktmutation in den Expressionsvektor pQE70 unter die Kontrolle des IPTG-induzierbaren T5Promotors kloniert. 
Dabei wurde zunächst XL1-Blue als Stamm verwendet. Western Blots der zu verschiedenen Zeiten nach der Induktion mit 0,5 bzw. $1 \mathrm{mM}$ IPTG genommenen Aliquots zeigten wiederholt keine Signale mit dem primären Anti-TetraHis-tagAntikörper (Biorad). Daraufhin wurden auch andere Stämme (BMH7118, HB101 und BL21) mit dem Expressionsplasmid pQEHDAC1NHIS bzw. dem Leervektor pQE70 transformiert und analoge Expressionsversuche unternommen.

Mit $100 \mu$ l einer Vorkultur eines Klons wurde jeweils die Hauptkultur angeimpft (50 ml LB/Amp). Als Kontrolle wurde immer eine Kultur mit dem Leervektor mitgeführt. Expressionskulturen von BMH7118-pQEHDAC1NHIS, HB101-pQEHDAC1NHIS und BL21-pQEHDAC1NHIS wurden bei 30 bzw. $37^{\circ} \mathrm{C}$ geschüttelt und bei unterschiedlichen Zelldichten (nach OD $_{600}$ : 0,5-1) mit 0, 0,5 bzw. 1 mM IPTG induziert. Aliquots der Kultur $(5 \mathrm{ml})$ wurden $\mathrm{zu}$ verschiedenen Zeitpunkten abgenommen, pelletiert und in $500 \mu \mathrm{l}$ PBS aufgenommen. Nach Sonifizierung der Zellen $(2$ x $30 \mathrm{sec}$ auf Eis, mit 1minütiger Pause dazwischen) wurde der Debris pelletiert und der lösliche Überstand in ein neues Reaktionsgefäß überführt. Je 15-20 $\mu$ l davon wurden mittels SDS-PAGE aufgetrennt. Das Gel wurde mittels Coomassie angefärbt bzw. geblottet (Semidry-Elektroblotting) und mittels Western Blot analysiert. Dabei konnte mit dem Anti-TetraHis-tag-AK (Qiagen, 1:2000) weder bei den Proben der löslichen LysatBestandteile noch bei den Pelletproben eine spezifische Bande detektiert werden. Als sekundärer Antikörper diente ein AP-Konjugat.

\subsubsection{Coexpression einer tRNA ${ }^{\text {Arg }}$}

Einer der Gründe für die geringe Expression der HDAC1 könnte die für den Wirt ungünstige codon usage gewesen sein. Da das Gen für HDAC1 einige Arginin-Codons ( $3 \times$ AGA und $3 \times$ AGG) beinhaltet, die von E. coli nur selten verwendet werden und deren Arg-tRNA dort somit unterrepräsentiert ist, sollte durch eine Coexpression des dnaY-Gens versucht werden, die Proteinbiosynthese zu erleichtern, wie es bei einer Reihe an Beispielen erfolgreich praktiziert wurde (Brinkmann et al., 1989; You et al., 1999). Das dnaY-Gen ( $\arg U)$ des Coexpressionsplasmides pUBS520 codiert für eine AGA-spezifische Arg-tRNA, die bei Überproduktion ebenfalls AGG-Codons bedient (Brinkmann et al., 1989). Die 4 Expressionsstämme XL1-Blue, BMH7118, HB101 und BL21 wurden daher zusätzlich zum Expressionsvektor mit pUBS520 transformiert, 
welcher einen ColE1-kompatiblen Replikationsursprung (p15A) und eine KanamycinResistenz trägt.

Um den Einfluß der coexprimierten Arg-tRNA auf die Produktion der HDAC1Konstrukte $\mathrm{zu}$ testen, wurden ebenfalls Pilotexpressionen im $50 \mathrm{ml}-\mathrm{Maßstab}$ unternommen, welche hier beispielhaft am Stamm BL21 beschrieben werden sollen. Mit je $100 \mu$ l einer Vorkultur von je 3 Klonen BL21-pQEHDAC1NHIS-pUBS520 bzw. einem Klon BL21-pQE70-pUBS520 als Negativ-Kontrolle wurden 2 x $50 \mathrm{ml}$ $\mathrm{LB} / \mathrm{Amp} / \mathrm{Kan}$ angeimpft, bei $37^{\circ} \mathrm{C}$ und $150 \mathrm{Upm}$ inkubiert und bei einer $\mathrm{OD}_{600}$ von 0,8-0,9 mit 0,5 mM bzw. $1 \mathrm{mM}$ IPTG induziert. Zu bestimmten Zeitpunkten nach der Induktion wurde die $\mathrm{OD}_{600}$ bestimmt und Aliquots von $5 \mathrm{ml}$ abgenommen. Die Zellen darin wurden pelletiert und in $500 \mu$ PBS resuspendiert. Nach dem Lysieren der Zellen auf Eis mittels Ultraschall ( 2 × $30 \mathrm{sec}, 30 \mathrm{sec}$ Pause dazwischen) wurden Zelldebris und Überstand durch Zentrifugation (13500 Upm, 2 min, $4{ }^{\circ} \mathrm{C}$ ) getrennt. Je $20 \mu 1$ der Proben wurden durch SDS-PAGE aufgetrennt und mit Coomassie gefärbt bzw. auf PVDFMembranen geblottet (Semidry-Elektroblotting) und mittels Western Blot analysiert. Zur Detektion der HDAC1 wurde ein Anti-TetraHis-tag-AK (Qiagen, 1:2000) und ein AP-Konjugat (Sigma, 1:5000) eingesetzt.

Die erstellten Wachstumskurven (Abb. 20) der Kulturen geben keinen Hinweis auf einen toxischen Effekt durch die Enzymproduktion. 


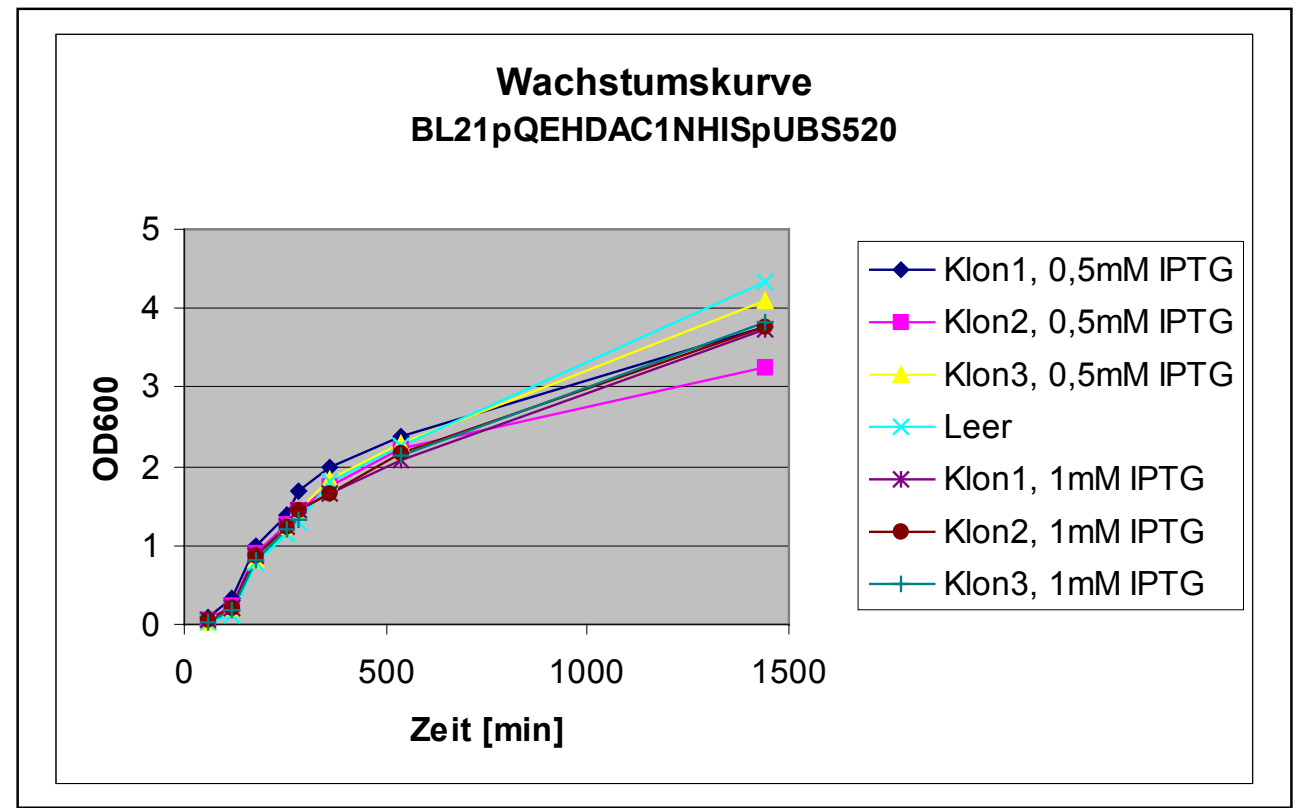

Abb. 20: Wachstumskurven der BL21-Expressionsklone bei 50 ml-Pilotexpressionen der HDAC1 mit N-terminalem Hexahistidin-tag.

Je 3 Klone von BL21-pQEHDAC1NHIS-pUBS520 wurden mit 0,5 bzw. 1 mM IPTG bei logarithmischem Wachstum in $\mathrm{LB} / \mathrm{Amp} / \mathrm{Kan}$ induziert. $\mathrm{Zu}$ verschiedenen Zeitpunkten wurde die $\mathrm{OD}_{600}$ photometrisch bestimmt. Es ist kein wachstumshemmender Einfluß durch die Induktion der HDAC1Expression zu erkennen. Die Klone coexprimieren zusätzlich von pUBS520 aus eine tRNA für 2 seltene Arginincodons.

Aber es konnte weder im Überstand noch in den Pelletfraktionen ein exprimiertes Protein mit His-tag detektiert werden (Daten nicht gezeigt).

\subsubsection{Expression mit C-terminalem Hexahistidin-tag}

Eine andere Ursache für die geringe Proteinproduktion mag der N-terminal fusionierte His $_{6}$-tag gewesen sein, der möglicherweise die korrekte Faltung stört und/oder zum proteolytischen Abbau beiträgt. Daher wurde mit den Primern HDAC1EcoRIfw und HDAC1HISHindIIIrev mit pQEHDAC1NHIS als Template ein PCR-Produkt amplifiziert, das stattdessen einen C-terminalen His $_{6}$-tag besitzt. Dieses wurde in pCR4TOPO subkloniert und anschließend über EcoRI und HindIII in pQE70 kloniert.

Nach Sequenzierung des Inserts wurden mit dem korrekten Expressionsvektor pQEHDAC1CHIS alle 4 schon erwähnten Expressionsstämme transformiert. Zusätzlich wurden diese ebenfalls mit pUBS520 transformiert. Auch diese Konstrukte wurden in gleicher Weise wie oben beschrieben in Pilotexpressionen getestet (als Beispiel wird hier die Expression in HB101 mit und ohne Coexpression der Arginin-tRNA gezeigt). Dabei wurde jeweils mit $0,5 \mathrm{mM}$ IPTG bei einer $\mathrm{OD}_{600}$ von $0,5-0,8$ induziert. Zur Detektion der HDAC1 wurde ein Anti-TetraHis-tag-AK (Qiagen, 1:2000) bzw. ein 
polyklonaler Anti-HDAC1-AK und das jeweils zugehörige, sekundäre Antikörper-APKonjugat (Sigma, 1:5000) eingesetzt.

Die erstellten Wachstumskurven der Kulturen (Abb. 21 zeigt die von HB101) geben auch hier keinen Hinweis auf einen toxischen Effekt durch die Enzymproduktion.

Mittels Immunodetektion wurden Proben des Lysat-Überstandes und des Pellets analysiert (Abb. 22, Immunoblots der Pelletproben nicht gezeigt). Im Gegensatz zu den (mit dem Leervektor transformierten) Negativkontrollen konnte bei den Proben aller drei Expressionsklone eine Hauptbande eines Proteins eines $M_{r}$ von etwa 70000 detektiert werden, wobei es sich wohl um das exprimierte HDAC1CHIS-Konstrukt handelte. Daneben traten mehrere Signale im Bereich eines $M_{r}$ von 23000 bis 36000 auf, welche wahrscheinlich proteolytische Abbauprodukte darstellten. Da auf Western Blots nach denaturierender PAGE in keinem Fall ein Signal von HDAC1NHIS zu sehen war, jedoch HDAC1 mit C-terminalem Hexahistidin-tag detektiert werden konnte (Abb. 22), scheint sich (zumindest in den untersuchten Stämmen) HDAC1CHIS wesentlich besser exprimieren zu lassen als das Konstrukt mit dem N-terminalen His-tag. Allerdings waren die nachgewiesenen Proteine mit einem $M_{r}$ von etwa 70000 etwas größer als berechnet $\left(\mathrm{M}_{\mathrm{r}} \sim 57000\right)$. Hier mag der stark positiv geladene C-Terminus der HDAC1 die Wanderungsgeschwindigkeit im Gel durch eine partielle Kompensation der negativen Ladungen der SDS-Moleküle verringert haben. Dafür spricht auch das Erscheinen des HDAC1-Signals auf der zu erwartenden Laufhöhe eines Proteins mit einem $M_{r}$ von ca. 60000 bei Detektion mit einem polyklonalen Anti-HDAC1-AK (Abb. 22). Hier wurden dieselben Proben auf einem 10\%igen PAA-Gel aufgetrennt, im Gegensatz dazu wurde für den Western Blot mit Anti-TetraHIS-AK ein 12\%iges Gel verwendet.

Desweiteren wurde der Einfluß der Coexpression der Arginin-tRNA auf die Expression und vor allem die Aktivität der HDAC1 mit C-terminalem Hexahistidin-tag untersucht, indem, wie schon geschildert, Pilotexpressionen in mit pUBS520 cotransformierten Klonen unternommen wurden. Hierbei stand nicht so sehr die mögliche Produktionssteigerung, als vielmehr die Frage im Vordergrund, ob die erwähnten seltenen Ariginincodons die Expression in aktiver Form behindern, indem es an diesen Stellen im Protein bei Mangel an korrekt beladener Arg-tRNA zu einem Fehleinbau 
eines Lysins und damit zum Verlust der HDAC-Aktivität kommt. Dieser Fehleinbau ist u. a. am Beispiel der Ubiquitinexpression gezeigt worden (You et al., 1999).

In Immunoblots konnte eine Expression von HDAC1 mit Hexahistidin-tag sowohl in Klonen, die die Arg-tRNA coexprimieren, als auch - wie bereits erwähnt - in jenen ohne pUBS520 nachgewiesen werden. Dabei erschien der Ertrag an HDAC1CHIS in beiden Fällen sehr ähnlich (Abb. 22) und der Einfluß der überexprimierten tRNA bestenfalls gering. Standard-HDAC-Assays mit $150 \mu \mathrm{M}$ Boc-Lys(Ac)-AMC und bis zu $50 \mu 1$ der löslichen Lysatfraktionen blieben aber in beiden Fällen erfolglos.

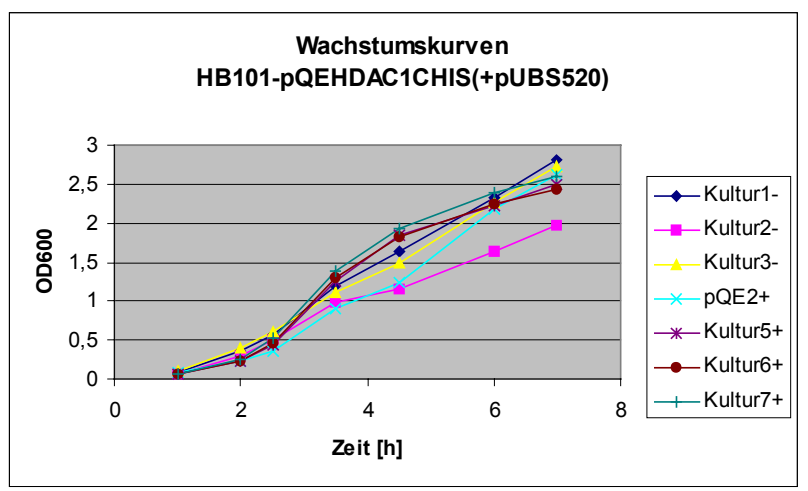

Abb. 21: Wachstumskurven der HB101-Expressionsklone bei 50 ml-Pilotexpressionen der HDAC1 mit C-terminalem Hexahistidintag.

Je 3 Klone von HB101-pQEHDAC1CHIS und HB101-pQEHDAC1CHIS-pUBS520 wurden mit 0,5 mM IPTG bei logarithmischem Wachstum in $\mathrm{LB} / \mathrm{Amp}(\mathrm{Kan})$ induziert. Zu verschiedenen Zeitpunkten wurde die $\mathrm{OD}_{600}$ photometrisch bestimmt. Es ist kein wachstumshemmender Einfluß durch die Induktion der HDAC1-Expression zu erkennen. Die Klone mit pUBS520 coexprimieren zusätzlich eine tRNA für 2 seltene Arginincodons. 

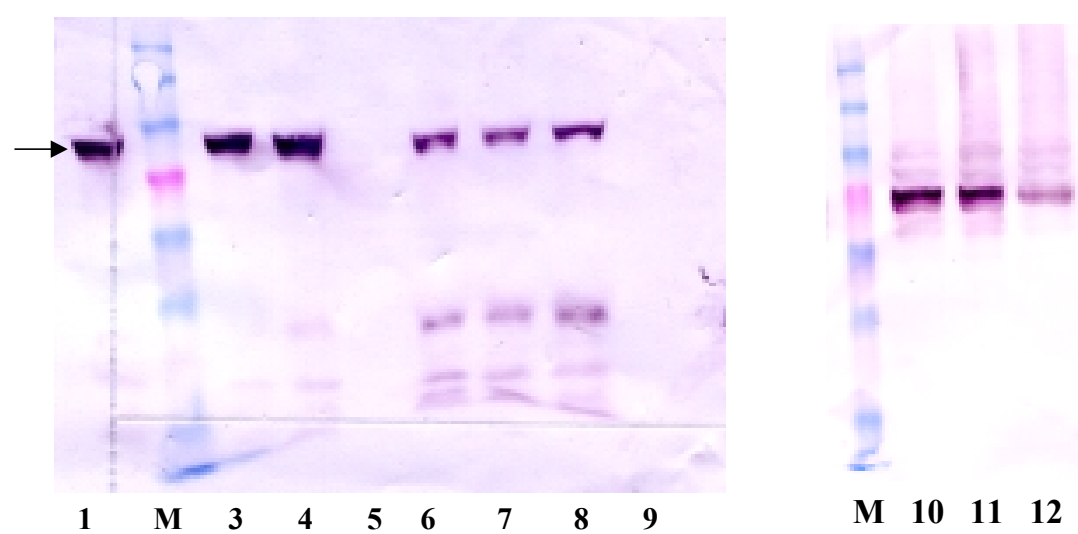

Abb. 22: Immunodetektion der HDAC1 mit C-terminalem Hexahistidin-tag mit Anti-TetraHIS-AK bzw. Anti-HDAC1-AK in Lysaten von HB101-Expressionskulturen mit und ohne Coexpression der Arginin-tRNA.

Je 3 Klone von HB101-pQEHDAC1CHIS und HB101-pQEHDAC1CHIS-pUBS520 wurden mit 0,5 mM IPTG bei logarithmischem Wachstum in $\mathrm{LB} / \mathrm{Amp}(/ \mathrm{Kan})$ induziert. Zu verschiedenen Zeitpunkten (hier beispielsweise 4,5 h nach Induktion) wurden Aliquots entnommen und die HDAC1 (Pfeil) im löslichen Anteil der Lysate mittels Western Blot analysiert. Als Kontrolle wurde ein mit dem Leervektor transformierter Klon mitgeführt. Die Klone mit pUBS520 coexprimieren zusätzlich eine tRNA für 2 seltene Arginincodons. Der linke Blot (Spuren 1-9) wurde mit Anti-TetraHIS-AK, der rechte Blot (Spuren 10-12) mit Anti-HDAC1-AK entwickelt. M: Prestained Marker (MBI) 10 - $160 \mathrm{kDa}$, 1, 3, 4, 10, 11: HB101-pQEHDAC1CHIS Klone, 5, 12: HB101-pQE70-pUBS520, 6-8 : HB101pQEHDAC1CHIS-pUBS520 Klone.

\subsubsection{Expression einer C-terminal verkürzten HDAC1-Variante}

Die einzig in E. coli bislang erfolgreich in aktiver Form exprimierten HDAC-ähnlichen Enzyme, HDLP aus A. aeolicus und die humane HDAC8 (Finnin et al., 1999; Hu et al., 2000), besitzen im Gegensatz zu HDAC der Klasse 1 keinen stark sauren und geladenen C-terminalen Bereich, den auch die HDAC1 des Menschen auszeichnet (Abb. 23, (Buggy et al., 2000). 

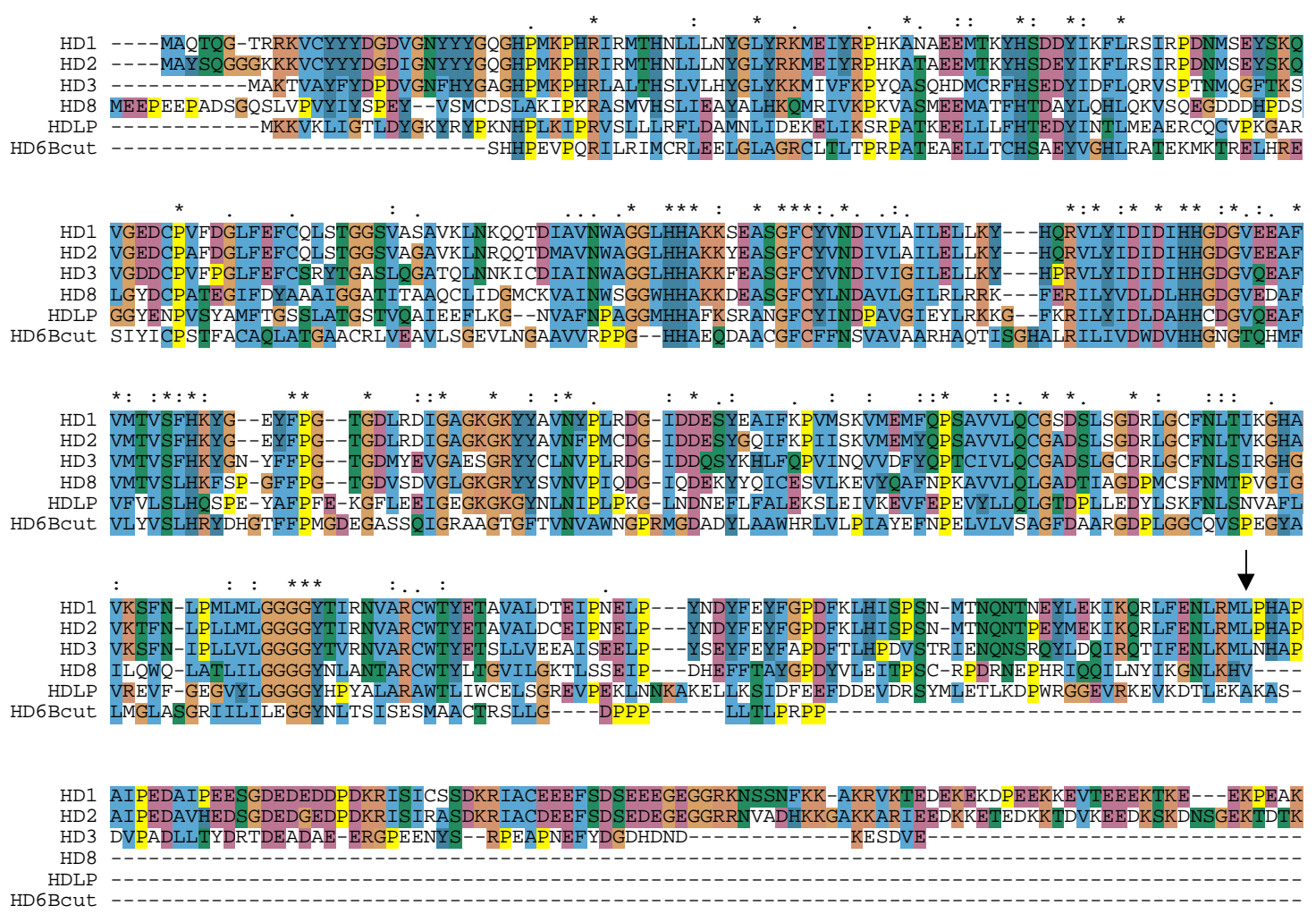

Abb. 23: Alignment der Primärsequenzen von humaner HDAC1 und HDAC8.

Mit dem Programm ClustalW wurden die Aminosäuresequenzen von HDAC1 (HD1), HDAC2 (HD2), HDAC3 (HD3) und der C-terminalen aktiven Domäne der HDAC6 (HD6Bcut) des Menschen mit der von HDAC8 (HD8) und der des bakteriellen Enzyms HDLP verglichen. Im Gegensatz zu HDAC1-3 tragen HDLP und HDAC8 keinen C-terminalen Schwanz mit gehäuft positiven und negativen Ladungen. Die Position 373 von HDAC1 ist durch einen Pfeil markiert.

Möglicherweise interferiert diese Ladungsballung mit der Faltung des Enzyms in E. coli oder stört auf irgendeine Weise die Expression in der Wirtszelle. Um dies zu überprüfen, wurde eine Variante ohne diesen Bereich erstellt. Dazu wurde mittels PCR mit pQEHDAC1CHIS als Template und dem Primerpaar HDAC1Repfor und HDAC1deltaCXHrev ein Konstrukt amplifiziert, das für die Aminosäuren 1 - 373 der HDAC1 und einen C-terminalen Hexahistidin-tag mit vorangestellter Erkennungssequenz für Faktor Xa codiert. Das PCR-Produkt wurde in pCR4TOPO subkloniert. Über die in der PCR angefügten Schnittstellen für HincII und HindIII konnte es in den ebenso geöffneten pQEHDAC1CHIS kloniert werden. Mit dem entstandenen und durch Sequenzierung überprüften Vektor pQEHDAC1dCHIS wurden die bereits angeführten vier Expressionsstämme transformiert. In Pilotexpressionen konnte mittels Western Blot mit einem gegen den Hexahistidin-tag gerichteten primären 
Antikörper zwar die Produktion der verkürzten HDAC1-Variante nachgewiesen werden (Abb. 24), aber Standard-HDAC-Assays mit $200 \mu \mathrm{M}$ Boc-Lys(Ac)-AMC bzw. Tos-GPK(Ac)AMC zeigten keine HDAC-Aktivität.

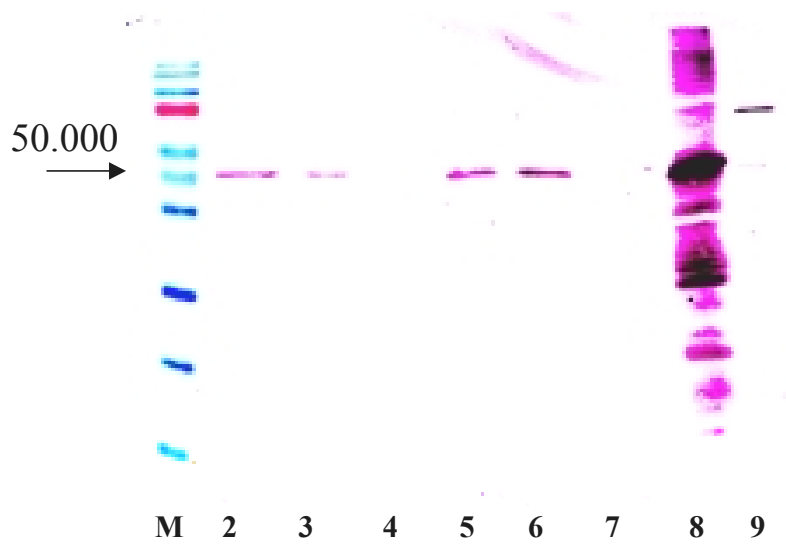

Abb. 24: Nachweis der Expression der C-terminal verkürzten HDAC1 (HDAC1dCHIS) in XL-1Blue durch Immunoblot mit Anti-PentaHis-AK.

Eine C-terminal verkürzte HDAC1 mit C-terminalem Hexahistidin-tag wurde in XL1-Blue exprimiert und die Zellen mittels Ultraschall aufgeschlossen. Der lösliche Anteil des Lysats wurde mittels SDSPAGE aufgetrennt und geblottet. Der Nachweis des rekombinanten Enzyms erfolgte immunologisch über Anti-PentaHis-Ak und einen AP-gekoppelten, sekundären AK durch die NBT/BCIP-Reaktion. M: Prestained Marker (MBI) 10-160 kDa, 2 und 3 : Klon 1 bzw 2 nach 2,5 h induziertem Wachstum, 4 : Klon mit Leervektor, 2,5 h ind. gewachsen, 5 und $6:$ Klon 1 bzw. 2, 22 h induziert gewachsen, 7: Klon mit Leervektor, nach 22 h, 8 : Gesamtzelllysat von Klon 1, 9 : Positiv-Kontrolle (WPA mit HIS-tag).

\subsubsection{Expression einer HDAC1-Variante ohne His-tag}

Ein HDAC1-Konstrukt voller Länge, aber ohne einen tag, wurde durch Klonierung eines durch Spaltung mit NdeI freigesetzten Fragmentes aus pQEHDAC1NHIS in den mit NdeI geöffneten Vektor pQEHDAC1CHIS erschaffen. Dabei konnte auf eine Abtrennung der jeweiligen nicht erwünschten Fragmente der Restriktionsverdaus verzichtet werden, da beide Vektoren zusätzlich zum Schnitt im Gen für HDAC1 im Replikationsursprung geschnitten wurden und daher nur Ligate aus der Fusion der gewünschten Fragmente mit der korrekten Orientierung nach Transformation im Wirt propagiert werden konnten. Pilotexpressionen mit dem durch Sequenzierung überprüften resultierenden Expressionsvektor pQEHDAC1otag in HB101-Zellen wiesen in Standard-HDAC-Assays mit Boc-Lys(Ac)-AMC aber ebenfalls keinerlei Deacetylase-Aktivität auf. 


\subsubsection{Klonierung der humanen HDAC8 und heterologe Expression in E. coli}

Da die humane HDAC1 in E. coli nicht in aktiver Form exprimiert werden konnte, wurde die Produktion von humaner HDAC8 angegangen. Für dieses Enzym ist eine erfolgreiche heterologe Expression in E. coli bereits belegt ( $\mathrm{Hu}$ et al., 2000). Auch dieses menschliche Enzym ist eine wertvolle Referenz bei Untersuchungen der Selektivität von HDACI und sollte als weiteres Beispielenzym neben der FB188-HDAH die generelle Anwendbarkeit des neuen Assays belegen. Ein weiterer Anreiz, sich näher mit diesem Enzym zu befassen, war durch auffallend wenige biochemischen Daten z. B. hinsichtlich der Substratspezifität oder der Funktion in vivo gegeben.

Die für HDAC8 codierende cDNA wurde mit den Primern HDAC8pQEEcoRIfor und HDAC8XaHISrev mittels PCR aus einer cDNA-Bibliothek aus humanem Lebergewebe amplifiziert, in pCR4TOPO zwischenkloniert und dann über EcoRI und HindIII in den Expressionsvektor pQE70 umkloniert. Die HDAC8 trägt C-terminal einen RGSHis $_{6}$ tag, dem eine Faktor Xa-Prozessierungssequenz voransteht. Da bei der Sequenzierung des Vektors eine Punktmutation endeckt wurde, die zu dem Aminosäureaustausch Val282Ala der HDAC8 führte, wurde dieser Austausch nach der Quik-Change-Methode (Li and Wilkinson, 1997; Wang and Malcolm, 1999; Wang and Malcolm, 2002) rückgängig gemacht. Dazu wurden in einer PCR die die Schadstelle überlappenden und zueinander völlig komplementären Primer QCM-HD8for und QCM-HD8rev mit dem Plasmid pQEHDAC8V282A als Matritze verwendet. 


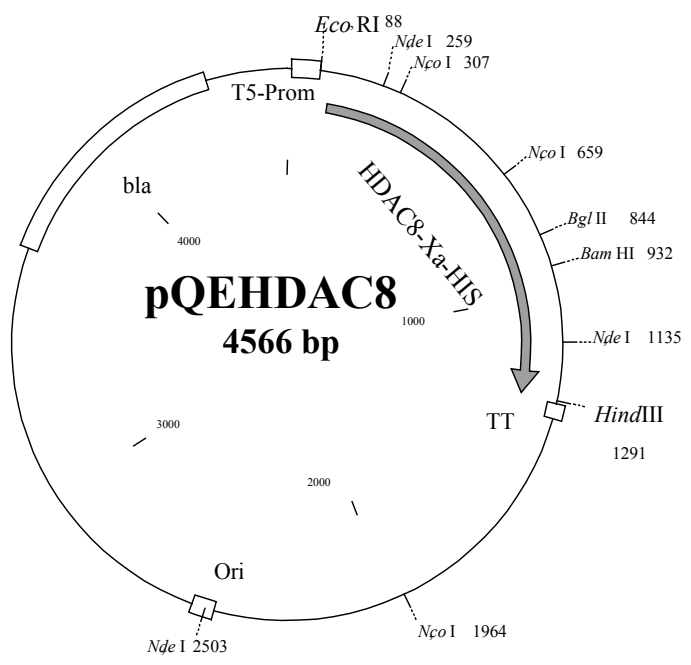

Abb 25: Vektorkarte des Expressionsvektors pQEHDAC8.

Dieser diente zur heterologen Produktion von humaner HDAC8 mit einem C-terminalen His ${ }_{6}$-tag und einer Faktor Xa-Spaltstelle. T5-Prom, T5-Promotor mit Lac-Operatorregion; bla, $\beta$-Laktamasegen für die Ampicillinresistenz; ori, Replikationsursprung ColE1.

Eine Testexpression wurde mit durch den korrekten Vektor pQEHDAC8 (Abb. 25) transformierten XL1-Blue-Zellen unternommen, indem mit $50 \mu \mathrm{l}$ aus einer $4 \mathrm{ml}$ Vorkultur $50 \mathrm{ml} \mathrm{dYT/Amp} \mathrm{angeimpft} \mathrm{und} \mathrm{nach} 3 \mathrm{~h}$ bei einer $\mathrm{OD}_{600}$ von ca. 0,4 mit $1 \mathrm{mM}$ IPTG induziert wurde. Nach $3 \mathrm{~h}$ und $20 \mathrm{~h}$ wurden Aliquots abgenommen, per Ultraschall aufgeschlossen, durch SDS-PAGE (12,5\% PAA) aufgetrennt und mittels Immunoblot mit Anti-PentaHis-AK ( $1: 3000)$ analysiert (Abb. 26), wobei sich in einer Bande bei $\mathrm{M}_{\mathrm{r}} \sim 50000$ die exprimierte HDAC8 $\left(\mathrm{M}_{\mathrm{r}}: \sim 45240\right.$, (Hu et al., 2000) nachweisen ließ.

Ein HDAC-Aktivitätstest der löslichen Lysatfraktion mit Boc-Lys(Ac)-AMC bzw. AcRGK(Ac)-AMC als Substrat bestätigte, daß die HDAC8 in aktiver Form produziert werden konnte (als Kontrolle diente ein mit dem Leervektor pQE70 transformierter Stamm). 


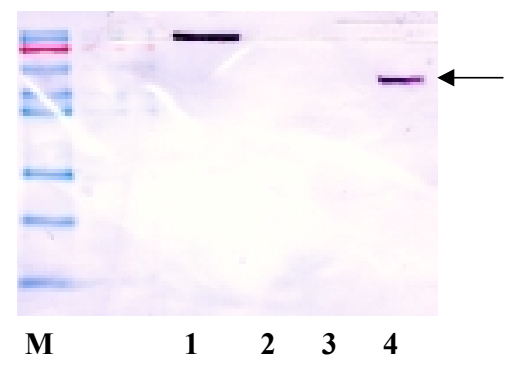

\begin{abstract}
Abb. 26: Immunodetektion der in XL1-Blue exprimierten, rekombinanten HDAC8 mit Anti-PentaHis-tag-AK.

Eine Pilotexpression von XL1-Blue-pQEHDAC8 wurde in $50 \mathrm{ml} \mathrm{LB/Amp} \mathrm{unternommen.} \mathrm{Als} \mathrm{Kontrolle}$ wurde ein mit dem Leervektor transformierter Stamm mitgeführt (XL1-Blue-pQE70). Nach Sonifizierung der Zellen wurde die lösliche Lysatfraktion per SDS-PAGE aufgetrennt und geblottet. Der Nachweis des rekombinanten Enzyms (Pfeil, $\mathrm{Mr} \sim 50000$ ) erfolgte immunologisch über Anti-PentaHis-AK und einen AP-gekoppelten, sekundären AK durch die NBT/BCIP-Reaktion. M: Prestained Marker (MBI) 10$160 \mathrm{kDa}, 1$ : Penicillin-Acylase (WPA) mit His-tag als Positivkontrolle (Ninkovic et al., 2001), 2 : FB188-HDAH mit N-terminalem Strep-tag, 3: XL1-Blue-pQE70, 4: XL1-Blue-pQEHDAC8.
\end{abstract}

\title{
4.3.3 Aufreinigung mittels Affinitätschromatographie an immobilisierten Metallionen (IMAC)
}

Mittels Affinitätschromatographie an immobilisierten Metallionen (Immobilized metal ion affinity chromatography, IMAC, (Porath et al., 1975)) lassen sich Proteine, die einen Hexahistidin-tag tragen, recht effektiv und schnell z. B. aus dem Lysat einer Expressionskultur isolieren (Sulkowski, 1985).

Für die Gewinnung der HDAC1 wurde mit HB101-pEHDAC1CHIS, einem Klon, für den die Pilotexpression gezeigt hatte, daß er HDAC1 mit C-terminalem His-tag produzierte, eine Expression in $50 \mathrm{ml} \mathrm{LB} / \mathrm{Amp}$ durchgeführt wie bereits beschrieben. Nach dem Aufschluß der geernteten und in 2 ml IMAC-Puffer I resuspendierten Zellen mittels Ultraschall wurden Zelltrümmer durch Zentrifugation entfernt und der Überstand des Lysates auf eine mit Nickel beladene und mit IMAC-Puffer I äquilibrierte Chelating-Sepharose-Säule (SV ca. $1 \mathrm{ml}$ ) geladen und der Durchfluß aufgefangen. Nach dem Wegwaschen nicht-bindender Proteine mit IMAC-Puffer I wurde HDAC1 mit einem Stufengradienten steigender Imidazol-Konzentration in IMAC-Puffer I eluiert. Alle Fraktionen wurden mittels Immunoblot mit Anti-TetraHistag-AK untersucht. Das Ergebnis ist in Abbildung 27 gezeigt. HDAC1 eluierte vor allem bei 100 - $200 \mathrm{mM}$ Imidazol. Da schon das Lysat im HDAC-Assay keine Deacetylase-Aktivität aufwies, wurde auf eine Dialyse und Enzymtests mit den Fraktionen verzichtet. 


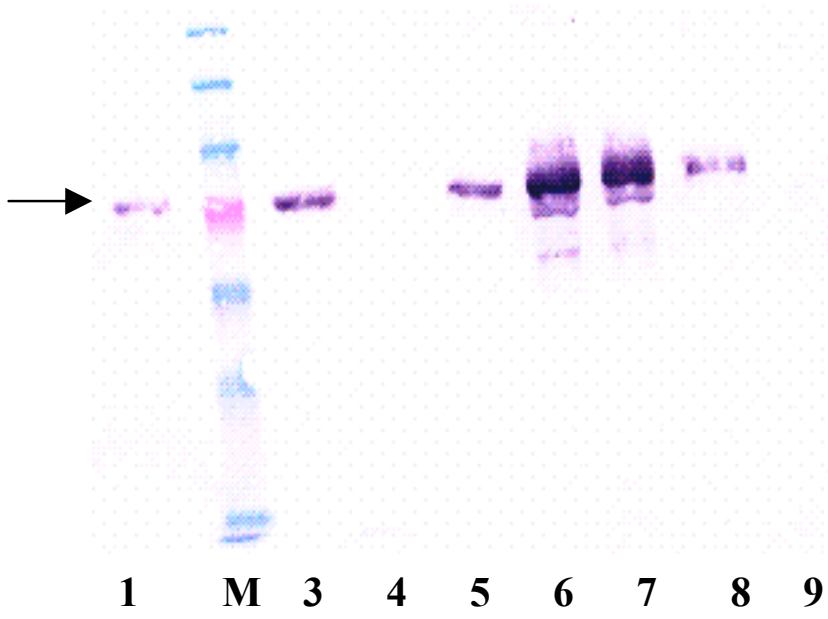

\begin{abstract}
Abb. 27: Immunochemischer Nachweis der Aufreinigung der HDAC1 mit C-terminalem Hexahistidin-tag über IMAC.

HDAC1 mit C-terminalem Hexahistidin-tag wurde in HB101 exprimiert und die Zellen mittels Ultraschall aufgeschlossen. Der lösliche Anteil des Lysats wurde auf eine IMAC-Säule geladen und das Enzym mit einem Stufengradienten steigender Imidazol-Konzentration eluiert. Aliquots der Fraktionen wurden mittels SDS-PAGE aufgetrennt und geblottet. Der Nachweis des rekombinanten Enzyms (Pfeil, $\mathrm{M}_{\mathrm{r}} \sim 65000$ ) erfolgte immunologisch über Anti-TetraHis-AK und einem AP-gekoppelten, sekundären $\mathrm{AK}$ durch die NBT/BCIP-Reaktion. M: Prestained Marker (MBI) 10-160 kDa, 1: Lysat, 3: Waschfraktion, 4: 40 mM Imidazol, 5: 80 mM Imidazol, 6: 100 mM Imidazol, 7: 200 mM Imidazol, 8: 300 mM Imidazol, 9: $500 \mathrm{mM}$ Imidazol.
\end{abstract}

Zur Gewinnung der humanen HDAC8 sollte zunächst (wie bei der HDAC1) der Cterminale Hexahistidin-tag bei der Aufreinigung an einer mit Nickel beladenen Chelating-Sepharose-Säule ausgenutzt werden. Dazu wurde der lösliche Lysatbestandteil einer 50 ml-Expressionskultur von XL1-Blue-pQEHDAC8 auf eine äquilibrierte IMAC-Säule mit Chelating-Sepharose-Matrix (SV etwa $1 \mathrm{ml}$ ) geladen und der Durchlauf aufgefangen. Nach dem Wegwaschen nicht-bindender Proteine mit HDAC8-Puffer wurde HDAC8 mit einem Stufengradienten steigender ImidazolKonzentration in HDAC8-Puffer eluiert. Alle Fraktionen wurden mittels Immunoblot mit Anti-PentaHis-tag-AK untersucht. Das Ergebnis ist in Abbildung 28 gezeigt. HDAC8 $\left(\mathrm{M}_{\mathrm{r}} \sim 45000\right)$ eluierte vor allem bei $100-200 \mathrm{mM}$ Imidazol. Diese Fraktionen wurden gepoolt und über Nacht gegen HDAC8-Puffer dialysiert. Mit dem HDACAssay konnte jedoch nur beim Lysat $(50 \mu \mathrm{l})$ eine Deacetylase-Aktivität mit $150 \mu \mathrm{M}$ Boc-Lys(Ac)-AMC als Substrat festgestellt werden. Ein Western Blot der dialysierten Fraktionen mit Anti-PentaHis-tag-AK bestätigte das Vorhandensein der HDAC8 auch nach der Dialyse (Daten nicht gezeigt). Alternativ wurde die IMAC-Aufreinigung mit 
einer Zink-beladenen Säule wiederholt, um eventuell durch die Säule herausgereinigtes Zink des aktiven Zentrums zu ersetzen. Auch hier konnte nur im Lysat eine Deacetylase-Aktivität detektiert werden. Ein Versuch, das eventuell verlorene Zink nach der Dialyse wieder zuzusetzen, erbrachte bei 1 bzw. $10 \mathrm{mM} \mathrm{ZnCl}_{2}$ ebenfalls keine Rekonstitution der Enzymaktivität. Desweiteren wurde durch Umpuffern des Eluates mit Hilfe von wiederholter Zentrifugation und Auffüllen mit HDAC8-Puffer in Microcon-Filtrationssäulchen das Imidazol entfernt. Aber auch danach war keine Enzymaktivität zu verzeichnen, obwohl die Kontrolle mittels Western Blot den Verbleib der HDAC8 im Filterüberstand anzeigte (Daten nicht gezeigt). Wahrscheinlich wird die Struktur der HDAC durch die Bindung an das Säulenmaterial irreversibel zerstört und/oder das Zink aus dem aktiven Zentrum entfernt, welches dann auch nicht mehr nachträglich eingefügt werden kann. Diese Befunde stehen im Widerspruch zu der erfolgreichen Aufreinigung der HDAC8 über Ni-NTA-Säulchen in aktiver Form durch Hu und Mitarbeiter (Hu et al., 2000). Im Unterschied zu Ni-NTA, das einen 4-zähnigen Komplexbildner darstellt und Nickel über 4 Stellen komplexiert, bindet der 3-zähnige Chelator Iminodiacetylsäure Nickel-Liganden über 3 Koordinationsstellen, womit 3 weitere des Nickel-Ions frei zur Bindung der Histidine des Proteintags bleiben (Hochuli, 1989; Porath et al., 1975). So könnte ein weiterer Grund für den Verlust der Aktivität bei der Aufreinigung in der leichteren Abgabe des Nickel-Ions von der IminodiacetylGruppe in die Enzymlösung und eine folgende irreversible Hemmung der HDAC sein.

Der Einsatz dieser Säulchen bei weiteren Aufreinigungsversuchen zeigte nach Dialyse der Eluate ü. N. gegen HDAC8-Puffer und ihrer Überprüfung mit $150 \mu \mathrm{M}$ BocLys(Ac)-AMC in HDAC-Assays, daß damit HDAC8 tatsächlich in aktiver Form bei 200 mM Imidazol eluiert werden konnte und die verwendete Matrix offensichtlich von ausschlaggebender Bedeutung ist (Daten nicht gezeigt). 


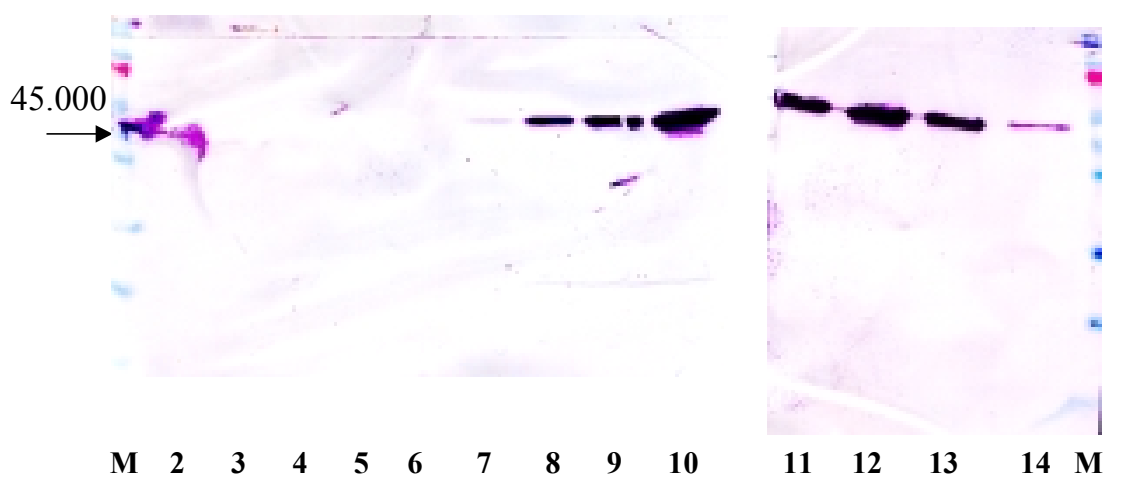

\begin{abstract}
Abb. 28: Immunochemischer Nachweis der Aufreinigung der HDAC8 mit C-terminalem Hexahistidin-tag über IMAC.

HDAC8 mit C-terminalem Hexahistidin-tag wurde in XL1-Blue exprimiert und die Zellen mittels Zelldisruptor aufgeschlossen. Der lösliche Anteil des Lysats wurde auf eine IMAC-Säule geladen und das Enzym mit einem Stufengradienten steigender Imidazol-Konzentration eluiert. Aliquots der Fraktionen wurden mittels SDS-PAGE aufgetrennt und geblottet. Der Nachweis des rekombinanten Enzyms erfolgte immunologisch über Anti-PentaHis-AK und einem AP-gekoppelten, sekundären AK durch die NBT/BCIP-Reaktion. M: Prestained Marker (MBI) 10-160 kDa, 2 : Lysat, 3 : Durchlauf, 4, 5 : Waschfraktionen, $6: 20 \mathrm{mM}$ Imidazol, $7: 40 \mathrm{mM}$ Imidazol, $8: 60 \mathrm{mM}$ Imidazol, $9: 100 \mathrm{mM}$ Imidazol, 10: 200 mM Imidazol, 11: 100 mM Imidazol, 12: 200 mM Imidazol, 13: 300 mM Imidazol, 14: $500 \mathrm{mM}$ Imidazol.
\end{abstract}

\title{
4.3.4 Aufreinigung mittels Anionenaustauschchromatographie
}

Da die Aufreinigung der HDAC8 über IMAC zunächst fehlgeschlagen war, erfolgte im weiteren eine Aufreinigung dieses Enzyms mittels Anionenaustausch-Chromatographie an einer Poros 20 HQ-Säule (quartäre Polyethylenimingruppen, SV ca. 7,8 ml) mit Hilfe einer Perfusionschromatographieeinheit. Im Vergleich zur IMAC konnte mit dieser Methode zwar nur eine partielle Reinigung realisiert werden, diese war aber ausreichend, um störende Medienbestandteile und einen großen Teil der Wirtsproteine zu entfernen, und hinreichend für die Enzymtests mit dem fluorogenen HDAC-Assay.

Mit einer Vorkultur von XL1-Blue-pQEHDAC8 wurde 11 LB-Medium mit Ampicillin in einem 3 1-Schikanekolben angeimpft und nach Erreichen einer $\mathrm{OD}_{600}$ von 0,6 mit $1 \mathrm{mM}$ IPTG induziert. Nach weiteren $16 \mathrm{~h}$ wurden die Zellen bei einer $\mathrm{OD}_{600}$ von etwa 4 geerntet und nach Resuspendierung in 50 ml HDAC8-Puffer I mit einem Zelldisruptor aufgeschlossen. 5-15 ml der per Zentrifugation geklärten und filtrierten, löslichen Lysatfraktion wurde auf den Anionenaustauscher geladen und die nicht-bindenden Lysatbestandteile weggewaschen. HDAC8 wurde mit einem linearen Salzgradienten von $0-1,8 \mathrm{M} \mathrm{NaCl}$ bei etwa $300 \mathrm{mM}$ eluiert (Abb. 29). Eluat-Fraktionen mit einer erhöhten $\mathrm{OD}_{280}$ wurden im HDAC-Assay mit $150 \mu \mathrm{M}$ Boc-Lys(Ac)-AMC vermessen 
und teilweise per Western Blot mit Anti-PentaHis-AK (1:5000) bzw. CoomassieFärbung analysiert (Abb. 31), um eine Abschätzung der Reinheit der Enzymfraktionen zu ermöglichen. Die aktivsten Fraktionen (Abb. 30) wurden zusammengeführt und ohne weitere Aufreinigung als HDAC8-Enzymlösung für alle Assays verwendet. Eine Lagerung dieser Enzym-Lösung von bis zu 3 Tagen in HDAC8-Puffer I mit $10 \%$ Glyzerin bzw. bis zu 7 Tagen in HDAC8-Puffer I ohne Glyzerin war mit weniger als $50 \%$ igem Aktivitätsverlust bei $+8{ }^{\circ} \mathrm{C}$ möglich.

Die HDAC8-Aktivität wie auch die HDAC8-Signale des Immunoblots konnten keinem reinen 'HDAC8-Peak' des Chromatogramms zugeordnet werden. Allerdings war die erzielte Abreicherung an Wirtsproteinen und sonstigen Stoffen hinreichend, um das Enzym ohne nennenswerten Hintergrund in HDAC-Assays einsetzen zu können.

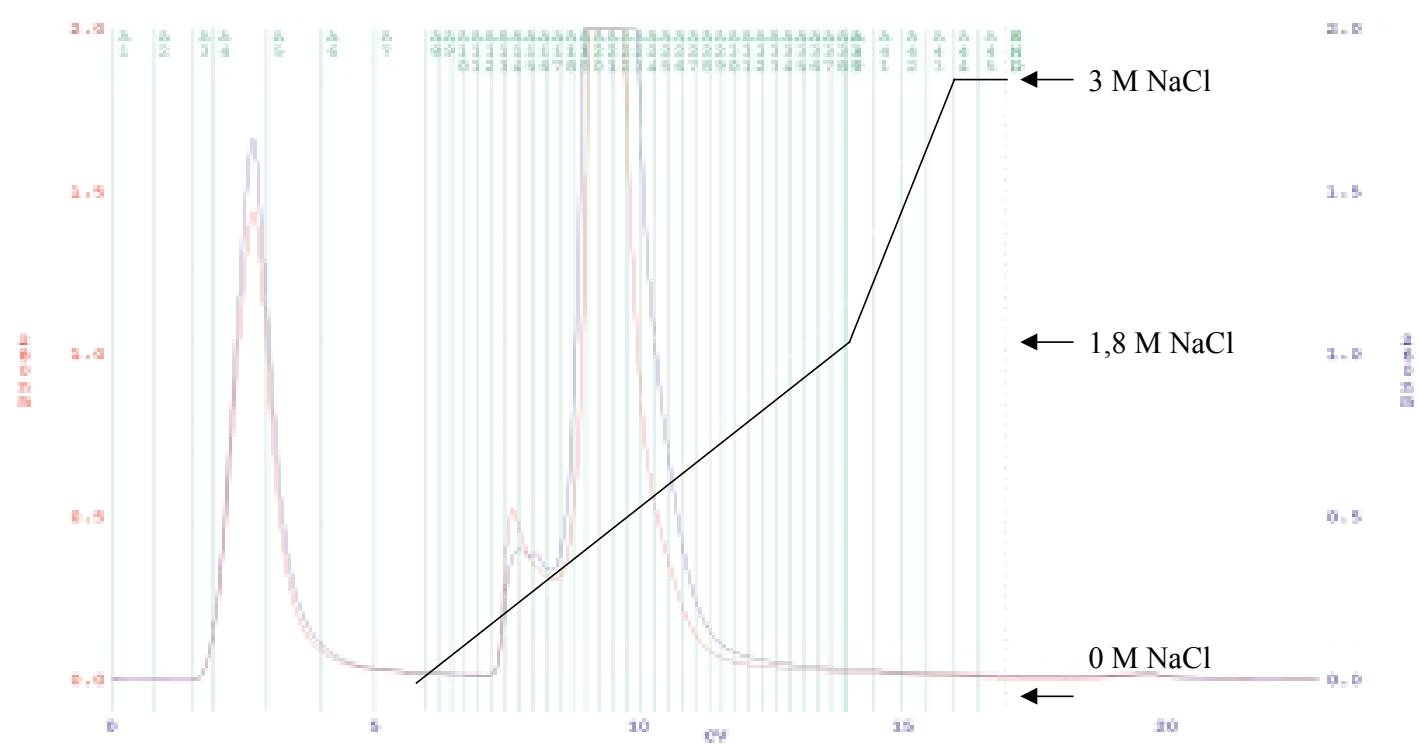

Abb. 29: Chromatogramm der Aufreinigung von HDAC8 aus E. coli-Zelllysat über einen Anionenaustauscher.

$15 \mathrm{ml}$ mittels Zelldisruptor aufgeschlossenes und per Zentrifugation geklärtes Lysat einer Expressionskultur von XL1-Blue-pQEHDAC8 wurde auf eine Poros 20 HQ-Anionenaustauschersäule (SV ca. 7,8 ml) geladen. Nach Waschen mit 4 SV HDAC8-Puffer wurde HDAC8 mit einem linearen $\mathrm{NaCl}-G r a d i e n t e n$ (graue Linie) bei ca. $300 \mathrm{mM}$ in Fraktionen von je $2 \mathrm{ml}$ eluiert. Die Extinktion des Eluates wurde bei 260 und $280 \mathrm{~nm}$ (blaue bzw. rote Kurve) photometrisch vermessen. 


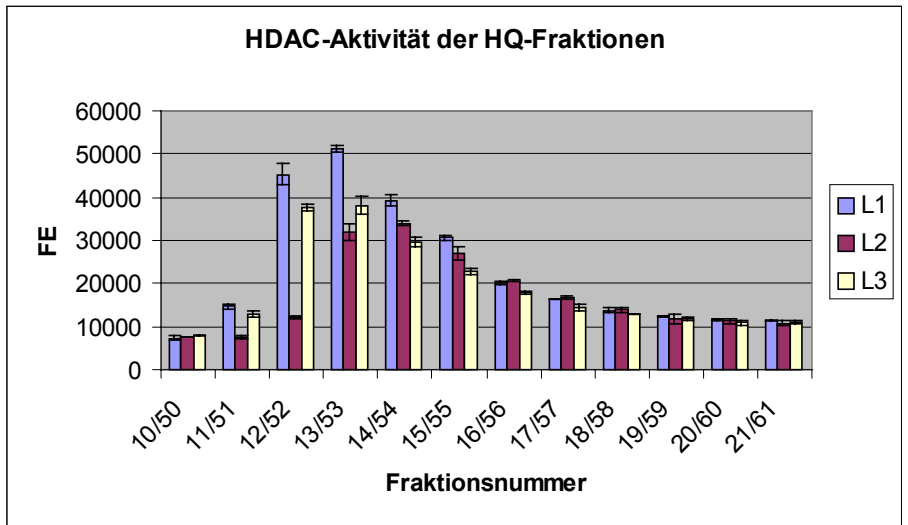

Abb. 30: HDAC-Aktivitäten einiger Fraktionen des Anionenaustauschers.

$50 \mu 1$ einiger Fraktionen aufeinander folgender Aufreinigungen (L1, L2, L3: Läufe1-3) wurden parallel mit dem fluorogenen HDAC-Assay mit $150 \mu \mathrm{M}$ Boc-Lys(Ac)-AMC vermessen. Bei den Hintergrundkontrollen wurde dem Ansatz Trypsin vor dem Substrat zugesetzt und die erhaltenen Fluoreszenzeinheiten vom Signal der jeweiligen Fraktion subtrahiert. Die resultiernden Fluoreszenzen für die einzelnen Fraktionen (in relativen Einheiten, FE) sind angegeben.

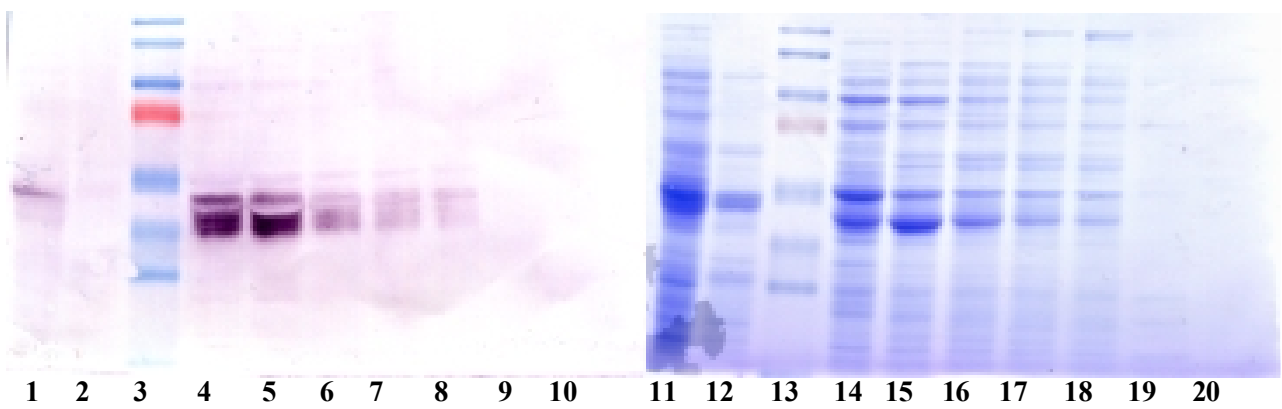

Abb. 31: Immunodetektion der HDAC8 in den Fraktionen des Anionenaustauscher mit einen AntiPentaHis-AK und Abschätzung des Aufreinigungseffektes über Coomassie-Färbung.

Je $20 \mu \mathrm{l}$ einiger Fraktionen des Anionenaustauschers wurden per SDS-PAGE (12\% PAA) aufgetrennt und die gesamten Proteine im Gel mit Coomassie Brilliant Blue R250 angefärbt bzw. mittels Western Blot mit Anti-PentaHIS-AK die HDAC8 darin nachgewiesen. 3 und 13: Prestained protein marker (MBI); 1 und 11: Lysat; 2 und 12: Durchlauf; 4 und 14: Fraktion \# 12; 5 und 15: \# 13; 6 und 16: \# 14; 7 und 17: \# 15; 8 und 18: \# 16; 9 und 19: \# 22; 10 und 20: \# 29.

\subsection{Substratspezifität der Histondeacetylasen}

Während mittlerweile recht zahlreiche Publikationen immer neue und meist potente HDACI präsentieren, sind doch erstaunlich wenig Isotypen-spezifische Inhibitoren darunter, und bemerkenswert wenig ist bislang über die Substratspezifität und Untersuchungen zum Katalysemechanismus der HDAC veröffentlicht worden. Eine 
abweichende Präferenz der untersuchten HDAC für diverse Substrate könnte wertvolle Hinweise für die Entwicklung von selektiven Inhibitoren liefern. So wäre es gegebenenfalls möglich, neben der Diversität der Aminosäuresequenzen am Rand des zum Katalysezentrum führenden Tunnels durch spezielles Design der Kappen der HDACI auch die unterschiedlichen räumlichen Gegebenheiten direkt am Katalysezentrum auszunutzen.

\subsubsection{Inhibition durch putative Übergangszustandsmimetika}

Finnin und Mitarbeiter leiteten aus der Röntgenstruktur des bakteriellen HDACähnlichen Enzyms HDLP aus Aquifex aeolicus im Komplex mit den Inhibitoren TSA bzw. SAHA einen potentiellen Katalysemechanismus ab, den sie an jenen der ZinkMetalloproteasen und Serinproteasen anlehnten (Finnin et al., 1999). Nach diesem Modell kommt es kurz vor der Spaltung der Amidbindung zur Ausbildung eines tetrahedralen Übergangszustandes am Carbonyl-Kohlenstoffatom mit Kontakten des Oxyanion-Intermediates zur Hydroxylgruppe des Tyrosin297 und gleichzeitig zum Zink-Ion am Boden des hydrophoben Tunnels von der Enzymoberfläche zum aktiven Zentrum. Unter der berechtigten Annahme, daß nicht nur die Primärsequenzen sondern auch die Topologien der verschiedenen Enzyme der Deacetylase-Super-Familie (Leipe and Landsman, 1997) konserviert sind, sollten nicht-spaltbare Lysin-Derivate, die diesen tetrahedralen Übergangszustand nachahmen, daher potente HDAC-Inhibitoren sein. Nach der Aufklärung dieser Röntgenstruktur war es jetzt möglich, einen im Vergleich zur reinen Durchmusterung von Molekülbibliotheken mehr rationalen Ansatz zur Entwicklung von HDACI zu verfolgen. Dazu wurden verschiedene, an der $\varepsilon$ Aminogruppe modifizierte Lysin-Derivate von D. Riester synthetisiert (Abb. 32). Darunter befanden sich Spezies, bei denen der Carbonyl-Kohlenstoff durch ein Schwefelatom ersetzt wurde. Auch die Strategie von Kapustin verfolgt diese Richtung, indem Phosphonamidate, Phosphonate und Phosphinate, abgeleitet von der Grundstruktur der SAHA, als tetrahedrale Übergangszustandsanaloga gewählt wurden, da diese mit ihren im Vergleich zu Kohlenstoff-Heteroatom-Bindungen längeren Phosphor-Heteroatom-Bindungen eher den 'gedehnten' Bindungen des Übergangszustandes ähneln (Kapustin et al., 2003). 
Zur Überprüfung der Analogie der HDAC-Reaktion mit dem Mechanismus der ZinkProteasen wurden Standard-HDAC-Assays mit je $150 \mu \mathrm{M}$ der potentiellen Übergangszustandsmimetika und HDAC aus Rattenleber bzw. HDAC8 mit ungehemmten Referenzreaktionen verglichen. Dabei konnte keine potente Hemmwirkung verzeichnet werden. Die stärkste Hemmung der HDAC aus Rattenleber lag bei etwa $20 \%$ durch AcPKAmbs \#5. Bei HDAC8 wurden nur die AcPKAmbs \#1-4 getestet; hier zeigte sich bis $800 \mu \mathrm{M}$ nur bei \#1 überhaupt eine Hemmungwirkung und zwar von etwa 20\%. Auch die Gruppe um Kapustin konnte keine potente Hemmungwirkung ihrer Phosphor-Übergangszustandsmimetika nachweisen $\left(\mathrm{IC}_{50}\right.$ für HDAC8 bei 0,28 - 0,41 mM (Kapustin et al., 2003)). In Konformität damit weisen die hier erhaltenen Ergebnisse auf einen von dem der Zink-Proteasen differierenden katalytischen Mechanismus hin oder zumindest auf eine abweichende Geometrie des Übergangszustandes. 


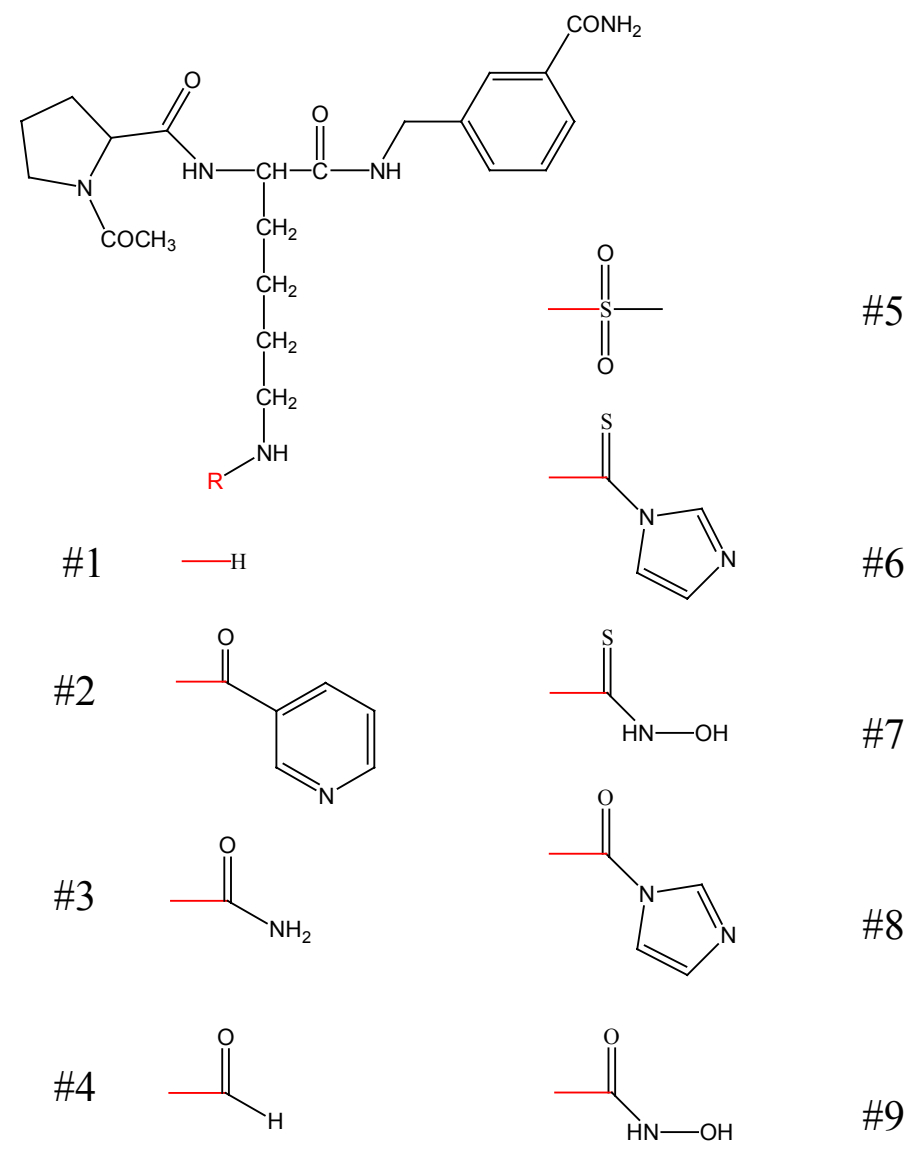

\section{Abb. 32: Darstellung der potentiellen Übergangszustandsmimetika.}

Die potentiellen HDACI sind alle vom Typ Ac-Pro-Lys(R)-3-Ambs. Ein mit dem Rest R an der $\varepsilon$ Aminogruppe modifiziertes Lysin ist peptidisch am N-Terminus mit einem N-acetylierten Prolin und über die Carboxygruppe amidisch mit einem Aminomethylbenzoesäureamid verknüpft. Die unterschiedlichen Reste R sind dargestellt, die Bindung zur gemeinsamen Struktur ist rot kenntlich gemacht. Den zugehörigen Molekülen wurden Nummern zugeordnet.

\subsubsection{Substratspezifität}

Wie die Suche nach Substanzen, die als HDACI wirken, litt auch die biochemische Charakterisierung der Histondeacetylasen unter dem Mangel an geeigneten, nichtradioaktiven, homogenen Enzymtests. So ist beispielsweise bislang nicht einmal für alle bekannten humanen HDAC eine Funktionszuordnung erfolgt oder die Substratspezifität genauer untersucht worden. Dies trifft auch für die HDAC8 des Menschen zu. Versuche mit acetylierten, aus dem Sequenzkontext von Histon 4 abgeleiteten TripeptidSubstraten (4.1.2) wie auch mit einem längeren H4-Peptid (Van den Wyngaert et al., 2000) legen die Vermutung nahe, daß HDAC8 nicht Histone, sondern andere Proteine 
als Substrate erkennt. Eine Möglichkeit, nach den nativen Substraten bzw. Interaktionspartnern $\mathrm{zu}$ fahnden und damit auch bessere Substratpeptide abzuleiten, liegt in der systematischen Testung von Peptidbibliotheken. So könnten z. B. alle Tripeptide $(20$ x $20=400)$ des Typs X-X-Lys(Ac)-AMC auf Umsatz durch HDAC8 untersucht und die besten aus dieser Bibliothek sukzessive N-terminal verlängert werden, um so über eine Datenbanksuche Proteine mit dieser Zielsequenz ausfindig zu machen. Peptide aus dem Kontext der nativen Zielproteine von HDAC8 (wahrscheinliche Kandidaten sind Transkriptionsfaktoren) sollten wiederum zumindest leidliche Substrate abgeben.

Ein anderer Weg, bessere Substrate für HDAC8 zu entwickeln, ist die Synthese von Lysinderivaten, die leichter spaltbar sind und/oder nach Einwirkung der HDAC bessere Abgangsgruppen freisetzen. Solche verbesserten Substrate würden eine Durchmusterung von Molekülbibliotheken nach HDAC8-spezifischen Inhibitoren sehr erleichtern, da die bislang untersuchten Substrate eine zu große Enzymmenge für ein ausreichend großes Fluoreszenzsignal verlangten, was dieses Unterfangen bislang unerschwinglich sein ließ. Zusätzlich wiesen die unter 4.4.1 erhaltenen und in der Literatur beschriebenen Ergebnisse mit potentiellen Übergangszustandsmimetika bzw. -analoga auf eine vom postulierten Mechanismus (Finnin et al., 1999) abweichende Katalyse der Deacetylierung hin (Kapustin et al., 2003; Vanommeslaeghe et al., 2003). Substrate mit der Acetylgruppe sterisch sehr ähnlichen, aber energetisch abweichenden Resten an der ع-Aminogruppe des Lysins könnten als Prüfsteine für den postulierten Katalyse-Mechanismus dienen. So müßte danach beispielsweise ein Rest an der $\varepsilon$-Aminogruppe des Lysins mit einem geringen $\mathrm{pK}_{\mathrm{a}}$ eine gute Abgangsgruppe darstellen und das entsprechende Substrat besser umgesetzt werden als ein Substrat mit vergleichsweise höherem $\mathrm{pK}_{\mathrm{a}}$ der Abgangsgruppe (Tab. 9). Die Untersuchung der Substratspezifität könnte allerdings ebenfalls Erkenntnisse zur Entwicklung von zwischen HDAC-Typen diskriminierenden Substraten liefern. Darüberhinaus könnten so Hinweise über die Geometrie und Ladungsverteilung im aktiven Zentrum für die Entwicklung von selektiven HDACI gewonnen werden.

Zur Untersuchung der Substratspezifität der HDAC im Hinblick auf die Art und Größe der abzuspaltenden Acylgruppe (Tab. 9) an der $\varepsilon$-Aminogruppe des Lysins wurden 
Substrate des Typs Boc-Lys(z)-AMC von D. Riester hergestellt, wobei z eine der in Abbildung 33 dargestellten Acyl-Reste bezeichnet.

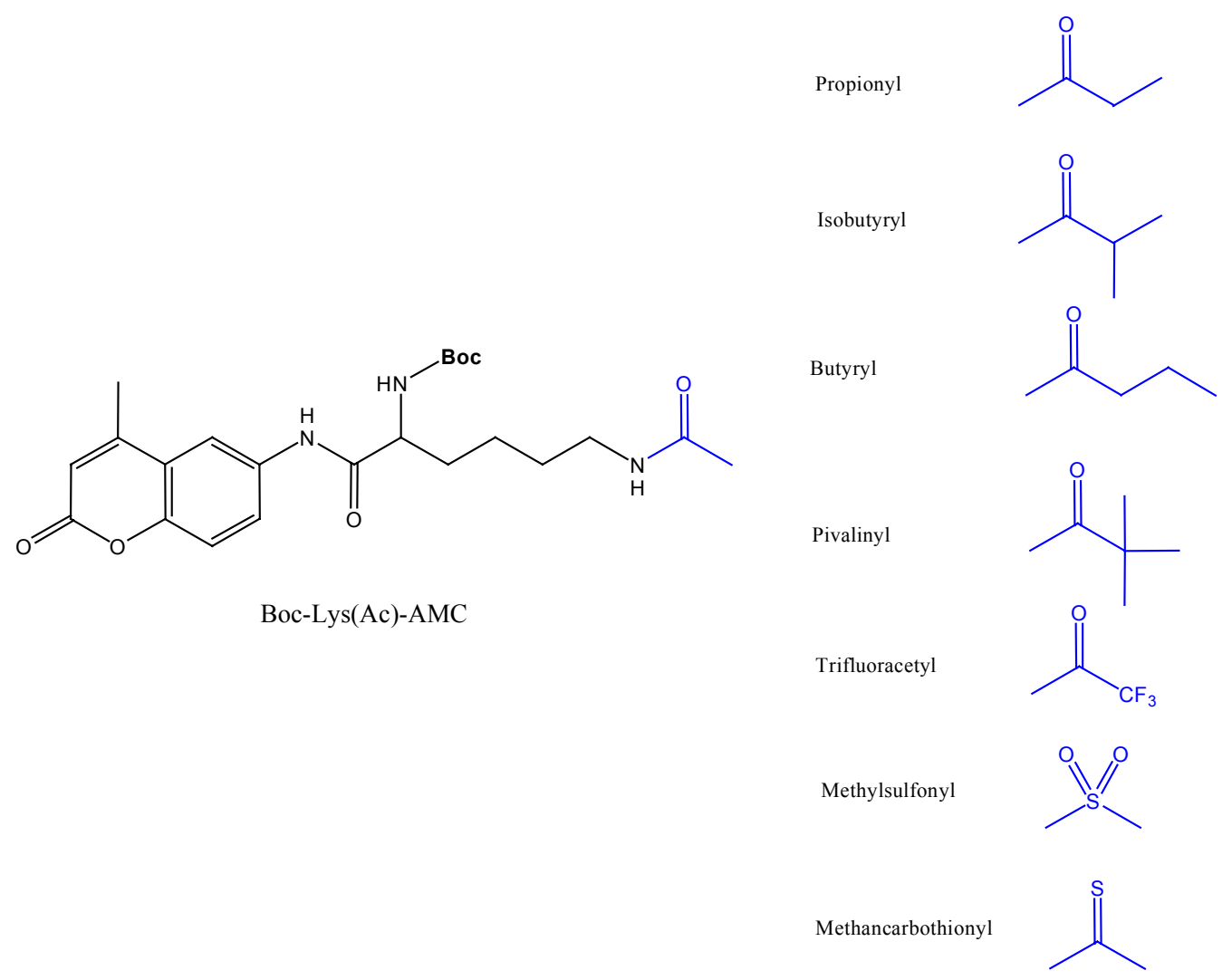

Abb. 33: Darstellung der synthetischen HDAC-Substrate mit unterschiedlichen Acyl-Resten am \&-modifizierten Lysin.

Links ist die Struktur des Substrates Boc-Lys(Ac)-AMC dargestellt, dabei ist der Acyl-Rest, in diesem Fall eine Acetylgruppe, blau gezeichnet. Rechts sind die anderen untersuchten Acyl-Reste dargestellt. 
Tab. 9: Volumina einiger Acylgruppen und $\mathrm{pK}_{\mathrm{a}}$-Werte der Säuren der Abgangsgruppen.

Volumina entnommen aus Xiang, 1998.

\begin{tabular}{|c|c|c|}
\hline Acylgruppe & Molekulares Volumen $\left[\mathbf{n m}^{\mathbf{3}}\right]$ & $\mathbf{p K} \mathbf{a}$ der freien Säure \\
\hline Acetyl- & 0,0612 & 4,76 \\
\hline Propionyl- & 0,0782 & 4,88 \\
\hline Butryl- & 0,0952 & 4,82 \\
\hline Isobutyril- & - & 4,86 \\
\hline Pivalinyl- & 0,1122 & 5,05 \\
\hline Trifluoracetyl- & - & 0,23 \\
\hline
\end{tabular}

Diese wurden mit HDAC aus Rattenleber bzw. heterolog exprimierter HDAC8 in Standard-HDAC-Assays umgesetzt und der Anstieg der Fluoreszenz mit der Zeit vermessen. Dabei wurden die Substrate jeweils 275 bzw. $250 \mu \mathrm{M}$ eingesetzt. Aus Abbildung 34 ist $\mathrm{zu}$ entnehmen, daß HDAC aus der Rattenleber neben dem Referenzsubstrat Boc-Lys(Ac)-AMC auch noch Boc-Lys(Propionyl)-AMC umsetzte, wenn auch merklich schlechter (ca. 50 \%). Substrate mit noch voluminöseren oder gar verzweigten Acylgruppe wurden nicht umgesetzt.

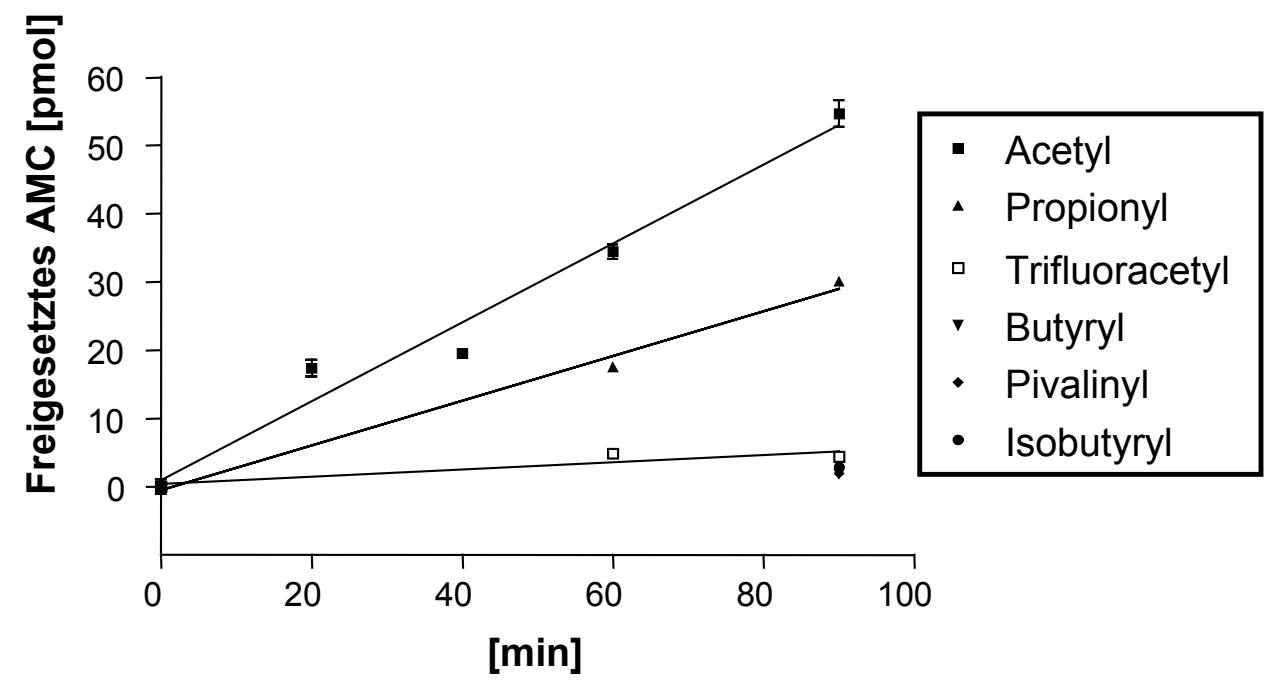

Abb. 34: Umsatzkurven verschiedener synthetischer Substrate für HDAC aus Rattenleber.

Standard-HDAC-Assays wurden mit Substraten durchgeführt, die sich im Acylrest an der $\varepsilon$-Aminogruppe des Lysins unterscheiden, und das freigesetzte AMC über der Zeit aufgetragen. Nur Boc-Lys(Ac)-AMC und Boc-Lys(Prop)-AMC wurden nennenswert umgesetzt. 
In weiteren Experimenten wurden Umsatzkurven aufgenommen, um zu sehen, ob eine Produkthemmung durch die bei der Spaltung der synthetischen Substrate entstehenden Abgangsgruppen bzw. deren Natriumsalze auftritt. Ein hemmender Einfluß auf die HDAC wäre bei höheren Konzentrationen des Salzes zu erwarten, falls eine reversible Amidspaltung nach dem Vorbild der Proteasen vorliegt. Vorab sollten Standard-HDACAssays mit steigenden Konzentrationen an NaAc und NaTFA und $125 \mu \mathrm{M}$ TosGPK(Ac)-AMC bzw. Boc-Lys(Ac)-AMC das Ausmaß des Salz-Effektes auf HDAC aus der Rattenleber bzw. heterolog exprimierter HDAC8 zeigen.
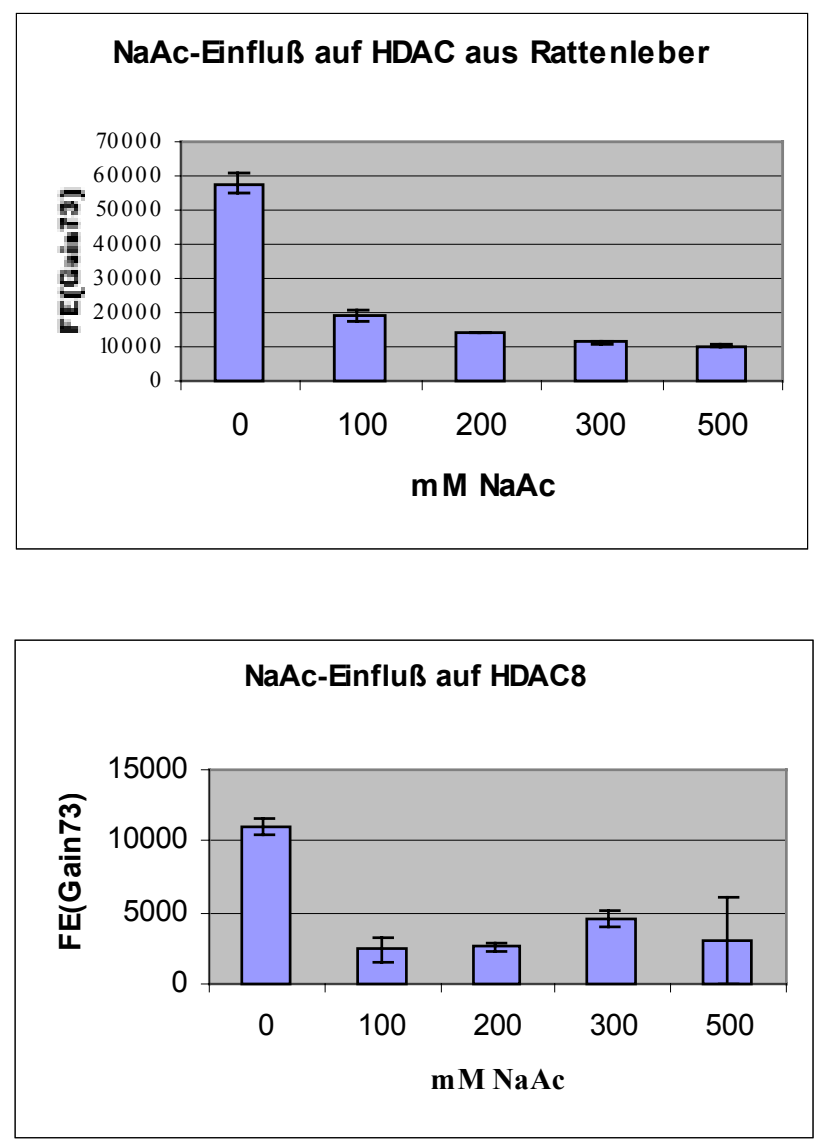

Abb. 35: Einfluß von Salzen auf HDAC.

Standard-HDAC-Assays wurden mit HDAC aus Rattenleber (oben) bzw. HDAC8 (unten) bei unterschiedlichen Konzentrationen an Salzen durchgeführt. Als Beispiel ist hier die Inhibition durch $\mathrm{NaAc}$ anhand der Verminderung der Endpunkt-Fluoreszenz (FE) gezeigt.

Anhand der in Abbildung 35 präsentierten Inhibitionsdiagramme wurden $50 \mathrm{mM} \mathrm{Salz}$ als geeignete Konzentration für die Umsatzkurvenexperimente ausgewählt. Dazu wurden Standard-HDAC-Assays mit $275 \mu \mathrm{M}$ Boc-Lys(Ac)-AMC und $50 \mathrm{mM}$ des 
jeweiligen Natriumsalzes durchgeführt. Abbildung 36 zeigt die erwartete Produkthemmung für HDAC aus Rattenleber tatsächlich nur bei NaAc und NaProp, also den Salzen der beiden einzig umgesetzten Acyl-Lysin-Derivate in Abbildung 34. Die Kontrollreaktionen mit $50 \mathrm{mM} \mathrm{NaCl}$ zeigten wie erwartet keine Hemmung durch etwaige Effekte der Ionenstärke. NaTFA hemmte bis zu einer Konzentration von 300 mM das Enzym nicht.

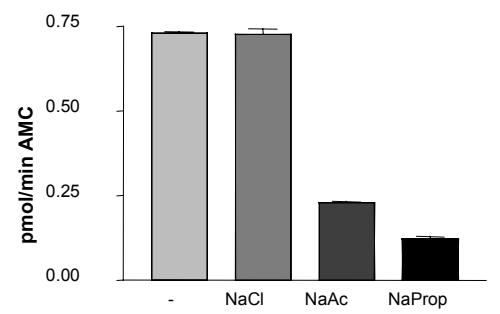

Abb. 36: Hemmung der HDAC aus Rattenleber durch Salze der Abgangsgruppen synthetischer HDAC-Substrate.

Standard-HDAC-Assays wurden mit und ohne Zusatz von $50 \mathrm{mM}$ eines Salzes durchgeführt und jeweils die Umsatzgeschwindigkeit von Boc-Lys(Ac)-AMC verglichen. Nur NaAc und NaProp hemmen das Enzym.

Die Umsatzkurven in Abbildung 38 bezeugen für HDAC8 ein anderes Substratspektrum: Hier wurde neben Boc-Lys(Ac)-AMC besonders gut Boc-Lys(TFA)AMC gespalten. Einige Kontrollen belegten, daß der beobachtete Umsatz von BocLys(TFA)-AMC tatsächlich auf die Aktivität von HDAC8 zurückgeht. So wurde kein Umsatz bei der Inkubation des Substrates mit Lysat-Überständen oder Fraktionen des Anionenaustauschers beobachtet, wenn ein mit dem Leervektor pQE70 transformierter Expressionsstamm unter denselben Bedingungen zur Anzucht und Aufreinigung eingesetzt wurde. Der Umsatz von Boc-Lys(TFA)-AMC war darüberhinaus durch verschiedene HDACI hemmbar (Daten nicht gezeigt). Boc-Lys(Prop)-AMC und BocLys(But)-AMC wurden hingegen nur in sehr geringem Umfang gespalten. 


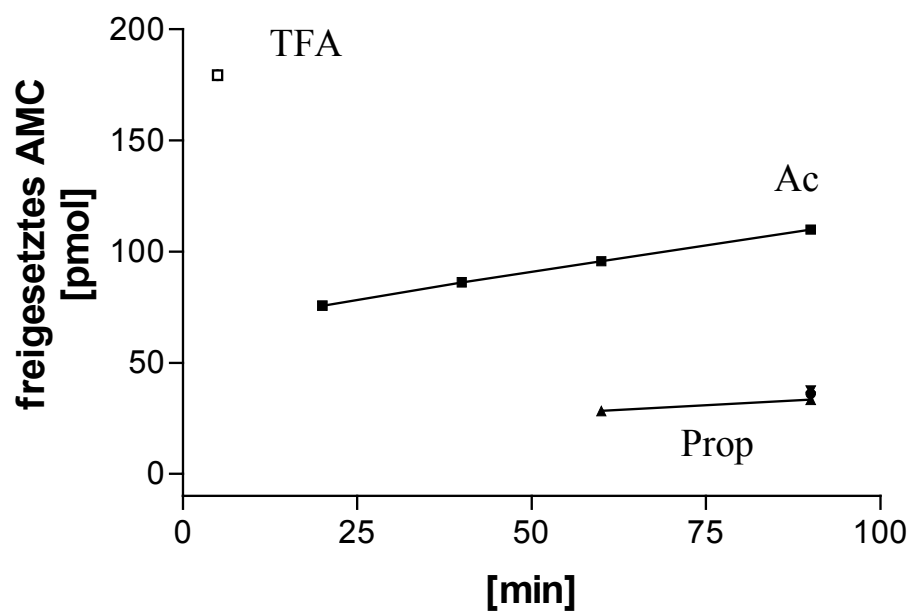

Abb. 37: Einfluß des Volumens der Acylreste an der \&-Aminogruppe des Lysins der synthetischen HDAC-Substrate auf HDAC8.

Standard-HDAC-Assays wurden mit unterschiedlichen Substraten durchgeführt und die Endpunktfluoreszenz nach dem angegebenen Zeitraum bestimmt. Zum Vergleich ist der Meßwert für Boc-Lys(TFA)-AMC (TFA) eingezeichnet, welcher das Signalmaximum des Fluoreszenzreaders wiedergibt. Regressionsgeraden für Boc-Lys(Ac)-AMC (Prop) und Boc-Lys(Prop)-AMC (Ac) sind eingzeichnet.

Bei HDAC-Assays mit heterolog exprimierter HDAC8 und $250 \mu \mathrm{M}$ Boc-Lys(Ac)-AMC konnte eine Produkthemmung ebenfalls nur durch $50 \mathrm{mM}$ NaAc bzw. NaProp festgestellt werden (Abb. 36). Die Kontrollreaktionen mit $50 \mathrm{mM} \mathrm{NaCl}$ zeigten auch hier keine Hemmung durch etwaige Effekte der Ionenstärke, die erhöhte NaClKonzentration wirkte sich sogar leicht positiv aus. Überraschenderweise inhibierte der Zusatz von 50 mM NaTFA die HDAC8 nicht, obwohl das entsprechende Substrat BocLys(TFA)-AMC am besten von allen untersuchten Substraten umgesetzt wurde (Abb. 38). 


\section{Umsatzkurven mit humaner HDAC8}

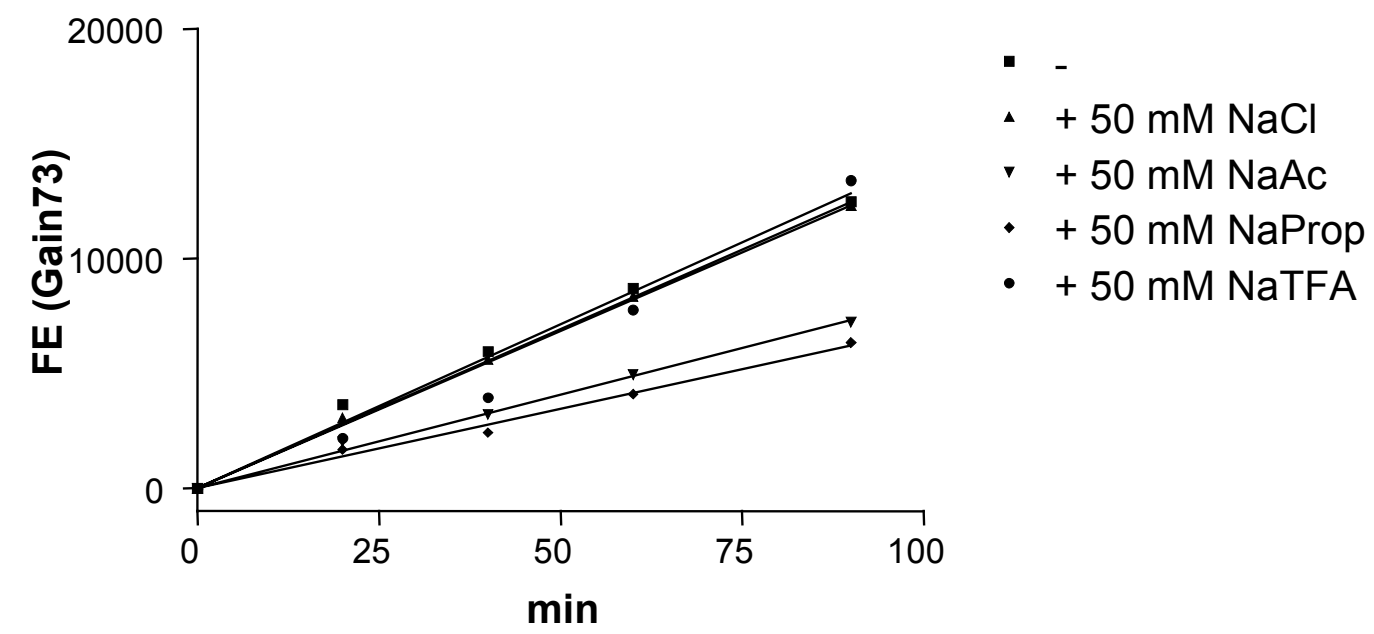

Abb. 38: Umsatzkurven mit Boc-Lys(Ac)-AMC und HDAC8 bei Zusatz von Salzen verschiedener Abgangsgruppen synthetischer HDAC-Substrate.

Standard-HDAC-Assays wurden mit und ohne Zusatz von $50 \mathrm{mM}$ eines Salzes durchgeführt und der Umsatz von Boc-Lys(Ac)-AMC nach den angegebenen Zeitintervallen verzeichnet. Nur NaAc und NaProp hemmen HDAC8.

Zusätzlich wurde der $\mathrm{K}_{\mathrm{M}}$ und $\mathrm{V}_{\max }$ mit den Substraten Boc-Lys(Prop)-AMC für HDAC aus der Rattenleber bzw. Boc-Lys(TFA)-AMC für HDAC8 bestimmt. Die Ergebnisse sind in Tabelle 10 eingetragen.

Table 10: $K_{M}$ and $V_{\max }$ für verschiedene HDAC-Substrate.

\begin{tabular}{|c|c|c|c|c|c|c|}
\hline \multirow[b]{2}{*}{ Boc-Lys(z)-MCA } & \multicolumn{2}{|c|}{ Rat liver HDAC } & \multicolumn{2}{|c|}{ Human HDAC 8} & \multicolumn{2}{|c|}{ FB188 HDAH * } \\
\hline & $\begin{array}{c}\mathrm{K}_{\mathrm{M}} \\
{[\mu \mathrm{M}]}\end{array}$ & $\begin{array}{c}\mathrm{V}_{\max } \\
{\left[\mathrm{pmol} \mathrm{sec}^{-1} \mathrm{mg}^{-1}\right]}\end{array}$ & $\begin{array}{c}\mathrm{K}_{\mathrm{M}} \\
{[\mu \mathrm{M}]}\end{array}$ & $\begin{array}{c}\mathrm{V}_{\max } \\
{\left[\mathrm{pmol} \mathrm{sec}^{-1} \mathrm{mg}^{-1}\right]}\end{array}$ & $\begin{array}{c}\mathrm{K}_{\mathrm{M}} \\
{[\mu \mathrm{M}]}\end{array}$ & $\begin{array}{c}\mathrm{V}_{\max } \\
{\left[\mathrm{pmol} \mathrm{sec}^{-1} \mathrm{mg}^{-1}\right]}\end{array}$ \\
\hline $\mathrm{CH}_{3} \mathrm{C}=\mathrm{O}$ & $3,7 \pm 1.7$ & $4,41 \pm 0.10$ & $>500$ & - & $14,0 \pm 3.0$ & $136 \pm 22$ \\
\hline $\mathrm{CH}_{3} \mathrm{CH}_{2} \mathrm{C}=\mathrm{O}$ & $105 \pm 14$ & $4,83 \pm 0,41$ & - & - & - & - \\
\hline $\mathrm{CF}_{3} \mathrm{C}=\mathrm{O}$ & - & - & $247 \pm 89$ & $530 \pm 30$ & $39,8 \pm 7.5$ & $136 \pm 12.9$ \\
\hline
\end{tabular}




\section{Diskussion}

Ein diffiziles dynamisches Gleichgewicht zwischen Acetylierung und Deacetylierung von Histonen wird in der Zelle durch Histonacetyltransferasen (HAT) und Histondeacetylasen (HDAC) aufrecht erhalten (Katan-Khaykovich and Struhl, 2002). Dabei reguliert das Acetylierungslevel und -muster der Nukleosomen eines Chromosomenabschnitts oder Gens zusammen mit anderen Modifikationen im Rahmen eines sich immer deutlicher abzeichnenden Histon-Codes (Strahl and Allis, 2000) unter anderem die Transkription (Agalioti et al., 2002; de Ruijter et al., 2003; Rice and Allis, 2001; Vogelauer et al., 2000). Eine aberrante Genexpression bzw. Repression von Tumorsuppressoren oder Zellzyklus-Regulatoren wurde als Charakteristikum in vielen Tumoren oder sogar als molekularer Auslöser der Tumorgenese gefunden (Grignani et al., 1998; Kim et al., 2001; Saito et al., 1999; Van Lint et al., 1996). In den letzten Jahren konnten einige Substanzen, die bei phänotypischen Screenings mit transformierten Zellinien aufgefallen waren und Antitumorwirkung gezeigt hatten, als HDAC-Inhibitoren identifiziert werden (Furumai et al., 2002; Kijima et al., 1993; Kraker et al., 2003; Kwon et al., 1998; Nakajima et al., 1998; Yoshida et al., 1990). Seitdem konnte in vielen Fällen eine Induktion von Hyperacetylierung, Reversion der transformierten Zellmorphologie, Zelldifferenzierung bzw. Apoptose in Tumorzellen durch strukturell verschiedene HDACI erreicht werden (Bouchain et al., 2003; Hoshikawa et al., 1994; Jung et al., 1999; Kim et al., 1999; Kraker et al., 2003; Saito et al., 1999). Interessanterweise war nur ein kleiner Prozentsatz an Genen nach Behandlung mit HDACI von Änderungen in der Expression betroffen (Butler et al., 2002; Glaser et al., 2003b; Marks et al., 2000). Vor allem der selektiven Induktion von Tumorsuppressoren wie p21 und p53 wurde eine entscheidende Rolle für die Antitumorwirkung zugesprochen (Kim et al., 2001; Richon et al., 2000; Woo et al., 2002). Tumorzellen scheinen auch wesentlich empfindlicher als normale Zellen auf die Behandlung mit diesen Wirkstoffen zu reagieren (Bouchain et al., 2003; Johnstone, 2002; Kim et al., 1999). Überraschenderweise wirken HDACI gerade bei multiresistenten Tumorzellen besonders stark (Castro-Galache et al., 2003). Auch 
künstlich induzierte bzw. verpflanzte Tumore in Mäusen wurden durch HDACI am Wachstum gehindert, wobei einige Inhibitoren wie SAHA sehr wenig Toxizität oder Nebenwirkungen zeigten (Butler et al., 2000; Jung, 2001; Plumb et al., 2003; Remiszewski et al., 2003).

Dies alles belegt eine Schlüsselrolle für HDAC bei der Karzinogenese (Kim et al., 2003; Marks et al., 2001) und führte dazu, daß HDACI als vielversprechende neue Chemotherapeutika gehandelt werden. Trotzdem sich einige bereits in klinischer Evaluation der Phase I bzw. II befinden (Chung, 2002; Jung, 2000; Kelly et al., 2002; Kwon et al., 2003), besteht nach wie vor ein Bedarf, neue, potentere Substanzen zu entwickeln und neue Leitstrukturen und chemische Strukturklassen zu erschließen. Das Erreichen dieses Ziels ist abhängig von geeigneten Testsystemen für die Wirkung von potentiellen HDACI auf die Zielenzyme in vitro. Dabei liegt besonderes Augenmerk auf der Eignung eines Assays für die Durchmusterung von Substanzbibliotheken per HTS. Darüberhinaus sollte ein solcher HDAC-Assay generell die Beantwortung biochemischer, HDAC-ähnliche Enzyme betreffende Fragestellungen sehr erleichtern.

\subsection{Ein Fluoreszenz-basierter, homogener HDAC-Assay}

Klassische HDAC-Assays beruhten auf der Inkubation von radioaktiv markierten Histonen oder peptidischen Substraten mit dem Enzym und anschließender Quantifizierung des freigesetzten, mittels Ethylacetat extrahierten, radioaktiven Acetats in einem Szintillationszähler. Dazu wurden Hühner mit radioaktivem Phenylhydrazin gespritzt, getötet und die Histone daraus präpariert (Kolle et al., 1998). Oder Histone wurden aus mit $\left[{ }^{3} \mathrm{H}\right]$-Acetyl-CoA gezogenen Zellkulturen gewonnen (Kijima et al., 1993). Dabei bestand die Schwierigkeit vor allem in der Standardisierung des Substrates, da der Acetylierungsgrad der Präparationen schwankte. Zusätzlich war es auch erst mit Verwendung einer HAT zur enzymatischen Acetylierung der Histone in vitro möglich, spezifische Acetylierungsmuster zu generieren (Wade et al., 1999). Auch die aufwendige Prozedur der Präparation und Isolierung einer bestimmten Histonart war ein weiterer Grund, neben Histonen (Inoue and Fujimoto, 1970) vor allem chemisch synthetisierte Oligopeptide nachträglich chemisch mit radioaktiven Acetylgruppen zu versehen und als Substrat einzusetzen (Buggy et al., 2000; Kervabon et al., 1979; Taunton et al., 1996). Die aufwendige Präparation bzw. Herstellung der Substrate, die 
nötige Extraktionsprozedur des Produktes wie auch die Verwendung teurer Szintillationscocktails bei dieser Art Enzymtest limitierten den Testdurchsatz. Dies gilt auch für Kompetitionsassays mit nicht-markierten Substanzen und radioaktivmarkiertem Trapoxin. Auch hier mußte vor der Messung im Szintillationszähler eine Extraktion des ungebundenen TPX erfolgen (Kwon et al., 1998).

Der Szintillations-Proximity-Assay(SPA) umging die Verwendung von teuren Szintillationscocktails, indem hier ein $\left[{ }^{3} \mathrm{H}\right]$-acetyliertes Oligopeptid (As 14-21 des H4) als Substrat eingesetzt wurde, das zusätzlich N-terminal biotinyliert war (Nare et al., 1999). Nach Inkubation mit HDAC wurden Streptavidin-beschichtete SPA-beads zugesetzt, wobei nicht durch HDAC abgespaltene, radioaktive Acetylgruppen den in der Nähe gebundenen Szintillator zu Lichtemission anregten. Die Zugabe von SPA-beads war ausreichend, die Reaktion abzustoppen (Nare et al., 1999), wahrscheinlich wegen sterischer Behinderung der HDAC durch die beads. Eine Trennung von Substrat und Produkt war nicht nötig (homogener Assay), da das Signal des frei in der Lösung befindlichen Acetats zu schwach für die Anregung des Szintillators war. Dies machte den SPA prinzipiell HTS-tauglich. Jedoch wurde hier die Abnahme eines Signals gemessen, und es fielen immer noch die typischen Probleme an, die mit Radioaktivität einhergehen wie radioaktiver Abfall, zusätzlicher Sicherheitsaufwand, Exposition von Personal und Dekontamination von Gerät.

Als erster nicht-radioaktiver HDAC-Assay wurde die Inkubation von MAL (BocLys(Ac)-AMC mit HDAC aus der Rattenleber und anschließender Trennung des deacetylierten Produktes vom Substrat über HPLC nach Extraktion mit Ethylacetat und Einkonzentrierung in einem Stickstoffstrahl beschrieben (Hoffmann et al., 1999; Hoffmann et al., 2000). Diese aufwendige Methode erlaubte keinen besonders hohen Durchsatz an Messungen. Das verwendete Minimalsubstrat MAL gibt den natürlichen Sequenzkontext innerhalb der Histontermini zwar nicht wieder, hat jedoch sogar einen geringeren $\mathrm{K}_{\mathrm{M}}(0,68 \mu \mathrm{M})$ als natürliche Histone $(20 \mu \mathrm{M})$ (Hoffmann et al., 1999). Für Untersuchungen zu Sequenzpräferenzen von HDAC waren Fluoreszenz-markierte Oktapeptide gedacht (Hoffmann et al., 2001b), jedoch gab es hier Hinweise auf eine sterische Behinderung der HDAC durch die verwendete, eher sperrige FluoresceinMarkierung ähnlich wie beim SPA durch SPA-beads (Nare et al., 1999). AMC als Fluorophor scheint dagegen nicht zu stören. Von Bedeutung ist ferner, daß gute 
Substrate keine freie $\alpha$-Aminogruppe am Lysin tragen dürfen (Hoffmann et al., 2000). Eine signifikante Verbesserung der Präzision des Assays erbrachte hingegen die Mitführung von fluoreszenten Standards wie BODIPY(530/550) oder EosinY bei der Extraktionsprozedur (Heltweg and Jung, 2002a; Heltweg and Jung, 2002b; Hoffmann et al., 2001a), was schließlich sogar die Durchführung des Enzymtests im MTP-Format erlaubte (Heltweg and Jung, 2002b). Allerdings war auch hier ein Extraktionsschritt nicht $\mathrm{zu}$ vermeiden, was eine Automatisierung des immer noch nicht-homogenen Assays erschwert.

Leicht automatisierbare, homogene Assays sind eine Voraussetzung bei einem Projekt, bei dem eine Vielzahl an Substanzen per HTS auf ihre Wirkung getestet werden sollen. Zusätzlich werden nicht-radioaktive und möglichst kostengünstige Alternativen angestrebt, wozu eine Miniaturisierung und somit Durchsatzsteigerung beiträgt (Wu et al., 2003). Daher stand im Fokus dieser Arbeit zunächst die Entwicklung des ersten, Fluoreszenz-basierten, homogenen HDAC-Assays und der Beleg seiner Eignung für das HTS (4.1) (Wegener et al., 2003a; Wegener et al., 2003c). Dieser koppelte die Deacetylierung durch HDAC in einer weiteren Stufe an die proteolytische Freisetzung des Fluoreszenzfarbstoffes AMC (Abb.4). Dabei konnte ein linearer Anstieg des Fluoreszenzsignals sowohl mit der Zeit als auch mit der HDAC-Konzentration verzeichnet werden. Somit konnten Effekte wie Adsorption von Enzym oder Substrat an den Kavitätenwänden der MTP oder Denaturierung der HDAC im Meßzeitraum ausgeschlossen werden. Die Eignung des Assays für Inhibitionsmessungen, welche ja auf der Linearität des Signals mit der HDAC-Konzentration (bzw. der Konzentation an Enzym ohne HDACI-Liganden) beruht, war so ebenfalls gewährleistet.

Sowohl das bereits beschriebene Minimalsubstrat Boc-Lys(Ac)-AMC (Hoffmann et al., 1999) als auch verschiedene acetylierte Tripeptid-Substrate wurden von HDAC aus Rattenleber umgesetzt. Die ermittelte $\mathrm{K}_{\mathrm{M}}$-Wert für MAL lag mit 3,7 $\mu \mathrm{M}$ im Bereich des Literaturwertes $\left(0,68 \mu \mathrm{M}\right.$ (Hoffmann et al., 1999)). Die $\mathrm{K}_{\mathrm{M}}$-Werte für die vom Aminoterminus des H4 abgeleiteten Substrate lagen mit 27,5 - 44,2 $\mu \mathrm{M}$ im Bereich der $\mathrm{K}_{\mathrm{M}}$-Werte von Histonen $(20 \mu \mathrm{M}$ (Hoffmann et al., 1999)). Auch HDAC aus anderen Organismen zeigten in radioaktiven in vitro-Assays $\mathrm{K}_{\mathrm{M}}$-Werte von $36-82 \mu \mathrm{M}$ für acetylierte Histone aus dem Huhn (Lechner et al., 1996) bzw. aus Maiskeimlingen (Brosch et al., 1996). Im Gegensatz zu HDAC-Komplexen aus Maisembryonen (Kolle 
et al., 1999) oder Erbsensamen (Clemente et al., 2001) zeigte HDAC aus der Rattenleber keine ausgeprägte Sequenzspezifität, was auch für humane HDAC1, 2 und 3 zutrifft (Emiliani et al., 1998; Hassig et al., 1998). So wurde ein neues, für die Spaltung von Trypsin optimiertes Substrat Tos-GPK(Ac)-AMC sogar besser umgesetzt als die H4-Tripetide und ein ähnlicher $\mathrm{K}_{\mathrm{M}}$ von $68,6 \mu \mathrm{M}$ gefunden. Im HDAC-Assay wurde allerdings eine teilweise aufgereinigte HDAC verwendet, die nicht in einem Komplex mit anderen Proteinen vorliegt. Gerade den mit HDAC assoziierten Proteinen wird neben der Promotorselektivität auch die Histon- bzw. Aminosäurekontextpräferenz zugeschrieben (Grozinger and Schreiber, 2002; Marmorstein, 2001b), so daß die beobachtete, geringe Sequenzspezifität eine Erklärung finden würde. Allerdings zeigte auch ein HDAC1-Komplex keine ausgeprägte Präferenz für einen Kernhistonsubtyp oder Spezifität für bestimmte Acetyllysinreste in Mononukleosomen, sondern nur einen Unterschied in der Umsatzrate in Immunoblot-Nachweisen mit Acetyllysin-spezifischen Antikörpern in vitro (Johnson et al., 2002). Im Gegensatz dazu besaß die heterolog exprimierte HDAC Hos3 eine Präferenz für bestimmte Acetyllysine in H4- und H2APeptiden und spaltete Acetylgruppen in H3- und H2B-Peptiden schlechter oder gar nicht, wie MALDI-TOF-Analysen der Peptide nach Hos3-Inkubation ergeben haben (Carmen et al., 1999). Hos3 gehört allerdings wohl nicht der HDAC-Klasse I oder II an (Trojer et al., 2003). Dies trifft auch auf HDAC der Sirtuin-Klasse zu, welche selbst eine kleinere, zusätzliche globuläre Domäne besitzen, die für die Substraterkennung verantwortlich sein könnte (Marmorstein, 2001b). Humane HDAC8 setzte TosGPK(Ac)-AMC schlecht um, ebenso wie ein aus H4 abgeleitetes Oktapeptid (Van den Wyngaert et al., 2000). HDAC8 wurde bislang nicht als Komponente eines HDACKomplexes gefunden und besitzt einen ihr eigenen Sequenzabschnitt mit vielen sauren Aminosäureresten (Abb. 23). Dies könnte in Analogie zu der zusätzlichen Domäne in Sirtuinen ein Hinweis auf eine stärker ausgeprägte Substratspezifität der HDAC8 sein. HDAC-Assays mit Histon-Peptiden mit unterschiedlichen Acetylierungsmustern, auch aus anderen Histonsubtypen abgeleitet, werden dies überprüfen helfen. Zusammen mit der Positionierung der HDAC8 am unteren Ende eines phylogenetischen Sequenzbaums (Buggy et al., 2000) und der Tatsache, daß es auch bakterielle HDAC wie FB188HDAH (die zumindest keine echten Histone als natürliches Substrat haben können) gibt (Hildmann et al., 2003), legen nahe, daß Nicht-Histon-Proteine das eigentliche Substrat 
darstellen. Zumindest für HDAC6 scheint mit dem Substrat Tubulin als Nicht-HistonProtein ein solcher Fall vorzuliegen (Hubbert et al., 2002). Auch für HDAC8 konnten in jüngster Zeit erste Evidenzen für ein solches Nicht-Histon-Substrat gefunden werden. Ein aus dem in vivo acetylierten Bereich von p53 abgeleitetes diacetyliertes Tetrapeptid wurde von HDAC8 besser umgesetzt als z. B. aus H4 abgeleitete Peptide (Biomol, 2003; Gu and Roeder, 1997; Sakaguchi et al., 1998). Allerdings ist nicht klar, ob p53 ein natürliches Substrat von HDAC8 darstellt oder ob die doppelte Acetylierung von entscheidender Bedeutung ist. Für HAT ist eine kontextabhängige Substratpräferenz im Einklang mit der Histon-Code-Hypothese (1.2.2) beobachtet worden (Lo et al., 2000; Makowski et al., 2001). Darüberhinaus weist der Befund, daß ein neuer HDAC8spezifischer Inhibitor nicht den Acetylierungsgrad der Histone in Zellen änderte und nicht zu einer Dereprimierung in einem Reportergen-basierten Assay führte, auch darauf hin, daß HDAC8 eher keine Histone als natürliches Substrat erkennt (Hu et al., 2003).

Die Verwendung von Tos-GPK(Ac)-AMC als Substrat für HDAC aus der Rattenleber führte zusammen mit einem optimierten Puffersystem und einer verbesserten Pipettierroutine für die robotische Screening-Anlage zu einer Steigerung der AssayQualität. Das für Trypsin optimale Substrat Tos-GPK-AMC, welches im Assay entsteht, hatte mit $7 \mu \mathrm{M}$ einen im Vergleich zu den anderen Tripeptid-Substraten $\left(\mathrm{K}_{\mathrm{M}}>500 \mu \mathrm{M}\right)$ wesentlich kleineren $\mathrm{K}_{\mathrm{M}}$-Wert und ermöglichte die Verwendung einer 1000fach geringeren Trypsinkonzentration. Der ermittelte $\mathrm{K}_{\mathrm{M}}$-Wert für Trypsin aus Schwein ist etwas niedriger als der Literaturwert für Rinder-Trypsin von $37 \mu \mathrm{M}$ (Grahn et al., 1998), welcher mit dem Trypsin-Assay in dieser Arbeit mit 36,7 $\mu \mathrm{M}$ bestimmt wurde (Daten nicht gezeigt). Im Vergleich zu Boc-Lys-AMC wurden die Tripeptide mindestens 100fach besser von der Endoprotease Trypsin umgesetzt, was auch Grahn und Kollegen bereits feststellten (Grahn et al., 1998). Das Reporterenzym Trypsin war aber immer noch ausreichend im Überschuß gegenüber HDAC vorhanden, um das im ersten Schritt des gekoppelten Assays entstandene, deacetylierte Produkt quantitativ zu spalten und dafür zu sorgen, daß unspezifisch hemmende Substanzen (mit $\mathrm{IC}_{50}$ für Trypsin im unteren mikromolaren Bereich) sich nicht auswirken können. In HDACAssays (dennoch) hemmend wirkende Substanzen sollten zusätzlich auf eine mögliche Trypsinhemmung überprüft werden, um falsch-positive Hits zu vermeiden. Allerdings 
ist dieser scheinbare Nachteil bei genauerer Betrachtung eine Möglichkeit zur gleichzeitigen Selektion gegen unspezifische Hemmstoffe.

Inhibitionsexperimente mit wohlbekannten $\mathrm{HDACI}$ ergaben für beide $\mathrm{HDAC} \mathrm{IC}_{50^{-}}$ Werte, die gut mit Literaturwerten übereinstimmen. Dabei wurden für einige Inhibitoren wie TSA auch bei Verwendung anderer Assay-Formate meist ähnliche $\mathrm{IC}_{50}$ gemessen (Wegener et al., 2003b). Die Werte für andere Inhibitoren wie SAHA schwanken zwischen verschiedenen Formaten für HDAC der Klasse I teilweise beträchtlich - ein für diese Substanzen schon länger bekanntes, aber noch unverstandenes Phänomen. Mit dem HDAC-Assay und HDAC aus der Rattenleber wurde für TSA ein $\mathrm{IC}_{50}$ von 1,3 nM und von 9,8 nM für SAHA bestimmt. Literaturwerte liegen für einen anderen homogenen, Fluoreszenz-basierten HDAC-Assay im MTP-Format („HDASH“, s.u.) mit HDAC aus der Rattenleber für TSA bei $6 \pm 0,7 \mathrm{nM}$ und für SAHA bei $115 \pm 11 \mathrm{nM}$ (Heltweg and Jung, 2002b). Für SAHA wurden darüberhinaus verschiedene $\mathrm{IC}_{50}$-Werte von 115 bis $158 \mathrm{nM}$, teilweise von derselben Arbeitsgruppe, in Abhängigkeit der Assay-Methode bestimmt (Heltweg and Jung, 2002a; Heltweg and Jung, 2003). Mit SAHA wurde aber auch ein $\mathrm{IC}_{50}$ von $10 \mathrm{nM}$ bzw. $20 \mathrm{nM}$ für humane HDAC1 bzw. 3 gemessen (Richon et al., 1998) bzw. von $30 \mathrm{nM}$ für HD1-B, ein Modellenzym für HDAC der Klasse I (Mai et al., 2003). Messungen mit dem klassischen, radioaktiven Enzymtest mit HDAC aus der Ratte ergab $\mathrm{IC}_{50}$-Werte von $21 \mathrm{nM}$ für TSA und $630 \mathrm{nM}$ für SAHA (Hoffmann et al., 2000). Der in dieser Arbeit mit TSA ermittelte $\mathrm{IC}_{50}$-Wert von $170 \mathrm{nM}$ für HDAC8 paßt zu publizierten Beobachtungen (Hu et al., 2000; Hu et al., 2003). Der mit MS275 bestimmte $\mathrm{IC}_{50}$-Wert von $8,8 \mu \mathrm{M}$ für HDAC aus der Rattenleber zeigt ebenfalls eine gute Übereinstimmung mit in der Literatur beschriebenen Werten von 4,8 $\mu \mathrm{M}$ (Suzuki et al., 1999) und $2 \mu \mathrm{M}$ (Wada et al., 2003). Diese wurden allerdings mit anderen Assays und HDAC bestimmt. Während für humane HDAC1 mit MS275 ein $\mathrm{IC}_{50}$ von ca. $300 \mathrm{nM}$ bestimmt wurde, liegt der Wert für humane HDAC3 bei $8 \mu \mathrm{M}$ (Hu et al., 2003) und damit näher an dem für HDAC aus Rattenleber. Hauptsächlich kommt HDAC3 in Rattenleberzellen vor (Van Ommeslaeghe et al., 2003), so daß spekuliert werden darf, daß HDAC3 die HDAC-Hauptaktivität in der in dieser Arbeit benutzten Rattenleberenzympräparation ausmacht. Dies gilt umso mehr, als in Western Blots mit Anti-HDAC1-AK eine distinkte HDAC-Bande nachgewiesen 
werden konnte (D. Wegener, unveröffentlichte Daten) und HDAC1 und HDAC3 sehr homologe Sequenzen haben (Emiliani et al., 1998).

Die Toleranz der HDAC für das standardmäßig zur Lagerung von chemischen Bibliotheken benutzte Lösungsmittel DMSO in den typischerweise verwendeten Konzentrationen (Cheng et al., 2003; Kozikowski et al., 2003; Macarron and Hertzberg, 2002) favorisiert die Nutzung dieses Lösungsmittels gegenüber MeCN und besonders NMP, welche sich kritischer auswirkten, aber auch weniger häufig Verwendung finden. Auch das relativ breite pH-Profil der HDAC bzw. des Assays läßt einige Flexibilität bei der Anpassung an andere HDAC-ähnliche Enzyme oder z. B. besonders alkalilabile Kandidaten-Moleküle zu. Der als optimal gefundene $\mathrm{pH}$-Wert von 8,5 spiegelt sich in den normalerweise für die Aufreinigung auch von anderen HDAC und in Enzymtests benutzten Puffern mit pH 7,5-8,5 wieder (Hoffmann et al., 2000; Hu et al., 2000; Huang and Kadonaga, 2001; Johnson et al., 2002; Lechner et al., 1996; Tong et al., 2002; Trojer et al., 2003).

Der ermittelte $Z^{\prime}$-Faktor von 0,8 für den verbesserten HDAC-Assay mit Tos-GPK(Ac)AMC als Substrat wird als „exzellent“ bewertet (Zhang et al., 1999a) und nur selten erreicht (s.u.).

Der HDAC-Assay ist wohl prinzipiell auch für HDAC der Sirtuin-Klasse geeignet, allerdings muß dann dem Ansatz NAD zugesetzt werden und dem Trypsin-Stop-Puffer sollte einer der kürzlich beschriebenen Sirtuin-Inhibitoren (z. B. Sirtinol) oder ein nichtspaltbares NAD-Derivat zugesetzt werden (Grozinger et al., 2001), da Sirtuine insensitiv gegen TSA sind. Sirtuine deacetylieren zumindest Boc-Lys(Ac)-AMC (Heltweg et al., 2003). Experimente auch mit Tripeptid-Substraten wie Tos-GPK(Ac)AMC werden zeigen, ob Sirtuine mit diesem Assay vermessen werden können.

Dank der hohen Sensitivität aufgrund der Verwendung fluorogener Substrate (Wegener et al., 2003c; Zimmerman et al., 1977) ließ sich der Assay auch an das 1536 wellFormat anpassen, wobei ein immer noch hoher, d. h. guter $Z^{\prime}$-Faktor von 0,47 erreicht wurde. Ein $Z^{\prime}$-Faktor $>0,4$ (entsprechend $S / B=3$ ) dient routinemäßig als Kriterium für einen lohnenden Einsatz des Assays für nachfolgende HTS-Läufe (Macarron and Hertzberg, 2002). Die von Zhang und Kollegen für Assays mit einem Z'-Faktor unter 0,5 geforderten replikativen Messungen (Zhang et al., 1999a) lassen sich in diesem Fall 
leicht realisieren, da durch die Miniaturisierung und Parallelisierung die Einbuße an Meßplätzen pro Platte mehr als kompensiert wurde. Auch die Ersparnis an verbrauchten Reagenzien im Vergleich zum 96 well-Format bleibt trotz Doppelung der Ansätze bestehen. Tatsächlich wird höchstens ein Zehntel an HDAC pro Ansatz im Vergleich zum 96er-Format benötigt. Obwohl hier die normalerweise bei der Miniaturisierung zum 1536 well-Format auftretenden Probleme wie starke Verdunstungseffekte, Rückgang der Signalsstärke, gesteigerte Genauigkeitsansprüche beim Pipettieren, gesteigertes Oberflächen-zu-Volumen Verhältnis (Berg, 1998; Schlingloff, 1999; Wu et al., 2003) hier nur grob berücksichtigt und nicht explizit untersucht worden sind, wurde doch die Eignung des HDAC-Assays für Mikroformate durch $\mathrm{IC}_{50}$-Bestimmungen von Standard-HDACI deutlich belegt. Die mit der CCD-Kamera der NanoSynTest-Anlage ermittelten Werte für TSA $(6,7 \mathrm{nM})$, SAHA $(22,3 \mathrm{nM})$ und CYPX $(3,8 \mu \mathrm{M})$ stimmen gut mit den im 96er-Format ermittelten Werten $(1,3 \mathrm{nM} ; 9,6 \mathrm{nM} ; 1 \mu \mathrm{M})$ überein, wobei bei Auslesen derselben Meß-Ansätze mit einem MTP-Reader (BMG) die Werte mit 1,3 nM, 12,8 nM und 0,5 $\mu \mathrm{M}$ noch ähnlicher sind. Hier spiegelt sich eventuell ein geräteabhängiger Effekt wieder, da die $\mathrm{IC}_{50}$-Bestimmungen im 96er-Format ebenfalls mit einem MTP-Reader des selben Typs (BMG) durchgeführt worden sind. Das geplante Screening einer von Dr. A. Groß (AG Schober/Merck, jetzt: TU Illmenau) synthetisierten Hydroxamat-Bibliothek mit der NanoSynTest-Anlage im 1536er-Format wird wahrscheinlich neue HDACI erbringen. Darüberhinaus soll der HDAC-Assay noch weiter miniaturisiert im Nanoliterbereich in Chip-Formaten (Schlingloff, 1999) erprobt werden.

Zeitlich nach dem, im Rahmen dieser Arbeit entwickelten und publizierten, ersten homogenen, nicht-radioaktiven HDAC-Assay wurden wenige andere homogene, nichtradioaktive HDAC-Assays beschrieben, die prinzipiell den Ansprüchen eines HTSAssays genügen (Heltweg and Jung, 2003; Wegener et al., 2003a; Wegener et al., 2003b; Wegener et al., 2003c).

Der neueste Vertreter dieser Klasse ist ebenfalls ein zweistufiger, gekoppelter Endpunkt-Assay, nutzt allerdings zur Entwicklung des Signals kein Reporterenzym, sondern eine chemische Derivatisierung der nach Deacetylierung des Substrates (z. B. Boc-Lys(Ac)-AMC) durch HDAC entstandenen $\varepsilon$-Aminogruppe mit NDA in Anwesenheit von Nukleophilen wie Cyanid oder Mercaptoethanol (Heltweg and Jung, 
2003). NDA löscht dabei das Fluoreszenzlicht der AMC-Gruppe der derivatisierten Produkte der HDAC-Reaktion, während die Fluoreszenz der verbliebenen SubstratMoleküle nicht beeinflußt wird. Dieser sogenannte „HDASH“-Assay mißt daher allerdings eine Signalabnahme proportional zur HDAC-Aktivität. Messungen der Signalabnahme erfordern typischerweise den Einsatz erhöhter Enzymkonzentrationen oder verlängerter Inkubationszeiten, da für das Erreichen brauchbarer Qualitätsparameter meist ein relativ großer Anteil des Substrates umgesetzt werden muß (Macarron and Hertzberg, 2002). Trotzdem wird mit dieser Methode ein Z'-Faktor von 0,61 erreicht (Heltweg and Jung, 2003), was neben dem in dieser Arbeit entwickelten HDAC-Assay mit einem $Z^{\prime}$-Faktor von 0,84 das einzige belegte Beispiel eines HDACAssays mit einem $Z^{\prime}$-Faktor über 0,5 darstellt. Der HDASH unterliegt allerdings einer Beschränkung in der Wahl der Puffer und in kompatiblen, chemischen Klassen von Testsubstanzen, da freie Aminogruppen z. B. des Tris-Puffers oder freie SH-Gruppen mit der NDA-Derivatisierung interferieren. Theoretisch könnte diese Methode eine kontinuierliche Messung der HDAC-Aktivität ermöglichen, da HDAC durch NDA wahrscheinlich nicht inaktiviert wird (wie etwa durch Trypsin). In der Praxis konnte allerdings keine eindeutige Korrelation zwischen HDAC-Aktivität und dem Fluoreszenzsignal mit der kontinuierlichen Test-Variante festgestellt werden (Heltweg and Jung, 2003).

Ein weiterer, kommerziell erhältlicher HDAC-Assay-Kit von Biomol (Hamburg) gehört auch in die Klasse der homogenen Fluoreszenz-Assays für HDAC im MTP-Format. Vom Hersteller wird allerdings keine Beschreibung der Substrate geliefert. Der mit diesem Kit bestimmte $\mathrm{IC}_{50}$-Wert für TSA (7 nM (Heltweg and Jung, 2002b) bzw. $5 \mathrm{nM}$ (Biomol)) liegt nahe dem, der mit dem in dieser Arbeit beschriebenen HDAC-Assay ermittelt wurde $(1,3 \mathrm{nM})$. Allerdings scheint die HDAC-Präparation aus Rattenleber aufgrund eines hohen Fluoreszenzhintergrundes nicht mit (Puffer-)Komponenten des Kits vereinbar zu sein (Heltweg and Jung, 2002b).

Ein Assay, der die durch die Deacetylierung im ersten Schritt entstehenden Aminogruppen durch chemische Derivatisierung mit dem Fluorophor Fluorescamin nachweist, wäre ebenfalls geeignet, HDAC-Aktivität in einem homogenen Format zu messen, da nicht abreagiertes Fluorescamin schnell spontan in nicht fluoreszierende Bestandteile zerfällt. Solch ein Assay wurde bereits für den Nachweis der 
Deacetylierung eines Alkohols durch FB188-HDAH (Hildmann et al., 2003) und der Deacetylierung von Zuckern durch LpxC von E. coli genutzt (Wang et al., 2001).

Keiner der oben beschriebenen, nicht-radioaktiven Assays ist in der Lage, die HDACReaktion kontinuierlich zu verfolgen (Wegener et al., 2003b). Nur in Ausnahmefällen, wenn das Zielenzym (HDAC) resistent gegen die Proteolyse durch das Reporterenzym ist, kann die Fluoreszenzentwicklung direkt vermessen werden. Dies wurde für FB188HDAH mit dem in dieser Arbeit entwickelten HDAC-Assay bereits dokumentiert (Wegener et al., 2003a). Eine genauere Beschreibung dieses Assays und des HDACähnlichen Enzyms erfolgt in der Dissertation von C. Hildmann (siehe auch Hildmann et al., 2003).

Ein seit kurzem erhältlicher Enzymtest-Kit für HDAC von CycLex (Nagano, Japan) bietet angeblich ebenfalls die Möglichkeit einer kontinuierlichen Messung der HDACAktivität in MTP. Dieser Kit verwendet die Lysin-spezifische Endoprotease LysC anstatt Trypsin als Reporterenzym in der zweiten Stufe des Assays zur EndpunktBestimmung der HDAC-Aktivität, ist aber ansonsten sehr ähnlich dem hier beschriebenen HDAC-Assay, indem ebenfalls nicht näher bestimmte Tripeptide der Form X-X-Lys(Ac)-AMC verwendet werden (CycLex, 2002). Die kontinuierliche Verfolgung der HDAC-Aktivität ermöglicht hier wahrscheinlich die im Vergleich zu Trypsin etwas ausgeprägtere Substratspezifität von LysC im Verein mit resistenter HDAC aus MCF7-Zellen. Standard-HDAC-Assays mit LysC anstelle von Trypsin werden zeigen, ob eine kontinuierliche Messung auch für HDAC aus der Rattenleber und HDAC8 möglich ist. Die Verwendung von LysC anstelle des Trypsin würde eine HTS-Kampagne jedoch wesentlich verteuern. Mit diesem Kit wurden kürzlich $\mathrm{IC}_{50^{-}}$ Werte für verschiedene Hydroxamate bestimmt, leider ohne die üblicherweise verwendeten Standard-HDACI als Referenzsubstanzen (Wada et al., 2003).

Prinzipiell geeignet als HDAC-Assay ist auch ein enzymatischer Standard-AcetatNachweis (Roche Diagnostics, Mannheim). Dieser koppelt den Verbrauch des (entstandenen) Acetats über eine Enzymkaskade mit der Entstehung von NADH, welches wiederum leicht photometrisch zu detektieren ist. Dabei kann also auf eine Markierung des Substrates etwa durch ein Fluorophor verzichtet werden, was besonders den Nachweis der Deacetylierung von komplexeren oder natürlichen Substraten z. B. 
Nicht-Histon-Proteinen begünstigt. Allerdings dürfte dieser Absorptions-Assay nicht ganz so sensitiv sein wie Fluoreszenz-Tests. Trotzdem wurde dieser Test bereits erfolgreich bei Enzymen angewandt, die Acetat freisetzen (Baumann et al., 2001; Hildmann et al., 2003). Bei der Suche nach natürlichen, Nicht-Histon-Substraten für HDAC8 wie Transkriptionsfaktoren oder Tubulin aber auch Acetyl-Spermidin soll dieser Assay in kommenden Experimenten eingesetzt werden.

Auch Zell-basierte Systeme haben eine lange Tradition in der Anwendung als HDACTests. So wurden schon seit Jahren Immunoblots mit Acetyllysin-spezifischen Antikörpern zum Nachweis des Acetylierungsniveaus in Zellen genutzt (CraneRobinson et al., 1997; Hebbes et al., 1988; Hebbes et al., 1989) - später auch für den Nachweis der HDAC-Aktivität (Bjerling et al., 2002; Kolle et al., 1999; Richon et al., 2000). Eine Kombination aus Chromatin-Immunopräzipitation aus ganzen Zellen und Immunoblot mit Acetyllysin-spezifischen Antikörpern ermöglichte die genomweite Analyse der Auswirkungen einer HDAC-Ablation (Robyr et al., 2002). Die Ergebnisse unterstützten die postulierte Arbeitsteilung und frühere Befunde über nicht-redundante Aufgaben der HDAC-Isotypen.

Eine Variante der Gesamtzell-Immunoblot-Methode (Cytoblot) erbrachte eine Steigerung des Durchsatzes durch die Analyse von Zell-Arrays und brachte kürzlich Tubacin hervor, einen HDAC6-spezifischen Inhibitor (Haggarty et al., 2003a; Haggarty et al., 2003b; Koeller et al., 2003; Stockwell et al., 1999). Eine andere Zell-basierte HTS-Strategie zielte auf zellmembrangängige Sirtuin-Inhibitoren ab und identifizierte den potenten und selektiven Sir2-Inhibitor Sirtinol (Grozinger et al., 2001), indem Hefemutanten auf Wachstum in Anwesenheit des Giftes 5-FOA analysiert wurden, deren ura3-Gene durch zelleigene Sirtuine reprimiert wurden, so daß das ura3Genprodukt 5-FOA nicht in das giftige Fluoruracil umsetzen konnte.

Zell-basierte Assays zur Identifizierung und Charakterisierung von HDACI nutzten auch oft Reportergenkonstrukte, deren Promotor durch HDAC reprimiert werden (Klan et al., 2003; Nie et al., 2001; Remiszewski et al., 2002; Skarpidi et al., 2003). Ihre Anwendung im HTS-Format zur Durchmusterung von Substanzbibliotheken wurde bereits dokumentiert ( $\mathrm{Su}$ et al., 2000). Eine Schwierigkeit ist die relativ geringe 
Spezifität für Substanzen, die HDAC hemmen. Prinzipiell werden auch Hemmstoffe für jede andere Komponente des Signaltransduktionsweges identifiziert.

Mögliche andere HDAC-Assays zur kontinuierlichen Aktivitätsmessung von HDAC in vitro könnten eine zweite enzymatische Reaktion an die Deacetylierung koppeln, die allerdings die HDAC nicht beeinflußt. So wäre eventuell der Einsatz von Lysinmodifizierenden Enzymen wie Lysin-Dehydrogenase möglich, welche wahrscheinlich nur nach Entfernung der Acetylgruppe in Aktion treten. Das hätte ebenfalls den Vorteil, daß die Position des modifizierten Lysins nicht so festgelegt wäre wie bei den Proteasegekoppelten Systemen.

Zusammenfassend kann gesagt werden, daß neben den eher aufwendigen und unspezifischen Zell-basierten Ansätzen und vielen radioaktiven in vitro-Methoden nur wenige andere HDAC-Assays ein Messen in einem homogenen MTP-Format erlauben. Trotz der ihnen gemeinsamen Schwierigkeit, die HDAC-Reaktion normalerweise nicht kontinuierlich verfolgen zu können, ist für die Entwicklung von HDACI durch HTS und nachfolgende in vitro-Inhibitionsstudien z. B. für Selektivitätsvergleiche ein in vitroAssay wohl am effektivsten. Im Vergleich mit anderen homogenen, Fluoreszenzbasierten MTP-Assays, die eine Signalabnahme messen, Beschränkungen in der Eignung für bestimmte Testsubstanzklassen unterliegen, teurere Reagenzien nutzen oder nicht publiziert und somit gegebenenfalls schlecht zu modifizieren sind, ist der in dieser Arbeit entwickelte HDAC-Assay der derzeit geeignetste.

\subsection{Potente und selektive Histondeacetylase-Inhibitoren}

Neben dem Wunsch zur Optimierung der Inhibitoren im Hinblick auf ihre Potenz treibt die Beobachtung der Arbeitsteilung der HDAC (Robyr et al., 2002), ihrer Involvierung in einer Vielzahl von Zellabläufen (Hamamori and Schneider, 2003; Hubbert et al., 2002; Kook et al., 2003; Lagger et al., 2002; Verdin et al., 2003), der Promotor- und Substratspezifität der verschiedenen HDAC-Komplexe (Bernstein et al., 2000; Clemente et al., 2001; de Ruijter et al., 2003; Grozinger and Schreiber, 2002; Kolle et al., 1999) verstärkte Anstrengungen zur Entwicklung Isotypen-selektiver HDACI (Hamamori and Schneider, 2003; Krämer et al., 2001; Kwon et al., 2003; Mai et al., 
2003). Bisher wurden nur wenige Versuche, selektiv hemmende Substanzen zu entwickeln, unternommen (Hu et al., 2003; Wittich et al., 2002; Yoshida et al., 2001). Dazu wurden teilweise besonders diversifizierte chemische Bibliotheken generiert (Sternson et al., 2001; Wong et al., 2003). Eine Strategie (chemical genetic modifier screen) nutzt beim Screening bislang bekannte unterschiedliche biologischen Funktionen einiger HDAC aus, indem aus entsprechenden phänotypischen Effekten auf die selektive Inhibition einer Isoform geschlossen wurde (Haggarty et al., 2003a; Koeller et al., 2003). Allerdings ist dieses Vorgehen durch das dürftige Wissen über die Aufgabenverteilung der HDAC in der Zelle bislang stark limitiert. Mit diesem Ansatz konnte zwar die Identifizierung eines HDAC6-spezifischen Inhibitors erreicht werden (Haggarty et al., 2003b). Die Aufgabe war allerdings insofern etwas erleichtert, daß HDAC6 ein Nicht-Histon-Substrat erkennt und in der den Inhibitor Tubacin bindenden Domäne besonders von der HDAC-Consensussequenz abweicht (Grozinger and Schreiber, 2002; Haggarty et al., 2003b). Es sind darüberhinaus noch keine wirklich selektiven HDACI bekannt geworden (Kelly et al., 2002; Mai et al., 2003).

In dieser Arbeit wurde eine gute Übereinstimmung in den mit Standard-HDACI ermittelten $\mathrm{IC}_{50}$-Werten für HDAC aus der Ratte mit denen von HDAC der Klasse I, besonders der HDAC3 festgestellt. Auch andere Evidenzen legten nahe, daß das Enzym aus der Rattenleber HDAC3 entspricht (s.o.) und somit als Modellenzym für HDAC der Klasse I dienen kann. FB188-HDAH wurde als Modellenzym der HDAC-Klasse II genutzt, da es Sequenzähnlichkeit zu HDAC6 aufweist (Hildmann et al., 2003). Darüberhinaus gibt es Hinweise, daß dieses Enzym neben HDAC- ebenfalls Tubulindeacetylase-Aktivität besitzt (P. Loidl, unveröffentlichte Ergebnisse, zitiert in: (Hildmann et al., 2003), so daß es möglicherweise insbesondere als Modell für HDAC6 angesehen werden kann. Weitere Experimente mit Tubulin als Substrat wären allerdings nötig, um diesen Gesichtspunkt zu untermauern. So könnte einerseits eine Entwicklung von Inhibitoren speziell gegen dieses Enzym entweder als Leitstruktur für Antibiotika gegen eng verwandte Enzyme aus Pseudomonas aeroginosa oder zur Entwicklung von HDAC6-spezifischen Inhibitoren dienen. Andererseits erlaubte es auch die Abschätzung der unerwünschten Wirkung der Inhibitoren für Klasse I-Enzyme auf Nicht-HistonDeacetylasen, welche möglicherweise Nebenwirkungen fördern könnte. HDAC8 ist als HDAC aus dem Menschen naturgemäß für Selektivitätsuntersuchungen bei der 
Wirkstoffentwicklung interessant. Außerdem könnte die ihr aufgrund von Sequenzvergleichen zugewiesene Stellung nahe der Wurzel zwischen den HDACKlassen I und II im Stammbaum eine intermediäre Sensitivität gegen selektive Inhibitoren beider HDAC-Klassen bewirken. Damit wäre HDAC8 ein besonderer Prüfstein für die Selektivität der Inhibitoren, zumal HDAC8 zu HDAC3 besonders homolog ist (34\% Identität, 54\% Ähnlichkeit) (Buggy et al., 2000).

Bislang erreichten nur Hydroxamate als reversible Inhibitoren $\mathrm{IC}_{50}$-Werte im unteren nanomolaren Bereich, während Inhibitoren ohne Hydroxamatgruppe wie das Benzamid MS275 HDAC etwa 100-1000fach schwächer hemmen und kurzkettige Fettsäuren erst in millimolaren Konzentrationen wirken (Jung, 2001; Suzuki et al., 1999). Diese Abstufung in der Potenz konnte hier bestätigt werden. Die in Tabelle 8 aufgelisteten $\mathrm{IC}_{50}$-Werte für SAHA und SAOH bestätigen für HDAC aus der Ratte und FB188-HDH die Wichtigkeit der Zink-chelatierenden Hydroxamat-Gruppe. Ähnlich wie bei TSA (Yoshida et al., 1990) ist auch bei SAHA ein Derivat des Inhibitors mit der Carbonsäuregruppe nahezu wirkungslos. Die Kristallstruktur von HDLP im Komplex mit TSA bzw. SAHA zeigt, daß die Hydroxamatgruppe den Zink-Cofaktor bindet und erklärt dieses Phänomen (Finnin et al., 1999). Auch der mit MS275 gemessene und im Vergleich zu TSA (1,3 nM) und SAHA $(9,6 \mathrm{nM})$ viel niedrigere IC50-Wert für HDAC aus der Ratte $(8,8 \mu \mathrm{M})$ gibt die in der Literatur beschriebene Abfolge in der Wirkung wieder.

Viele Arbeitsgruppen haben die These der Existenz einer generellen HDACI-Struktur (1.3.3) der Form „Kappe-Linker-Hydroxamatgruppe“ aufgestellt (Jung, 2001; Remiszewski et al., 2003), wobei die Kappe sowohl für die Hemm-Potenz verantwortlich zeichnete (Curtin et al., 2002) als auch die Selektivität des Inhibitors modulieren können soll (Grozinger and Schreiber, 2002). Die Kappenstruktur hatte in anderen Fällen allerdings nur einen moderaten Einfluß auf die erreichten $\mathrm{IC}_{50}$-Werte für HDAC aus der Rattenleber (Wittich et al., 2002) oder HDAC1 (Woo et al., 2002). Unterstützende Hinweise für die Idee der Kappenstruktur als Selektivitätsdeterminante wurde durch das Beispiel des HDAC6-spezifischen Inhibitors erbracht (Haggarty et al., 2003b; Wong et al., 2003). Tubacin weicht nur in der Kappenstruktur von dem unspezifischen Inhibitor SAHA ab. Es ist bislang aber nur indirekt entweder über phänotypische und Genexpressionsanalysen oder über den Nachweis der Induktion 
einer Histon-Hyperacetylierung gezeigt worden, daß Tubacin andere HDAC etwa 75 mal schlechter hemmt (Haggarty et al., 2003b; Wong et al., 2003). Ebenfalls ist nicht explizit ausgeschlossen worden, daß die Hemmung der Tubulindeacetylase-Aktivität durch Tubacin auf einer selektiven Interaktion mit dem Substrat Tubulin anstatt auf der selektiven Interaktion der Substanz mit der HDAC6 beruht. Es könnte sich also um einen Inhibitor der Protein-Protein-Interaktion handeln, der dann ebenfalls die Interaktion vieler anderer HDAC mit Tubulin verhindern würde.

Die Länge des aliphatischen Linkers, der die Kappe mit der funktionellen Gruppe verbindet, wurde mit 5-6 C-Atomen als optimal für die Hemmwirkung beschrieben (Jung et al., 1999; Wada et al., 2003; Woo et al., 2002). Dabei sind potente HDACI sowohl mit gesättigtem (z.B. SAHA) als auch mit ungesättigtem (z. B. TSA oder Oxamflatin) und daher weniger flexiblem Linker beschrieben. Eine Einführung von Doppelbindungen in den Linker führte in einigen Fällen zu einem dramatischen Verlust der Hemmaktivität (ca.100fach bei MD85 (Van Ommeslaeghe et al., 2003))), was auf eine damit einhergehende Verringerung in der Flexibilität des Linkers und in der Drehbarkeit der Kappenstruktur zurückgeführt wurde (Wada et al., 2003).

Die im Screening aktiven Substanzen A4, B4 und F5 (Abb. 16) weisen eine ähnliche Struktur wie SAHA, aber mit einem auf 7 C-Atome verlängerten Linker auf, der zusätzlich amidisch mit der aromatischen Kappe verknüpft ist. Diese Abweichungen dürften die im Vergleich wesentlich schwächere Hemmwirkung (ca. 100fach) für HDAC aus der Rattenleber erklären. SAHA-ähnliche Inhibitoren mit einem Linker von 7 C-Atomen hemmten allerdings HDAC1 stärker $\left(\mathrm{IC}_{50} 135 \pm 65 \mathrm{nM}\right)$ und waren nur ca. 2-3fach schwächer als das Derivat mit einem 6-C-Linker (Woo et al., 2002). Hier war allerdings der Linker nicht amidisch gekoppelt. Das den drei im Screening gefundenen Substanzen sehr ähnliche Dimethylaminobenzamidylcaprylhydroxamat (DBCH) wies einen 5-C-Linker und einen $\mathrm{IC}_{50}$ von $244 \pm 38 \mathrm{nM}$ in vitro für eine HDAC aus einer Lungenkrebszellinie auf (Remiszewski et al., 2002). Eine weitere Möglichkeit besteht darin, daß die Konzentrationen der Stoffe in den Vorrats-MTP, bei der Verdünnung und damit auch im Screening durch Effekte wie Adsoption an der Kavitätenwand oder schlechte Löslichkeit im Puffer niedriger als gewünscht ausfielen. Da für die Bestimmung der $\mathrm{IC}_{50}$ in diesem Fall die HDACI aus den Vorratsplatten entnommen wurden, spiegeln sich diese Effekte ggf. dort ebenfalls wieder. 
Während einige der HDACI mit einem kurzen 4-C-Linker, wie nach der These vom 6C-Linker-Optimum zu erwarten, nur mikromolare $\mathrm{IC}_{50}$-Werte aufwiesen (z. B. HDACI\#124), lagen einige der „kurzen“ HDACI mit ihren $\mathrm{IC}_{50}$-Werten überraschenderweise jedoch deutlich im nanomolaren Bereich. HDACI\#83 etwa hemmt HDAC8 nahezu ebenso gut wie SAHA. Selbst CYPX mit einem noch um 2 C-Atome kürzeren Linker hemmt deutlich. Eine mögliche Erklärung wäre, daß diese Substanzen wegen der geringen Größe der Kappengruppe ganz in den hydrophoben Substrat-Tunnel des Enzyms hineinrutschen und so trotz ihrer geringen Länge das Zink-Ion binden können. So weist besonders HDACI\#83 ( $\mathrm{IC}_{50} 130 \mathrm{nM}$ für HDAC aus der Rattenleber) eine sehr große Ähnlichkeit mit der Zink-bindenden Grundstruktur des von Remiszewski und Kollegen in einem Screening bei Novartis gefundenen HDACI NVPLAK974 auf, welcher in vitro eine sehr ähnliche Hemmwirkung $\left(\mathrm{IC}_{50} 150 \pm 94 \mathrm{nM}\right)$ für HDAC aus einer Lungenkrebszellinie zeigte (Remiszewski et al., 2003). Die stärkere Potenz einiger anderer Komponenten aus dieser Serie resultiert wahrscheinlich aus der dort vorhandenen Kappengruppe (Remiszewski et al., 2003) oder gründet sich auf den anderen HDAC-Typ. Leider wurden keine $\mathrm{IC}_{50}$ von Substanzen ohne eine der während der Synthese von dieser Gruppe angehängten Kappengruppen ermittelt. Inhibitionsexperimente mit einem mit einer Kappenstruktur versehenen Derivat von HDACI\#83 werden zeigen, ob die Trifluormethylgruppe dieses Inhibitors eventuell das Fehlen einer echten Kappenstruktur kompensierte oder ob eine Kappenstruktur in diesem Fall tatsächlich kaum Einfluß hat.

Die HDACI\#123, \#124, A08/P03hx und Thiox haben einen gleich langen, aber im Gegensatz zu Thiox ungesättigten Linker. Die ermittelten $\mathrm{IC}_{50}$-Werte $(2,8-10 \mu \mathrm{M})$ für HDAC8 unterscheiden sich nur moderat von dem für Thiox $(25 \mu \mathrm{M})$, was ein Hinweis darauf sein könnte, daß die Drehbarkeit des Linkers für die Orientierung der Kappe im Substrat-Tunnel nicht von großer Bedeutung ist. Eventuell sind aber die $\pi-$ Systeme der ungesättigten Bindungen für die etwas bessere Hemmung verantwortlich. Auch HDACI\#83 hat im Gegensatz zu CYPX einen ungesättigten Linker. Ob diese Tatsache, die aromatische Kappe oder die Trifluormethylgruppe für die bessere Hemmung aller drei HDAC durch HDACI\#83 verantwortlich ist, bleibt offen. Zur Klärung der Fragen nach dem Einfluß der Länge des Linkers oder dessen Sättigungsgrad müssen weitere Inhibitionsexperimente mit neuen HDACI unterschiedlicher Länge und Sättigung 
durchgeführt werden. Ebenso müssen weitere Experimente zur Klärung der Frage herangezogen werden, ob HDACI\#127 FB188-HDAH irreversibel inhibiert oder ob es sich um einen potenten reversiblen, aber langsam bindenden Inhibitor handelt, während er HDAC aus der Ratte nur mit einem moderaten $\mathrm{IC}_{50}$ von $154 \mu \mathrm{M}$ hemmt. Inhibitionsexperimente mit HDAC8 könnten die Frage beleuchten, ob mit diesem Inhibitor ein Werkzeug zur Unterscheidung von HDAC der Klasse I und bakteriellen Enzymen gefunden wurde. In diesem Zusammenhang wäre auch die Wirkung auf HDAC6 interessant, um zu sehen, wie weit die Idee von FB188-HDAH als Modell für HDAC6 trägt. Zuerst müßte allerdings herausgefunden werden, ob es sich wirklich um eine irreversible Inhibition handelt. Dann könnte HDACI\#127 als Instrument zur Bestimmung der aktiven Enzymkonzentration mittels active site titration genutzt werden (Knight, 1995). Zu diesem Zweck könnte ein HDAC-Assay z. B. nach Dialyse der gehemmten HDAC herangezogen werden.

Neben dem bereits erwähnten Unterschied in der Potenz für HDAC aus der Rattenleber trotz ähnlicher Struktur, gibt es auch einen Unterschied in der Selektivität von CYPX und HDACI\#83. CYPX hemmt FB188-HDAH etwa 14 mal bzw. 29 mal besser als HDAC aus der Rattenleber bzw. HDAC8, während HDACI\#83 FB188-HDAH nur 4 fach bzw. 16fach stärker hemmt. Auch hier müssen weitere Inhibitionsmessungen mit neuen Inhibitoren wie z. B. einem CYPX-Derivat mit aromatischer Kappe oder einem HDACI\#83-Derivat ohne Trifluormethylgruppe helfen, den Einfluß der Strukturunterschiede näher zu beleuchten. Zusätzlich sollten Strukturdaten eines Komplexes der FB188-HDAH mit CYPX wertvolle Hinweise für die Selektivität der Inhibitoren liefern. Kristalle dieses Enzyms wurden bereits erhalten (C. Hildmann, persönliche Mitteilung).

Während HDACI A08/P03hx HDAC aus der Rattenleber und HDAC8 etwa gleich inhibierte ( $\mathrm{IC}_{50}$ von 3,5 bzw. $10 \mu \mathrm{M}$ ), zeigte der sehr ähnliche HDACI\#123 hingegen eine etwa 53fache Präferenz für HDAC aus der Ratte. Für FB188-HDAH ergab sich sogar ein Faktor von 58 gegenüber HDAC8. Diese Selektivität beruht wahrscheinlich auf den beiden Chlorsubstituenten, die bei A08/P03hx fehlen und HDACI\#123 eine bessere Hemmung für HDAC aus der Rattenleber ( $\mathrm{IC}_{50}$ von $53 \mathrm{nM}$ ) im Vergleich zu A08/P03hx ( $\mathrm{IC}_{50}$ von 3,5 $\left.\mu \mathrm{M}\right)$ verleihen. Es bleibt jedoch unklar, ob der Effekt auf elektrostatischen Interaktionen mit Resten des Enzymtunnels oder auf sterischen 
Effekten beruht. Ein Austausch der Chlorgruppen z. B. gegen Methylgruppen oder Sauerstoff mag einen Hinweis geben. Ein sterischer Effekt würde zu Befunden zur Substratspezifität der drei HDAC passen (s. u.), welche für HDAC aus der Rattenleber eine etwas weitere Substrattasche vorhersagt.

Der mit HDACI\#123 im Vergleich zu beiden anderen Enzymen ( $\mathrm{IC}_{50}$ von ca. $\left.50 \mathrm{nM}\right)$ hohe $\mathrm{IC}_{50}$ von $2,8 \mu \mathrm{M}$ steht im Widerspruch zu der Theorie, daß HDAC8 als intermediäres und vielleicht eher ursprüngliches Enzym Eigenschaften beider HDACKlassen in sich vereinen und daher auch durch selektive Inhibitoren für HDAC der Klasse II anfällig sein sollte.

Bisher publizierte selektive Inhibitoren erreichen einen Unterschied in der Wirkung auf zwei HDAC-Isoformen mit einem Faktor von ca. 2-100. So hemmt Tubacin HDAC6 etwa 80 mal besser als andere HDAC, was allerdings nur indirekt gemessen wurde (Wong et al., 2003). Mit HDAC aus Mais als Modellenzyme für HDAC der Klasse I (HD-1B) bzw. der Klasse II (HD1-A) wurden kürzlich Inhibitoren entwickelt, welche in ihrer Hemmung zwischen beiden Klassen mit dem Faktor 7-78 diskriminieren (Mai et al., 2003). Kürzlich wurde von selektiven Inhibitoren gegen humane HDAC1 (SB429201, $\mathrm{IC}_{50}$ von ca. $1,5 \mu \mathrm{M}$ ) und HDAC8 (SB-379872, $\mathrm{IC}_{50}$ von ca. 0,5 $\mu \mathrm{M}$ ) berichtet, die mittels HTS bei identifiziert worden sind (Hu et al., 2003). Leider wurde hier kein Selektivitätsfaktor explizit angegeben, aber es war der Publikation zu entnehmen, daß keiner der beiden HDACI die jeweils andere HDAC bei $30 \mu \mathrm{M}$ mehr als um $40 \%$ hemmte. Zusätzlich fand diese Arbeitsgruppe auch eine selektive Wirkung von MS275 auf humane HDAC1 ( $\mathrm{IC}_{50}$ von ca. $300 \mathrm{nM}$ ), wobei die humane HDAC3 wesentlich schlechter inhibiert wurde ( $\mathrm{IC}_{50}$ von ca. $8 \mu \mathrm{M}$ ) und auf HDAC8 keine Wirkung erzielt wurde. Selbst bei HDAC aus so unterschiedlichen Organismen wie Mais und Ratte konnten aber meist nur moderate Selektivitäten der Inhibitoren von etwa einem Faktor 10-20 beobachtet werden (Wittich et al., 2002).

In dieser Arbeit wurden HDACI entwickelt, die im unteren nanomolaren Bereich hemmen und die im Falle von CYPX, HDACI\#83, \#123 und eventuell auch im Falle von HDACI\#127 eine deutliche Selektivität, teilweise sogar innerhalb der Klasse I aufweisen (Faktor 4-58). Die zur Synthese der Inhibitoren genutzte Strategie erschließt offenbar den Zugang zu effektiven chemischen Strukturen. 
Allerdings wurde für FB188-HDAH mit TSA ein bis zu 140fach höherer IC $_{50}$ (1200 $\mathrm{nM})$ als bei HDAC der Klasse II wie HDAC6 (8,6 $\pm 1,4 \mathrm{nM})$, HDAC4 $(38 \pm 4 \mathrm{nM})$ und HDAC10 (10 nM) gemessen, ähnlich dem der Enzyme vom Hos3-Typ (40 bzw. 60\%ige Hemmung bei $1 \mu \mathrm{M}$ TSA für Hos3 bzw. HosB)(Carmen et al., 1999; Tong et al., 2002; Trojer et al., 2003; Yoshida et al., 2001). Daher könnte es sich herausstellen, daß die hier beobachtete potente und selektive Hemmung durch CYPX sich nicht bei HDAC6 feststellen läßt. Dann müßte zur weiteren Entwicklung von selektiven Inhibitoren wohl eine humane HDAC der Klasse II herangezogen werden. Dazu paßt auch, daß TSA eine etwa 900fache Präferenz für HDAC aus der Rattenleber gegenüber der FB188-HDAH zeigte. Tendenziell verhielt sich auch SAHA so (Faktor 100). TSA und SAHA hatten bislang sonst als recht unspezifische Inhibitoren gegolten.

Finnin und Kollegen leiteten aus der Aufklärung der Struktur eines HDAC-ähnlichen Enzyms im Komplex mit TSA bzw. SAHA einen potentiellen Katalysemechanismus ab und eröffneten damit die Möglichkeit zum Entwurf potentieller Übergangszustandsmimetika. Diese stellen normalerweise potente Inhibitoren eines Enzyms dar. In weiteren Inhibitionsexperimenten wurde daher eine Serie von LysinDerivaten mit identischer Hauptkette (AcPK(R)Ambs) im HDAC-Assay bei $150 \mu \mathrm{M}$ Inhibitor auf ihre Wirkung gegen HDAC aus Rattenleber untersucht (4.4.1). Dabei war der Lysin-Rest durch verschiedene Gruppen am Ende der Seitenkette (R) modifiziert. Es wurde jedoch keine starke Hemmwirkung dieser Substanzen beobachtet. Maximal wurde eine 20\%ige Inhibition der HDAC durch AcPKAmbs\#5 erreicht, welcher eine Methylsulphonylgruppe trug und damit dem postulierten tetrahedralen Übergangszustand ähnlich sein sollte. Auch für FB188-HDAH konnte mit dieser Substanz keine Hemmung beobachtet werden (C. Hildmann, persönliche Mitteilung). Natürlich ist nicht ausgeschlossen, daß einige der anderen Moleküle sterisch nicht in die Substrattasche der HDAC passen. Allerdings hemmte auch ein Derivat mit einer Hydroxamsäuregruppe (AcPKAmbs\#9) nur moderat, welches jedoch im Unterschied zu allen anderen Hydroxamat-HDACI amidisch mit dem Lysin verknüpft war. Die Möglichkeit, daß der allen diesen Inhibitoren gemeinsame Kontext bereits einer Interaktion mit der HDAC entgegensteht, ist unwahrscheinlich, da AcPKAmbs\#1 bei HDAC8, wenn auch erst bei $800 \mu \mathrm{M}$, eine 20\%ige Hemmung zeigte. AcPKAmbs\#1 entspricht mit der freien $\varepsilon$-Aminogruppe des Lysins dem bei der Deacetylase-Reaktion 
entstehenden Produkt. Die beobachtete, leichte „Produkt“-Hemmung ist dabei durchaus stärker als aufgrund des Fehlens einer Produkthemmung bei der Erstellung von Umsatzkurven mit dem Standard-HDAC-Assay zu erwarten war. Diese Ergebnisse könnten ein Hinweis darauf sein, daß die postulierte Geometrie des Übergangszustandes von der tatsächlichen abweicht. Dies wurde bereits im Lichte der Ergebnisse aus Berechnungen der Energieminimierung für gebundenes Wasser im Aktiven Zentrum von HDLP vorgeschlagen (Vanommeslaeghe et al., 2003). Auch andere Gruppen konnten mit Analoga zu dem postulierten Übergangszustand keine potente Hemmung erzielen (Kapustin et al., 2003).

Der entwickelte HDAC-Assay wurde nicht nur zu Inhibitionsstudien mit rational entworfenen Molekülen eingesetzt, sondern sollte vor allem für die Durchmusterung von Substanzbibliotheken im MTP-Format eingesetzt werden. Im Screening einer peptidischen Bibliothek (4.2.1) mit HDAC aus Rattenleber fiel auf, daß nur Tripeptide mit einem N-terminalen Lysin-Derivat (Citrullin, Formyllysin bzw. Nicotinyllysin) hemmend wirkten. Dabei waren besonders Substanzen mit dem Dipeptid D-Phe-D-His (FR) und Trp-Lys (WK) aktiv, wobei ein $\mathrm{IC}_{50}$ von $4-40 \mu \mathrm{M}$, je nach $\mathrm{N}$-terminalem Rest, gemessen wurde. Tripeptide, die diese Dipeptide am N-Terminus trugen, waren hingegen auch bei $400 \mu \mathrm{M}$ inaktiv. Letztere waren jedoch an einen anderen Aminosäurerest (Acryloylsäureamidlysin bzw. Mecaptobernsteinsäureamidlysin) gekoppelt. Daher muß in weiteren $\mathrm{IC}_{50}$-Bestimmungen geklärt werden, wie groß dabei der Einfluß der Position der Dipeptide bzw. die Art der Lysinderivate ist. Dazu sollten besonders Tripeptide mit den beiden aktiven Dipeptidsequenzen (FR, WK) am CTerminus der Lysinderivate aus den inaktiven Teilbibliotheken (A, M) vermessen werden wie auch Tripeptide mit einem Lysinderivat der Teilbibliotheken C, F, N am CTerminus.

Da ein gekoppelter HDAC-Assay entworfen wurde, müssen die Substrate auch mit dem Reporterenzym Trypsin kompatibel sein. Somit ist die C-terminale Position der Lys(Ac)-AMC-Gruppe festgeschrieben. Daher ist ein Screening mit einer erweiterten Peptidbibliothek sinnvoll, die vor allem alle 400 Kombinationen der natürlichen Aminosäuren als C-terminales Dipeptid umfassen sollte und in einem Kompetitionsassay untersucht werden könnte. So ließe sich mit einer zur Untersuchung der Sequenzabhängigkeit der HDAC mit fluorogenen Substraten komplementären 
Strategie der bevorzugte Aminosäurekontext auch C-terminal des im Substrat vorkommenden Acetyllysins ermitteln. Dieses Vorgehen könnte wertvolle Hinweise auf das natürliche Substrat von HDAC8 geben, indem mittels Abgleich mit einer SequenzDatenbank Proteine, die das optimale Sequenzmotiv enthalten als Kandidaten für weitere Untersuchungen ermittelt werden. Vorausgesetzt, daß isolierte HDAC außer HDAC8 eine nennenswerte Sequenzspezifität aufweisen, könnten so letztlich auch selektive Inhibitoren generiert werden. Dabei sollte dann der Aminosäurekontext als selektivitätsvermittelnde Kappe dienen, ähnlich wie bei der peptidischen Kappenstruktur des HDACI Trapoxin. Diese scheint für das selektive Wirken auf HDAC1 verantwortlich zu sein (Furumai et al., 2001; Kijima et al., 1993; Komatsu et al., 2001; Yoshida et al., 2001). Bei Trapoxin besteht sie allerdings aus vier zyklisch verknüpften Aminosäuren. Die Eignung des HDAC-Assays für das Screening konnte also auch hier bestätigt werden. Der Umfang der hier untersuchten Bibliothek (ca. 500) entsprach dabei etwa der Größe einer Kollektion, die in der Regel als repräsentativer Ausschnitt (1\%) einer größeren Gesamt-Bibliothek in einem Pilotscreening vermessen wird (Macarron and Hertzberg, 2002).

Bei allen Inhibitionsstudien darf auch nicht vergessen werden, daß die ermittelten $\mathrm{IC}_{50^{-}}$ Werte abhängig sind von der Art des Assays und des Substrates, besonders von der verwendeten HDAC-Quelle. So wurde in einem Beispiel keine Hemmung durch MS275 festgestellt, während andere Gruppen durchaus einen niedrigen mikromolaren $\mathrm{IC}_{50}$ gemessen hatten (Remiszewski et al., 2003). Außerdem ist die Tragweite der Erkenntnisse aus Hemmstudien insofern limitiert, daß oft eine viel höhere InhibitorKonzentration in Zellkulturexperimenten oder Tiermodellen eingesetzt werden muß, als der vorher in vitro ermittelte $\mathrm{IC}_{50}$ vermuten ließ. Darüberhinaus wurden oft beträchtliche Unterschiede in der Wirkung einer Substanz auf unterschiedliche KrebsZellinien gefunden (Remiszewski et al., 2003; Richon et al., 1996; Wada et al., 2003). Auch andere Parameter wie Toxizität, in vivo-Stabilität, Membrangängigkeit und Bioverfügbarkeit bei Erhalt der Potenz der Wirkstoffe sollten bei der Modifikation von Leitstrukturen berücksichtigt werden. So wurde etwa wegen der Labilität und schlechten Bioverfügbarkeit der Hydroxamate danach getrachtet, diese Gruppe durch andere wie etwa Trifluormethylketone (Frey et al., 2002) oder auch $\alpha$-Ketoamide (Wada et al., 2003) zu ersetzen. Am effektivsten wäre wohl eine HTS-begleitende Evaluierung 
der Wirksubstanzen durch Untersuchungen möglichst vieler der genannten anderen Parameter etwa im Rahmen einer Computer-unterstützten Multiparameter-Optimierung (Riester et al., 2003), um möglichst frühzeitig und damit kostensparend vor einer klinischen Phase ungeeignete, z. B. toxische Kandidaten aussieben zu können.

\subsection{Substratspezifität und Katalysemechanismus}

Bislang wurde in einigen Fällen die Präferenz von HDAC-Komplexen oder rekombinanten HDAC für Histonsubtypen, den Aminosäurekontext oder das Modifikationsmuster um das Acetyllysin untersucht (Bjerling et al., 2002; Clemente et al., 2001; Kolle et al., 1999; Wegener et al., 2003c), aber es wurden keine Untersuchungen der Substratspezifität von HDAC im Hinblick auf Modifikationen der Acylgruppe bekannt. Bislang wurde im Hinblick auf Substratspezifität für fluorogene Substrate nur von der leichten Präferenz für Z-MAL gegenüber Boc-Lys(Ac)-AMC von HDAC aus der Rattenleber berichtet (Heltweg et al., 2003). Z-MAL trägt eine andere Schutzgruppe anstelle von Boc an der $\alpha$-Aminogruppe. Aus dem Vergleich des Umsatzes von Minimalsubstraten des Typs Boc-Lys(z)-AMC (Abb. 33), die sich in der Größe (dem molekularen Volumen) ihrer Acylreste (z) an der Lysinseitenkette unterscheiden, kann auf die sterischen Verhältnisse im Aktiven Zentrum der HDAC geschlossen werden. Somit können Hinweise zum Entwurf selektiver HDACI abgeleitet werden. Diese könnten zusätzlich zu bereits untersuchten Modifikationen der Kappenregion als unterscheidendes Strukturmerkmal unterschiedlich große Gruppen am anderen Ende des Linkers tragen. HDAC mit wenig geräumiger Substrattasche würden wohl nicht von sperrigeren HDACI gehemmt. Zusätzlich sollte untersucht werden, ob Substrate mit anderen Acylgruppen eventuell besser, aber vor allem selektiv von den HDAC umgesetzt werden. Solche Substrate könnten als biochemische Werkzeuge z. B. zur Differenzierung des Beitrages unterschiedlicher HDAC zur Aktivität eines HDACKomplexes dienen. Die hier haupsächlich verfolgte Strategie zur Entwicklung von besseren Substraten, vor allem für HDAC8 sieht die Substituierung der $\varepsilon$-Aminogruppe am Lysin mit anderen Acylgruppen vor, welche nach Abspaltung bessere Abgangsgruppen als Acetat darstellen. Dabei sollten die Substrate umso besser umgesetzt werden, desto niedriger der $\mathrm{pK}_{\mathrm{a}}$ der entstehenden Säure ist. Auch hier könnten die erhaltenen Ergebnisse mit Substraten, die ein nucleophileres Carbonyl- 
Kohlenstoffatom enthalten, Hinweise über die Ladungsverteilung im Aktiven Zentrum des Enzyms geben.

Alle drei untersuchten HDAC hatten ein recht enges Substratspektrum und setzten die Substrate mit voluminösen oder verzweigten Acylgruppen (Propionyl-, Butyryl-, Isobutyryl-, Pivalyl- ) so gut wie nicht um. Daher ist anzunehmen, daß alle drei Enzyme eine recht beengte Substrattasche aufweisen, wie sie für HDLP aus der Kristallstruktur abzulesen ist (Finnin et al., 1999).

Für HDAC aus der Rattenleber war Boc-Lys(Ac)-AMC zwar das bevorzugte Substrat $\left(\mathrm{K}_{\mathrm{M}}: 3,7 \pm 1,7 \mu \mathrm{M}, \mathrm{V}_{\text {max }}: 4,41 \pm 0,1 \mathrm{pmol} \mathrm{sec}^{-1} \mathrm{mg}^{-1}\right)$. Als einzige Ausnahme konnte hier ein (etwa um 50\% schlechterer) Umsatz von Boc-Lys(Prop)-AMC ( $\mathrm{K}_{\mathrm{M}}: 105 \pm$ $14 \mu \mathrm{M}, \mathrm{V}_{\text {max }}: 4,38 \pm 0,41 \mathrm{pmol} \mathrm{sec}^{-1} \mathrm{mg}^{-1}$ ) beobachtet werden, was für eine etwas geräumigere Tasche im Aktiven Zentrum des Enzyms spricht. Unterschiede in der Aminosäuresequenz um das Aktive Zentrum einiger HDAC (Grozinger and Schreiber, 2002) könnten auch in diesem Fall zu abweichenden Geometrien führen, welche die Substratspezifität beeinflußt. Auch die gute Hemmung durch HDACI\#123 oder \#83 mit substituierten Kappen (4.2.2) legt eine etwas weitere Substrattasche nahe. Der geringe Unterschied in den $\mathrm{pK}_{\mathrm{a}}$-Werten der beiden Acylgruppen (Tab. 10) gab wohl nicht den Ausschlag für den unterschiedlichen Umsatz. Das Auftreten einer Produkthemmung durch die Natrium-Salze der Abgangsgruppen der umgesetzten Substrate, aber nicht durch NaTFA war nach dem postulierten Katalysemechanismus zu erwarten. Mit BocLys(Prop)-AMC konnte also tatsächlich ein für HDAC aus der Rattenleber spezifisches Substrat entwickelt werden.

Für HDAC8 hingegen war Boc-Lys(TFA)-AMC das mit Abstand beste Substrat $\left(\mathrm{K}_{\mathrm{M}}\right.$ : $247 \pm 89 \mu \mathrm{M}, \mathrm{V}_{\max }: 530 \pm 30 \mathrm{pmol} \mathrm{sec}^{-1} \mathrm{mg}^{-1}$ ). Hier scheint die saurere Abgangsgruppe $\left(\mathrm{pK}_{\mathrm{a}}\right.$ von 0,23$)$ tatsächlich, wie geplant, einen besseren Umsatz als mit acetyliertem Substrat $\left(\mathrm{pK}_{\mathrm{a}}\right.$ von 0,23$)$ zu bewirken. Zusätzlich wurde auch ein niedrigerer $\mathrm{K}_{\mathrm{M}}$-Wert als für bisherige fluorogen Substrate gefunden $(>500 \mu \mathrm{M})$. Dieses neue Substrat für HDAC8 dürfte biochemische Untersuchungen und besonders ein Screening nach Inhibitoren für HDAC8 sehr erleichtern. Ein spezifisches Substrat scheint es aber nicht zu sein, da auch FB188-HDAH Boc-Lys(TFA)-AMC etwa gleich gut wie Boc-Lys(Ac)AMC mit sehr ähnlichen kinetischen Parametern umsetzte (Dissertation von 
C. Hildmann, Tab. 10). Zumindest eine Unterscheidung von einigen HDAC sollte jedoch möglich sein, da ja HDAC aus der Rattenleber dieses Substrat nicht umsetzt, obwohl es wahrscheinlich ebenfalls der HDAC-Klasse I angehört. Seltsamerweise wurde aber in Kompetitionsversuchen keine Hemmung durch NaTFA gefunden, wohl aber durch NaAc und NaProp. Falls nicht elektrostatische oder sterische Hindernisse bei HDAC aus der Ratte verhinderten, daß sich der positive Effekt der besseren Abgangsgruppe auswirken konnte, ist dieses Ergebnis nicht gut mit dem postulierten, proteaseähnlichen Katalysemechanismus in Einklang zu bringen. Wobei mögliche sterische Effekte ja nicht die Bindung des Substrates mit der im Vergleich zu TFA wohl voluminöseren Propionylgruppe verhindert haben.

Auch andere Ergebnisse beleuchten Schwächen des für HDAC postulierten Katalysemechanismus. Inhibitionsexperimente mit Übergangszustandsmimetika (4.4.1 und 5.2) oder -analoga (Kapustin et al., 2003), welche nur sehr moderate Hemmwirkung zeigten, legen zumindest eine etwas andere Geometrie des Aktiven Zentrums nahe. Dies unterstützen auch $a b$ initio-Berechnungen der Energieminimierung für im Aktiven Zentrum von HDLP gebundenes Wasser (Vanommeslaeghe et al., 2003).

\subsection{Heterologe Expression von HDAC}

Da eine Schlüsselfunktion von HDAC1 als katalytische Komponente in NuRD- und mSin3-Komplexen bei der Transkriptionsreprimierung und der Tumorgenese gut belegt ist (Hauser et al., 2002; Kim et al., 2001; Lagger et al., 2002; Wade, 2001; You et al., 2001; Zhang et al., 1998; Zhang et al., 1999b), wird dieses Enzym als wichtiges neues Ziel für die therapeutische Intervention bei Krebs gesehen (Davie, 2003; Glaser et al., 2003a; Hu et al., 2003; Kim et al., 2003). Eine Entwicklung potenter Hemmstoffe gegen HDAC1 verlangt allerdings größere Mengen dieses Enzyms nicht nur für das primäre Screening als auch für eine nachfolgende Validierung der Ergebnisse in sekundären Tests bzw. allgemeinen biochemischen Untersuchungen z. B. zur Substratspezifität.

Bei der Entwicklung eines Wirkstoffes ist neben dessen Potenz ein anderes wichtiges Kriterium die Selektivität. Die unterschiedlichen und teilweise gegenläufigen 
biologischen Aufgaben verschiedener Isoformen der HDAC machen die Wichtigkeit der Entwicklung möglichst selektiver HDACI deutlich (Glaser et al., 2003a; Hu et al., 2003; Kook et al., 2003; Verdin et al., 2003; Zhang et al., 2003b), um möglicherweise fatale Wirkungen auf nicht-transformierte Zellen bzw. normale Zellabläufe zu minimieren. Daher sollte neben der humanen HDAC1 auch die Wirkung der Inhibitoren auf HDAC8 des Menschen und FB188-HDAH untersucht werden, welche als Modellenzyme für HDAC der Klasse I bzw. II dienten (5.2). Die HDAC8-Expression ist in einer Reihe von Krebszellinien stark erhöht (Van den Wyngaert et al., 2000) und somit wahrscheinlich ebenfalls ein medizinisch relevantes Zielenzym. Zudem war interessant zu sehen, ob die Sensitivität und die Substratspezifität von HDAC8 ihre Stellung nahe am Ursprung der Verzweigung des Homologie-Stammbaumes zwischen den beiden HDAC-Klassen (Buggy et al., 2000) wiederspiegeln würde.

Escherichia coli hat sich als effektives Expressions-System für eukaryotische Enzyme in vielen Fällen bewährt, und die HDAC-ähnliche FB188-HDAH wurde bereits erfolgreich heterolog in E. coli BL21 produziert (Hildmann et al., 2003). Daher wurde eine heterologe Expression von HDAC1 und HDAC8 unternommen. Dazu wurde mittels RT-PCR die für HDAC1 kodierende cDNA aus Osteoblasten-mRNA amplifiziert und in das Expressionsplasmid pQE70 kloniert. Von diesem Vektor aus wurde in verschiedenen Stämmen versucht, HDAC1 als Fusion mit einem N-terminalen Hexahistidin-tag zu exprimieren. Aber in keinem Fall konnte HDAC1 mittels Immunodetektion weder mit gegen den His-tag noch mit polyklonalen, gegen HDAC1 gerichteten Antikörpern nachgewiesen werden. Da aufgrund der unterschiedlichen codon usage von E. coli im Vergleich zum Menschen vermutet werden konnte, daß die in HDAC1 vorkommenden, seltenen Arginin-Codons die Translation behindern (Brinkmann et al., 1989), wurde eine entsprechende Arg-tRNA coexprimiert. Diese Strategie konnte bereits erfolgreich zur Steigerung der Produktion von diversen Proteinen mit seltenen Arg-Codons in E. coli angewandt werden (Brinkmann et al., 1989; You et al., 1999). Aber auch dadurch ließ sich HDAC1 nicht exprimieren. FB188-HDAH wurde hingegen erfolgreich mit N-terminalem His-tag in aktiver Form heterolog exprimiert (Hildmann et al., 2003). Auch die Expression von HDAC1 und anderer HDAC als C-terminale Fusion mit GST oder einer Gal4-Domäne allerdings in eukaryontischen Zellen zeigen, daß wohl keine prinzipielle Schwierigkeit der 
Expression in aktiver Form wie z. B. eine sterische Behinderung der Proteinfaltung mit einer N-terminalen Fusion verbunden ist (Hu et al., 2003; Huang and Kadonaga, 2001). Auch eine Fusion der HDAC1 aus Drosophila mit einem Hexahistidin-tag (Huang and Kadonaga, 2001) oder humaner HDAC1 mit einem FLAG-tag war aktiv (Finnin et al., 1999). Leider war der Publikation nicht die Position des His-tags zu entnehmen.

Ein HDAC1-Konstrukt mit C-terminalem His-tag konnte sehr wohl in verschiedenen E. coli-Stämmen exprimiert werden, was auch die Auswirkung der seltenen ArgCodons auf die Translation vernachlässigbar erscheinen läßt. Jedoch konnte keine HDAC1-Aktivität in Standard-HDAC-Assays mit HDAC1CHIS nachgewiesen werden, unabhängig von einer Coexpression der Arg-tRNA. Daher scheint auch eine Mißinkorporation von Lysin anstelle von Arginin, welche aufgrund seltener ArgCodons beobachtet worden ist (You et al., 1999), nicht als Erklärung für die Inaktivität tauglich zu sein. Die Expression einer C-terminal verkürzten HDAC1-Variante (HDAC1 $1 \Delta$ CHIS) wurde unternommen, da im Gegensatz zu HDAC1, 2 und 3 die bereits in E. coli in aktiver Form exprimierte, humane HDAC8 keinen verlängerten, stark sauren C-Terminus aufweisen ( $\mathrm{Hu}$ et al., 2000). Doch auch bei diesem Konstrukt konnte nur eine Expression, aber keine HDAC-Aktivität nachgewiesen werden. Ein positiver Einfluß auf die HDAC1-Aktivität wurde für die Phosphorylierung von zwei Serinen innerhalb einer Konsensussequenz für die Casein-Kinase 2 im C-Terminus der HDAC1 gefunden (Pflum et al., 2001). Diese postranslationale Modifikation der HDAC1 erfolgt in E. coli selbst bei der HDAC1-Variante voller Länge nicht. Interessanterweise weist HDAC8 ebenfalls drei theoretische Phosphorylierungsstellen auf, welche aber wohl für die Produktion aktiven Enzyms in E. coli keine große Rolle spielen (Hu et al., 2000). Darüberhinaus wurde der C-Terminus von HDAC1 als essentiell für die Aktivität in vivo beschrieben. Eine nach As390 abgeschnittene HDAC1-Variante zeigte nur noch ca. $20 \%$ der Wildtyp-Aktivität (Pflum et al., 2001). Andere C-terminal verkürzte HDAC wiesen ebenfalls durchaus Aktivität auf (Tong et al., 2002). Auch RPD3 aus S. cerevisiae fehlt der verlängerte, geladene Schwanz (Pflum et al., 2001). Es besteht natürlich die Möglichkeit, daß die Position, an der die HDAC1CHIS-Variante abbricht, zufällig ungünstig gewählt wurde und andere Positionen geeigneter gewesen wären. Allerdings endet die Homologie zwischen HDAC1 und HDAC8 bzw. HDLP etwa an dieser Stelle (mit Leu373, Abb. 23). Eine 
HDAC1-Variante ohne tag konnte zwar exprimiert werden, war aber in StandardHDAC-Assays ebenfalls inaktiv. Somit scheint der His-tag nicht das ausschlaggebende Detail für die fehlende Aktivität des Enzyms zu sein, wohingegen die Position des Histags sehr wohl einen starken Effekt auf die Expression dieser HDAC in E. coli zu haben scheint. Auch bei der FB188-HDAH wirkte sich die Position des His-tags auf die Aktivität stark aus (Hildmann et al., 2003 und Dissertation C. Hildmann).

Die Aktivität einer über Ni-NTA-Säulen aufgereinigten HDAC1 mit His-tag aus Drosophila zeigt die Unabhängigkeit der Enzymaktivität von anderen Proteinen oder Cofaktoren (außer dem Metall-Ion im aktiven Zentrum) (Huang and Kadonaga, 2001). Über den Phosphorylierungsgrad des Enzyms wird allerdings nicht berichtet. Auch konnte bei einer Aufreinigung der HDAC1 über Affinitätschromatographie unter Nutzung des FLAG-tags kein Verlust des Metall-Cofaktors beobachtet werden (Finnin et al., 1999).

Möglicherweise im Lysat der Expressionskulturen vorhandene reversible Inhibitoren der HDAC1 sollten durch die anschließend erfolgte IMAC-Aufreinigung und Dialyse der Fraktionen entfernt worden sein. Aber auch in diesen Fraktionen war zwar HDAC1 über einen Western Blot nachweisbar, aber keine HDAC-Aktivität zu finden. Daher kommt eigentlich nur eine irreversible Inaktivierung der HDAC1 in Frage. Allerdings haben die Aufreinigungsversuche der in aktiver Form exprimierten HDAC8 über IMAC mit Chelating-Sepharose-Matrix gezeigt, daß eine zusätzliche Inaktivierung auch auf der Säule erfolgt sein könnte (s. u.). Um einen möglichen hemmenden Einfluß von Komponenten des Lysates auszuschließen, müßte aktive HDAC1 z. B. aus einer heterologen Expression in Insektenzellen (Finnin et al., 1999; Huang and Kadonaga, 2001) mit Lysat vorinkubiert und nachfolgend mit Hilfe des HDAC-Assay Umsatzkurven mit unbehandelter und frisch mit Lysat versetzter HDAC vermessen werden. Da HDAC8 und FB188-HDAH jedoch keine Inaktivierung im Lysat zeigten, müßte es sich zusätzlich noch um einen recht spezifischen Hemmer für HDAC1 handeln. Abschließende Expressionsversuche der HDAC1CHIS in E.coli mit nachfolgender Aufreinigung über NiNTA-Säulen bzw. einen Anionenaustauscher und Analyse im HDAC-Assay erscheinen aufgrund der schnellen Durchführbarkeit sinnvoll. Besonders im Hinblick auf die Wichtigkeit von Phosphorylierungen mag die Nutzung von eukaryotischen Expressionssystemen möglicherweise unumgänglich zu sein. Auch 
in der Literatur wurde mit Ausnahme von HDAC8 (Hu et al., 2000), Hos3 (Carmen et al., 1999) und HosB (Trojer et al., 2003) keine Expression von HDAC in E. coli in aktiver Form beschrieben, obwohl die bloße Expression von HDAC und auch von HDAC-Fragmenten vor allem als GST-Fusionsproteine häufig gelang (Dressel et al., 2001; Fischle et al., 2001a; Taplick et al., 2001; Trojer et al., 2003; Zhang et al., 2001a). Explizit genannt wird das Scheitern der Expression von aktiver HDAC1 und HDAC3 des Menschen mit C-terminalem His-tag in E. coli (Hu et al., 2003). Die Expression von aktivem HosB bzw. Hos3 erfolgte ebenfalls in Fusion mit GST (Trojer et al., 2003) bzw. mit CBP, einem Calmodulin-Bindeprotein (Carmen et al., 1999).

Im Gegensatz zur aufwendigen Produktion in Insektenzellen erscheinen Expressionswirte wie die methylotrophe Hefe Pichia pastoris als eine gute Alternative (Cereghino and Cregg, 2000). Hier müssen aber aller Voraussicht nach endogene HDAC von der produzierten HDAC1 abgetrennt werden, was bei prokaryotischen Systemen nicht nötig ist. Außerdem kann selbst in eukaryotischen Systemen wie etwa Insektenzellen mitunter nur eine C-terminal verkürzte HDAC-Variante exprimiert werden (Tong et al., 2002).

Im Gegensatz zu HDAC1 war für humane HDAC8 die heterologe Expression in E. coli als aktives Enzym mit einem C-terminalen His-tag möglich (4.3.2). Mehrere Aufreinigungsversuche mittels IMAC über eine Chelating-Sepharose-Säule scheiterten jedoch, obwohl von einer erfolgreichen Aufreinigung der HDAC8 über IMAC berichtet worden war (Hu et al., 2000). Dabei war nach Dialyse der Eluat-Fraktionen über Western Blot durchaus noch ausreichende Mengen HDAC8 nachzuweisen, allerdings keine HDAC-Aktivität mehr (4.3.3). Ein Verlust des Cofaktors des Enzyms bei der Aufreinigung käme als Grund in Frage. Der Zusatz von hohen Zink-Konzentrationen wirkte sich positiv auf die Aktivität von FB188-HDAH aus (Hildmann et al., 2003). Und Finnin und Kollegen berichteten über einen Verlust des Metall-Cofaktors während der Aufreinigung von HDLP (über den GST-tag) (Finnin et al., 1999). Aber im Gegensatz zu HDLP und FB188-HDAH konnte bei HDAC8 ein Zusatz von $\mathrm{ZnCl}_{2}$ zum dialysierten HDAC8-Eluat die Enzymaktivität nicht restaurieren. Ein mögliches 'Ausbluten' des Nickels von der Säule könnte die HDAC8 inhibiert haben, indem das Zink-Ion im Enzym durch Nickel verdrängt worden ist. Im Unterschied zu ChelatingSepharose-Säulen, die Metalliganden über ihre Iminodiacetylgruppen nur 3-zähnig 
komplexieren (Porath et al., 1975), bindet die Nitrilotriacetylgruppe (NTA) der NTAAgarose-Matrix Metalliganden 4-zähnig und somit fester (Hochuli, 1989). Dies könnte durch die Abgabe von Nickel durch die Chelating-Sepharose-Matrix im Unterschied zur NTA-Agarose zur Inaktivierung der HDAC8 nur bei Verwendung der Sepharose-Matrix beitragen und erklären, warum $\mathrm{Hu}$ und Kollegen aktive HDAC8 eluieren konnten. Ein hemmender Effekt des Nickels bei Konzentrationen über $1 \mathrm{mM}$ wurde z. B. auf FB188HDAH verzeichnet (Hildmann et al., 2003). Von einer ca. 90\%igen Inhibition der HDAC8 durch $1 \mathrm{mM} \mathrm{ZnCl}_{2}$ wurde ebenfalls berichtet, leider wurde der Einfluß von $\mathrm{Ni}^{2+}$-Ionen dort nicht untersucht (Hu et al., 2000). So besteht nach diesem Befund auch die Möglichkeit, daß der HDAC8-Fraktion zu viel Zink zugesetzt wurde. Damit würde auch der Umstand etwas verständlicher, weshalb nach Aufreinigung des Enzyms über eine mit Zink beladene Säule ebenfalls keine Aktivität zu detektieren war. Dabei wird aber nicht klar, warum auch nach Abtrennung des überschüssigen $\mathrm{ZnCl}_{2}$ durch Dialyse oder Entsalzungssäulchen das Enzym inaktiv bleibt. Vielleicht erfolgt durch hohe Metallionen-Konzentration eine irreversible Denaturierung oder Umfaltung des Enzyms.

Schließlich waren Versuche zur Aufreinigung der HDAC8 über eine Ni-NTA-AgaroseMatrix erfolgreich, indem nach Dialyse die HDAC8-Fraktionen im HDAC-Assay aktiv waren. Weitere Aufreinigungsversuche mit dieser Matrix im größeren Maßstab werden zeigen, ob die HDAC8-Produktion auf diese Weise im Vergleich zu der in dieser Arbeit sonst verwendeten Anionenaustausch-Chromatographie (s. u.) beschleunigt werden kann. Dabei sollte ein Vergleich der kinetischen Parameter von HDAC8-Präparationen einer mit Nickel bzw. mit Zink beladenen Matrix entscheiden, ob das Metallion einen Einfluß hat, der berücksichtigt werden muß.

Die Aufreinigung der HDAC8 über einen Anionenaustauscher war ebenfalls eine effektive Methode, um Medienkomponenten und die meisten Wirtsproteine der Expressionskultur abzutrennen (4.3.4). Zudem beschleunigte die Verwendung hoher Flußraten $(10 \mathrm{ml} / \mathrm{min})$ bei der Chromatographie das Verfahren sehr, wodurch das Enzym zudem schnell von Proteasen abgetrennt werden konnte. Die erhaltene, partiell aufgereinigte HDAC8-Präparation war völlig ausreichend für den Einsatz in den HDAC-Assay. Aus einem Liter Expressionskultur konnten dabei etwa 1,4 mg HDAC8Präparation in ca. $12 \mathrm{ml}$ Eluat präpariert werden, was ausreichend für über 200 HDAC- 
Assays mit Boc-Lys(Ac)-AMC wäre. Die anfangs verwendete, kommerzielle HDAC8Präparation (Biomol) litt deutlich unter wiederholtem Auftauen und Einfrieren und wäre als Zielenzym beim Screening viel zu teuer. Die Eigenproduktion ermöglichte die Verwendung möglichst frischer HDAC8. Auch sonst werden HDAC für in vitroEnzymtests verwandt, die nur partiell über einen Anionenaustauscher aufgereinigt wurden (Hoffmann et al., 1999; Hoffmann et al., 2000; Remiszewski et al., 2002). 


\section{Zusammenfassung und Ausblick}

Krebs ist eine der häufigsten Todesursachen in Europa, den USA und anderen Industrieländern und verursacht einen enormen Leidensdruck bei den Betroffenen und hohe Kosten für die Gesellschaft insgesamt. Erst in den letzten Jahren wurde die entscheidende Rolle der Histondeacetylasen (HDAC) bei der Pathogenese von bestimmten Tumoren erkannt und diese folgerichtig als wichtiges molekulares Zielenzym eingestuft (Jung, 2000; Jung, 2001). Die Entwicklung von selektiven und hoch potenten Inhibitoren dieser Enzyme wurde damit zum erklärten Ziel der Pharmaforschung (Krämer et al., 2001). Eine oft verfolgte Strategie zur Entwicklung von neuen Leitstrukturen stellt die Durchmusterung chemischer Bibliotheken nach Substanzen dar (das sogenannte Screening), die das Zielenzym hemmen (Macarron and Hertzberg, 2002). Dabei ist es wegen der riesigen Zahl an inerten Kandidaten, die normalerweise als häufigste Fraktion der Bibliothek den Hintergrund bilden, unumgänglich, Tausende von Substanzen zu testen, um die statistische Chance, einen Wirkstoff (Hit) zu finden, nicht verschwindend klein werden zu lassen. So zeigte eine Langzeitstudie bei Pfizer, daß im Mittel bei einem gegebenen Zielprotein mit einer HitRate von 1 pro 120000 Kandidatenmolekülen zu rechnen ist (Spencer, 1998). Diese Einsicht zwingt zur Parallelisierung, d. h. der Testung vieler Substanzen gleichzeitig, und zur Miniaturisierung, d. h. zur Durchführung der Assays in Mikroformaten, um Zeit und Reagenzien und damit schließlich Kosten zu sparen. In den letzten Jahren sind daher verstärkt Bemühungen unternommen worden, die Durchmusterung von Bibliotheken mit hohem Durchsatz (high-throuput screening, HTS) zu automatisieren und zu optimieren (Macarron and Hertzberg, 2002).

Der Mangel an einem für dieses Vorgehen geeigneten, nicht-radioaktiven, biochemische Assays stellte bislang ein großes Hindernis in der Entwicklung von HDAC-Inhibitoren (HDACI), wie auch insgesamt der biochemischen Charakterisierung dieser Enzymklasse dar (Wegener et al., 2003b). 


\section{Der erste HTS-fähige, homogene Fluoreszenzassay für Histondeacetylasen}

Im Rahmen dieser Arbeit wurde der erste HTS-geeignete, homogene, Fluoreszenzbasierte HDAC-Assay entwickelt, welcher in einem zweistufigem Prozess ein gekoppeltes Enzymsystem und acetylierte peptidische Substrate ausnutzt. Eine Validierung des Assays mit HDAC aus Rattenleber bzw. humaner HDAC8 und bekannten HDACI sowie die Auffindung von Hemmern in einer kleinen Substanzbibliothek belegte dessen Sensitivität, Reproduzierbarkeit und Eignung für HTS-Anwendungen. Die Entwicklung eines für alle HDAC nutzbaren, kontinuierlichen Fluoreszenz-Assays wird in einer begleitenden Arbeit vorangetrieben. Der HDACAssay konnte im folgenden, vor allem durch die Verwendung eines neuen fluorogenen Substrates, weiter optimiert werden und erreichte einen $Z^{\prime}$-Faktor von 0,8, was als exzellent eingestuft (Zhang et al., 1999a) und selten erreicht wird. Darüber hinaus waren erste Versuche erfolgreich, den Assay über das 96 well-Format hinaus an echte Mikroformate anzupassen. Die erzielten Ergebnisse mit dem NanoSynTest ${ }^{\text {TM }}$ Prototypen (Groß, 2002; Schlingloff, 1999) im 1536 well-Format lassen eine weitere Miniaturisierung hin zum Nanoliterbereich realistisch erscheinen.

\section{Potente und selektive HDAC-Inhibitoren}

Jüngste Untersuchungen belegen eine Aufgabenverteilung verschiedener HDAC und legen nahe, daß auch Nicht-Histon-Substrate und damit andere Rollen von HDAC wahrgenommen werden. Daher wären selektive Inhibitoren von großer Bedeutung für die Krebstherapie sowie für die Aufklärung der zellulären Funktion einzelner HDAC (Kim et al., 2003; Krämer et al., 2001).

Rational entworfene HDACI wurden in vitro in Inhibitionsexperimenten evaluiert. Die ermittelten $\mathrm{IC}_{50}$-Werte für HDAC aus der Rattenleber, humane HDAC8 und FB188HDAH wiesen einige der Substanzen als neue potente HDACI mit Wirkung im niedrigen nanomolaren Bereich aus. Für FB188-HDAH kam eine in diesem Fall anwendbare, kontinuierliche Variante des HDAC-Assay zum Einsatz. Darüber hinaus konnten selektive HDACI entwickelt werden, welche entweder präferenziell das Modellenzym für HDAC der Klasse II hemmen (Faktor 14-29) oder sogar innerhalb der Klasse I-Enzyme differenzieren (Faktor 58). Dabei konnte gezeigt werden, daß potente 
HDACI entwickelt werden können, die nicht dem sonst realisierten Schema „KappeLinker-Hydroxamat" zuzuordnen sind. Die zur Synthese der Inhibitoren genutzte Strategie erschließt offenbar den Zugang zu effektiven chemischen Strukturen, so daß weitere Inhibitoren synthetisiert und vermessen werden können. Anhand des vorgeschlagenen Katalyse-Modells für HDAC (Finnin et al., 1999) synthetisierte putative Übergangszustandsmimetika zeigten hingegen kaum Hemmwirkung.

Bei der Durchmusterung von chemischen Bibliotheken im Hochdurchsatzverfahren mit dem HDAC-Assay wurden neue HDACI identifiziert. Für diese konnten mit Hilfe des Assays Dosis-Wirkungs-Kurven aufgenommen werden. Weitere Screening-Runden (auch im 1536 well- bzw. Nanoliter-Format) werden sicherlich neuartige Leitstrukturen aufzeigen, welche dann gemeinsam mit den bereits gefundenen Kandidaten im Hinblick auf andere, pharmakologisch wichtige Parameter wie Toxizität und Membrangängigkeit, aber auch auf ihre Wirkung auf Tumorzellinien geprüft werden sollen.

Das Durchmustern einer Bibliothek peptidischer Inhibitoren stellt eine zur Untersuchung der Sequenzabhängigkeit der HDAC mit Substraten komplementäre Herangehensweise dar, da sie die Untersuchung des Kontextes C-terminal vom Acetyllysin ermöglicht. Diese Strategie soll im weiteren zur Identifizierung des natürlichen Substrates von HDAC8 und zur Entwicklung von selektiven HDACI genutzt werden.

\section{Auf dem Weg zu HDAC-spezifischen Assays und Substraten}

Bereits bei der Assay-Entwicklung und Optimierung wurden für einige, aus dem Histon-Kontext abgeleitete, peptidische Substrate $\mathrm{K}_{\mathrm{M}}$ und $\mathrm{V}_{\max }$ ermittelt. Nachfolgend wurde die Substratspezifität der Enzyme eingehender im Hinblick auf die mit dem Lysin der Substrate über dessen $\varepsilon$-Aminogruppe gekoppelten Reste untersucht. Dabei wurde sowohl bei HDAC aus der Rattenleber als auch bei humaner HDAC8 ein recht enges Substratspektrum mit Bevorzugung kleinerer Acylgruppen gefunden.

Weiterhin ist es gelungen, mit Boc-Lys(Prop)-AMC ein Substrat zu entwickeln, welches zwischen HDAC aus der Rattenleber und HDAC8 bzw. FB188-HDAH diskriminiert. Die breitere Substratspezifität für HDAC aus der Rattenleber korreliert 
dabei mit den Befunden aus Inhibitionsexperimenten für dieses Enzym. Beide Untersuchungen sagen eine etwas erweiterte Substrattasche voraus. Im Rahmen dieser Untersuchungen gelang es weiterhin, mit Boc-Lys(TFA)-AMC auch für HDAC8 ein noch geeigneteres Substrat zu entwickeln. Damit wurde die Möglichkeit erschlossen, Inhibitoren für HDAC8 mittels HTS zu gewinnen. Die Befunde aus Kompetitionsstudien mit Salzen der Abgangsgruppen weisen ebenso wie die Inhibitionsstudien mit HDACI auf einen möglicherweise abweichenden Katalysemechanismus hin.

\section{Produktion von HDAC}

Im Rahmen dieser Arbeit ist es gelungen, die für humane HDAC1 bzw. HDAC8 kodierende cDNA zu klonieren. In einem E. coli-System wurde die heterologe Expression beider HDAC erreicht. Im Falle der HDAC1 konnte jedoch keinerlei Enzymaktivität detektiert werden. Im Gegensatz dazu ließ sich HDAC8 in aktiver Form exprimieren. Das Enzym konnte in hinreichender Reinheit und Menge über Anionenaustauschchromatographie aufgereinigt werden. Letztlich gelang auch eine alternative Aufreinigung über IMAC. 


\section{Literaturverzeichnis}

Agalioti, T., Chen, G. and Thanos, D. (2002). Deciphering the transcriptional histone acetylation code for a human gene. Cell, (111), 381-92.

Ahmad, K. and Henikoff, S. (2002). Epigenetic consequences of nucleosome dynamics. Cell, (111), 281-4.

Allan, G. (1989) Sequencing of Proteins and PeptidesElsevier, Amsterdam.

Alland, L., Muhle, R., Hou, H., Jr., Potes, J., Chin, L., Schreiber-Agus, N. and DePinho, R.A. (1997). Role for N-CoR and histone deacetylase in Sin3-mediated transcriptional repression. Nature, (387), 49-55.

Allfrey, V.G., Faulkner, R. and Mirsky, A.E. (1964). Acetylation and Methylation of Histones and Their Possible Role in the Regulation of Rna Synthesis. Proc Natl Acad Sci U S A, (51), 786-94.

Baek, S.H., Ohgi, K.A., Rose, D.W., Koo, E.H., Glass, C.K. and Rosenfeld, M.G. (2002). Exchange of N-CoR corepressor and Tip60 coactivator complexes links gene expression by NF-kappaB and betaamyloid precursor protein. Cell, (110), 55-67.

Balbas, P. (2001). Understanding the art of producing protein and nonprotein molecules in Escherichia coli. Mol Biotechnol, (19), 251-67.

Ball, L.J., Murzina, N.V., Broadhurst, R.W., Raine, A.R., Archer, S.J., Stott, F.J., Murzin, A.G., Singh, P.B., Domaille, P.J. and Laue, E.D. (1997). Structure of the chromatin binding (chromo) domain from mouse modifier protein 1. Embo J, (16), 2473-81.

Bannister, A.J., Schneider, R. and Kouzarides, T. (2002). Histone methylation: dynamic or static? Cell, (109), 801-6.

Bartl, S., Taplick, J., Lagger, G., Khier, H., Kuchler, K. and Seiser, C. (1997). Identification of mouse histone deacetylase 1 as a growth factor-inducible gene. Mol Cell Biol, (17), 5033-43.

Baumann, M., Stürmer, R. and Bornscheuer, U.T. (2001). A high-throughput-screening method for the identification of enantioselective hydrolases. Angew Chem Int Ed Engl, (40), 4201-4.

Becker, P.B. and Horz, W. (2002). ATP-dependent nucleosome remodeling. Annu Rev Biochem, (71), 247-73.

Belotserkovskaya, R., Oh, S., Bondarenko, V.A., Orphanides, G., Studitsky, V.M. and Reinberg, D. (2003). FACT facilitates transcription-dependent nucleosome alteration. Science, (301), 1090-3.

Berg, M. (1998) Methodenentwicklung und Etablierung von Fluoreszenzassays zur Wirkstoffsuche im 1536-Well Format. Institut für Mechanische Verfahrenstechnik und Mechanik. Universität Karlsruhe, Karlsruhe.

Bernstein, B.E., Tong, J.K. and Schreiber, S.L. (2000). Genomewide studies of histone deacetylase function in yeast. Proc Natl Acad Sci US A, (97), 13708-13.

Biomol. (2003) Product News.

Bird, A. (2001). Molecular biology. Methylation talk between histones and DNA. Science, (294), 2113-5.

Bird, A.W., Yu, D.Y., Pray-Grant, M.G., Qiu, Q., Harmon, K.E., Megee, P.C., Grant, P.A., Smith, M.M. and Christman, M.F. (2002). Acetylation of histone H4 by Esal is required for DNA doublestrand break repair. Nature, (419), 411-5.

Birnboim, H.C. and Doly, J. (1979). A rapid alkaline extraction procedure for screening recombinant plasmid DNA. Nucleic Acids Res, (7), 1513-23. 
Bjerling, P., Silverstein, R.A., Thon, G., Caudy, A., Grewal, S. and Ekwall, K. (2002). Functional divergence between histone deacetylases in fission yeast by distinct cellular localization and in vivo specificity. Mol Cell Biol, (22), 2170-81.

Bonadies, F., Cardilli, A., Lattanzi, A., Orelli, L.R. and Scettri, A. (1994). Tetrahedron Letters, (35), 3383.

Bouchain, G., Leit, S., Frechette, S., Khalil, E.A., Lavoie, R., Moradei, O., Woo, S.H., Fournel, M., Yan, P.T., Kalita, A., Trachy-Bourget, M.C., Beaulieu, C., Li, Z., Robert, M.F., MacLeod, A.R., Besterman, J.M. and Delorme, D. (2003). Development of potential antitumor agents. Synthesis and biological evaluation of a new set of sulfonamide derivatives as histone deacetylase inhibitors. $J$ Med Chem, (46), 820-30

Bradford, M.M. (1976). A rapid and sensitive method for the quantitation of microgram quantities of protein utilizing the principle of protein-dye binding. Anal. Biochem., (72), 248-54.

Briggs, S.D., Xiao, T., Sun, Z.W., Caldwell, J.A., Shabanowitz, J., Hunt, D.F., Allis, C.D. and Strahl, B.D. (2002). Gene silencing: trans-histone regulatory pathway in chromatin. Nature, (418), 498.

Brinkmann, U., Mattes, R.E. and Buckel, P. (1989). High-level expression of recombinant genes in Escherichia coli is dependent on the availability of the dnaY gene product. Gene, (85), 109-14.

Brosch, G., Lusser, A., Goralik-Schramel, M. and Loidl, P. (1996). Purification and characterization of a high molecular weight histone deacetylase complex (HD2) of maize embryos. Biochemistry, (35), 15907-14.

Brosch, G., Ransom, R., Lechner, T., Walton, J.D. and Loidl, P. (1995). Inhibition of maize histone deacetylases by HC toxin, the host-selective toxin of Cochliobolus carbonum. Plant Cell, (7), 1941-50.

Buggy, J.J., Sideris, M.L., Mak, P., Lorimer, D.D., McIntosh, B. and Clark, J.M. (2000). Cloning and characterization of a novel human histone deacetylase, HDAC8. Biochem J, (350 Pt 1), 199-205.

Bullock, W.O., Fernandez, J.M. and Short, J.M. (1987). XL1-Blue: A high efficiency plasmid transforming recA Escherichia coli strain with $\beta$-galactosidase selection. Biotechniques, (5), 376-379.

Butler, L.M., Agus, D.B., Scher, H.I., Higgins, B., Rose, A., Cordon-Cardo, C., Thaler, H.T., Rifkind, R.A., Marks, P.A. and Richon, V.M. (2000). Suberoylanilide hydroxamic acid, an inhibitor of histone deacetylase, suppresses the growth of prostate cancer cells in vitro and in vivo. Cancer Res, (60), 5165-70.

Butler, L.M., Zhou, X., Xu, W.S., Scher, H.I., Rifkind, R.A., Marks, P.A. and Richon, V.M. (2002). The histone deacetylase inhibitor SAHA arrests cancer cell growth, up-regulates thioredoxin-binding protein-2, and down-regulates thioredoxin. Proc Natl Acad Sci U S A, (99), 11700-5.

Carmen, A.A., Griffin, P.R., Calaycay, J.R., Rundlett, S.E., Suka, Y. and Grunstein, M. (1999). Yeast HOS3 forms a novel trichostatin A-insensitive homodimer with intrinsic histone deacetylase activity. Proc Natl Acad Sci U S A, (96), 12356-61.

Castro-Galache, M.D., Ferragut, J.A., Barbera, V.M., Martin-Orozco, E., Gonzalez-Ros, J.M., Garcia-Morales, P. and Saceda, M. (2003). Susceptibility of multidrug resistance tumor cells to apoptosis induction by histone deacetylase inhibitors. Int J Cancer, (104), 579-86.

Cereghino, J.L. and Cregg, J.M. (2000). Heterologous protein expression in the methylotrophic yeast Pichia pastoris. FEMS Microbiol Rev, (24), 45-66.

Chan, H.M., Krstic-Demonacos, M., Smith, L., Demonacos, C. and La Thangue, N.B. (2001). Acetylation control of the retinoblastoma tumour-suppressor protein. Nat Cell Biol, (3), 667-74.

Chang, C.H. and Luse, D.S. (1997). The H3/H4 tetramer blocks transcript elongation by RNA polymerase II in vitro. $J$ Biol Chem, (272), 23427-34.

Cheng, X., Hochlowski, J., Tang, H., Hepp, D., Beckner, C., Kantor, S. and Schmitt, R. (2003). Studies on Repository Compound Stability in DMSO under Various Conditions. J Biomol Screen, (8), 292-304. 
Cheung, P., Tanner, K.G., Cheung, W.L., Sassone-Corsi, P., Denu, J.M. and Allis, C.D. (2000). Synergistic coupling of histone H3 phosphorylation and acetylation in response to epidermal growth factor stimulation. Mol Cell, (5), 905-15.

Chung, D. (2002). Histone modification: the 'next wave' in cancer therapeutics. Trends Mol Med, (8), S10-1.

Clapier, C.R., Langst, G., Corona, D.F., Becker, P.B. and Nightingale, K.P. (2001). Critical role for the histone H4 N terminus in nucleosome remodeling by ISWI. Mol Cell Biol, (21), 875-83.

Clemente, S., Franco, L. and Lopez-Rodas, G. (2001). Distinct site specificity of two pea histone deacetylase complexes. Biochemistry, (40), 10671-6.

Clements, A., Poux, A.N., Lo, W.S., Pillus, L., Berger, S.L. and Marmorstein, R. (2003). Structural basis for histone and phosphohistone binding by the GCN5 histone acetyltransferase. Mol Cell, (12), 46173.

Cohen, S.N., Chang, A.C. and Hsu, L. (1972). Nonchromosomal antibiotic resistance in bacteria: genetic transformation of Escherichia coli by R-factor DNA. Proc Natl Acad Sci U S A, (69), 2110-4.

Contreras, A., Hale, T.K., Stenoien, D.L., Rosen, J.M., Mancini, M.A. and Herrera, R.E. (2003). The Dynamic Mobility of Histone H1 Is Regulated by Cyclin/CDK Phosphorylation. Mol Cell Biol, (23), 8626-36.

Cornish-Bowden, A. (1999) Fundamentals of Enzyme Kinetics. Revised Edition. Portland Press, London.

Covault, J. and Chalkley, R. (1980). The identification of distinct populations of acetylated histone. $J$ Biol Chem, (255), 9110-6.

Crane-Robinson, C., Hebbes, T.R., Clayton, A.L. and Thorne, A.W. (1997). Chromosomal mapping of core histone acetylation by immunoselection. Methods, (12), 48-56.

Curtin, M.L., Garland, R.B., Heyman, H.R., Frey, R.R., Michaelides, M.R., Li, J., Pease, L.J., Glaser, K.B., Marcotte, P.A. and Davidsen, S.K. (2002). Succinimide hydroxamic acids as potent inhibitors of histone deacetylase (HDAC). Bioorg Med Chem Lett, (12), 2919-23.

CycLex. (2002). CycLex HDAC Assay kit. HDAC Assay Kit Manual.

Czermin, B., Schotta, G., Hulsmann, B.B., Brehm, A., Becker, P.B., Reuter, G. and Imhof, A. (2001). Physical and functional association of SU(VAR)3-9 and HDAC1 in Drosophila. EMBO Rep, (2), 915-9.

Dangond, F. and Gullans, S.R. (1998). Differential expression of human histone deacetylase mRNAs in response to immune cell apoptosis induction by trichostatin A and butyrate. Biochem Biophys Res Commun, (247), 833-7.

Dangond, F., Hafler, D.A., Tong, J.K., Randall, J., Kojima, R., Utku, N. and Gullans, S.R. (1998). Differential display cloning of a novel human histone deacetylase (HDAC3) cDNA from PHA-activated immune cells. Biochem Biophys Res Commun, (242), 648-52.

David, G., Turner, G.M., Yao, Y., Protopopov, A. and DePinho, R.A. (2003). mSin3-associated protein, $\mathrm{mSds} 3$, is essential for pericentric heterochromatin formation and chromosome segregation in mammalian cells. Gen Dev, (17), 2396-2405.

Davie, J.R. (2003). Inhibition of histone deacetylase activity by butyrate. J Nutr, (133), 2485S-93S.

De Rubertis, F., Kadosh, D., Henchoz, S., Pauli, D., Reuter, G., Struhl, K. and Spierer, P. (1996). The histone deacetylase RPD3 counteracts genomic silencing in Drosophila and yeast. Nature, (384), 589-91.

de Ruijter, A.J., van Gennip, A.H., Caron, H.N., Kemp, S. and van Kuilenburg, A.B. (2003). Histone deacetylases (HDACs): characterization of the classical HDAC family. Biochem J, (370), 737-49.

De Souza, C.P., Osmani, A.H., Wu, L.P., Spotts, J.L. and Osmani, S.A. (2000). Mitotic histone H3 phosphorylation by the NIMA kinase in Aspergillus nidulans. Cell, (102), 293-302. 
Dequiedt, F., Kasler, H., Fischle, W., Kiermer, V., Weinstein, M., Herndier, B.G. and Verdin, E. (2003). HDAC7, a thymus-specific class II histone deacetylase, regulates Nur77 transcription and TCRmediated apoptosis. Immunity, (18), 687-98.

Dhalluin, C., Carlson, J.E., Zeng, L., He, C., Aggarwal, A.K. and Zhou, M.M. (1999). Structure and ligand of a histone acetyltransferase bromodomain. Nature, (399), 491-6.

Dower, W.J., Miller, J.F. and Ragsdale, C.W. (1988). High efficiency transformation of E. coli by high voltage electroporation. Nucleic Acids Res, (16), 6127-45.

Dressel, U., Bailey, P.J., Wang, S.C., Downes, M., Evans, R.M. and Muscat, G.E. (2001). A dynamic role for HDAC7 in MEF2-mediated muscle differentiation. J Biol Chem, (276), 17007-13.

Edwards, C.P. and Aruffo, A. (1993). Current applications of COS cell based transient expression systems. Curr Opin Biotechnol, (4), 558-63.

Emiliani, S., Fischle, W., Van-Lint, C., Al-Abed, Y. and Verdin, E. (1998). Characterisation of a human RPD3 ortholog, HDAC3. PNAS, (95), 2295-2800.

Evnin, L.B., Vasquez, J.R. and Craik, C.S. (1990). Substrate specificity of trypsin investigated by using a genetic selection. Proc Natl Acad Sci U S A, (87), 6659-63.

Finnin, M.S., Donigian, J.R., Cohen, A., Richon, V.M., Rifkind, R.A., Marks, P.A., Breslow, R. and Pavletich, N.P. (1999). Structures of a histone deacetylase homologue bound to the TSA and SAHA inhibitors. Nature, (401), 188-93.

Fischetti, V.A., Medaglini, D., Oggioni, M. and Pozzi, G. (1993). Expression of foreign proteins on gram-positive commensal bacteria for mucosal vaccine delivery. Curr Opin Biotechnol, (4), 603-10.

Fischle, W., Dequiedt, F., Fillion, M., Hendzel, M.J., Voelter, W. and Verdin, E. (2001a). Human HDAC7 histone deacetylase activity is associated with HDAC3 in vivo. J Biol Chem, (276), 35826-35.

Fischle, W., Kiermer, V., Dequiedt, F. and Verdin, E. (2001b). The emerging role of class II histone deacetylases. Biochem Cell Biol, (79), 337-48.

Fischle, W., Wang, Y. and Allis, C.D. (2003). Histone and chromatin cross-talk. Curr Opin Cell Biol, (15), 172-83.

Frey, R.R., Wada, C.K., Garland, R.B., Curtin, M.L., Michaelides, M.R., Li, J., Pease, L.J., Glaser, K.B., Marcotte, P.A., Bouska, J.J., Murphy, S.S. and Davidsen, S.K. (2002). Trifluoromethyl ketones as inhibitors of histone deacetylase. Bioorg Med Chem Lett, (12), 3443-7.

Frye, R.A. (1999). Characterization of five human cDNAs with homology to the yeast SIR2 gene: Sir2like proteins (sirtuins) metabolize NAD and may have protein ADP-ribosyltransferase activity. Biochem Biophys Res Commun, (260), 273-9.

Frye, R.A. (2000). Phylogenetic classification of prokaryotic and eukaryotic Sir2-like proteins. Biochem Biophys Res Commun, (273), 793-8.

Fu, M., Rao, M., Wang, C., Sakamaki, T., Wang, J., Di Vizio, D., Zhang, X., Albanese, C., Balk, S., Chang, C., Fan, S., Rosen, E., Palvimo, J.J., Janne, O.A., Muratoglu, S., Avantaggiati, M.L. and Pestell, R.G. (2003). Acetylation of Androgen Receptor Enhances Coactivator Binding and Promotes Prostate Cancer Cell Growth. Mol Cell Biol, (23), 8563-8575.

Fuks, F., Hurd, P.J., Wolf, D., Nan, X., Bird, A.P. and Kouzarides, T. (2003). The methyl-CpGbinding protein MeCP2 links DNA methylation to histone methylation. J Biol Chem, (278), 4035-40.

Furumai, R., Komatsu, Y., Nishino, N., Khochbin, S., Yoshida, M. and Horinouchi, S. (2001). Potent histone deacetylase inhibitors built from trichostatin A and cyclic tetrapeptide antibiotics including trapoxin. Proc Natl Acad Sci US A, (98), 87-92.

Furumai, R., Matsuyama, A., Kobashi, N., Lee, K.H., Nishiyama, M., Nakajima, H., Tanaka, A., Komatsu, Y., Nishino, N., Yoshida, M. and Horinouchi, S. (2002). FK228 (depsipeptide) as a natural prodrug that inhibits class I histone deacetylases. Cancer Res, (62), 4916-21.

Gao, L., Cueto, M.A., Asselbergs, F. and Atadja, P. (2002). Cloning and functional characterization of HDAC11, a novel member of the human histone deacetylase family. J Biol Chem, (277), 25748-55. 
Geisse, S., Gram, H., Kleuser, B. and Kocher, H.P. (1996). Eukaryotic expression systems: a comparison. Protein Expr Purif, (8), 271-82.

Glaser, K.B., Li, J., Staver, M.J., Wei, R.Q., Albert, D.H. and Davidsen, S.K. (2003a). Role of class I and class II histone deacetylases in carcinoma cells using siRNA. Biochem Biophys Res Commun, (310), 529-36.

Glaser, K.B., Staver, M.J., Waring, J.F., Stender, J., Ulrich, R.G. and Davidsen, S.K. (2003b). Gene Expression Profiling of Multiple Histone Deacetylase (HDAC) Inhibitors: Defining a Common Gene Set Produced by HDAC Inhibition in T24 and MDA Carcinoma Cell Lines. Mol Cancer Ther, (2), 151-63.

Graessle, S., Loidl, P. and Brosch, G. (2001). Histone acetylation: plants and fungi as model systems for the investigation of histone deacetylases. Cell Mol Life Sci, (58), 704-20.

Grahn, S., Ullmann, D. and Jakubke, H. (1998). Design and synthesis of fluorogenic trypsin peptide substrates based on resonance energy transfer. Anal Biochem, (265), 225-31.

Grignani, F., De Matteis, S., Nervi, C., Tomassoni, L., Gelmetti, V., Cioce, M., Fanelli, M., Ruthardt, M., Ferrara, F.F., Zamir, I., Seiser, C., Lazar, M.A., Minucci, S. and Pelicci, P.G. (1998). Fusion proteins of the retinoic acid receptor-alpha recruit histone deacetylase in promyelocytic leukaemia. Nature, (391), 815-8.

Groß, G.A. (2002) Miniaturisierung von kombinatorischen Festphasensynthesen zur Automatisierung der Wirkstofffindung. Fakultät für Naturwissenschaften und Mathematik. Universität Wien, Wien.

Grozinger, C.M., Chao, E.D., Blackwell, H.E., Moazed, D. and Schreiber, S.L. (2001). Identification of a class of small molecule inhibitors of the sirtuin family of NAD-dependent deacetylases by phenotypic screening. J Biol Chem, (276), 38837-43.

Grozinger, C.M., Hassig, C.A. and Schreiber, S.L. (1999). Three proteins define a class of human histone deacetylases related to yeast Hda1p. Proc Natl Acad Sci U S A, (96), 4868-73.

Grozinger, C.M. and Schreiber, S.L. (2002). Deacetylase enzymes. Biological functions and the use of small-molecule inhibitors. Chem Biol, (9), 3-16.

Grunstein, M. (1997a). Histone acetylation in chromatin structure and transcription. Nature, (389), 34952.

Grunstein, M. (1997b). Molecular model for telomeric heterochromatin in yeast. Curr Opin Cell Biol, (9), 383-7.

Gu, W. and Roeder, R.G. (1997). Activation of p53 sequence-specific DNA binding by acetylation of the p53 C-terminal domain. Cell, (90), 595-606.

Haggarty, S.J., Koeller, K.M., Wong, J.C., Butcher, R.A. and Schreiber, S.L. (2003a). Multidimensional chemical genetic analysis of diversity-oriented synthesis-derived deacetylase inhibitors using cell-based assays. Chem Biol, (10), 383-96.

Haggarty, S.J., Koeller, K.M., Wong, J.C., Grozinger, C.M. and Schreiber, S.L. (2003b). Domainselective small-molecule inhibitor of histone deacetylase 6 (HDAC6)-mediated tubulin deacetylation. Proc Natl Acad Sci U S A, (100), 4389-94.

Hamamori, Y. and Schneider, M.D. (2003). HATs off to Hop: recruitment of a class I histone deacetylase incriminates a novel transcriptional pathway that opposes cardiac hypertrophy. J Clin Invest, (112), 824-6.

Hansen, J.C. and Wolffe, A.P. (1992). Influence of chromatin folding on transcription initiation and elongation by RNA polymerase III. Biochemistry, (31), 7977-88.

Hansen, J.C. and Wolffe, A.P. (1994). A role for histones H2A/H2B in chromatin folding and transcriptional repression. Proc Natl Acad Sci U S A, (91), 2339-43.

Hashimshony, T., Zhang, J., Keshet, I., Bustin, M. and Cedar, H. (2003). The role of DNA methylation in setting up chromatin structure during development. Nat Genet, (34), 187-92. 
Hassan, A.H., Prochasson, P., Neely, K.E., Galasinski, S.C., Chandy, M., Carrozza, M.J. and Workman, J.L. (2002). Function and selectivity of bromodomains in anchoring chromatin-modifying complexes to promoter nucleosomes. Cell, (111), 369-79.

Hassig, C.A., Tong, J.K., Fleischer, T.C., Owa, T., Grable, P.G., Ayer, D.E. and Schreiber, S.L. (1998). A role for histone deacetylase activity in HDAC1-mediated transcriptional repression. Proc Natl Acad Sci U S A, (95), 3519-24.

Hauser, C., Schuettengruber, B., Bartl, S., Lagger, G. and Seiser, C. (2002). Activation of the mouse histone deacetylase 1 gene by cooperative histone phosphorylation and acetylation. Mol Cell Biol, (22), 7820-30.

Hayes, J.J. and Hansen, J.C. (2001). Nucleosomes and the chromatin fiber. Curr Opin Genet Dev, (11), 124-9.

He, L.Z., Tolentino, T., Grayson, P., Zhong, S., Warrell, R.P., Jr., Rifkind, R.A., Marks, P.A., Richon, V.M. and Pandolfi, P.P. (2001). Histone deacetylase inhibitors induce remission in transgenic models of therapy-resistant acute promyelocytic leukemia. J Clin Invest, (108), 1321-30.

Hebbes, T.R., Thorne, A.W. and Crane-Robinson, C. (1988). A direct link between core histone acetylation and transcriptionally active chromatin. Embo J, (7), 1395-402.

Hebbes, T.R., Turner, C.H., Thorne, A.W. and Crane-Robinson, C. (1989). A "minimal epitope" antiprotein antibody that recognises a single modified amino acid. Mol Immunol, (26), 865-73.

Heinzel, T., Lavinsky, R.M., Mullen, T.M., Soderstrom, M., Laherty, C.D., Torchia, J., Yang, W.M., Brard, G., Ngo, S.D., Davie, J.R., Seto, E., Eisenman, R.N., Rose, D.W., Glass, C.K. and Rosenfeld, M.G. (1997). A complex containing N-CoR, mSin3 and histone deacetylase mediates transcriptional repression. Nature, (387), 43-8.

Heltweg, B., Dequiedt, F., Verdin, E. and Jung, M. (2003). Nonisotopic substrate for assaying both human zinc and NAD(+)-dependent histone deacetylases. Anal Biochem, (319), 42-8.

Heltweg, B. and Jung, M. (2002a). Eosin Y as an internal standard for a plate reader-based quantitation of a histone deacetylase substrate. Arch Pharm (Weinheim), (335), 296-300.

Heltweg, B. and Jung, M. (2002b). A microplate reader-based nonisotopic histone deacetylase activity assay. Anal Biochem, (302), 175-83.

Heltweg, B. and Jung, M. (2003). A Homogeneous Nonisotopic Histone Deacetylase Activity Assay. J Biomol Screen, (8), 89-95.

Hendrich, B., Guy, J., Ramsahoye, B., Wilson, V.A. and Bird, A. (2001). Closely related proteins MBD2 and MBD3 play distinctive but interacting roles in mouse development. Genes Dev, (15), 710-23.

Hildmann, C., Ninkovic, M., Dietrich, R., Wegener, D., Riester, D., Zimmermann, T., Birch, O.M., Bernegger, C., Loidl, P. and Schwienhorst, A. (2003). A new amidohydrolase from Bordetella/Alcaligenes strain FB188 with similarities to histone deacetylases. J Bacteriol, (in press).

Hochuli, E. (1989). Genetically designed affinity chromatography using a novel metal chelate absorbent. Biologically active Molecules, 217-239.

Hoffmann, K., Brosch, G., Loidl, P. and Jung, M. (1999). A non-isotopic assay for histone deacetylase activity. Nucleic Acids Res, (27), 2057-8.

Hoffmann, K., Brosch, G., Loidl, P. and Jung, M. (2000). First non-radioactive assay for in vitro screening of histone deacetylase inhibitors. Pharmazie, (55), 601-6.

Hoffmann, K., Heltweg, B. and Jung, M. (2001a). Improvement and validation of the fluorescencebased histone deacetylase assay using an internal standard. Arch Pharm (Weinheim), (334), 248-52.

Hoffmann, K., Soll, R.M., Beck-Sickinger, A.G. and Jung, M. (2001b). Fluorescence-labeled octapeptides as substrates for histone deacetylase. Bioconjug Chem, (12), 51-5.

Hollenberg, C.P. and Gellissen, G. (1997). Production of recombinant proteins by methylotrophic yeasts. Curr Opin Biotechnol, (8), 554-60. 
Hoshikawa, Y., Kwon, H.J., Yoshida, M., Horinouchi, S. and Beppu, T. (1994). Trichostatin A induces morphological changes and gelsolin expression by inhibiting histone deacetylase in human carcinoma cell lines. Exp Cell Res, (214), 189-97.

Hu, E., Chen, Z., Fredrickson, T., Zhu, Y., Kirkpatrick, R., Zhang, G.F., Johanson, K., Sung, C.M., Liu, R. and Winkler, J. (2000). Cloning and characterization of a novel human class I histone deacetylase that functions as a transcription repressor. J Biol Chem, (275), 15254-64.

Hu, E., Dul, E., Sung, C.M., Chen, Z., Kirkpatrick, R., Zhang, G.F., Johanson, K., Liu, R., Lago, A., Hofmann, G., Macarron, R., De Los Frailes, M., Perez, P., Krawiec, J., Winkler, J. and Jaye, M. (2003). Identification of Novel Isoform-Selective Inhibitors within Class I Histone Deacetylases. $J$ Pharmacol Exp Ther, (307), 720-8.

Huang, E.Y., Zhang, J., Miska, E.A., Guenther, M.G., Kouzarides, T. and Lazar, M.A. (2000). Nuclear receptor corepressors partner with class II histone deacetylases in a Sin3-independent repression pathway. Genes Dev, (14), 45-54.

Huang, X. and Kadonaga, J.T. (2001). Biochemical analysis of transcriptional repression by Drosophila histone deacetylase 1. J Biol Chem, (276), 12497-500.

Huang, Y., Myers, S.J. and Dingledine, R. (1999). Transcriptional repression by REST: recruitment of Sin3A and histone deacetylase to neuronal genes. Nat Neurosci, (2), 867-72.

Hubbert, C., Guardiola, A., Shao, R., Kawaguchi, Y., Ito, A., Nixon, A., Yoshida, M., Wang, X.F. and Yao, T.P. (2002). HDAC6 is a microtubule-associated deacetylase. Nature, (417), 455-8.

Hüser, J., Mundt, S., Allin, C. and Meyer-Almes, F.-J. (2002) Schnelle Wirkstofffindung mit automatisierter 1536-Loch Screening Technologie. Biospektrum, Vol. 8, pp. 301-6.

Ikonomou, L., Schneider, Y.J. and Agathos, S.N. (2003). Insect cell culture for industrial production of recombinant proteins. Appl Microbiol Biotechnol, (62), 1-20.

Inoue, A. and Fujimoto, D. (1970). Histone deacetylase from calf thymus. Biochim Biophys Acta, (220), 307-16.

Jackman, J.E., Fierke, C.A., Tumey, L.N., Pirrung, M., Uchiyama, T., Tahir, S.H., Hindsgaul, O. and Raetz, C.R. (2000). Antibacterial agents that target lipid A biosynthesis in gram-negative bacteria. Inhibition of diverse UDP-3-O-(r-3-hydroxymyristoyl)-n-acetylglucosamine deacetylases by substrate analogs containing zinc binding motifs. J Biol Chem, (275), 11002-9.

Jacobs, S.A. and Khorasanizadeh, S. (2002). Structure of HP1 chromodomain bound to a lysine 9methylated histone H3 tail. Science, (295), 2080-3.

Jenuwein, T. and Allis, C.D. (2001). Translating the histone code. Science, (293), 1074-80.

Jenuwein, T., Laible, G., Dorn, R. and Reuter, G. (1998). SET domain proteins modulate chromatin domains in eu- and heterochromatin. Cell Mol Life Sci, (54), 80-93.

Jeppesen, P. and Turner, B.M. (1993). The inactive X chromosome in female mammals is distinguished by a lack of histone H4 acetylation, a cytogenetic marker for gene expression. Cell, (74), 281-9.

Johnson, C.A., White, D.A., Lavender, J.S., O'Neill, L.P. and Turner, B.M. (2002). Human class I histone deacetylase complexes show enhanced catalytic activity in the presence of ATP and coimmunoprecipitate with the ATP-dependent chaperone protein Hsp70. J Biol Chem, (277), 9590-7.

Johnstone, R.W. (2002). Histone-deacetylase inhibitors: novel drugs for the treatment of cancer. Nat Rev Drug Discov, (1), 287-99.

Jones, P.L., Veenstra, G.J., Wade, P.A., Vermaak, D., Kass, S.U., Landsberger, N., Strouboulis, J. and Wolffe, A.P. (1998). Methylated DNA and MeCP2 recruit histone deacetylase to repress transcription. Nat Genet, (19), 187-91.

Juan, L.J., Shia, W.J., Chen, M.H., Yang, W.M., Seto, E., Lin, Y.S. and Wu, C.W. (2000). Histone deacetylases specifically down-regulate p53-dependent gene activation. J Biol Chem, (275), 20436-43.

Jung, M. (2000). [Inhibitors of histone deacetylase as new agents for prevention and treatment of cancer]. Pharm Unserer Zeit, (29), 385-8. 
Jung, M. (2001). Inhibitors of histone deacetylase as new anticancer agents. Curr Med Chem, (8), 150511.

Jung, M., Brosch, G., Kolle, D., Scherf, H., Gerhauser, C. and Loidl, P. (1999). Amide analogues of trichostatin A as inhibitors of histone deacetylase and inducers of terminal cell differentiation. $J$ Med Chem, (42), 4669-79.

Kao, H.Y., Downes, M., Ordentlich, P. and Evans, R.M. (2000). Isolation of a novel histone deacetylase reveals that class I and class II deacetylases promote SMRT-mediated repression. Genes Dev, (14), 55-66.

Kapustin, G.V., Fejer, G., Gronlund, J.L., McCafferty, D.G., Seto, E. and Etzkorn, F.A. (2003). Phosphorus-based SAHA analogues as histone deacetylase inhibitors. Org Lett, (5), 3053-6.

Katan-Khaykovich, Y. and Struhl, K. (2002). Dynamics of global histone acetylation and deacetylation in vivo: rapid restoration of normal histone acetylation status upon removal of activators and repressors. Genes Dev, (16), 743-52.

Kelly, W.K., O'Connor, O.A. and Marks, P.A. (2002). Histone deacetylase inhibitors: from target to clinical trials. Expert Opin Investig Drugs, (11), 1695-713.

Kelly, W.K., Richon, V.M., O'Connor, O., Curley, T., MacGregor-Curtelli, B., Tong, W., Klang, M., Schwartz, L., Richardson, S., Rosa, E., Drobnjak, M., Cordon-Cordo, C., Chiao, J.H., Rifkind, R., Marks, P.A. and Scher, H. (2003). Phase I clinical trial of histone deacetylase inhibitor: suberoylanilide hydroxamic acid administered intravenously. Clin Cancer Res, (9), 3578-88.

Kervabon, A., Mery, J. and Parello, J. (1979). Enzymatic deacetylation of a synthetic peptide fragment of histone H4. FEBS Lett, (106), 93-6.

Khmelnitsky, Y.L., Mozhaev, V.V., Belova, A.B., Sergeeva, M.V. and Martinek, K. (1991). Denaturation capacity: a new quantitative criterion for selection of organic solvents as reaction media in biocatalysis. Eur J Biochem, (198), 31-41.

Khochbin, S., Verdel, A., Lemercier, C. and Seigneurin-Berny, D. (2001). Functional significance of histone deacetylase diversity. Curr Opin Genet Dev, (11), 162-6.

Khochbin, S. and Wolffe, A.P. (1997). The origin and utility of histone deacetylases. FEBS Lett, (419), 157-60.

Kijima, M., Yoshida, M., Sugita, K., Horinouchi, S. and Beppu, T. (1993). Trapoxin, an antitumor cyclic tetrapeptide, is an irreversible inhibitor of mammalian histone deacetylase. J Biol Chem, (268), 22429-35.

Kim, D.H., Kim, M. and Kwon, H.J. (2003). Histone deacetylase in carcinogenesis and its inhibitors as anti-cancer agents. J Biochem Mol Biol, (36), 110-9.

Kim, M.S., Kwon, H.J., Lee, Y.M., Baek, J.H., Jang, J.E., Lee, S.W., Moon, E.J., Kim, H.S., Lee, S.K., Chung, H.Y., Kim, C.W. and Kim, K.W. (2001). Histone deacetylases induce angiogenesis by negative regulation of tumor suppressor genes. Nat Med, (7), 437-43.

Kim, Y.B., Lee, K.H., Sugita, K., Yoshida, M. and Horinouchi, S. (1999). Oxamflatin is a novel antitumor compound that inhibits mammalian histone deacetylase. Oncogene, (18), 2461-70.

Kirsh, O., Seeler, J.S., Pichler, A., Gast, A., Muller, S., Miska, E., Mathieu, M., Harel-Bellan, A., Kouzarides, T., Melchior, F. and Dejean, A. (2002). The SUMO E3 ligase RanBP2 promotes modification of the HDAC4 deacetylase. Embo J, (21), 2682-91.

Klan, N., Seuter, S., Schnur, N., Jung, M. and Steinhilber, D. (2003). Trichostatin A and structurally related histone deacetylase inhibitors induce 5-lipoxygenase promoter activity. Biol Chem, (384), 777-85.

Kline, T., Andersen, N.H., Harwood, E.A., Bowman, J., Malanda, A., Endsley, S., Erwin, A.L., Doyle, M., Fong, S., Harris, A.L., Mendelsohn, B., Mdluli, K., Raetz, C.R., Stover, C.K., Witte, P.R., Yabannavar, A. and Zhu, S. (2002). Potent, novel in vitro inhibitors of the Pseudomonas aeruginosa deacetylase LpxC. J Med Chem, (45), 3112-29.

Knight, C.G. (1995) Active-Site Titration of Peptidases. Academic Press, Vol. 248. 
Koeller, K.M., Haggarty, S.J., Perkins, B.D., Leykin, I., Wong, J.C., Kao, M.C. and Schreiber, S.L. (2003). Chemical genetic modifier screens. Small molecule trichostatin suppressors as probes of intracellular histone and tubulin acetylation. Chem Biol, (10), 397-410.

Köhler, J.M. (1995). Microsystems Technologies, (1), 202-8.

Kolle, D., Brosch, G., Lechner, T., Lusser, A. and Loidl, P. (1998). Biochemical methods for analysis of histone deacetylases. Methods, (15), 323-31.

Kolle, D., Brosch, G., Lechner, T., Pipal, A., Helliger, W., Taplick, J. and Loidl, P. (1999). Different types of maize histone deacetylases are distinguished by a highly complex substrate and site specificity. Biochemistry, (38), 6769-73.

Komatsu, Y., Tomizaki, K.Y., Tsukamoto, M., Kato, T., Nishino, N., Sato, S., Yamori, T., Tsuruo, T., Furumai, R., Yoshida, M., Horinouchi, S. and Hayashi, H. (2001). Cyclic hydroxamic-acidcontaining peptide 31 , a potent synthetic histone deacetylase inhibitor with antitumor activity. Cancer Res, (61), 4459-66.

Kook, H., Lepore, J.J., Gitler, A.D., Lu, M.M., Wing-Man Yung, W., Mackay, J., Zhou, R., Ferrari, V., Gruber, P. and Epstein, J.A. (2003). Cardiac hypertrophy and histone deacetylase-dependent transcriptional repression mediated by the atypical homeodomain protein Hop. J Clin Invest, (112), 86371.

Kornberg, R.D. and Lorch, Y. (1999). Twenty-five years of the nucleosome, fundamental particle of the eukaryote chromosome. Cell, (98), 285-94.

Kost, T.A. (1997). Expression systems: Gene expression systems in the genomics era. Curr Opin Biotechnol, (8), 539-41.

Kost, T.A. and Condreay, J.P. (1999). Recombinant baculoviruses as expression vectors for insect and mammalian cells. Curr Opin Biotechnol, (10), 428-33.

Kouzarides, T. (2000). Acetylation: a regulatory modification to rival phosphorylation? Embo J, (19), 1176-9.

Kozikowski, B.A., Burt, T.M., Tirey, D.A., Williams, L.E., Kuzmak, B.R., Stanton, D.T., Morand, K.L. and Nelson, S.L. (2003). The Effect of Freeze/Thaw Cycles on the Stability of Compounds in DMSO. J Biomolec Screen, (8), 210-5.

Kraker, A.J., Mizzen, C.A., Hartl, B.G., Miin, J., Allis, C.D. and Merriman, R.L. (2003). Modulation of histone acetylation by [4-(acetylamino)-N-(2-amino-phenyl) benzamide] in HCT-8 colon carcinoma. Mol Cancer Ther, (2), 401-8.

Krämer, O.H., Gottlicher, M. and Heinzel, T. (2001). Histone deacetylase as a therapeutic target. Trends Endocrinol Metab, (12), 294-300.

Kubinyi, H. (1998). Molekulare Ähnlichkeit. 2: Strukturbasierter Entwurf von Wirkstoffen. Pharm Unserer Zeit, (27), 158-72.

Kuntz, I.D. (1992). Structure-based strategies for drug design and discovery. Science, (257), 1078-82.

Kwon, H., Imbalzano, A.N., Khavari, P.A., Kingston, R.E. and Green, M.R. (1994). Nucleosome disruption and enhancement of activator binding by a human SW1/SNF complex. Nature, (370), 477-81.

Kwon, H.J., Kim, M. and Kim, D.H. (2003). Histone Deacetylase in Carcinogenesis and Its Inhibitors as Anti-cancer Agents. J Biochem Mol Biol, (36), 110-9.

Kwon, H.J., Kim, M.S., Kim, M.J., Nakajima, H. and Kim, K.W. (2002). Histone deacetylase inhibitor FK228 inhibits tumor angiogenesis. Int J Cancer, (97), 290-6.

Kwon, H.J., Owa, T., Hassig, C.A., Shimada, J. and Schreiber, S.L. (1998). Depudecin induces morphological reversion of transformed fibroblasts via the inhibition of histone deacetylase. Proc Natl Acad Sci U S A, (95), 3356-61.

Lachner, M., O'Carroll, D., Rea, S., Mechtler, K. and Jenuwein, T. (2001). Methylation of histone H3 lysine 9 creates a binding site for HP1 proteins. Nature, (410), 116-20. 
Laemmli, U.K. (1970). Cleavage of structural proteins during the assembly of the head of bacteriophage T4. Nature, (227), 680-5.

Lagger, G., O'Carroll, D., Rembold, M., Khier, H., Tischler, J., Weitzer, G., Schuettengruber, B., Hauser, C., Brunmeir, R., Jenuwein, T. and Seiser, C. (2002). Essential function of histone deacetylase 1 in proliferation control and CDK inhibitor repression. Embo J, (21), 2672-81.

Landry, J., Slama, J.T. and Sternglanz, R. (2000). Role of NAD(+) in the deacetylase activity of the SIR2-like proteins. Biochem Biophys Res Commun, (278), 685-90.

Langst, G. and Becker, P.B. (2001). Nucleosome mobilization and positioning by ISWI-containing chromatin-remodeling factors. J Cell Sci, (114), 2561-8.

Lechner, T., Lusser, A., Brosch, G., Eberharter, A., Goralik-Schramel, M. and Loidl, P. (1996). A comparative study of histone deacetylases of plant, fungal and vertebrate cells. Biochim Biophys Acta, (1296), 181-8.

Lee, D.Y., Hayes, J.J., Pruss, D. and Wolffe, A.P. (1993). A positive role for histone acetylation in transcription factor access to nucleosomal DNA. Cell, (72), 73-84.

Legube, G. and Trouche, D. (2003). Regulating histone acetyltransferases and deacetylases. EMBO Rep, (4), 944-7.

Lehninger, A.L., Nelson, D.L. and Cox, M.M. (1994) Prinzipien der Biochemie. 2. Auflage. Spektrum Akademischer Verlag, Heidelberg, Berlin, Oxford.

Leipe, D.D. and Landsman, D. (1997). Histone deacetylases, acetoin utilization proteins and acetylpolyamine amidohydrolases are members of an ancient protein superfamily. Nucleic Acids Res, (25), 3693-7.

Li, J., Wang, J., Nawaz, Z., Liu, J.M., Qin, J. and Wong, J. (2000). Both corepressor proteins SMRT and N-CoR exist in large protein complexes containing HDAC3. Embo J, (19), 4342-50.

Li, S. and Wilkinson, M.F. (1997). Site-directed mutagenesis: a two-step method using PCR and DpnI. Biotechniques, (23), 588-590.

Li, X., Uchiyama, T., Raetz, C.R. and Hindsgaul, O. (2003). Synthesis of a Carbohydrate-Derived Hydroxamic Acid Inhibitor of the Bacterial Enzyme (LpxC) Involved in Lipid A Biosynthesis. Org Lett, (5), 539-41.

Liebecq, C. (1978) Biochemical nomenclature and related documentsInternational Union for Biochemistry. The Biochemical Society, London.

Lin, R.J., Nagy, L., Inoue, S., Shao, W., Miller, W.H., Jr. and Evans, R.M. (1998). Role of the histone deacetylase complex in acute promyelocytic leukaemia. Nature, (391), 811-4.

Linseman, D.A., Bartley, C.M., Le, S.S., Laessig, T.A., Bouchard, R.J., Meintzer, M.K., Li, M. and Heidenreich, K.A. (2003). Inactivation of the myocyte enhancer factor-2 repressor histone deacetylase-5 by endogenous $\mathrm{Ca}(2+) / /$ calmodulin-dependent kinase II promotes depolarization-mediated cerebellar granule neuron survival. J Biol Chem, (278), 41472-81.

Lo, W.S., Trievel, R.C., Rojas, J.R., Duggan, L., Hsu, J.Y., Allis, C.D., Marmorstein, R. and Berger, S.L. (2000). Phosphorylation of serine 10 in histone H3 is functionally linked in vitro and in vivo to Gcn5-mediated acetylation at lysine 14. Mol Cell, (5), 917-26.

Lottspeich, F. and Zorbas, H. (1998) Bioanalytik Spektrum Akademischer Verlag, Heidelberg, Berlin.

Luger, K., Mader, A.W., Richmond, R.K., Sargent, D.F. and Richmond, T.J. (1997). Crystal structure of the nucleosome core particle at 2.8 A resolution. Nature, (389), 251-60.

Lusser, A., Brosch, G., Loidl, A., Haas, H. and Loidl, P. (1997). Identification of maize histone deacetylase HD2 as an acidic nucleolar phosphoprotein. Science, (277), 88-91.

Macarron, R. and Hertzberg, R.P. (2002) Design and Implementation of High Throughput Screening Assays. In Janzen, W.P. (ed.) High Throughput Screening: Methods and Protocols. Humana Press, Totowa, New Jersey, Vol. 190, pp. 1-29. 
Magnaghi-Jaulin, L., Groisman, R., Naguibneva, I., Robin, P., Lorain, S., Le Villain, J.P., Troalen, F., Trouche, D. and Harel-Bellan, A. (1998). Retinoblastoma protein represses transcription by recruiting a histone deacetylase. Nature, (391), 601-5.

Mai, A., Massa, S., Pezzi, R., Rotili, D., Loidl, P. and Brosch, G. (2003). Discovery of (Aryloxopropenyl)pyrrolyl Hydroxamides as Selective Inhibitors of Class IIa Histone Deacetylase Homologue HD1-A. J Med Chem, (46), 4826-9.

Makowski, A.M., Dutnall, R.N. and Annunziato, A.T. (2001). Effects of acetylation of histone H4 at lysines 8 and 16 on activity of the Hat1 histone acetyltransferase. J Biol Chem, (276), 43499-502.

Mandel, M. and Higa, A. (1970). Calcium-dependent bacteriophage DNA infection. J Mol Biol, (53), 159-62.

Maniatis, T., Fritsch, E.F. and Sambrook, J. (1989) Molecular cloning : a laboratory manual. 2nd Edition. Cold Spring Harbor Laboratory Press, Cold Spring Harbor, New York.

Mao, Z., Bonni, A., Xia, F., Nadal-Vicens, M. and Greenberg, M.E. (1999). Neuronal activitydependent cell survival mediated by transcription factor MEF2. Science, (286), 785-90.

Marks, P., Rifkind, R.A., Richon, V.M., Breslow, R., Miller, T. and Kelly, W.K. (2001). Histone deacetylases and cancer: causes and therapies. Nat Rev Cancer, (1), 194-202.

Marks, P.A., Richon, V.M. and Rifkind, R.A. (2000). Histone deacetylase inhibitors: inducers of differentiation or apoptosis of transformed cells. J Natl Cancer Inst, (92), 1210-6.

Marmorstein, R. (2001a). Protein modules that manipulate histone tails for chromatin regulation. Nat Rev Mol Cell Biol, (2), 422-32.

Marmorstein, R. (2001b). Structure of histone deacetylases: insights into substrate recognition and catalysis. Structure (Camb), (9), 1127-33.

Martinez-Balbas, M.A., Bauer, U.M., Nielsen, S.J., Brehm, A. and Kouzarides, T. (2000). Regulation of E2F1 activity by acetylation. Embo $J,(\mathbf{1 9}), 662-71$.

McCarthy, C. (1995). Chromas. Southport, Australia.

McKinsey, T.A., Zhang, C.L., Lu, J. and Olson, E.N. (2000a). Signal-dependent nuclear export of a histone deacetylase regulates muscle differentiation. Nature, (408), 106-11.

McKinsey, T.A., Zhang, C.L. and Olson, E.N. (2000b). Activation of the myocyte enhancer factor-2 transcription factor by calcium/calmodulin-dependent protein kinase-stimulated binding of 14-3-3 to histone deacetylase 5. Proc Natl Acad Sci US A, (97), 14400-5.

McKinsey, T.A., Zhang, C.L. and Olson, E.N. (2001a). Control of muscle development by dueling HATs and HDACs. Curr Opin Genet Dev, (11), 497-504.

McKinsey, T.A., Zhang, C.L. and Olson, E.N. (2001b). Identification of a signal-responsive nuclear export sequence in class II histone deacetylases. Mol Cell Biol, (21), 6312-21.

Meinke, P.T., Colletti, S.L., Doss, G., Myers, R.W., Gurnett, A.M., Dulski, P.M., Darkin-Rattray, S.J., Allocco, J.J., Galuska, S., Schmatz, D.M., Wyvratt, M.J. and Fisher, M.H. (2000). Synthesis of apicidin-derived quinolone derivatives: parasite-selective histone deacetylase inhibitors and antiproliferative agents. $J$ Med Chem, (43), 4919-22.

Meinke, P. and Liberator, P. (2001). Histone deacetylase: a target for antiproliferative and antiprotozoal agents. Curr Med Chem, (8), 211-35.

Min, J., Zhang, Y. and Xu, R.M. (2003). Structural basis for specific binding of Polycomb chromodomain to histone $\mathrm{H} 3$ methylated at Lys 27. Genes Dev, (17), 1823-8.

Morin, V., Diaz, F., Montecino, M., Fothergill-Gilmore, L., Puchi, M. and Imschenetzky, M. (1999). Poly(ADP-ribosylation) protects maternally derived histones from proteolysis after fertilization. Biochem $J$, (343 Pt 1), 95-8. 
Muegge, K., Young, H., Ruscetti, F. and Mikovits, J. (2003). Epigenetic control during lymphoid development and immune responses: aberrant regulation, viruses, and cancer. Ann N Y Acad Sci, (983), 55-70.

Mullis, K.B. and Faloona, F.A. (1987). Specific synthesis of DNA in vitro via a polymerase-catalyzed chain reaction. Methods Enzymol, (155), 335-50.

Munshi, N., Agalioti, T., Lomvardas, S., Merika, M., Chen, G. and Thanos, D. (2001). Coordination of a transcriptional switch by HMGI(Y) acetylation. Science, (293), 1133-6.

Murray, K. (1964). The Occurrence of Epsilon-N-Methyl Lysine in Histones. Biochemistry, (127), 10-5.

Nagy, L., Kao, H.Y., Chakravarti, D., Lin, R.J., Hassig, C.A., Ayer, D.E., Schreiber, S.L. and Evans, R.M. (1997). Nuclear receptor repression mediated by a complex containing SMRT, mSin3A, and histone deacetylase. Cell, (89), 373-80.

Nakajima, H., Kim, Y.B., Terano, H., Yoshida, M. and Horinouchi, S. (1998). FR901228, a potent antitumor antibiotic, is a novel histone deacetylase inhibitor. Exp Cell Res, (241), 126-33.

Nan, X., Ng, H.H., Johnson, C.A., Laherty, C.D., Turner, B.M., Eisenman, R.N. and Bird, A. (1998). Transcriptional repression by the methyl-CpG-binding protein $\mathrm{MeCP} 2$ involves a histone deacetylase complex. Nature, (393), 386-9.

Nare, B., Allocco, J.J., Kuningas, R., Galuska, S., Myers, R.W., Bednarek, M.A. and Schmatz, D.M. (1999). Development of a scintillation proximity assay for histone deacetylase using a biotinylated peptide derived from histone-H4. Anal Biochem, (267), 390-6.

Nie, L., Ueki, M., Kakeya, H. and Osada, H. (2001). A facile and effective screening method for p21WAF1 promoter activators from microbial metabolites. J Antibiot (Tokyo), (54), 783-8.

Nielsen, S.J., Schneider, R., Bauer, U.M., Bannister, A.J., Morrison, A., O'Carroll, D., Firestein, R., Cleary, M., Jenuwein, T., Herrera, R.E. and Kouzarides, T. (2001). Rb targets histone H3 methylation and HP1 to promoters. Nature, (412), 561-5.

Ninkovic, M., Riester, D., Wirsching, F., Dietrich, R. and Schwienhorst, A. (2001). Fluorogenic assay for penicillin G acylase activity. Anal Biochem, (292), 228-33.

Nishioka, K., Chuikov, S., Sarma, K., Erdjument-Bromage, H., Allis, C.D., Tempst, P. and Reinberg, D. (2002). Set9, a novel histone H3 methyltransferase that facilitates transcription by precluding histone tail modifications required for heterochromatin formation. Genes Dev, (16), 479-89.

Norton, V.G., Imai, B.S., Yau, P. and Bradbury, E.M. (1989). Histone acetylation reduces nucleosome core particle linking number change. Cell, (57), 449-57.

Norton, V.G., Marvin, K.W., Yau, P. and Bradbury, E.M. (1990). Nucleosome linking number change controlled by acetylation of histones H3 and H4. J Biol Chem, (265), 19848-52.

Nygren, P.A., Stahl, S. and Uhlen, M. (1994). Engineering proteins to facilitate bioprocessing. Trends Biotechnol, (12), 184-8.

Ogden, R.C. and Adams, D.A. (1987). Electrophoresis in agarose and acrylamide gels. Methods Enzymol, (152), 61-87.

Oka, M.S. and Rupp, R.G. (1990). Large-scale animal cell culture: a biological perspective. Bioprocess Technol, (10), 71-92.

Patra, S.K., Patra, A. and Dahiya, R. (2001). Histone deacetylase and DNA methyltransferase in human prostate cancer. Biochem Biophys Res Commun, (287), 705-13.

Peterson, C.L. (2002). HDAC's at Work. Everyone Doing Their Part. Mol Cell, (9), 921-2.

Petrij, F., Giles, R.H., Dauwerse, H.G., Saris, J.J., Hennekam, R.C., Masuno, M., Tommerup, N., van Ommen, G.J., Goodman, R.H., Peters, D.J. and et al. (1995). Rubinstein-Taybi syndrome caused by mutations in the transcriptional co-activator CBP. Nature, (376), 348-51.

Pflum, M.K., Tong, J.K., Lane, W.S. and Schreiber, S.L. (2001). Histone deacetylase 1 phosphorylation promotes enzymatic activity and complex formation. J Biol Chem, (276), 47733-41. 
Pina, I.C., Gautschi, J.T., Wang, G.Y., Sanders, M.L., Schmitz, F.J., France, D., Cornell-Kennon, S., Sambucetti, L.C., Remiszewski, S.W., Perez, L.B., Bair, K.W. and Crews, P. (2003). Psammaplins from the sponge Pseudoceratina purpurea: inhibition of both histone deacetylase and DNA methyltransferase. J Org Chem, (68), 3866-73.

Pipal, A., Goralik-Schramel, M., Lusser, A., Lanzanova, C., Sarg, B., Loidl, A., Lindner, H., Rossi, V. and Loidl, P. (2003). Regulation and Processing of Maize Histone Deacetylase Hda1 by Limited Proteolysis. Plant Cell, (15), 1904-1917.

Piperno, G., LeDizet, M. and Chang, X.J. (1987). Microtubules containing acetylated alpha-tubulin in mammalian cells in culture. J Cell Biol, (104), 289-302.

Plumb, J.A., Finn, P.W., Williams, R.J., Bandara, M.J., Romero, M.R., Watkins, C.J., La Thangue, N.B. and Brown, R. (2003). Pharmacodynamic response and inhibition of growth of human tumor xenografts by the novel histone deacetylase inhibitor PXD101. Mol Cancer Ther, (2), 721-8.

Pogo, B.G., Allfrey, V.G. and Mirsky, A.E. (1966). RNA synthesis and histone acetylation during the course of gene activation in lymphocytes. Proc Natl Acad Sci U S A, (55), 805-12.

Polevoda, B. and Sherman, F. (2002). The diversity of acetylated proteins. Genome Biol, (3).

Porath, J., Carlsson, J., Olsson, I. and Belfrage, G. (1975). Metal chelate affinity chromatography, a new approach to protein fractionation. Nature, (258), 598-599.

Puig, O.M., Belles, E., Lopez-Rodas, G., Sendra, R. and Tordera, V. (1998). Interaction between Nterminal domain of $\mathrm{H} 4$ and DNA is regulated by the acetylation degree. Biochim Biophys Acta, (1397), $79-90$.

Razin, A. (1998). CpG methylation, chromatin structure and gene silencing-a three-way connection. Embo J, (17), 4905-8.

Rea, S., Eisenhaber, F., O'Carroll, D., Strahl, B.D., Sun, Z.W., Schmid, M., Opravil, S., Mechtler, K., Ponting, C.P., Allis, C.D. and Jenuwein, T. (2000). Regulation of chromatin structure by sitespecific histone $\mathrm{H} 3$ methyltransferases. Nature, (406), 593-9.

Redon, C., Pilch, D., Rogakou, E., Sedelnikova, O., Newrock, K. and Bonner, W. (2002). Histone H2A variants H2AX and H2AZ. Curr Opin Genet Dev, (12), 162-9.

Reeve, J.N. (2003). Archaeal chromatin and transcription. Mol Microbiol, (48), 587-98.

Remiszewski, S.W., Sambucetti, L.C., Atadja, P., Bair, K.W., Cornell, W.D., Green, M.A., Howell, K.L., Jung, M., Kwon, P., Trogani, N. and Walker, H. (2002). Inhibitors of human histone deacetylase: synthesis and enzyme and cellular activity of straight chain hydroxamates. $J$ Med Chem, (45), 753-7.

Remiszewski, S.W., Sambucetti, L.C., Bair, K.W., Bontempo, J., Cesarz, D., Chandramouli, N., Chen, R., Cheung, M., Cornell-Kennon, S., Dean, K., Diamantidis, G., France, D., Green, M.A., Howell, K.L., Kashi, R., Kwon, P., Lassota, P., Martin, M.S., Mou, Y., Perez, L.B., Sharma, S., Smith, T., Sorensen, E., Taplin, F., Trogani, N., Versace, R., Walker, H., Weltchek-Engler, S., Wood, A., Wu, A. and Atadja, P. (2003). N-hydroxy-3-phenyl-2-propenamides as novel inhibitors of human histone deacetylase with in vivo antitumor activity: discovery of (2E)-N-hydroxy-3-[4-[[(2hydroxyethyl)[2-(1H-indol-3-yl)ethyl]amino]methyl ]phenyl]-2-propenamide (NVP-LAQ824). J Med Chem, (46), 4609-24.

Rice, J.C. and Allis, C.D. (2001). Histone methylation versus histone acetylation: new insights into epigenetic regulation. Current Opinion in Cell Biology, (13), 263-73.

Richards, E.J. and Elgin, S.C. (2002). Epigenetic codes for heterochromatin formation and silencing: rounding up the usual suspects. Cell, (108), 489-500.

Richmond, T.J. and Davey, C.A. (2003). The structure of DNA in the nucleosome core. Nature, (423), $145-50$.

Richon, V.M., Emiliani, S., Verdin, E., Webb, Y., Breslow, R., Rifkind, R.A. and Marks, P.A. (1998). A class of hybrid polar inducers of transformed cell differentiation inhibits histone deacetylases. Proc Natl Acad Sci U S A, (95), 3003-7. 
Richon, V.M., Sandhoff, T.W., Rifkind, R.A. and Marks, P.A. (2000). Histone deacetylase inhibitor selectively induces p21WAF1 expression and gene-associated histone acetylation. Proc Natl Acad Sci U $S$ A, (97), 10014-9.

Richon, V.M., Webb, Y., Merger, R., Sheppard, T., Jursic, B., Ngo, L., Civoli, F., Breslow, R., Rifkind, R.A. and Marks, P.A. (1996). Second generation hybrid polar compounds are potent inducers of transformed cell differentiation. Proc Natl Acad Sci U S A, (93), 5705-8.

Riester, D., Wirsching, F., Salinas, G., Keller, M., Gebinoga, M., Kamphausen, S., Merkwart, C., Goetz, R., Wiesenfeldt, M., Stürzebecher, J., Thürk, M. and Schwienhorst, A. (2003). Novel thrombin inhibitors identified by computer-assisted multiparameter design. eingereicht.

Robyr, D., Suka, Y., Xenarios, I., Kurdistani, S.K., Wang, A., Suka, N. and Grunstein, M. (2002). Microarray deacetylation maps determine genome-wide functions for yeast histone deacetylases. Cell, (109), 437-46.

Rosato, R.R., Almenara, J.A. and Grant, S. (2003). The histone deacetylase inhibitor MS-275 promotes differentiation or apoptosis in human leukemia cells through a process regulated by generation of reactive oxygen species and induction of p21CIP1/WAF1 1. Cancer Res, (63), 3637-45.

Rundlett, S.E., Carmen, A.A., Kobayashi, R., Bavykin, S., Turner, B.M. and Grunstein, M. (1996). HDA1 and RPD3 are members of distinct yeast histone deacetylase complexes that regulate silencing and transcription. Proc Natl Acad Sci U S A, (93), 14503-8.

Rundlett, S.E., Carmen, A.A., Suka, N., Turner, B.M. and Grunstein, M. (1998). Transcriptional repression by UME6 involves deacetylation of lysine 5 of histone H4 by RPD3. Nature, (392), 831-5.

Russell, W.K., Park, Z.Y. and Russell, D.H. (2001). Proteolysis in mixed organic-aqueous solvent systems: applications for peptide mass mapping using mass spectrometry. Anal Chem, (73), 2682-5.

Saiki, R.K., Gelfand, D.H., Stoffel, S., Scharf, S.J., Higuchi, R., Horn, G.T., Mullis, K.B. and Erlich, H.A. (1988). Primer-directed enzymatic amplification of DNA with a thermostable DNA polymerase. Science, (239), 487-91.

Saito, A., Yamashita, T., Mariko, Y., Nosaka, Y., Tsuchiya, K., Ando, T., Suzuki, T., Tsuruo, T. and Nakanishi, O. (1999). A synthetic inhibitor of histone deacetylase, MS-27-275, with marked in vivo antitumor activity against human tumors. Proc Natl Acad Sci U S A, (96), 4592-7.

Sakaguchi, K., Herrera, J.E., Saito, S., Miki, T., Bustin, M., Vassilev, A., Anderson, C.W. and Appella, E. (1998). DNA damage activates p53 through a phosphorylation-acetylation cascade. Genes Dev, (12), 2831-41.

Sakurada, K., Ohta, T., Fujishiro, K., Hasegawa, M. and Aisaka, K. (1996). Acetylpolyamine amidohydrolase from Mycoplana ramosa: gene cloning and characterization of the metal-substituted enzyme. J Bacteriol, (178), 5781-6.

Sandman, K., Pereira, S.L. and Reeve, J.N. (1998). Diversity of prokaryotic chromosomal proteins and the origin of the nucleosome. Cell Mol Life Sci, (54), 1350-64.

Sandman, K. and Reeve, J.N. (1998). Origin of the eukaryotic nucleus. Science, (280), 501, 503.

Sanger, F., Nicklen, S. and Coulson, A.R. (1977). DNA sequencing with chain-terminating inhibitors. Proc Natl Acad Sci U S A, (74), 5463-7.

Saunders, N., Dicker, A., Popa, C., Jones, S. and Dahler, A. (1999). Histone deacetylase inhibitors as potential anti-skin cancer agents. Cancer Res, (59), 399-404.

Schillberg, S., Fischer, R. and Emans, N. (2003). Molecular farming of recombinant antibodies in plants. Cell Mol Life Sci, (60), 433-45.

Schlingloff, G. (1999) Aufbau eines Meßplatzes mit miniaturisierter Evolutions- und Synthesemaschine. Institut für Theoretische Chemie und Strahlenchemie. Universität Wien, Wien.

Sedkov, Y., Cho, E., Petruk, S., Cherbas, L., Smith, S.T., Jones, R.S., Cherbas, P., Canaani, E., Jaynes, J.B. and Mazo, A. (2003). Methylation at lysine 4 of histone H3 in ecdysone-dependent development of Drosophila. Nature, (426), 78-83. 
Shiio, Y. and Eisenman, R.N. (2003). From The Cover: Histone sumoylation is associated with transcriptional repression. Proc Natl Acad Sci U S A, (100), 13225-30.

Shuman, S. (1994). Novel approach to molecular cloning and polynucleotide synthesis using vaccinia DNA topoisomerase. J Biol Chem, (269), 32678-84.

Siddique, H., Zou, J.P., Rao, V.N. and Reddy, E.S. (1998). The BRCA2 is a histone acetyltransferase. Oncogene, (16), 2283-5.

Sittampalam, S.G. (1997). design of signal windows in high throughput screening assays for drug discovery. Journal of Biomolecular Screening, (2), 159-169.

Skarpidi, E., Cao, H., Heltweg, B., White, B.F., Marhenke, R.L., Jung, M. and Stamatoyannopoulos, G. (2003). Hydroxamide derivatives of short-chain fatty acids are potent inducers of human fetal globin gene expression. Exp Hematol, (31), 197-203.

Spencer, R.W. (1998). High-Throughput Screening of Historic Collections: Observations on File Size, Biological Targets, and File Diversity. Biotechnol Bioeng, (61), 61-67.

Spotswood, H.T. and Turner, B.M. (2002). An increasingly complex code. J Clin Invest, (110), 577-82.

Sternson, S.M., Wong, J.C., Grozinger, C.M. and Schreiber, S.L. (2001). Synthesis of 7200 small molecules based on a substructural analysis of the histone deacetylase inhibitors trichostatin and trapoxin. Org Lett, (3), 4239-42.

Stockwell, B.R., Haggarty, S.J. and Schreiber, S.L. (1999). High-throughput screening of small molecules in miniaturized mammalian cell-based assays involving post-translational modifications. Chem Biol, (6), 71-83.

Strahl, B.D. and Allis, C.D. (2000). The language of covalent histone modifications. Nature, (403), 415 .

Strahl, B.D., Briggs, S.D., Brame, C.J., Caldwell, J.A., Koh, S.S., Ma, H., Cook, R.G., Shabanowitz, J., Hunt, D.F., Stallcup, M.R. and Allis, C.D. (2001). Methylation of histone H4 at arginine 3 occurs in vivo and is mediated by the nuclear receptor coactivator PRMT1. Curr Biol, (11), 996-1000.

Strahl, B.D., Ohba, R., Cook, R.G. and Allis, C.D. (1999). Methylation of histone H3 at lysine 4 is highly conserved and correlates with transcriptionally active nuclei in Tetrahymena. Proc Natl Acad Sci $U S A$, (96), 14967-72.

Studier, F.W., Rosenberg, A.H., Dunn, J.J. and Dubendorff, J.W. (1990). Use of T7 RNA polymerase to direct expression of cloned genes. Methods Enzymol, (185), 60-89.

Su, G.H., Sohn, T.A., Ryu, B. and Kern, S.E. (2000). A novel histone deacetylase inhibitor identified by high-throughput transcriptional screening of a compound library. Cancer Res, (60), 3137-42.

Sudbery, P.E. (1996). The expression of recombinant proteins in yeasts. Curr Opin Biotechnol, (7), 51724.

Sugita, K., Koizumi, K. and Yoshida, H. (1992). Morphological reversion of sis-transformed NIH3T3 cells by trichostatin A. Cancer Res, (52), 168-72.

Sulkowski, E. (1985). Purification of Proteins by IMAC. Trends Biotechnol, (3), 1-7.

Sun, Z.W. and Allis, C.D. (2002). Ubiquitination of histone H2B regulates H3 methylation and gene silencing in yeast. Nature, (418), 104-8.

Suzuki, T., Ando, T., Tsuchiya, K., Fukazawa, N., Saito, A., Mariko, Y., Yamashita, T. and Nakanishi, O. (1999). Synthesis and histone deacetylase inhibitory activity of new benzamide derivatives. J Med Chem, (42), 3001-3.

Tamaru, H. and Selker, E.U. (2001). A histone H3 methyltransferase controls DNA methylation in Neurospora crassa. Nature, (414), 277-83.

Taplick, J., Kurtev, V., Kroboth, K., Posch, M., Lechner, T. and Seiser, C. (2001). Homooligomerisation and nuclear localisation of mouse histone deacetylase 1. J Mol Biol, (308), 27-38. 
Taunton, J., Hassig, C.A. and Schreiber, S.L. (1996). A mammalian histone deacetylase related to the yeast transcriptional regulator Rpd3p. Science, (272), 408-11.

Taverna, S.D., Coyne, R.S. and Allis, C.D. (2002). Methylation of histone h3 at lysine 9 targets programmed DNA elimination in tetrahymena. Cell, (110), 701-11.

Timmermann, S., Lehrmann, H., Polesskaya, A. and Harel-Bellan, A. (2001). Histone acetylation and disease. Cell Mol Life Sci, (58), 728-36.

Tissenbaum, H.A. and Guarente, L. (2001). Increased dosage of a sir-2 gene extends lifespan in Caenorhabditis elegans. Nature, (410), 227-30.

Tong, J.J., Liu, J., Bertos, N.R. and Yang, X.J. (2002). Identification of HDAC10, a novel class II human histone deacetylase containing a leucine-rich domain. Nucleic Acids Res, (30), 1114-23.

Trojer, P., Brandtner, E.M., Brosch, G., Loidl, P., Galehr, J., Linzmaier, R., Haas, H., Mair, K., Tribus, M. and Graessle, S. (2003). Histone deacetylases in fungi: novel members, new facts. Nucleic Acids Res, (31), 3971-81.

Turner, B.M. (2000). Histone acetylation and an epigenetic code. Bioessays, (22), 836-45.

Turner, B.M. (2002). Cellular memory and the histone code. Cell, (111), 285-91.

Turner, B.M. (2003). Memorable transcription. Nat Cell Biol, (5), 390-3.

Turner, B.M., Birley, A.J. and Lavender, J. (1992). Histone H4 isoforms acetylated at specific lysine residues define individual chromosomes and chromatin domains in Drosophila polytene nuclei. Cell, (69), $375-84$.

Van den Wyngaert, I., de Vries, W., Kremer, A., Neefs, J., Verhasselt, P., Luyten, W.H. and Kass, S.U. (2000). Cloning and characterization of human histone deacetylase 8. FEBS Lett, (478), 77-83.

Van Lint, C., Emiliani, S. and Verdin, E. (1996). The expression of a small fraction of cellular genes is changed in response to histone hyperacetylation. Gene Expr, (5), 245-53.

Van Ommeslaeghe, K., Elaut, G., Brecx, V., Papeleu, P., Iterbeke, K., Geerlings, P., Tourwe, D. and Rogiers, V. (2003). Amide analogues of TSA: synthesis, binding mode analysis and HDAC inhibition. Bioorg Med Chem Lett, (13), 1861-4.

Vanommeslaeghe, K., Van Alsenoy, C., De Proft, F., Martins, J.C., Tourwe, D. and Geerlings, P. (2003). Ab initio study of the binding of Trichostatin A (TSA) in the active site of histone deacetylase like protein (HDLP). Org Biomol Chem, (1), 2951-7.

Verdin, E., Dequiedt, F. and Kasler, H.G. (2003). Class II histone deacetylases: versatile regulators. Trends Genet, (19), 286-93.

Vogelauer, M., Wu, J., Suka, N. and Grunstein, M. (2000). Global histone acetylation and deacetylation in yeast. Nature, (408), 495-8.

Wada, C.K., Frey, R.R., Ji, Z., Curtin, M.L., Garland, R.B., Holms, J.H., Li, J., Pease, L.J., Guo, J., Glaser, K.B., Marcotte, P.A., Richardson, P.L., Murphy, S.S., Bouska, J.J., Tapang, P., Magoc, T.J., Albert, D.H., Davidsen, S.K. and Michaelides, M.R. (2003). Alpha-keto amides as inhibitors of histone deacetylase. Bioorg Med Chem Lett, (13), 3331-5.

Wade, P.A. (2001). Transcriptional control at regulatory checkpoints by histone deacetylases: molecular connections between cancer and chromatin. Hum Mol Genet, (10), 693-8.

Wade, P.A., Jones, P.L., Vermaak, D. and Wolffe, A.P. (1999). Purification of a histone deacetylase complex from Xenopus laevis: preparation of substrates and assay procedures. Methods Enzymol, (304), $715-25$.

Wade, P.A., Pruss, D. and Wolffe, A.P. (1997). Histone acetylation: chromatin in action. Trends Biochem Sci, (22), 128-32.

Wang, J., Hoshino, T., Redner, R.L., Kajigaya, S. and Liu, J.M. (1998). ETO, fusion partner in $\mathrm{t}(8 ; 21)$ acute myeloid leukemia, represses transcription by interaction with the human $\mathrm{N}$ CoR/mSin3/HDAC1 complex. Proc Natl Acad Sci U S A, (95), 10860-5. 
Wang, W. and Malcolm, B.A. (1999). Two-stage PCR protocol allowing introduction of multiple mutations, deletions and insertions using QuikChange Site-Directed Mutagenesis. Biotechniques, (26), $680-2$.

Wang, W. and Malcolm, B.A. (2002). Two-stage polymerase chain reaction protocol allowing introduction of multiple mutations, deletions, and insertions, using QuikChange site-directed mutagenesis. Methods Mol Biol, (182), 37-43.

Wang, W. and Malcom, B.A. (2002) Two-Stage Polymerase Chain Reaction Protocol Allowing Introduction of Multiple Mutations, Deletions, and Insertions, Using QuikChange ${ }^{\mathrm{TM}}$ Site-Directed Mutagenesis. In Braman, J. (ed.) In Vitro Mutagenesis Protocols. Humana Press Inc., Totowa, Vol. 282, pp. 37-43.

Wang, W., Maniar, M., Jain, R., Jacobs, J., Trias, J. and Yuan, Z. (2001). A fluorescence-based homogeneous assay for measuring activity of UDP-3-O-(R-3-hydroxymyristoyl)-N-acetylglucosamine deacetylase. Anal Biochem, (290), 338-46.

Wang, X., Moore, S.C., Laszckzak, M. and Ausio, J. (2000). Acetylation increases the alpha-helical content of the histone tails of the nucleosome. J Biol Chem, (275), 35013-20.

Warrell, R.P., Jr., He, L.Z., Richon, V., Calleja, E. and Pandolfi, P.P. (1998). Therapeutic targeting of transcription in acute promyelocytic leukemia by use of an inhibitor of histone deacetylase. J Natl Cancer Inst, (90), 1621-5.

Wegener, D., Hildmann, C., Riester, D. and Schwienhorst, A. (2003a). Improved fluorogenic histone deacetylase assay for high-throughput-screening applications. Anal Biochem, (321), 202-8.

Wegener, D., Hildmann, C. and Schwienhorst, A. (2003b). Recent progress in the development of assays suited for histone deacetylase inhibitor screening. Mol Genet Metab, (80), 138-47.

Wegener, D., Wirsching, F., Riester, D. and Schwienhorst, A. (2003c). A fluorogenic histone deacetylase assay well suited for high-throughput activity screening. Chem Biol, (10), 61-8.

Wen, Y.D., Perissi, V., Staszewski, L.M., Yang, W.M., Krones, A., Glass, C.K., Rosenfeld, M.G. and Seto, E. (2000). The histone deacetylase-3 complex contains nuclear receptor corepressors. Proc Natl Acad Sci U S A, (97), 7202-7.

Werner, R.G., Noe, W., Kopp, K. and Schluter, M. (1998). Appropriate mammalian expression systems for biopharmaceuticals. Arzneimittelforschung, (48), 870-80.

Weston, A.D., Blumberg, B. and Underhill, T.M. (2003). Active repression by unliganded retinoid receptors in development: less is sometimes more. J Cell Biol, (161), 223-8.

Wittich, S., Scherf, H., Xie, C., Brosch, G., Loidl, P., Gerhauser, C. and Jung, M. (2002). Structureactivity relationships on phenylalanine-containing inhibitors of histone deacetylase: in vitro enzyme inhibition, induction of differentiation, and inhibition of proliferation in Friend leukemic cells. $J$ Med Chem, (45), 3296-309.

Wolffe, A.P. and Hayes, J.J. (1999). Chromatin disruption and modification. Nucleic Acids Res, (27), 711-20.

Wong, J.C., Hong, R. and Schreiber, S.L. (2003). Structural biasing elements for in-cell histone deacetylase paralog selectivity. J Am Chem Soc, (125), 5586-7.

Woo, S.H., Frechette, S., Abou Khalil, E., Bouchain, G., Vaisburg, A., Bernstein, N., Moradei, O., Leit, S., Allan, M., Fournel, M., Trachy-Bourget, M.C., Li, Z., Besterman, J.M. and Delorme, D. (2002). Structurally simple trichostatin A-like straight chain hydroxamates as potent histone deacetylase inhibitors. J Med Chem, (45), 2877-85.

Wu, G., Irvine, J., Luft, C., Pressley, D., Hodge, C.N. and Janzen, B. (2003). Assay development and high-throughput screening of caspases in microfluidic format. Comb Chem High Throughput Screen, (6), 303-12.

Xiang, T.-X. (1998). Influence of Chain Ordering on the Selectivity of Dipalmitoylphosphatidylcholine Bilayer Membranes for Permeant Size and Shape. Biophysical Journal, (75), 2658-71. 
Xue, Y., Wong, J., Moreno, G.T., Young, M.K., Cote, J. and Wang, W. (1998). NURD, a novel complex with both ATP-dependent chromatin-remodeling and histone deacetylase activities. Mol Cell, (2), 851-61.

Yamagoe, S., Kanno, T., Kanno, Y., Sasaki, S., Siegel, R.M., Lenardo, M.J., Humphrey, G., Wang, Y., Nakatani, Y., Howard, B.H. and Ozato, K. (2003). Interaction of histone acetylases and deacetylases in vivo. Mol Cell Biol, (23), 1025-33.

Yang, W.M., Inouye, C., Zeng, Y., Bearss, D. and Seto, E. (1996). Transcriptional repression by YY1 is mediated by interaction with a mammalian homolog of the yeast global regulator RPD3. Proc Natl Acad Sci U S A, (93), 12845-50.

Yang, W.M., Yao, Y.L., Sun, J.M., Davie, J.R. and Seto, E. (1997). Isolation and characterization of cDNAs corresponding to an additional member of the human histone deacetylase gene family. $J$ Biol Chem, (272), 28001-7.

Yanisch-Perron, C., Vieira, J. and Messing, J. (1985). Improved M13 phage cloning vectors and host strains: nucleotide sequences of the M13mp18 and pUC19 vectors. Gene, (33), 103-19.

Yarden, R.I. and Brody, L.C. (1999). BRCA1 interacts with components of the histone deacetylase complex. PNAS, (96), 4983-8.

Yoshida, M., Furumai, R., Nishiyama, M., Komatsu, Y., Nishino, N. and Horinouchi, S. (2001). Histone deacetylase as a new target for cancer chemotherapy. Cancer Chemother Pharmacol, (48 Suppl 1), S20-6.

Yoshida, M., Horinouchi, S. and Beppu, T. (1995). Trichostatin A and trapoxin: novel chemical probes for the role of histone acetylation in chromatin structure and function. Bioessays, (17), 423-30.

Yoshida, M., Kijima, M., Akita, M. and Beppu, T. (1990). Potent and specific inhibition of mammalian histone deacetylase both in vivo and in vitro by trichostatin A. J Biol Chem, (265), 17174-9.

Yoshida, M., Matsuyama, A., Komatsu, Y. and Nishino, N. (2003). From discovery to the coming generation of histone deacetylase inhibitors. Curr Med Chem, (10), 2351-8.

You, A., Tong, J.K., Grozinger, C.M. and Schreiber, S.L. (2001). CoREST is an integral component of the CoREST- human histone deacetylase complex. Proc Natl Acad Sci U S A, (98), 1454-8.

You, J., Cohen, R.E. and Pickart, C.M. (1999). Construct for high-level expression and low misincorporation of lysine for arginine during expression of pET-encoded eukaryotic proteins in Escherichia coli. Biotechniques, (27), 950-4.

Youn, H.D., Grozinger, C.M. and Liu, J.O. (2000). Calcium regulates transcriptional repression of myocyte enhancer factor 2 by histone deacetylase 4. J Biol Chem, (275), 22563-7.

Youn, H.D. and Liu, J.O. (2000). Cabin1 represses MEF2-dependent Nur77 expression and T cell apoptosis by controlling association of histone deacetylases and acetylases with MEF2. Immunity, (13), $85-94$.

Youn, H.D., Sun, L., Prywes, R. and Liu, J.O. (1999). Apoptosis of T cells mediated by Ca2+-induced release of the transcription factor MEF2. Science, (286), 790-3.

Yu, J., Li, Y., Ishizuka, T., Guenther, M.G. and Lazar, M.A. (2003). A SANT motif in the SMRT corepressor interprets the histone code and promotes histone deacetylation. Embo J, (22), 3403-3410.

Zegerman, P., Canas, B., Pappin, D. and Kouzarides, T. (2002). Histone H3 lysine 4 methylation disrupts binding of nucleosome remodeling and deacetylase (NuRD) repressor complex. J Biol Chem, (277), 11621-4.

Zeng, L., Zhang, Y., Chien, S., Liu, X. and Shyy, J.Y. (2003). Deacetylation of p53 by laminar flow: The role in p21Wafl regulation. J Biol Chem, (25), 25.

Zeng, L. and Zhou, M.M. (2002). Bromodomain: an acetyl-lysine binding domain. FEBS Lett, (513), 124-8.

Zhang, C.L., McKinsey, T.A., Chang, S., Antos, C.L., Hill, J.A. and Olson, E.N. (2002a). Class II histone deacetylases act as signal-responsive repressors of cardiac hypertrophy. Cell, (110), 479-88. 
Zhang, C.L., McKinsey, T.A., Lu, J.R. and Olson, E.N. (2001a). Association of COOH-terminalbinding protein (CtBP) and MEF2-interacting transcription repressor (MITR) contributes to transcriptional repression of the MEF2 transcription factor. J Biol Chem, (276), 35-9.

Zhang, C.L., McKinsey, T.A. and Olson, E.N. (2001b). The transcriptional corepressor MITR is a signal-responsive inhibitor of myogenesis. Proc Natl Acad Sci U S A, (98), 7354-9.

Zhang, C.L., McKinsey, T.A. and Olson, E.N. (2002b). Association of class II histone deacetylases with heterochromatin protein 1: potential role for histone methylation in control of muscle differentiation. Mol Cell Biol, (22), 7302-12.

Zhang, J.H., Chung, T.D. and Oldenburg, K.R. (1999a). A Simple Statistical Parameter for Use in Evaluation and Validation of High Throughput Screening Assays. J Biomol Screen, (4), 67-73.

Zhang, X., Yang, Z., Khan, S.I., Horton, J.R., Tamaru, H., Selker, E.U. and Cheng, X. (2003a). Structural basis for the product specificity of histone lysine methyltransferases. Mol Cell, (12), 177-85.

Zhang, Y., LeRoy, G., Seelig, H.P., Lane, W.S. and Reinberg, D. (1998). The dermatomyositisspecific autoantigen Mi2 is a component of a complex containing histone deacetylase and nucleosome remodeling activities. Cell, (95), 279-89.

Zhang, Y., Li, N., Caron, C., Matthias, G., Hess, D., Khochbin, S. and Matthias, P. (2003b). HDAC6 interacts with and deacetylates tubulin and microtubules in vivo. Embo J, (22), 1168-79.

Zhang, Y., Ng, H.H., Erdjument-Bromage, H., Tempst, P., Bird, A. and Reinberg, D. (1999b). Analysis of the NuRD subunits reveals a histone deacetylase core complex and a connection with DNA methylation. Genes Dev, (13), 1924-35.

Zhang, Y. and Reinberg, D. (2001). Transcription regulation by histone methylation: interplay between different covalent modifications of the core histone tails. Genes Dev, (15), 2343-60.

Zhou, Q., Melkoumian, Z.K., Lucktong, A., Moniwa, M., Davie, J.R. and Strobl, J.S. (2000). Rapid induction of histone hyperacetylation and cellular differentiation in human breast tumor cell lines following degradation of histone deacetylase-1. J Biol Chem, (275), 35256-63.

Zhou, X., Marks, P.A., Rifkind, R.A. and Richon, V.M. (2001). Cloning and characterization of a histone deacetylase, HDAC9. Proc Natl Acad Sci U S A, (98), 10572-7.

Zhou, Y.B., Gerchman, S.E., Ramakrishnan, V., Travers, A. and Muyldermans, S. (1998). Position and orientation of the globular domain of linker histone H5 on the nucleosome. Nature, (395), 402-5.

Zimmerman, M., Ashe, B., Yurewicz, E.C. and Patel, G. (1977). Sensitive assays for trypsin, elastase, and chymotrypsin using new fluorogenic substrates. Anal Biochem, (78), 47-51.

\section{Diplomarbeit:}

Wegener, D. (2000). Klonierung und heterologe Expression der Cystein-Protease Cathepsin $\mathrm{K}$ in Pichia pastoris als Basis für die Entwicklung selektiver Inhibitoren. Diplomarbeit an der Georg-August-Universität Göttingen.

\section{Eigene Veröffentlichungen:}

Jürgens, C., Strom, A., Wegener, D., Hettwer, S., Wilmanns, M. and Sterner, R. (2000). Directed evolution of a $(\beta \alpha)_{8}$-barrel enzyme to catalyze related reactions in two different metabolic pathways. PNAS, (97), 9925-30.

Wegener, D., Wirsching, F., Riester, D. and Schwienhorst, A. (2003a). A fluorogenic histone deacetylase assay well suited for high-throughput activity screening. Chem Biol, (10), 61-8. 
Wegener, D., Hildmann, C., Riester, D. and Schwienhorst, A. (2003b). Improved fluorogenic histone deacetylase assay for high-throughput-screening applications. Anal Biochem, (321), 202-8.

Wegener, D., Hildmann, C. and Schwienhorst, A. (2003c). Recent progress in the development of assays suited for histone deacetylase inhibitor screening. Mol Genet Metab, (80), 138-47.

Hildmann, C., Ninkovic, M., Dietrich, R., Wegener, D., Riester, D., Zimmermann, T., Birch, O.M., Bernegger, C., Loidl, P. and Schwienhorst, A. (2003). A new amidohydrolase from Bordetella/Alcaligenes strain FB188 with similarities to histone deacetylases. J Bacteriol, (in press).

\section{Anhang}

\subsection{Abkürzungsverzeichnis}

Für Nukleinsäurebausteine und für Aminosäuren wurden die Ein- und Dreibuchstabenkürzel nach dem ,,white book“ der IUPAC-IUBMB Joint Commission on Biochemical Nomenclature and Nomenclature Commission of IUBMB (Liebecq, 1978) benutzt. Dies gilt ebenfalls für physikalische Größen, Einheiten und eventuelle Präfixe.

$\begin{array}{ll}\varnothing & \text { Durchmesser } \\ \# & \text { Nummer } \\ \text { A } & \text { Adenin } \\ \text { Abb. } & \text { Abbildung } \\ \text { abs. } & \text { absolut } \\ \text { Ac } & \text { Acetat, Acetyl- } \\ \text { AFU } & \text { arbitrary fluorescence units, relative Fluoreszenzeinheiten } \\ \text { AK } & \text { Antikörper } \\ \text { AMC } & \text { 7-Amino-4-Methylcoumarin } \\ \text { amp } & \text { Ampicillin (-resistenzgen) } \\ \text { AP } & \text { Alkalische Phosphatase } \\ \text { APS } & \text { Ammoniumperoxodisulfat } \\ \text { As } & \text { Aminosäure(n) } \\ \text { ATP } & \text { Adenosin-5'-triphosphat } \\ \text { BB } & \text { blocking buffer, Blockierungspuffer } \\ \text { BBT } & \text { blocking buffer Tween 20, Blockierungspuffer mit Tween 20 } \\ \text { BCIP } & \text { 5-Brom-4-Chlor-3-Indolylphosphat } \\ \text { bla } & \text { Gen für } \beta \text {-Laktamase } \\ \text { bp } & \text { Basenpaare } \\ \text { BSA } & \text { bovine serum albumine, Rinderserumalbumin } \\ \text { bzw. } & \text { beziehungsweise } \\ \text { c } & \text { concentration, Stoffkonzentration }\end{array}$




\begin{tabular}{|c|c|}
\hline $\mathrm{C}$ & Cytosin \\
\hline${ }^{\circ} \mathrm{C}$ & Grad Celsius \\
\hline C-terminal & carboxyterminal \\
\hline C-Terminus & Carboxyterminus \\
\hline ca. & circa \\
\hline cDNA & copy DNA, komplementäre DNA \\
\hline $\mathrm{cfu}$ & colony forming unit, Koloniebildende Einheit \\
\hline CRX & crude extract, lösliche Fraktion des Zellysates \\
\hline $\mathrm{CV}$ & column volume, SV \\
\hline ddNTP & 2', 3'-Didesoxyribonukleosid-5'-triphosphat \\
\hline dem. & demineralisiert \\
\hline d. h. & das heißt \\
\hline DMF & Dimethylformamid \\
\hline DMSO & Dimethylsulfoxid \\
\hline DNA & desoxyribonucleic acid, Desoxyribonukleinsäure \\
\hline dNTP & Desoxynukleosidtriphosphat \\
\hline dsDNA & double stranded DNA, doppelsträngige DNA \\
\hline DTT & Dithiothreitol \\
\hline $\mathrm{dYT}$ & double Yeast Tryptone (-Medium) \\
\hline$\varepsilon$ & molarer Extinktionskoeffizient \\
\hline $\mathrm{E}^{\mathrm{x}}$ & Extinktion bei $\mathrm{x} \mathrm{nm}$ \\
\hline E. coli & Escherichia coli \\
\hline EDTA & Ethylendiamintetraacetat \\
\hline $\begin{array}{l}\text { Em } \\
\text { et al. }\end{array}$ & $\begin{array}{l}\text { Emission, Abstrahlungswellenlänge } \\
\text { et alii, und andere }\end{array}$ \\
\hline $\mathrm{EtOH}$ & Ethanol \\
\hline Ex & Exitation, Anregungswellenlänge \\
\hline $\mathrm{F}$ & Farad \\
\hline Fa. & Firma \\
\hline G & Guanin \\
\hline g & Gramm \\
\hline $\begin{array}{l}\text { G2L } \\
\text { ggf. }\end{array}$ & $\begin{array}{l}\text { Göttingen Genomics Lab (Göttinger Labor für Genomanalyse) } \\
\text { gegebenenfalls }\end{array}$ \\
\hline$h$ & Stunde(n) \\
\hline HAT & Histonacetyltransferase(n) \\
\hline HDAC & Histondeacetylase(n) \\
\hline HDACI & Histondeacetylase-Inhibitor(n) \\
\hline His-tag & lineares Epitop aus sechs Histidinen \\
\hline HMT & Histonmethyltransferase(n) \\
\hline HPLC & high pressure liquid chromatography \\
\hline HTS & high-throughput screening, Hochdurchsatz-Durchmusterung \\
\hline IC50 & Inhibitorkonzentration bei 50\%iger Inhibition \\
\hline IMAC & immobilisierte Metallchelat-Affinitätschromatographie \\
\hline IPTG & Isopropyl- $\beta$-D-thiogalactopyranosid \\
\hline $\mathrm{k}$ & Kilo- \\
\hline kan & Kanamycin(-resistenzgen) \\
\hline $\mathrm{Kan}^{75}$ & $75 \mu \mathrm{g} / \mathrm{ml}$ Kanamycin enthaltend \\
\hline $\mathrm{kb}$ & Kilobasenpaare \\
\hline
\end{tabular}




\begin{tabular}{|c|c|}
\hline $\mathrm{K}_{\mathrm{M}}$ & Michaelis-Menten-Konstante \\
\hline KP & Kaliumphosphat(-Puffer) \\
\hline$\lambda$ & Bakteriophage Lambda \\
\hline$\lambda$ & Wellenlänge \\
\hline 1 & Liter \\
\hline lac & zum Laktose-Operon gehörig \\
\hline LB & Luria Bertani(-Medium) \\
\hline $\mathrm{m}$ & Meter \\
\hline $\mathrm{m}$ & Milli- \\
\hline M & mol/1, molar \\
\hline $\mathrm{mA}$ & Milliampère \\
\hline MCS & multiple cloning site, Mehrfachklonierungsstelle \\
\hline $\mathrm{MeCN}$ & Acetonitril \\
\hline $\mathrm{MeOH}$ & Methanol \\
\hline $\min$ & Minute(n) \\
\hline $\mathrm{ml}$ & Milliliter \\
\hline $\mathrm{M}_{\mathrm{r}}$ & relatives Molekulargewicht \\
\hline mRNA & messenger RNA \\
\hline MTP & Mikrotiterplatte(n) \\
\hline$\mu$ & Mikro- \\
\hline$\mu$ & Mittelwert \\
\hline $\mathrm{n}$ & Nano- \\
\hline $\mathrm{NaP}$ & Natriumphosphat-Puffer \\
\hline N-terminal & aminoterminal \\
\hline N-Terminus & Aminoterminus \\
\hline NBT & 4-Nitrotetrazoliumchloridblau \\
\hline NMP & 1-Methyl-2-Pyrrolidon \\
\hline $\mathrm{Nr}$. & Nummer \\
\hline nt & Nukleotid(e) \\
\hline OD260 & Optische Dichte bei $260 \mathrm{~nm}$ \\
\hline OD280 & Optische Dichte bei $280 \mathrm{~nm}$ \\
\hline OD600 & Optische Dichte bei $600 \mathrm{~nm}$ \\
\hline ORF & open reading frame, Offenes Leseraster eines Genes \\
\hline ori & origin of replication, Replikationsursprung \\
\hline $\mathrm{p}$ & Pico- \\
\hline p.A. & pro analysi, höchster Reinheitsgrad, zur Analyse geeignet \\
\hline PAA & Polyacrylamid \\
\hline PAGE & Polyacrylamid-Gelelektrophorese \\
\hline PBS & phosphat buffered saline-Puffer \\
\hline PBST & phosphat buffered saline Tween 20-Puffer \\
\hline PCR & polymerase chain reaction, Polymerase-Kettenreaktion \\
\hline $\mathrm{pH}$ & negativer dekadischer Logarithmus der Protonenkonzentration \\
\hline PEG & Polyethylenglykol \\
\hline P. pastoris & Pichia pastoris \\
\hline Prop & Propionat, Propionyl- \\
\hline PVDF & Polyvinylidenfluorid \\
\hline RNA & ribonucleic acid, Ribonukleinsäure \\
\hline RT & Raumtemperatur \\
\hline
\end{tabular}




\begin{tabular}{|c|c|}
\hline RT-PCR & Reverse Transkription mit anschließender PCR \\
\hline QCM & Quik $^{\text {TM }}$ Change Mutagenesis, Mutagenese nach dem QCM-Verfahren \\
\hline$\sigma$ & Standardabweichung \\
\hline S & Sekunde(n) \\
\hline SAHA & suberoylanilide hydroxamic acid \\
\hline SAP & shrimp alkaline phosphatase, Alkalische Phosphatase aus Shrimp \\
\hline SDS & sodiumdodecylsulfate, Natriumdodecylsulfat \\
\hline S. cerevisiae & Saccharomyces cerevisiae \\
\hline s. o. & siehe oben \\
\hline ssDNA & single stranded DNA, einzelsträngige DNA \\
\hline s. u. & siehe unten \\
\hline SV & Säulenvolumen, -volumina \\
\hline $\mathrm{T}$ & Thymin \\
\hline Tab. & Tabelle \\
\hline TAE & Tris-Acetat-EDTA-Puffer \\
\hline $\mathrm{TE}$ & Tris-EDTA-Puffer \\
\hline TEMED & N,N,N',N'-Tetramethylethylendiamin \\
\hline TFA & Trifluoracetat, Trifluoracetyl- \\
\hline Tet & Tetracyclin \\
\hline TPX & Trapoxin \\
\hline Tris & Tris(hydoxymethyl)aminomethan \\
\hline TSA & Trichostatin A \\
\hline U & Uracil \\
\hline $\mathrm{u}, \mathrm{U}$ & unit(s), Enzymeinheit(en) \\
\hline u. a. & unter anderem \\
\hline ü.N. & über Nacht \\
\hline Upm & Umdrehungen pro Minute \\
\hline ÜS & Überstand \\
\hline usw. & und so weiter \\
\hline UV & Ultraviolett \\
\hline V & Volt \\
\hline$(\mathrm{v} / \mathrm{v})$ & Volumenprozent \\
\hline Vol. & Volumen \\
\hline wt & Wildtyp \\
\hline$(\mathrm{w} / \mathrm{v})$ & Gewichtsprozent \\
\hline X-Gal & 5-Bromo-4-Chloro-3-Indolyl-ß-D-Galactopyranosid \\
\hline
\end{tabular}

\section{Einbuchstabenkürzel der Aminosäuren}

$\begin{array}{llllllll}\text { A } & \text { Alanin } & \text { G } & \text { Glycin } & \text { M } & \text { Methionin } & \text { S } & \text { Serin } \\ \text { C } & \text { Cystein } & \text { H } & \text { Histidin } & \text { N } & \text { Asparagin } & \text { T } & \text { Threonin } \\ \text { D } & \text { Aspartat } & \text { I } & \text { Isoleucin } & \text { P } & \text { Prolin } & \text { V } & \text { Valin } \\ \text { E } & \text { Glutamat } & \text { K } & \text { Lysin } & \text { Q } & \text { Glutamin } & \text { W } & \text { Tryptophan } \\ \text { F } & \text { Phenylalanin } & \text { L } & \text { Leucin } & \text { R } & \text { Arginin } & \text { Y } & \text { Tyrosin }\end{array}$




\subsection{Fluoreszenz-Kalibrierungsgeraden (BMG-Reader)}

Um die gerätespezifischen, relativen Fluoreszenzeinheiten (FE) in Stoffkonzentrationen des verwendeten Fluoreszenzfarbstoffes AMC umrechnen zu können, wurden Proben bekannter AMC-Konzentration unter Standard-Assaybedingungen vermessen und die Beziehung zwischen FE und AMC-Stoffmenge für den jeweiligen Verstärkungsfaktor des Fluoreszenz-Readers (Gain) in einer Kalibrierungskurve aufgetragen. Diese läßt über den gesammten relevanten $\mathrm{Meß-}$ und Konzentrationsbereich eine lineare Beziehung der beiden Größen erkennen. Es wurde ausschließlich bei $\lambda=390 \mathrm{~nm}$ angeregt und bei $\lambda=460 \mathrm{~nm}$ detektiert. Die ermittelten Umrechnungsgleichungen lauten wie folgt:

bei Gain 73: $\quad$ pmol $\mathrm{AMC}=\mathrm{FE} / 365$

bei Gain 65: $\quad$ pmol $\mathrm{AMC}=\mathrm{FE} / 206$
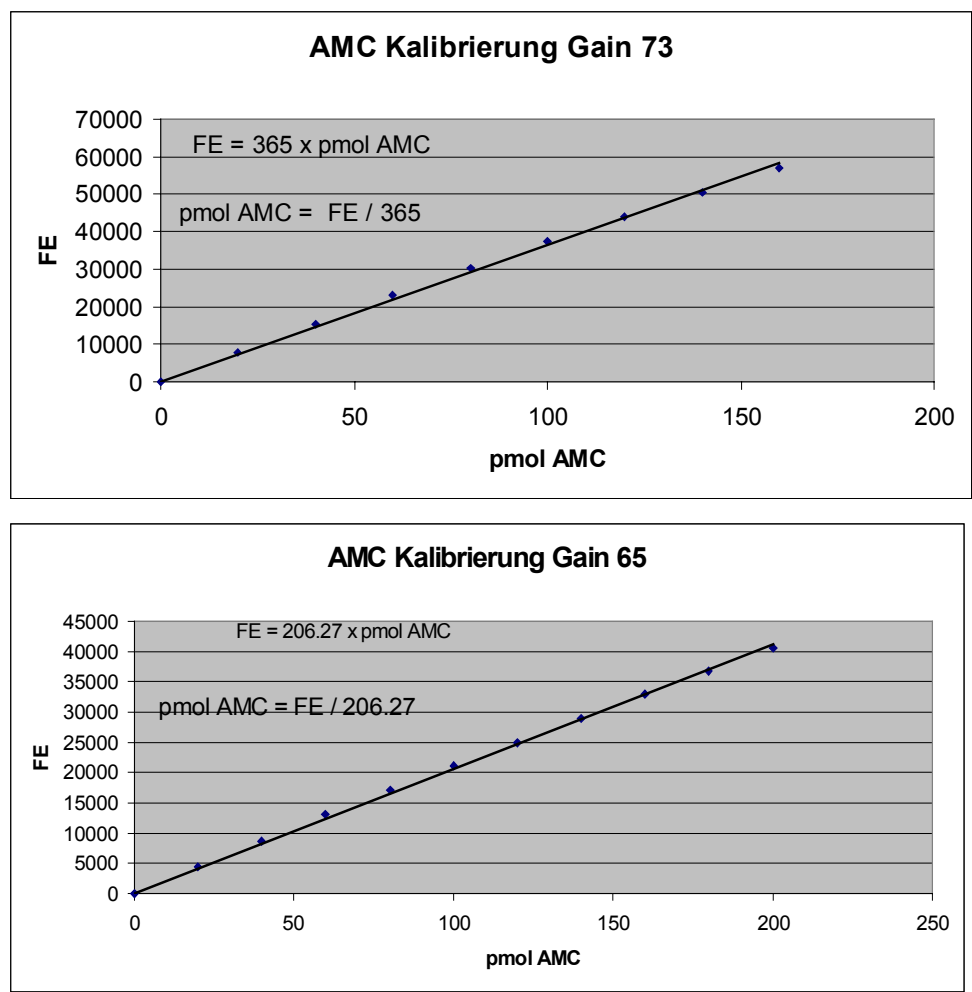

Abbildung 39: Kalibrierungsgeraden für AMC. Die Fluoreszenz von $200 \mu$ l-Proben bekannter AMCKonzentration wurden bei Gain 73 bzw. Gain 65 im BMG-Fluoreszenzreader bestimmt und die FE gegen die Menge AMC im well aufgetragen. 


\subsection{Bradford-Kalibrierungsgerade}

Um die gemessenen Extinktionen in Proteinkonzentrationen umrechnen zu können, wurden von Christian Hildmann (diese Arbeitsgruppe) Proben bekannter BSAKonzentration vermessen und die Beziehung zwischen Extinktion und c (BSA) für den jeweiligen Verstärkungsfaktor (Gain 73) des mit einem Absorptionskopf bestückten BMG-Readers in einer Kalibrierungskurve aufgetragen. Diese läßt über den gesamten relevanten Meß- und Konzentrationsbereich eine ausreichend lineare Beziehung der beiden Größen erkennen. Es wurde ausschließlich bei $\lambda=580 \mathrm{~nm}$ detektiert. Die ermittelte Umrechnungsgleichung lautet wie folgt:

bei Gain 73: $\quad[\mu \mathrm{g} / \mathrm{ml}] \mathrm{BSA}=\mathrm{E}^{580} / 0,0037$

Damit errechnet sich die Konzentration an Gesamtprotein in der Probe unter der Annahme, daß sich die Probe in der Messung wie BSA verhält, folgendermaßen :

$\mathrm{c}\left(\right.$ Probe) $[\mu \mathrm{g} / \mathrm{ml}]=$ Verdünnungsfaktor * $\mathrm{c}(\mathrm{BSA})[\mu \mathrm{g} / \mathrm{ml}]=\mathrm{E}^{580} / 0,0037$

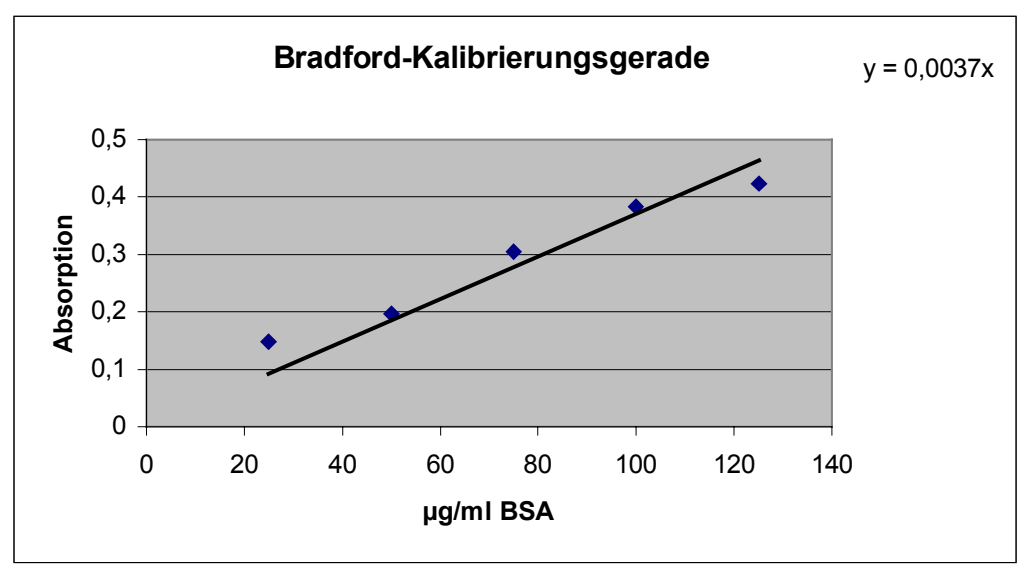

Abbildung 40: Kalibrierungsgerade für Konzentrationsbestimmung von Proteinen nach Bradford. Proben bekannter BSA-Konzentration wurden vermessen und die Beziehung zwischen Extinktion bei $580 \mathrm{~nm}$ und c (BSA) gegeneinander aufgetragen. 


\subsection{Danksagung}

Die vorliegende Arbeit wurde in der Abteilung für Molekulare Genetik und Präparative Molekularbiologie des Institutes für Mikrobiologie und Genetik der Georg-AugustUniversität Göttingen angefertigt.

Prof. Dr. Hans-Joachim Fritz bin ich dankbar dafür, daß ich alle Einrichtungen und Geräte der Abteilung nutzen durfte.

PD. Dr. Wilfried Kramer danke ich für die Übernahme des Korreferates.

Besonders herzlich möchte ich mich bei PD Dr. Andreas Schwienhorst für sein Interesse an und sein Engagement für meine Arbeit und die stete Diskussionsbereitschaft bedanken. Dafür, daß ich viel lernen konnte (nicht nur biologisches), aber auch dafür, daß er meinen Fähigkeiten vertraut hat und mir alle Freiheiten ließ. Auch in schwierigen Zeiten hat er mich immer unterstützt und hatte einen „Plan“ im Ärmel.

Marita Kalck, die immer ein offenes Ohr für mich hatte und viel Geduld bei meinen Schwierigkeiten in bürokrat(echn)ischen Fragen bewiesen hat, Dr. Reiner Merkl, Olaf Waase und Patrick Regin, die oft halfen, Probleme in Computerfragen und anderen technischen Angelegenheiten niederzuringen, bin ich ebenfalls sehr $\mathrm{zu}$ Dank verpflichtet.

Elisabeth Schafflick, Marlies Bartels und Angelika Löffers ließen den Laden erst funktionieren. Vielen Dank!

Allen derzeitigen und ehemaligen Mitarbeitern und Mitstreitern der Abteilung und natürlich besonders denen aus meinem Labor möchte ich meinen Dank aussprechen für die sehr angenehme und kollegiale Atmosphäre - bei Arbeit, Sport und Spiel - und die vielen Tips, Ratschläge und Anregungen, die ich von allen Seiten erhalten konnte (natürlich auch für solche Dinge wie das berühmte Samstag-mal-Platten-rausnehmen oder das ebenso beliebte Sonntag-mal-animpfen).

Milenas und Güldens 'Hintergrundmusik' hab ich in den letzten Wochen der Doktorarbeit sehr vermisst. René-(mit é) Hempel danke ich dafür, daß er mich immer 
selbstlos seinen Taschenrechner, sein Radiergummi, seinen Bleistift, seinen Textmarker, sein Tesafilm etc.pp. hat abnutzen lassen und mir (meist geduldig) mit Rat und Tat geholfen hat. Christian Hildmann danke ich für die FB188-Amidase und viele Diskussionen. Außerdem wünsche ich ihm, daß er (als erster und einziger Doktorand der Welt) tatsächlich „mit dem experimentellen Teil fertig“ werden möge.

Daniel Riester und Dr. Michael Gebinoga sei Dank für so allerlei aus ihrer Hexenküche, ohne das diese Arbeit nicht durchführbar gewesen wäre, aber vor allem für die tolle Zusammenarbeit.

Dr. Frank Wirsching bin ich für vielerlei Diskussionen und die richtige Starthilfe zu Beginn des Projektes sehr zu Dank verpflichtet.

Dr. Andreas Schober, Dr. Gregor Schlingloff und Dr. Alexander Gross danke ich für die herzliche Aufnahme in ihrem Labor und die fruchtbare und unkomplizierte Zusammenarbeit bei der Adaption des Assays an ihr 'Spielzeug'.

Dem Team des Göttingen GenOmics Laboratory $\left(\mathrm{G}_{2} \mathrm{~L}\right)$ gebührt Dank und Anerkennung für die wirklich sehr guten Sequenzierdaten, welche mir die Arbeit sehr erleichtert haben.

Besonders bedanken möchte ich mich bei Dr. H. Siggelkow für die großzügige Überlassung der Osteoblasten-mRNA und bei Dr. Florentina Soto für die Leber-cDNA.

Ein wirklich großes Dankeschön steht meinen Eltern zu, die mir das Studium ermöglicht und mich auch in allen anderen Dingen des Lebens stets nach Kräften unterstützt haben.

Zuletzt möchte ich mich herzlichst bei meiner Freundin Ute bedanken, die trotz ihrer eigenen Promotion immer noch Geduld und Verständnis für mich hatte und das 'wirkliche Leben' mit mir teilt. 


\subsection{Lebenslauf}

Name:

Geburtsdatum:

Geburtsort:

Staatsangehörigkeit:

Familienstand:

Schulzeit:

Wehrdienst:

Studium der Biologie:

Diplomarbeit:

Doktorarbeit:
Dennis Wegener

13.4.1974

Northeim

deutsch

ledig

1980 - 1984 Grundschule Höckelheim

1984-1986 Orientierungstufe der ThomasMann-Schule Northeim

1986 - 1993 Gymnasium Corvinianum Northeim

1993 Abitur am Gymnasium Corvinianum Northeim

$1993-1994$ in Wesendorf

$1994-2003$ an der Georg-August-Universität zu Göttingen

1999-2000 in der Abteilung für Molekulare Genetik und Präparative Molekularbiologie des Institutes für Mikrobiologie und Genetik der Georg-August-Universität zu Göttingen mit dem Titel:

„Klonierung und heterologe Expression der Cystein-Protease Cathepsin $\mathrm{K}$ in Pichia pastoris als Basis für die Entwicklung selektiver Inhibitoren"

Gesamtnote: „Mit Auszeichnung““

Seit 2000 in der Abteilung für Molekulare Genetik und Präparative Molekularbiologie des Institutes für Mikrobiologie und Genetik der Georg-August-Universität zu Göttingen, unterstützt durch Fa. NSCI GmbH, Göttingen und Fa. Medigene, München 